I GOT A STORY TO TELL: HOW HIP HOP PEDAGOGY INFORMS COLLEGE COUNSELING PRACTICES

\author{
A dissertation submitted to the faculty of \\ San Francisco State University \\ In partial fulfillment of \\ The Requirements for \\ The Degree \\ Doctor of Education \\ In \\ Educational Leadership
}

by

Nathaniel Soriano Nevado

San Francisco, California

May 2020 
Copyright by

Nathaniel Soriano Nevado

2020 


\section{CERTIFICATION OF APPROVAL}

I certify that I have read I Got A Story To Tell: How Hip Hop Pedagogy Informs College Counseling Practices by Nathaniel Soriano Nevado, and that in my opinion this work meets the criteria for approving a dissertation submitted in partial fulfillment of the requirements for the degree: Doctor of Education in Educational Leadership at San Francisco State University.

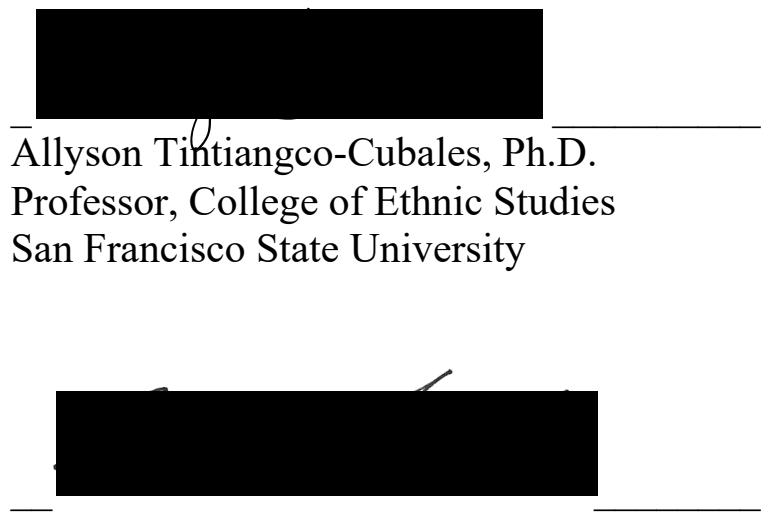

Rebecca Toporek, Ph.D.

Professor, College of Health \& Social Sciences San Francisco State University

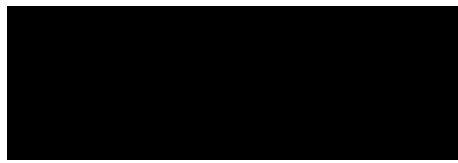

Jamal Cooks, Ph.D.

Dean, Language Arts

Chabot College 


\title{
I GOT A STORY TO TELL: HOW HIP HOP PEDAGOGY INFORMS COLLEGE COUNSELING PRACTICES
}

\author{
Nathaniel Nevado \\ San Francisco State University \\ 2020
}

Community colleges serve as open-access educational institutions that meet the needs of diverse learners accessing educational attainment such as associate degree programs, certificate programs, transfer, and lifelong learning. Community colleges are exploring ways of becoming more "student-ready" by closely examining the access and equity of programs, processes, and practices for all students. One of the major areas examined are the processes and practices of community college counseling. Drawing from research that illustrates the impact on student engagement and sense of belonging using culturally responsive and relevant practices serving students of color, the purpose of this study is to explore how four California community college counselors' lived histories, experiences, and understanding of Hip Hop culture shaped and informed their college counseling practices with students. In examining the "aesthetics" of Hip Hop pedagogy in college counseling through the lens of Rendón's Sentipensante Pedagogy, I used the methodology of portraiture to mix and blend both traditional research disciplines with ethnography and storytelling. Portraiture artfully and methodically captures the contours and complexities of the counselors' experiences. This study proposes that the following four aesthetics of Hip Hop when used in counseling practices: 1) keepin' it real (authenticity), 2) show and prove, 3) politics of space, and 4) sampling and remix, can assist with co-constructing empathic and humanizing counseling experiences with students. Further recommendations and research include capturing students' voices and experiences, professional development and training, curricular integration into counselor education programs, and Hip Hop's applicability and practice in online counseling.

I certify that the Abstract is a correct representation of the content of this dissertation.

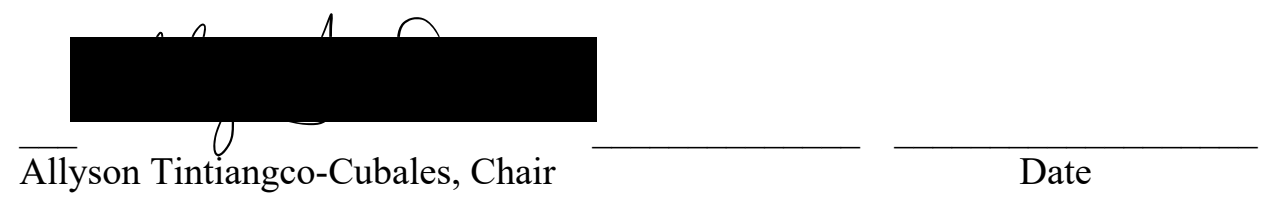


TABLE OF CONTENTS

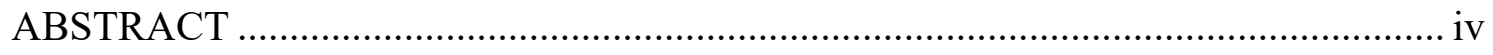

LIST OF FIGURES ……………………………............................................... vii

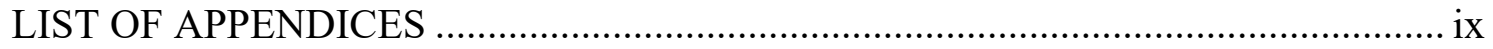

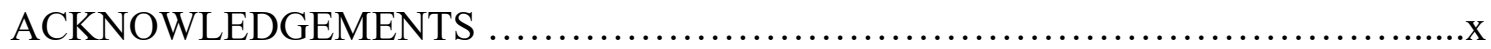

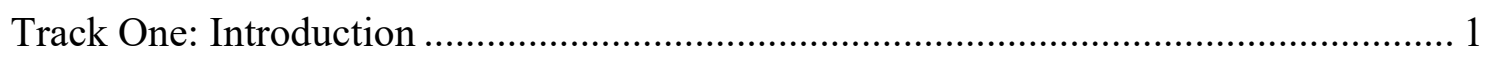

Introduction and Problem Statement .............................................................. 5

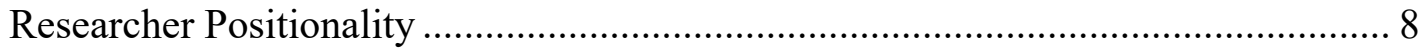

Operationalization of Concepts ...................................................................... 10

Academic Advising and College Counseling .................................................. 10

Hip Hop Pedagogy \& Hip Hop Based Education .............................................. 11

Purpose of Study ............................................................................................. 13

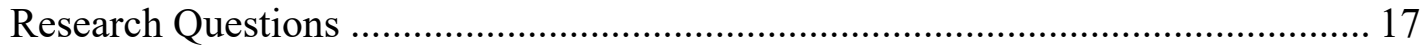

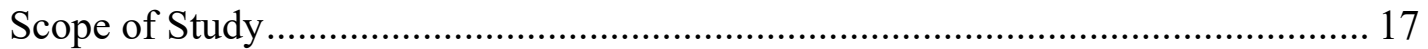

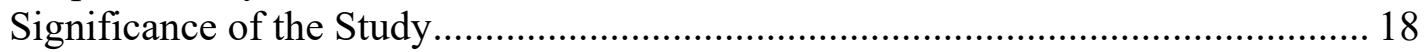

Cultural Appreciation versus Cultural Appropriation ............................................. 19

Aesthetics of Hip Hop in Counseling - Conceptual Framework ............................... 28

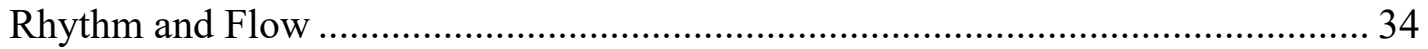

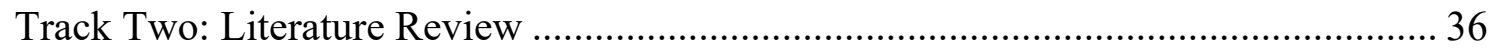

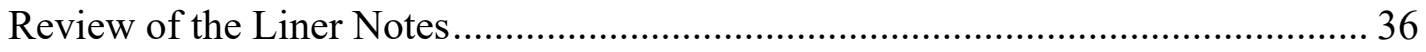

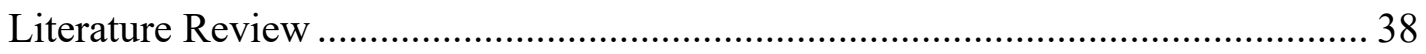

Historical Overview of the Community Colleges .............................................. 38

Academic Advising ........................................................................................ 41

Prescriptive and Developmental Advising Approaches ............................ 43

Other Academic Advising Approaches ........................................................ 44

Students' Perception and Satisfaction of Academic Advising ................... 46

The Impact of Advising on Retention and Persistence ............................. 50

Moving Towards Culturally Responsive Advising and Counseling .......... 51

Hip Hop's Educational Possibilities................................................................ 54

Beats, Rhymes, and Life: Contextual Practices of Hip Hop Education .... 60

Show and Prove: Crossing New Boundaries with Hip Hop Aesthetics .... 64

It's Bigger Than Hip Hop: Student Engagement and Sense of Belonging 69

Track Three: Methodology and Methods ................................................................. 77

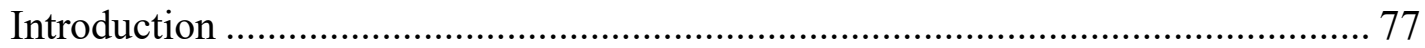

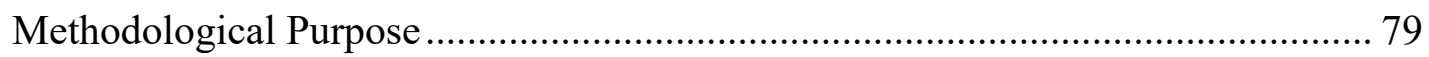

Moving From a Bad Rap to the Search for Goodness...................................... 79

Turn It Up: Voices Amplified through Hip Hop Aesthetics ............................... 83

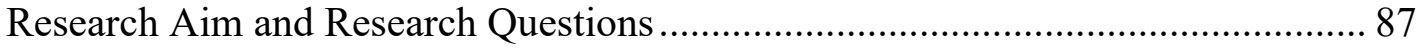




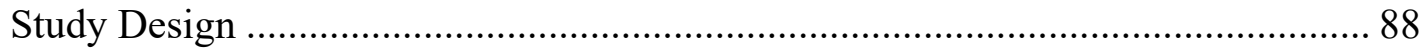

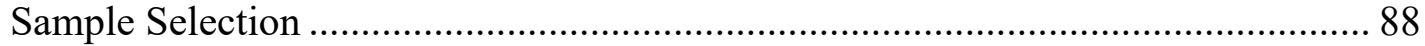

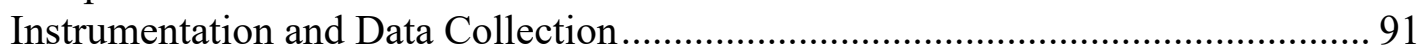

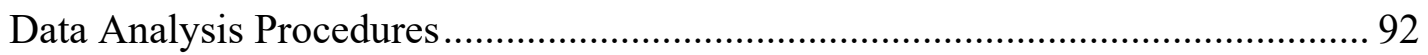

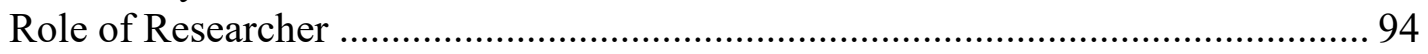

Strengths and Limitations of the Research............................................................. 95

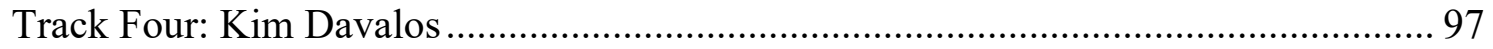

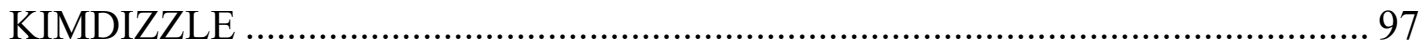

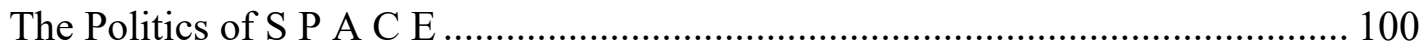

Generation of Reclamation............................................................................... 103

Show and Prove: More Than Just Schoolwork ………………………………..... 110

Lost Ones: I'm Not Black But I'm Not White …………....................................... 114

Getting Her PH.D.: Planned Happenstance + Destiny ............................................. 117

The Miseducation of Kim Davalos..................................................................... 121

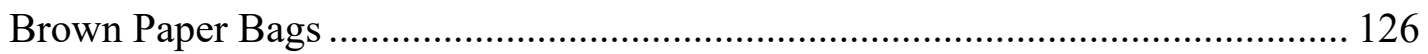

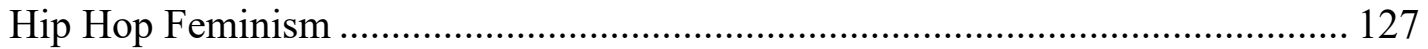

I Got Hot Sauce In My Bag - SWAG! ............................................................... 129

Can I Kick It?: Aesthetics of Hip Hop ……………….................................... 135

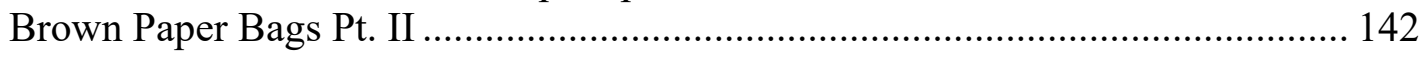

Track Five: Adam Freas ..................................................................................... 146

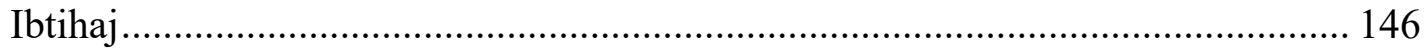

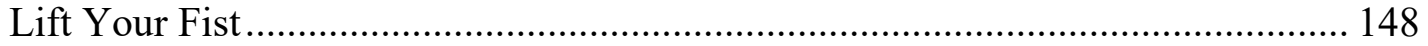

Freas' Instinctive Travels and The Paths of Riddim.......................................... 152

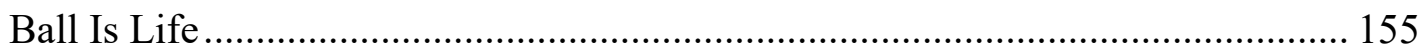

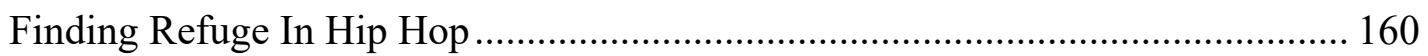

Act Your Age Not Your Color ....................................................................... 163

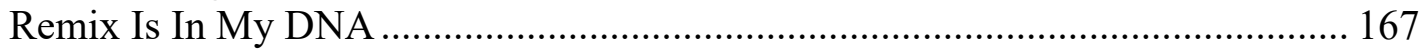

Dropping G.E.M.S.................................................................................... 170

Fuck The Bullshit, Get Down With The Real Real............................................. 175

Steel Sharpens Steel ..................................................................................... 179

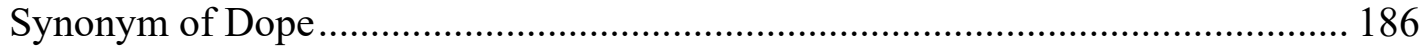

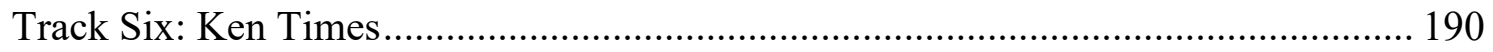

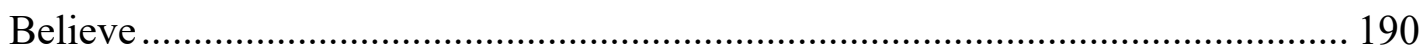

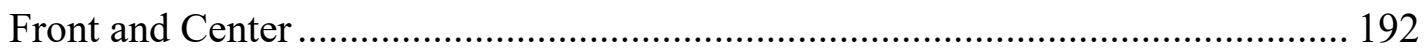

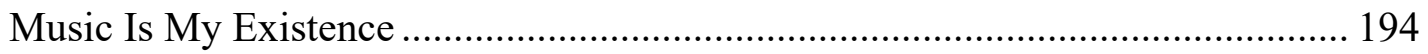

Stand On This Culture, It'll Be There For You ................................................... 198

A Plan Is A Powerful Thing ………………………...................................... 202

By All Means Necessary ............................................................................... 205

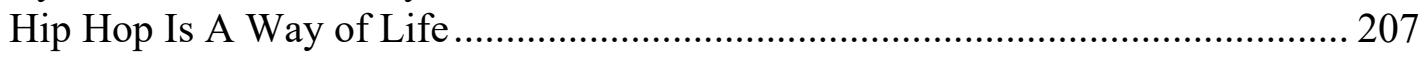

From Low End Theory To Practice ................................................................... 211

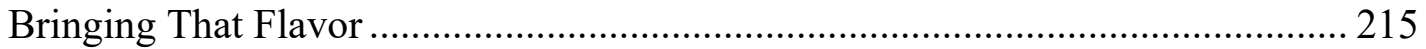

Peace, Love, Unity, and Having Fun................................................................... 217

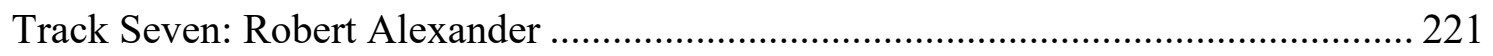




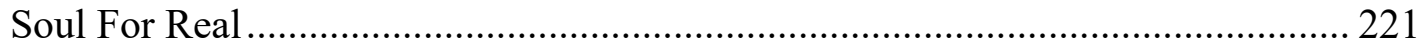

From The City of Dope To The City of Hope ...................................................... 225

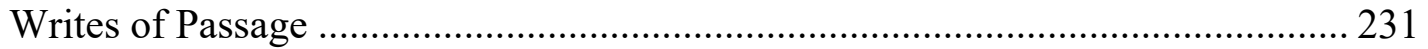

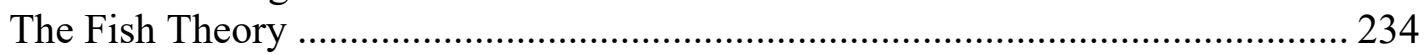

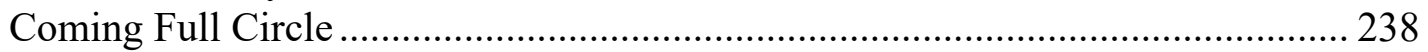

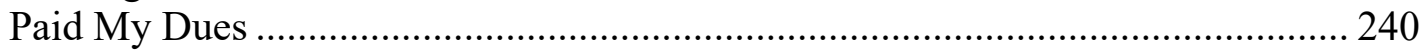

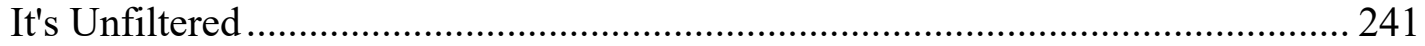

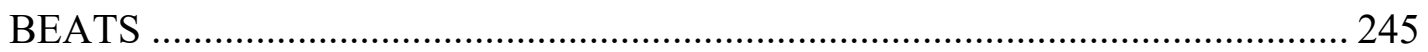

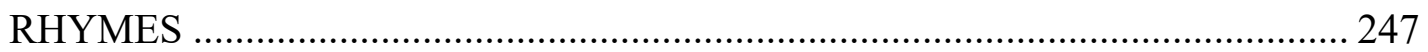

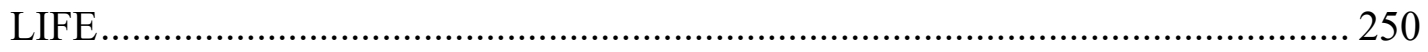

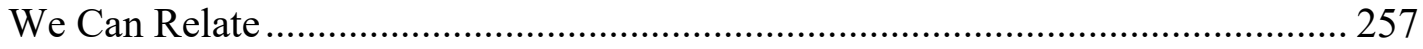

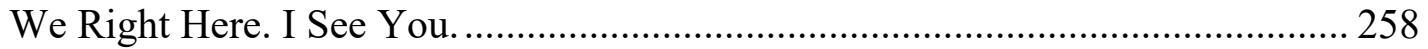

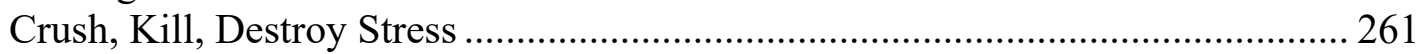

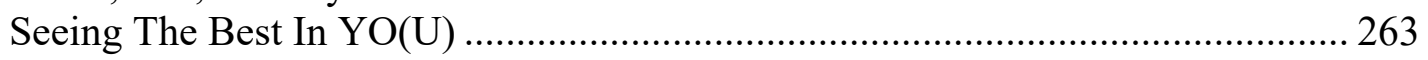

Can't Let Nobody Ride My Bike..................................................................... 266

Track Eight: The Remix: The Aesthetics of Hip Hop in Counseling.......................... 271

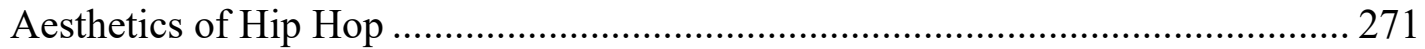

Aesthetic \#1: Keepin' It Real (Authenticity) ................................................... 278

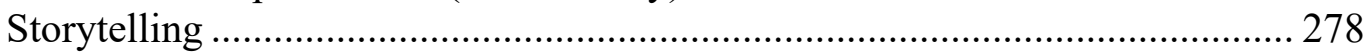

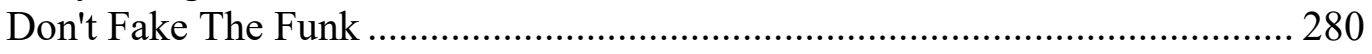

Linguistic and Cultural Capital ................................................................... 281

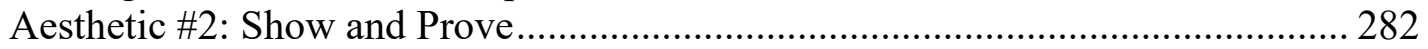

Motivated By Struggles and Invalidation....................................................... 284

Feel Our Presence and Existence ……………………………………….... 285

Aesthetic \#3: The Politics of S P A C E ........................................................... 288

How We Redefine Space and Place ……………………………………..... 290

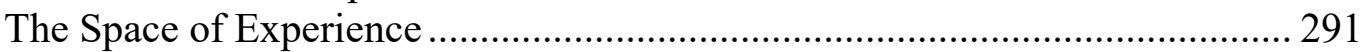

Acknowledging Student Voices in Spaces ........................................................ 293

Aesthetic \#4: Sampled Beats ................................................................................ 294

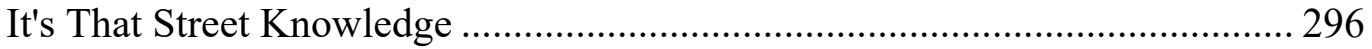

Check The Counseling Techniques ............................................................... 298

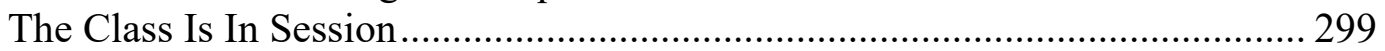

Attuning To The Beat and Critical Listening ......................................................... 301

The Remix: Moving Towards a Sampled Consciousness ……………………….... 304

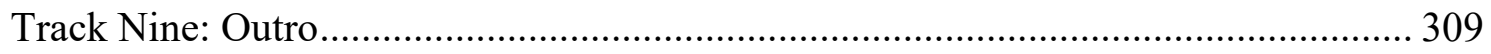

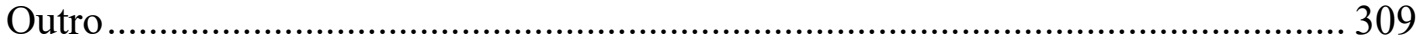

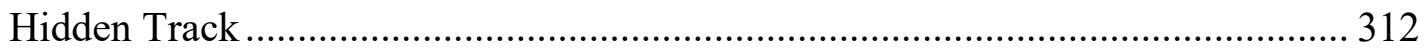

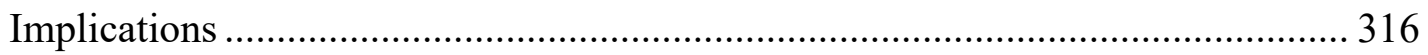

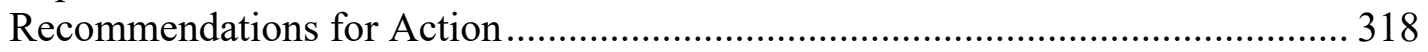

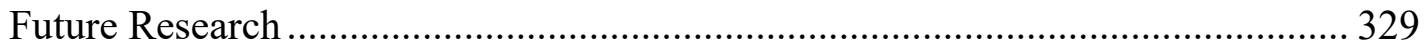

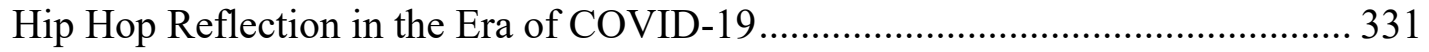

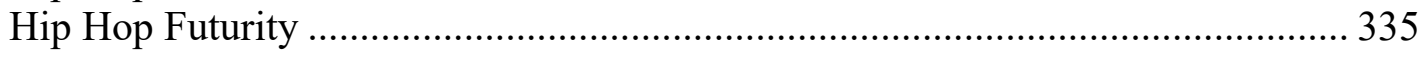

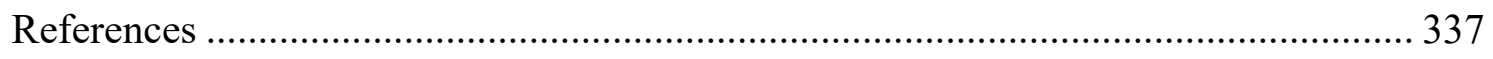

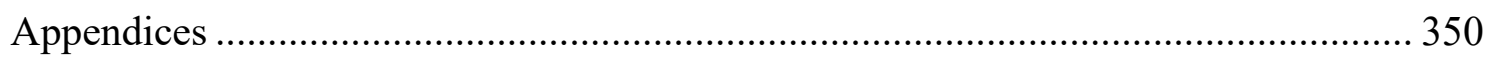




\section{LIST OF FIGURES}

Figure

Page

1. A conceptual framework with Rendón's Sentipensante pedagogy and Hip Hop aesthetics ...34

2. SWAG counseling framework 


\section{LIST OF APPENDICES}

Appendix

Page

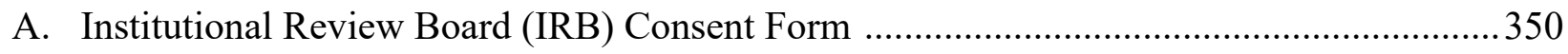

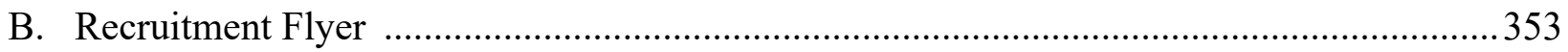

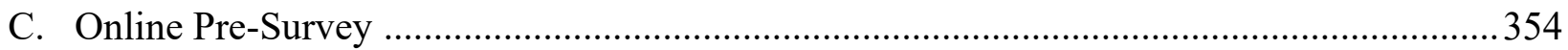

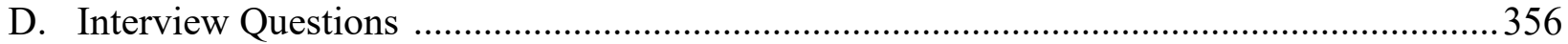




\section{ACKNOWLEDGEMENTS}

This doctoral journey draws me to a quote by the late, great Nipsey Hussle: "The game will test you, never fold. Stay ten toes down, it's not on you. It's in you. And what's in you, they can never take away." By far, this academic journey has been the most challenging thing I've done in my life. I was tested many times throughout my journey with thoughts of pressing pause or even giving up on this chapter of my life. However, with the support of an extended community of folks, I was able to acquire the strength, will, and perseverance to push through. P.U.S.H. Persevere until something happens. And this happened. Whether they were gentle nudges or hard shoves, I felt supported through and through. For that, I am eternally grateful.

This dissertation would not have come to life without the beautiful portraits of Kim Davalos, Adam Freas, Ken Times, and Rob Alexander. Thank you immensely for allowing me to tell your story. I learned so much from each of you through layers of love, struggles, pain, and resilience. Thank you for trusting in me in creating and bringing life to your lived experiences through Hip Hop. It is truly an honor and privilege to have you all be part of this collective dissertation from the beginning to the end. I hope I was able to amplify your voices and make your presence shine. With Hip Hop as a canvas, you all provided gentle strokes of compassion, humility, and authenticity for your students. They are all blessed to have you as their counselors and mentors.

Writing this dissertation is a labor of love and purpose. It has stretched me emotionally, physically, and mentally in unimaginable ways. It is truly heart work. I am honored to be supported by a phenomenal and extremely supportive dissertation committee who provided me with concrete and timely feedback but also honored my work and voice throughout the process. To Dr. Allyson Tintinagco-Cubales - I remember our early conversations when we talked about 
how to achieve balance between family, work, and school. You told me, "There is no such thing as finding balance. You have to find harmony." Little did I know that this gem would serve as the mental foundation that helped me navigate the numerous challenges and barriers during these last three years. Thank you for allowing me tap into my creative energies and providing me with so much wisdom and knowledge in bringing life to my portraits. I was literally "soaking up game." Your unwavering support throughout this journey has continuously reminded me that this work is so important. To Dr. Rebecca Toporek -Throughout this dissertation process, you have provided me with thought-provoking questions, curious wonderments, and moments of clarity that really strengthened my writing. In addition, your support has also sharpened my ability to articulate the importance of this work in the field of college counseling. To Dr. Jamal Cooks - Thank you Coach for believing in me from Day 1. Whether it was in your corner spot at Starbucks or in your office at Chabot College, you provided me with the space to dive deeper in my own work by asking me the "tough" questions. You taught me to always stay ready. And, just like a true coach, you always see the greatness in others even if they don't see it themselves yet.

To my community of folks, there are so much gratitude to express that there are not enough words to share. To our cohort, the \#WarriorScholars and \#expensive friends, being in community with you all have been the highlight of my journey. I am blessed to be surrounded by $30+$ brilliant, unapologetic, and fierce scholar-practitioners. I cannot wait to build with you. To my Rock The School Bells family from Skyline College, Sacramento, De Anza College, and UH-Manoa - I am extremely humbled by your dedication and commitment to transforming the experiences of students through Hip Hop education. To my Skyline College counseling family This work is an extension to the transformative work that you all embody. I am extremely 
humbled to be surrounded by counseling faculty who continue to advocate and fight for equity for all students. To the Barangay Dokz Naman family, Michelle, Liza, and Jonell - we just done did that. Thank you all for being my lifeline. We promised each other from the beginning that we would support each other and that we would all finish together. Despite experiencing so many ups and downs throughout the last three years, we accomplish this milestone together. It has truly been an honor to be part of each other's growth throughout this process. Our work is just beginning.

To my family - you all have been the strength I needed to see this vision through. To Mom, thank you for always believing in me and reminding me to always take care of myself. I am not the person I am today without the lessons you've taught me growing up. You taught me kindness, compassion, and humility. I love you so much! Mom, Papa Boy, and Mama Helen thank you for taking care of DJ during these last three years especially during this last year of writing. I don't know how I would've done it without you all. To my siblings, nieces, and nephews - Eunice, John, Olivia, Charles, Mackenzie, Lourdes, Calvin, Saylor, Syre, Adrienne, Sophia, and AJ, this one's for y'all. Thank you for being one of the greatest sources of inspiration. You kept me going. To my wife, Dana, and son, DJ - Dana, you made the ultimate sacrifice taking care of DJ, working full-time as a nurse, and holding down the house. You always reminded me about the "big picture"; that this is a sacrifice worth taking to build a better life together. This doctoral journey challenged us emotionally, mentally, and physically. I am so humbled to have you by my side. You are the rock of this family that kept us grounded and rooted. DJ, for all the times when I told you "next time, next time", this is accomplishment is for you. I cannot wait to spend hours with you and watching you grow. I hope I made you proud. Now, you can tell your classmates that I'm a doctor and a teacher. I love you both. 
Last but not least, this one's for you Pops. When I graduated with my Bachelor's degree in 1999, you wrote on my card "Dr. Nevado." You always wanted a doctor in the family. I still remember vividly our last conversation together in the hospital. You were complaining about the nurses and doctors and you jokingly told me that I should've pursued becoming a doctor. You even said, “I don't care what kind of doctor. You can even be Dr. Dre.” Those were your last words to me. Even up to that point in your life, you knew that I would someday become a doctor. You saw something in me that I couldn't. For that, I am grateful. While you are not here in the physical sense to celebrate with me, I know you are looking down at me saying, "I told you so." Thank you always for believing in me. I hope I've made you proud. 


\section{TRACK ONE}

\section{INTRODUCTION}

I lean back in my office chair, legs extended with my Nike Air Max 90 "Infrareds" in full view. It's about 10 minutes before my last appointment for the day shows up. I'm working on my lesson plan for my College Success class while listening to J Cole's album "2014 Forest Hills Drive." I'm specifically listening to the song, "Fire Squad", and he's talking about white privilege and white appropriation on Hip Hop culture. He's going in hard, really hard. I turn down the volume slightly to not disrupt my colleague's counseling session next door, even though I'm tempted to do so, especially since he's made subtle remarks about how he can't understand what the rappers were saying and that half of the time, it's just noise. On second thought, I turn it up slightly.

This is the first year of the CIPHER Hip Hop Learning Community. I just got one of my walls painted in a burgundy color to offset the all-white interior of my new office. Adorned all throughout my walls are paintings, portraits, and posters my students have gifted me over the years. You know you're entering a Hip Hop space when you see directly in front of you an accent burgundy wall with paintings of Chance The Rapper, QuestLove, and A Tribe Called Quest. As you look to the left, a Tupac Shakur wall quote speaks to you: "If you want something you've never had, then you've got to do something you've never done." Right above my dual-screen computer, hangs a vinyl record cut-out clock that embodies Notorious BIG laced with a golden Basquiat-inspired crown. Being in the space feels like the colors of the room are moving to the beats of J Cole.

A knock on the door layers right on top of the high hat of the J Cole beat. It was my student, Vince, who was decked out with his red 49er Faithful snapback, baggy jeans, and a black denim 
jacket. His Lowrider Club name was neatly sewn right above his right jacket pocket and across his back between his shoulder blades. He was what we call an OG, an Original Gangsta, from the Mission in San Francisco. He's half Filipino and half Latino and has that Frisco swag. When you hear him speak, you almost hear Tony Robles, the People's Poet of San Francisco reciting his piece titled, "Friscopino II."

\author{
Friscopino is a pot \\ Of mispronounced \\ Names that go \\ Undigested, burning \\ In our ears and throat \\ Friscopino is Filipino \\ From SF \\ Filipino and black \\ Black and Filipino \\ Filipino and Mexican \\ Mexican and Filipino \\ Filipino and Italian \\ Italian and Filipino \\ Filipino and Chinese \\ Chinese and Filipino \\ Filipino and Native \\ Native and Filipino \\ And other mixtures \\ In our Lola's pot \\ That gave birth to \\ What is Friscopino
}

We greet with a fist bump and a head nod and he sits squarely in the chair. "What's good Vince? How you doing these days?" Vince leans back in the chair as if he's dipped low in his cherry red 1972 Chevy Impala. “I'm good man. I've been thinking about our last meeting. I was straight stressin'. All I got was that last Math class and I be good to go." I nodded in agreement and replied, "You was a hot mess." We both laughed hysterically. He responded, "I wasn't 
about to let Math take me out like that. You know Math ain't my thing. I just couldn't give up right then and there. I was two classes away from getting that degree." I then asked him, "What would that mean? You getting that degree?" Vince takes a deep breath, carefully composing himself from getting too emotional and with his Friscopino raspy voice, he replied, "It'd be a proud feeling. How can I face my family and my friends and letting them know I failed? What message would I be sending to all of them? They'd say things like, 'Oh, I told you so. School ain't for you.' I wanted to prove to them that I can do this. And maybe my friends' kids would work hard at getting an education. I want to be a role model for their kids, my kids." I met with Vince four times prior to this meeting and this was the most emotional and inspiring moment we've shared. I validated him by saying, "That's real inspiring. Knowing your story, where you came from, what you have endured being locked up for many years. It's amazing how resilient you are but also how intentional you are in doing this for your family and friends." As the words of encouragement reached his ears, he sat up from the chair, leaned towards me and said, "Man, I lost a lot of years in prison. I know coming out, no one would believe in my capability to be successful. I could have easily continued the street life, but I know where that road leads to. Man, I want to be a role model for these kids, you know? Some of these kids don't have fathers." I extended my fist towards him and as his fists collided with mines, I said, "That's for real. So what do you say? You ready?" He quickly responded, "I've been waiting all semester for this meeting."

I turned towards the computer, logged into my Counselors portal to pull up Vince's graduation application. We filled out the application, verifying that he has all of the classes completed for his degree requirements. I scrolled my arrow towards the green submit button. I got up from my chair and told him to take my seat so he can personally press submit. He looks at 
me with his eyes glossed with held back tears, accompanied with his trembling voice, he said, “This has been a long journey. It's been a long struggle. But it was definitely a beautiful struggle." I nodded in agreement and responded, “Yes, there's beauty in the struggle so don't ever forget that. Always remember how far you came. Your struggles taught you everything you needed to know to get to this point. And here we are, submitting your application for graduation! Congratulations Vince!"

\section{"It's beauty in the struggle, ugliness in the success, hear my words or listen to my signal of my distress."}

“Love Yourz", J Cole (2014)

J Cole's verse from the song, "Love Yourz", vividly captures not only the narrative described in the introduction but also represents the type of counseling approach that is humanizing, strengths-based, and culturally responsive. When students walk into our offices, they are more than just student ID numbers. They are more than just degree-seeking, transfer, or undeclared students. They are more than just a box to show statistically that we are serving a certain number or a certain type of student. This excerpt highlights the importance of personal narratives and the power of lived experiences. As counselors, we take their struggles and have them re-envision them as beautiful pieces of themselves. We tell them that success is never a straight line; that there will be ups and downs, and twists and turns. It is through that ugliness that adds beauty in the struggle. One of the many roles that we have as counselors is to create these brave spaces to draw out their lived experiences and how they make meaning of them. We hear their words intentionally and listen with our ears and our hearts because the signals of distress can manifest in various forms. We can see it on their faces. We can hear it in their voices. We can observe it by their posture. We can feel it from their energy. J Cole's verse 
illustrates exactly how we should build meaningful working relationships with our students. To that end, this study aims to explore how Hip Hop pedagogy informs college counseling practices working with traditionally marginalized students of color.

\section{Problem Statement}

Educational spaces have always been connected to negative and exclusionary experiences. In the narrative of Vince, success to exist is stemmed from changing the relationship that educational spaces hold for him. His experiences in prison allowed him to recognize how to adapt to certain situations in the classrooms. While Vince's educational journey has proven to be successful, that is not the case for many students of color. Many of these students experience numerous barriers such as lack of culturally relevant curriculum (Von Robertson, Bravo, \& Chaney, 2016) and racial microaggressions (Hall, 2017). Many higher education institutions will need to address these barriers. At the heart of this improvement is the interface between students and academic advising (Mitchell \& Rosiek, 2005). By addressing the various barriers that students face, providing supportive academic advising leads to positive student outcomes around graduation and student persistence (Pascarella \& Terenzini, 2005).

While college counseling approaches have evolved over the years, a review of the literature identified prescriptive advising and developmental advising as being the most prevalent (Smith \& Allen, 2008). Because there are no established theories around academic advising, most theories that help inform academic advising approaches are rooted in education and the social sciences such as psychosocial and cognitive theories. These theories also range with various perspectives such as career development, student development, cognitive development, and motivation (Creamer, 2000). Although these theories can provide important foundations for counseling students, there are major limitations in utilizing theories that were created from 
Eurocentric, westernized epistemology. Creamer (2000) argues that these theories may not be applicable to student populations such as women, minoritized students, the LGBTQI community, or students from different religious backgrounds.

When we review degree completion and graduation rates in community colleges for students of color, specifically African American and Latinx students, we see that these students are identified as experiencing disproportionate impact across several performance indicators of success in comparison to their White and Asian counterparts (National Center for Educational Statistics, 2018). The overall completion rate for students who started in two-year public institutions was much higher for White and Asian students (45.1\% and 43.8\%) than Latinx and Black students (33\% and 25.8\%, respectively). In addition, Latinx (44.8\%) and Black students (56.7\%) have the highest stop-out rates in comparison to White and Asian students (41.5\% and 32\%) (Shapiro, Dundar, Huie, Wakhungu, Yuan, \& Hwang, 2017). While Latinx and Black students do not complete their degrees within 2-3 years, they are also not enrolled at any institutions of higher education.

This poses a significant social justice and equity issue for this student population. Research shows that students who do not have higher education degrees or certificates will accrue lower lifetime earnings and are more likely to be at or near poverty levels (Museus \& Saelua, 2017). The Bureau of Labor Statistics indicated that, in 2018 and beyond, more than $60 \%$ of future careers will demand more formal education credentials (Schott, 2012). Unless major changes are created, the significantly low graduation rates of students of color will result in lower long-term wealth acquisition, greater income gaps across race and/or educational levels, and a negative impact on the nation's overall intellectual capital and global competitiveness (Hall, 2017). Based on the Economic Policy Institute (2015), the average unemployment rate for 
Black college graduates has been $4.1 \%$, nearly two times the average unemployment rate for White college graduates (2.4\%) and equivalent to the unemployment rate of Whites with an Associate's degree or who have not completed college (4\%). The largest disparity occurs among students with less than a high school diploma where White students have an unemployment rate of $6.9 \%$, while the unemployment rate of Black students is at a staggering $16.9 \%$. While Black employment is significantly higher than White unemployment regardless of educational attainment, having an educational degree does contribute to long-term wealth acquisition.

To address these social justice and equity issues, it is important for educational leaders to focus on how they can strengthen, enhance, and support academic advising and college counseling services through professional development opportunities, leveraging the intellectual capital of college counselors to create innovative strategies, and advocate for institutionalized funding sources to support these strategies. College counselors play a significant role in assisting students throughout their educational journey in a variety of ways. They can communicate information around general education, transfer requirements, and degree requirements. In addition, they can co-construct educational plans with students through collaborative goal setting, cultural responsiveness, and career exploration. Because there is not one single academic advising approach to effectively serve all students, it is important for educational leaders at higher educational institutions to be open to new counseling approaches such as one that employs Hip Hop pedagogy. Grounded in equity, educational leaders can thoughtfully examine current counseling practices and develop new knowledge of how we can meaningfully serve and support our students.

It is also important to critically look at our existing academic advising approaches and examine not only how we help students achieve their educational goals but also how we create 
the spaces that help shape them to become active participants in their own educational journeys. Drawing from critical and poststructural perspectives, Hip Hop pedagogy acknowledges and reconsiders three elements of knowledge that need to exist in academic advising: a) the role of context, b) intersectionality, and c) acknowledgment of individual agency (Jones \& LazarusStewart, 2016). These elements of knowledge are not universally applied in prominent academic approaches such as prescriptive and developmental approaches. In addition to these elements of knowledge, there is an aesthetic to Hip Hop that makes this culture unique. The aesthetics of Hip Hop represents the "ways of doing and being" (Petchauer, 2015). How does one embody Hip Hop? Rose (1994) challenges us to imagine Hip Hop aesthetics as a blueprint. What might this look like in our counseling spaces?

\section{Researcher Positionality}

In studying how California community college counselors who utilize Hip Hop pedagogy in their counseling practices, it is important for me to acknowledge how I locate and position myself in this research. Not only have I served as a college counselor at a community college for close to 15 years, I have also had life experiences that are rooted in Hip Hop culture. My relationship with Hip Hop started as early as the late 1980s, and has served as a tool for healing, empowerment, communication, innovation, and emotional intelligence in my own personal growth and development.

Recognizing the power and influence Hip Hop has made on me and countless youth around the world, it only made sense for me to understand how it can be utilized in educational and counseling spaces. My desire and commitment to Hip Hop in education manifested in the creation of Rock The School Bells (RTSB), an annual Hip Hop educational conference for youth and students in 2007. The conference is aimed to educate youth around the importance of higher 
education and career exploration, increase awareness around healthy lifestyles and mental health, and provide tools and strategies for social justice and equity through the cultural elements of Hip Hop. RTSB paved the way to create the Center for Innovative Practices through Hip Hop Education and Research also known as the CIPHER Hip Hop Learning Community in 2014, providing students an educational pathway of general educational courses that are contextualized through Hip Hop along with embedded educational experiences such as mentoring, service learning opportunities, and leadership development. In addition to engaging in culturally relevant curriculum in courses such as English, History, and Business, students also work closely with me as their CIPHER college counselor during their entire educational journey.

My counseling experiences in CIPHER have led me to examine how Hip Hop can be used as a tool to heal, liberate, and create agency in college counseling. For many decades, prescriptive and developmental academic advising approaches have been widely used in college counseling. However, research has shown that these approaches to academic advising have created incongruent student experiences leaving many students with unmet needs (Hale, Graham, \& Johnson, 2009; Smith \& Allen, 2013).

Hip Hop as a musical genre has experienced many evolutions within the culture. Similarly, our students have also adapted and evolved. Hip Hop as a process disrupts the formulaic methods that some academic advising approaches uphold and remains an untapped resource that has immense potential to inspire creative fluidity within the field of college counseling (Freas, Limon-Guzman, Carnero, \& Times, 2017). 


\section{Operationalization of Concepts}

\section{Academic Advising and College Counseling}

The terms academic advising and college counseling will be used interchangeably throughout the dissertation as several resources and studies offer a mix of definitions for both terms. Kuhn, Gordon, and Webber (2006) describe this as the advising and counseling continuum. Generally, academic advising is seen as being more informational and explanatory while college counseling focuses on the collaborative, developmental process of helping students realize their educational, career, and personal goals. In addition, the terms are also used differently depending on states, college districts, and educational institutions.

For this dissertation, I will utilize the term, college counseling, to denote a range of counseling functions. College counselors who practice at California community colleges take on many roles and responsibilities with students such as goal setting, course planning, providing degree and transfer requirements, and connecting students to specific programs and services. Community college counselors are also involved in group counseling, program coordination, curriculum development, and professional development. Academic advisors in community colleges tend to focus more on information giving and course planning and registration. The term academic advising is used prominently in the body of research related to academic advising, college counseling, and student development. However, this term does not describe the wide range of roles and functions that college counselors in California community colleges engage in.

\section{Hip Hop Spelling, Hip Hop Pedagogy (HHP), Critical Hip Hop Pedagogy (CHHP), Hip Hop-Based Education (HHBE)}

The spelling of Hip Hop will be used interchangeably throughout the proposal such as hip hop, hip-hop, Hip hop, Hiphop, and Hip Hop. While there is no specific or official way of 
spelling the term, I intend to spell it "Hip Hop" as explained by the Hip Hop pioneer and rapper,

\section{KRS-ONE:}

"Hip Hop never enters the physical world, never. We can't drink it. We can't eat it. We can't go to it. We can't wear it. But somehow we all know that it's here. We all are feeling it, well not all, but those who feel it are sensing it psychically. We all feel and sense the same thing, which, by the way, I find magnificent and phenomenal about a culture like this; it's a kulture of consciousness. Hip Hop is not physical. It's an idea. It's shared. It's a behavior. It's a way to view the world (Jam, 2010)."

Hip Hop is seen by those familiar with it as a culture that embodies music, fashion, language, art, and dance. As with any culture, whether Asian, Latin, or Hawaiian, the term itself is always capitalized. While this term "capitalism and capitalization" is rooted in patriarchy, power, and white supremacy, addressing Hip Hop in this way allows Hip Hop scholars, practitioners, pioneers, and artists to argue heavily the importance of the professionalization and intellectual legitimacy of Hip Hop in the spheres of higher education and counseling scholarship.

There are several concepts that have been used interchangeably to describe the utilization of Hip Hop in various educational spaces. However, each term has its own distinction, its own style. Hip Hop pedagogy refers to teaching and learning that are grounded and rooted in the four elements of Hip Hop - DJing, breaking, emceeing, and graffiti. Knowledge of self has also been noted as the fifth element of Hip Hop. This particular element of Hip Hop is used to recognize, affirm, and cultivate youth's sensibilities of self-determination and self-knowledge (Love, 2015).

Critical Hip Hop Pedagogy (CHHP) refers to the way we engage students in educational spaces utilizing Hip Hop as a way to analyze social and political issues and representation of marginalized communities. According to Akom (2009), the fundamentals of CHHP are as follows:

- It is participatory and youth-driven. 
- It is cooperative, engaging students in a joint research process in which each contributes equitably.

- It foregrounds race, racism, gender, and other axis of social difference in the design, data collection, and analysis.

- It helps prospective teachers focus on the racialized, gendered, and other intersections of social difference, experiences within and by communities of color.

- It challenges the traditional paradigms, methods, and texts as a way to engage in a discourse on race that is informed by the actual conditions and experiences of people of color.

- It is committed to co-learning, co-facilitating, and multidirectionality.

- It is transdisciplinary, drawing on Black/Africana Studies, Raza Studies, Ethnic Studies, and Women's Studies.

- It involves local capacity building.

- It is an empowering process through which all participants can increase control of their lives.

- It seeks a balance among critical thinking, reflection, analysis, and action.

- It emphasizes a union of mind, body, and spirit rather than a separation of these elements.

Drawing from what Freire (1970) calls "critical praxis", the necessary process of reflection and action, CHHP situates the power of knowledge onto the students. Giving youth the ability to construct knowledge based on their lived experiences and focused research allows them to understand much more deeply how their own power can disrupt and dismantle structures of oppression.

Hip Hop-based education (HHBE) focuses on how to incorporate Hip Hop culture into school-based curricula, most notably within English Language Arts curricula (Hill \& Petchauer, 2013; Morrell, 2002; Morrell \& Duncan-Andrade, 2002). Additionally, HHBE has illustrated ways in which Hip Hop culture can be used to create and produce culturally relevant and responsive environments resulting in improving student retention, increasing achievement, and strengthening classroom communities (Camangian, 2015; Emdin, 2010). As an umbrella term, HHBE encompasses Hip Hop as forms of curricula, critical and culturally relevant pedagogies, and aesthetics. 
As these concepts begin to crystallize into clearer delineations, it is equally important to remind the academy that Hip Hop culture and pedagogy are more than just rap music and analyzing lyrics. While there is extensive literature regarding utilizing Hip Hop pedagogy effectively in classrooms (Emdin, 2010; Hill, 2009; Morrell \& Duncan-Andrade, 2002), there is also a need to explore the ways Hip Hop pedagogy can inform college counseling practices with students. Further research is necessary to move beyond examining content through Hip Hop in the classroom to what Petchauer (2014) refers to as Hip Hop aesthetics - "ways of doing and being." Given that effective counseling approaches call for centering our students' knowledge and experiences (Museus \& Ravello, 2010), understanding Hip Hop aesthetics as a Hip Hop pedagogical tool will inform college counselors use of alternative ways of placing students at the core of their counseling work.

\section{Purpose of the Study}

The purpose of this study is to explore in depth how specific California community college counselors make meaning of their lived histories and experiences within Hip Hop culture and how they have shaped and informed their own college counseling practices with community college students. Community college counselors provide a wide range of services that include assisting and guiding students in navigating through academic, career, vocational, transfer, and personal situations in the California community colleges. Research has acknowledged the importance and the need for counselors in supporting students to attain their educational goals (Barnett, 2011; Hatch \& Garcia, 2017; White, 2015).

Students view community colleges as having the opportunity to receive a postsecondary education due to open access, accessibility, and affordability. Many students of color, specifically African American and Latinx students, attend community colleges because they see 
these institutions as venues that facilitate their social and economic advancement (Bush \& Bush, 2005). In a report in Fall 2014, 56\% of Latinx students and 44\%of Black students who are enrolled at institutions of higher education are enrolled in community colleges; while the percentages of Asian and White undergraduates had higher enrollment rates at the public fouryear universities (National Center for Educational Statistics, 2015). Specifically, in California community colleges, $46 \%$ of all community college students are Latinx students. Interestingly enough, only 5.9\% were African American students (California Community Colleges Chancellor's Office, 2018). Nationally, over two-thirds of Latino and African American students who enroll in college after high school, choose to attend community colleges (National Center for Educational Statistics, 2018). More specifically, 85\% of Latino college students indicated attending community colleges as a first step to obtaining a Bachelor's degree (Crisp \& Nora, 2010). While the intent to transfer is evident for Latino students, less than $25 \%$ of all Latino students who began at the community colleges actually transferred to four-year universities and/or earned a Bachelor's degree (Fry, 2004).

Carnevale \& Strohl (2013) found that ability and academic achievement do not fully and adequately account for the disproportionate impact across indicators of college success. There are a number of barriers that impact student success outcomes for many students from marginalized communities such as significant family obligations (Rodriguez, Massey, \& Saenz, 2016; Tovar, 2015; Wood, 2012), lack of culturally relevant curriculum (Von Robertson, Bravo, \& Chaney, 2016), racial microaggressions (Hall, 2017), lack of sense of belonging (Brooms \& Davis, 2017; Museus, Yi, \& Saelua, 2017; Tovar, 2015; Wood, 2012), and lack of faculty mentoring and advising (Museus \& Ravello, 2010; Wood \& Williams, 2013). Higher education institutions will need to improve to address these barriers including re-examining the structures, 
systems, and policies that are in place that continually perpetuate the status quo. Rather than requiring students to be college-ready, how do educational institutions engage in critical selfreflection and accountability to become student-ready? At the center of this improvement, reimagination and comprehensive redesign are the interface between students and academic advising (Mitchell \& Rosiek, 2005).

The dominant narrative that students have internalized is that college education is a means to an end such as direct employment upon graduation; however, discussions about contributing to the betterment of society and self-development become less prioritized in their college education. In a 2013 study administered by the Higher Education Research Institute (HERI) at UCLA's Graduate School of Education and Information Studies, they found that students were placing a high premium on the job-related benefits of going to college. $87.9 \%$ of incoming freshmen at UCLA cited "to be able to get a better job" as a very important reason to go to college. This narrative also supports this notion of an educational system that is meritocratic, capitalistic, and colorblind; that higher education is where students "learn to earn" and not "learn for freedom" (Ladson-Billings \& Tate, 1995). However, this narrative does not apply to all students, specifically students from marginalized communities, as it dismisses the complexities and experiences these students face in comparison to their White and Asian counterparts.

One of the keys to student success in college is the level of involvement students have with college activities. Astin's Theory of Involvement (1985) defines involvement as the level of investment a particular student puts into an institution. However, this does not take into consideration the relationship and perception that students of color have with the institution. Students of color who have experienced microaggressions, limited or no sense of 
belonging, classroom alienation, or the absence of culturally relevant curriculum had negative perceptions and relationships with their institutions (Lee, 2018; Maramba, 2003; Museus, Yi, \& Saelua, 2017). As a result, these experiences create difficulties for students of color to invest into the institutions and access the support services that literature suggests are essential to college success (Bush \& Bush, 2010; Tovar, 2013).

As Hip Hop education continues to evolve its own identity through research, there is a need to bring awareness to the development of best practices within college counseling as an integral part of Hip Hop education. A move towards a college counseling framework rooted in culturally responsive pedagogy is not intended to replace, dismiss, nor reject the existing approaches to academic advising and college counseling but rather to inform another counseling pedagogical approach that is reflective of the needs of historically neglected and traditionally marginalized students.

Petchauer (2015) indicated that aesthetics is a thread that flows throughout larger bodies of Hip Hop educational disciplines. Aesthetics is the idea that counselors and students can find "ways of doing and being." There is this energy and collective spirit; a mutual understanding through interactions that is experienced both verbally and nonverbally. Oscar Wilde, an Irish poet and playwright in the late nineteenth century, was an influential leader in the Aesthetic Movement that believed that art in its various forms should seek "to exist beautifully." Our youth and students come into our educational spaces with stories and lived experiences that can inform how we can honor and serve them. Their presence matters and that they belong in these spaces. In today's youth vernacular, there's an acronym that goes, "IYKYK", which stands for "if you know, you know." Because it has no exact direction or operational method, this plays as the strength and beauty of Hip Hop aesthetics as an effective framework to college 
counseling. It shifts away from prescription and rigid structures to creating counseling environments that are rooted in authenticity and culturally responsiveness. When counselors reflect on the process of transformative change with students, we envision college counseling as Hip Hop. Every move, every action, every word, and every beat are informed and influenced by something, whether they be stories, lived experiences, values, thoughts, and/or ideas.

\section{Research Questions}

1. What are the life stories and experiences of community college counselors who engage in Hip Hop pedagogy?

2. How does their lived experiences and their understanding of Hip Hop shape and inform their college counseling practices?

\section{Scope of the Study}

The scope of this study is to examine four California community college counselors who utilize Hip Hop pedagogy in their counseling practices. These counselors are also current and/or former practitioners in Hip Hop, meaning that they have experience within the four Hip Hop elements of DJing, graffiti, emceeing, and breakin' (breakdancing). Conceptualizations of advising as supporting student development are over 40 years old, almost the same age as Hip Hop itself (Anderson, Motto, \& Bourdeaux, 2014; Smith \& Allen, 2006). This is further exemplified by a saying in Hip Hop that "a fresh beat today ain't a fresh beat tomorrow." We live in a digitally advanced society where social media can be accessed at the tips of our fingers and serves as a major source of information. We are inundated with information nearly every second of the day and, as a result, we are consciously and unconsciously influenced in the way we act, think, create, and live. Given the rapid social, economic, and cultural changes in society, in what ways can we keep up with the evolution of student development? 
The sources of data being collected for this study include interviews, field notes, data memos, examples of their work, and classroom observations. More specifically, I will be employing phenomenological interviewing using Seidman's (2006) three-interview method to explore three areas. The first interview will focus on their life histories, educational experiences (i.e. K-12 experiences, college experiences), and their personal experiences with Hip Hop. The second interview will focus on their current occupation and will explore their roles and responsibilities as college counselors at various California community colleges. The last interview will focus on the connection between their Hip Hop lived experiences and their current work in counseling. We will also explore, from their perspectives, how Hip Hop has informed the way they counsel students. All of the interviews will be 60-90 minutes in length and will be conducted at a location where the participant is comfortable (i.e. office, classroom, home) where there is privacy. These interviews will take place from September - December 2019.

\section{Significance of the Study}

This research will add to the scholarship of educational leadership and practice as well as college counseling. Research has shown that our students who are traditionally marginalized, such as African American and Latino men, are more successful when they experience a sense of belonging at their institutions and have access to faculty and peer mentoring (Harper, 2015; Harris, Wood, \& Luke, 2014; Tovar, 2013). Additionally, research shows that these students also need counselors who can create meaningful and purposeful relationships. Culturally responsive pedagogical approaches such as Hip Hop pedagogy utilized in college counseling allow us to work with students from marginalized communities in empathic and humanizing ways.

In addition, this research will add to the knowledge production in the area of Hip Hop education. While this research is focused on college counseling, most of the existing research 
regarding the usage of Hip Hop pedagogy comes from the classroom. Consequently, there is very little research on how Hip Hop pedagogy informs our counseling practices as well as the impact on the success outcomes for students such as retention and success rates.

\section{Cultural Appreciation versus Cultural Appropriation of Hip Hop}

Since Hip Hop hit the mainstream in the early 1980s, the culture of Hip Hop has transcended from its roots in the Black and Brown communities of South Bronx into a global phenomenon. The global impact of Hip Hop has stretched beyond the music and into the sphere of global marketing from selling products, personalities, and lifestyles. As a result, people who are drawn to Hip Hop culture adopt a certain way of being and doing that embodies Hip Hop such as the clothes they wear and the language they use.

While scholars recognize that Hip Hop provides a voice and platform for self-expression for people around the world, it can also be problematic if the historical origins of Hip Hop are not understood or acknowledged. Cultural appropriation results from the borrowing or taking of aesthetics and elements that are endemic to a particular culture without acknowledging the historical and cultural origins.

The term "cultural appropriation" generally carries a negative tone that calls out an act of conscious and unconscious expression of dominance. Within the context of Hip Hop culture, a dismissal of the historical and cultural origins of it can be seen as an "exploitation of Blackness." A huge part of this "exploitation of Blackness" emerged when multinational corporations such as Universal Music Group, Sony, and AOL Times Warner, began to wield its power and money in Hip Hop culture (Love, 2010; Rose, 2008). With this power and influence, these corporations saw the immense value of Hip Hop culture and capitalized on it to maximize profits at the expense resulting from corporatizing and culturally appropriating Black 
culture. This became very problematic particularly for Black communities because these major corporations run by White, male executives began to "create representations embedded with essentialized notions of Blackness" (Love, 2010, p. 223). Many of these essentialized notions of Blackness are typically negative and stereotypical such as images and words that represent poverty, violence, drugs, lavish lifestyles, and money. These major corporations essentially took Hip Hop culture created by Black and Brown youth, repackaged it to make it more marketable to a wide audience, and sold Hip Hop back to the masses in mainstream America. As a result, Hip Hop became a multibillion-dollar industry where those who had the most power and influence, benefitted at the expense of Black and Brown communities.

As these notions around Blackness through Hip Hop have entered the psyche of mainstream America, it is also important to note that ever since the industry acknowledged Hip Hop in 1991 as a musical genre, nearly 80\% of consumers of Hip Hop music have been White, suburban teenagers. Prior to the movement of the digital music age in the late 2000s such as Spotify, Youtube, and Pandora, the percentage of consumers of Hip Hop continued to be largely White male teenagers. Once music made a shift to online streaming services, music became more accessible to a more global audience where the percentage of consumers of Hip Hop based on different ethnicities surpassed the number of White male teenagers. The carefully, corporatedriven, constructed notions of Blackness and the massive consumption of Hip Hop by White teenagers are examples of two contextual factors that drive these tensions of cultural appropriation. Cultural appropriation calls to attention the flows of power and benefits based on race, class, gender, and sexuality. Hip Hop culture, in its historical origins, depicted the lived experiences of Black and Brown youth who were subjected to social, economic, and political oppression. Through these experiences, many youth from these communities turned to art forms 
of self-expression such as rapping, DJing, breakdancing, and aerosol writing also known as graffiti. Hip Hop was a way of life for many youth in the South Bronx. Hip Hop is about authenticity and those who identify with Hip Hop culture relate to these lived experiences. Rodriguez (2006) reflected on some of the White participants' perspectives about their engagement in Hip Hop. The participants shared that Hip Hop was "cool”; that Black culture was "cool." Some of these participants also stated that they didn't see too much a connection between the "cool" music and the lived experiences of African Americans. People who are part of the dominant culture based on race, class, and gender have a choice to participate in and out of Hip Hop culture. They may listen and engage in lyrics that illustrate themes of violence, poverty, and drugs but may not necessarily have lived in those conditions.

For Black communities, the corporatization of Hip Hop has been a double-edged sword in that: 1) they don't benefit from the culture as much as those in power and influence; and, 2) they are subjected to the essentialization of Blackness created by these corporations. As a result, many artists such as P Diddy, Jay-Z, and Nipsey Hussle built and developed their own companies to take back Hip Hop from corporations that feed into the cultural appropriation existing today. By doing this, they are able to take back a culture that was inherently Black culture and shape Black and Brown communities using narratives that authentically represented those communities. They are able to gain power and privilege in an industry that profited immensely off Black and Brown culture. By being able to control their own assets within Hip Hop, artists such as P Diddy (Daddy’s House Social Programs), Jay-Z (Shawn Carter Foundation), and Nipsey Hussle (Vector90) are able to give back to their own communities in education, healthcare, social work, and the arts. 
It is very clear that cultural appropriation can be seen as acts of dominance, exploitation, and misrepresentation of a culture. However, differentiating cultural appropriation from cultural appreciation can be difficult and complex. Within the context of Hip Hop, this culture has evolved over the last four decades with cultural and aesthetic contributions from artists worldwide. For example, Filipino DJs in the Bay Area such as DJ Q-Bert, Shortkut, and Apollo were responsible for elevating and advancing the art of DJing or turntablism in Hip Hop in the 1980s. Where is the line between cultural appropriation and cultural appreciation?

Lees (2001) shares a poignant story about Phil Woods, a jazz saxophonist who went on tour with trumpeter Dizzy Gillespie in the late 1950s. Phil Woods began to openly question his position as a white musician playing in a decidedly Black music genre where he drew inspiration from the music of Charlie Parker. He asked Gillespie and his other bandmates if he could "make it" as a white man playing jazz. Gillespie responded, "No one can steal a gift. Charlie Parker gave the world his music, and if you can hear it, you can have it.” W.E.B. Du Bois (1903) shared a similar sentiment in The Souls of Black Folk, describing Black music as "the singular spiritual heritage of the nation and the greatest gift of the Negro people (p. 155)." While these statements may come as acts of generosity, it doesn't give other people permission to use this gift however they please. In fact, these statements come with much stronger implications that can easily be missed. They speak largely and broadly about the impact and influence of African American music in the fabric of American history and they also speak to the idea that this is a gift given by African Americans.

Many Hip Hop scholars, practitioners, and artists debate about who gets to utilize Hip Hop in their practice. It can be argued that cultural appropriation of Hip Hop exists today in educational spaces. While this is true, there are educators who don't necessarily identify 
themselves as part of Hip Hop culture, have utilized Hip Hop in meaningful and transformative ways in their educational practices. Exploration of the notions of intentionality and interpretation can help to evaluate if Hip Hop culture is appropriated or appreciated. When scholars engage in these conversations around using Hip Hop in educational spaces such as conferences, symposiums, and workshops, scholars, in general, tend to center around questions regarding their personal and professional intent, who they intend to serve, and the overall goals of using Hip Hop in their work. By addressing these points, scholars within Hip Hop education seek to develop professional development opportunities and trainings that can inform educators and educational institutions about ways to minimize acts of misrepresentation and exploitation. This is an additional area of future research as the interest of Hip Hop pedagogy in higher education has grown steadily in the past decade. It should be highly noted that cultural appropriation can be harmful and emotionally triggering for traditionally marginalized student populations.

Intentionality requires a level of authenticity and self-reflection. When educators are interested in learning the various pedagogical approaches to Hip Hop, it is important for them to enter the work with a level of authenticity. It is also critical to be transparent of what they do and don't know about Hip Hop culture especially since Hip Hop culture is always evolving. Hall (2019) also describes this notion around generational positionality even within Hip Hop culture. He argues that educators who do identify with Hip Hop culture has to be aware of their own generational positionality when it comes to Hip Hop. He used an example of an educator whose lens of Hip Hop and the ways he works with his students are rooted in 1990's Hip Hop. This particular educator had a difficult time connecting with students who were listening to more current styles of Hip Hop. Hall argues that this can be as problematic as someone who is 
culturally appropriating Hip Hop. There is a balance and harmony between content knowledge and contextual knowledge; the knowledge that educators bring into the space while providing opportunities for students to provide their knowledge. To engage in Hip Hop educational work, educators must enter from an exploratory stance and be open to learning Hip Hop culture. In doing so, practicing intentionality calls for engaging in reflective understanding of their own positions of power and privilege.

While intentionality addresses the why and purpose of utilizing Hip Hop in educational spaces, the issue around interpretation focuses on the how. In what ways are educators utilizing Hip Hop in their educational settings? Educators will often enter the work with good intentions but may lack the breadth and depth of Hip Hop culture. This can elicit some unintended, indirect forms of trauma and microaggressions. Sachs and Schonfeldt-Aultman (2018) argue that because Hip Hop culture is fluid and is constantly evolving, it becomes less about race and more about the consequence of people's uses of Hip Hop. They do contend that there is a need to acknowledge its historical origins of Black arts and culture but rather focus their attention on the usage or interpretation of Hip Hop culture.

Interpretation of Hip Hop culture in educational settings can directly and indirectly impact students' experiences. In what ways is Hip Hop being utilized and recognized? How are assignments, activities, and projects created to provide a level of breadth and depth of Hip Hop? What level of understanding are students learning about the history and culture of Hip Hop? By engaging in surface level conversations around Hip Hop culture, the ways students will understand and engage with the culture will only be at that level. An example of this would be a teacher instructing the class to make a rap song about what they learned in their assigned reading. While this may provide a creative way in engaging students to learn in a different way, 
it is still creating a rap song. By not facilitating critical dialogues around the intersection of race, class, gender, and sexuality with Hip Hop culture, the way the culture is interpreted in this example is minimized into just a simple activity.

This pedagogical critique on utilizing Hip Hop in this manner is not to diminish the attempts of educators who genuinely appreciate Hip Hop culture. It calls for a pause. Because Hip Hop culture has impacted youth worldwide, the history of the culture can be lost. One of the most significant ways that cultural appreciation can be called out as cultural appropriation is when those who engage and participate in Hip Hop define the culture as "Hip Hop is for everyone." Hip Hop culture is about bringing and elevating our communities despite the differences in race, class, gender, and sexuality. This is where the issue of interpretation of Hip Hop culture can be complex and complicated.

Rodriguez (2006) reminds us that adopting this notion that Hip Hop is for everyone without the historical and cultural acknowledgment of Black culture can be processed as this color-blind ideology. Drawing from the Civil Rights movement, color-blind ideology asserts that there is an essential sameness between racial and ethnic groups despite their unique histories and relationships to power. Rodriguez (2006) did a study to examine how White youths culturally appropriate Hip Hop by adhering the demands of color-blind ideology. He found that they all used color-blind ideologies to justify their presence at various Hip Hop concerts. Much of their justification is influenced by major corporations who are responsible for mass marketing this idea of Blackness. Perry (2002) shares that Whites who pick up on African American styles and music don't necessarily want to be Black; they seek to acquire the characteristics of Blackness associated with being cool. Rodriguez (2006) also found that the White participants 
in his study often avoided the topic around race and addressed Hip Hop as "cool" and "just music." One participant even went on to say, "Hip Hop is so not a black-white thing."

Sachs and Schonfeldt-Aultman (2018) caution educators that utilizing Hip Hop in educational spaces without exploring the history and culture of Hip Hop and the intersectionalities within race, class, gender, and sexuality, can be very damaging and problematic. They call to question whether or not educators' interpretation of Hip Hop culture in educational settings may perpetuate color-blind ideologies which ultimately dismisses notions around race, class, gender, and sexuality.

Given that Hip Hop culture has become a global phenomenon, how do we begin to measure and assess what's deemed as cultural appropriation or cultural appreciation of Hip Hop in educational spaces? Hip Hop as a culture, similar to our students' experiences, is fluid and always shifting. Even through these changes and evolution of the culture, how do we prevent from succumbing to color-blind ideologies? How do we honor and acknowledge the "gift" that has been bestowed unto us by Black culture? It is absolutely necessary and imperative for educators and educational institutions to hold each other accountable when engaging in Hip Hop culture. Rodriguez (2006) cautions educators that by not pushing back on color-blind ideologies, the corporatized version of Hip Hop culture itself will become the ultimate form of African American historical erasure.

It is necessary to explore and examine issues around cultural appropriation and cultural appreciation of Hip Hop culture when articulating the need to have Hip Hop pedagogy be part of the college counseling scholarship. As a Filipino American male engaging in Hip Hop education work, I recognize that I am a guest of this culture. I owe so much to Hip Hop culture for shaping my own identity throughout the various chapters of my life. I remember seeing Hip Hop for the 
first time on many walks to the bus stop in Virginia when I was in elementary school. I remember seeing them rap and breakdance on cardboards for the first time. I remember moving to Chicago and being the new kid in school. I remember tuning into Casey Kasem's Top 40 every Sunday while going to church to catch the three songs that piqued my interest in the early mainstream of Hip Hop. I remember it was Tone Loc's "Wild Thing" and "Funky Cold Medina" and Young MC's “Bust A Move." I remember moving to Alameda a year after the 1989 Loma Prieta Earthquake in the Bay Area. I remember MC Hammer. I remember baggy jeans and Starter parkas. I remember moving from one high school to another. I remember feeling disconnected and lost in an all majority White high school. I remember 1992. I remember that year in Hip Hop. I remember Nuthin' But A G Thang, Passin' Me By, They Want EFX, and It Was A Good Day. I remember my high school counselor telling me that I wouldn't amount to anything. I remember getting kicked out of school. I remember the disappointment on my parents' faces. I remember from then on, I started writing poems and raps. I remember winning a rap competition at our local Black Student Union event. I remember breakdancing in church halls and high school gyms. I remember spray painting my tag name on white walls near our high school. I remember fumbling over my friend's turntables. I remember my first heartbreak. I remember the song I wrote about the heartbreak. I remember house parties in Daly City with DJs in the garages. I remember rap battling against an entire gang. I remember escaping harm from said gang. I remember freestyling on the radio. I remember winning. I remember losing. I've experienced a lot growing up with Hip Hop. But what I do remember most about Hip Hop from Virginia, Chicago, Alameda, and all of the places I've lived in is how Hip Hop made me feel. 
As a guest to the culture, Hip Hop made me feel welcome. Using the analogy of being a guest at someone's place, if you stay there for a longer period of time, you are expected to help around the house such as taking out the garbage or washing the dishes. Similarly, as a guest of Hip Hop culture, I reflected on how I can advance and contribute to Hip Hop culture. For a culture that gave me life, meaning, and purpose during the many chapters of my life, how can I give back? How can I pay the "gift" forward? It is through this study that I hope to contribute to the scholarship of Hip Hop education and college counseling. How can counselors enter this work around Hip Hop with humility and authenticity? How can counselors do better in acknowledging the historical and cultural origins derived from the experiences of Black and Brown communities in their counseling practices? It is important to approach this work with an authentic level of intentionality and a deep reflection on how counselors make meaning and interpretation of Hip Hop culture within their own counseling practices.

\section{Hip Hop Aesthetics in College Counseling - A Conceptual Framework}

Drawing from the concept of aesthetics, or "ways of being and doing", this study is intended to explore how Hip Hop pedagogy in counseling spaces weaved with Rendón's Sentipensante Pedagogy impacts student success outcomes. The effect of Hip Hop pedagogy on student success outcomes can manifest in the following ways: increased students' awareness of self, identity, and goals; develop self-advocacy, creating spaces for discovery and healing, building community by creating meaningful relationships, and highlighting the importance of personal narratives as sources of knowledge (Emdin, 2010; Hill, 2009; Morrell \& DuncanAndrade, 2002).

As we explore how Hip Hop pedagogy is utilized in college counseling spaces, it's important to differentiate the concepts of "Hip Hop content" and "Hip Hop 
aesthetics." Petchauer (2009) defines aesthetics as not of artistic value but more as what makes certain practices unique to Hip Hop culture. For example, the content core or "elements" that make up Hip Hop culture include: rapping (i.e. emceeing), DJing or turntablism, graffiti or aerosol writing, and breakdancing (i.e. b-boying/b-girling). However, when we describe the aesthetics of Hip Hop we begin to examine what's endemic to Hip Hop culture. Within these Hip Hop practices, content refers to what the rapper or emcee says in a song, but the aesthetic for rap could be "freestyling" (Alim, 2007). Content is what records a DJ plays; aesthetic form is how they are being played such as cutting, blending, or beat juggling from one record to another. A cypher can also be seen as an aesthetic element to Hip Hop. Hip Hop cyphers are highly codified yet unstructured practices where youth who identify with Hip Hop culture exchange information in the form of raps or dance (Levy, Emdin, \& Adjapoing, 2018).

There are also several forms of aesthetic elements of Hip Hop that have been researched as valuable tools in education ranging from sampling (Pabon, 2006; Schloss, 2004; Schur, 2009), kinetic consumption (Kline, 2007), layering (Rose, 1994), flow (Krims, 2000), and rupture (i.e. break in flow, beat juggling, scratching) (Schur, 2009). Rose (1994) describes how we might reimagine utilizing these salient aesthetic forms of Hip Hop in education. What might that look like?

Let us imagine these Hip Hop principles as a blueprint for social resistance and affirmation: create sustaining narratives, accumulate them, layer, embellish, and transform them. However, be also prepared for rupture, find pleasure in it, in fact, plan on social rupture. When those ruptures occur, use them in creative ways that will prepare you for a future in which survival will demand a sudden shift in ground tactics (Rose, 1994, p. 39).

In addition to understanding the aesthetics of Hip Hop, it is also important to note that in Hip Hop culture, there is this notion of "show and prove." Hip Hop culture is performative and participatory by nature. In order for those practicing in the art and culture of Hip Hop, one must 
"show and prove" their skills in order to be validated. They must demonstrate either a mastery over form (i.e. one or more of the performative elements of Hip Hop) or they must reveal a mastery of knowledge of Hip Hop culture, its histories, and the plethora of philosophical and pedagogical ideas, while keeping abreast of the evolution and manifestations of Hip Hop culture.

This concept of "show and prove", this form of validation, draws me to Laura Rendón's (1994) Theory of Validation. The Theory of Validation proposes necessary efforts for getting students to be more connected to the institution. Shifting the responsibility of college success from the students to the institution is monumental in understanding ways to engage students more meaningfully. Astin's (1985) seminal work around student involvement does acknowledge that students enter college with identified inputs or descriptors such as age, socioeconomic status, gender, and high school GPA. However, these inputs were not explicitly used to define the ways the institutions can create spaces that acknowledge what students bring with them.

Rendón's Theory of Validation gives college counselors and other institutional agents a framework that they can use to validate students' inputs and experiences. She defined validation as "enabling, confirming, and supportive process initiated by in-and out-of-class agents that fosters academic and interpersonal development." Validation reflects a process rather than an end goal as the dominant narrative of higher education suggests (Patton, Renn, Guido, Quave, 2016).

Like all theories, the theory of validation has its strengths and limitations. While Rendón's original study on validation focused directly on student voices, the analysis did not specify how the theory can be applied to different groups of students with various backgrounds such as race/ethnicity, socioeconomic status, gender, and academic abilities. This study also did not fully engage within the context of social justice. How might the theory of validation explore 
why students from traditionally underserved and marginalized populations choose to go to college or even stay in college? In what ways can we explore how students can develop selfefficacy and advocacy when faced with oppressive, invalidating experiences such as racism and monocultural curriculum? Lastly, how can educators, specifically college counselors, be able to engage in self-reflexivity to challenge and interrogate our own identities, assumptions, positionalities, and biases within the context of college counseling?

These sets of questions lead to Rendón's Sentipensante Pedagogy (2009) where she argues for a need for a new dream of education that focuses on educating for wholeness, social justice, and liberation. This pedagogy represents a reunification of sensing and thinking to foster acquisition of knowledge and wisdom. This reunification is intended to disrupt and transform an oppressive educational system that privileges separation of knowledge, competition, and monodisciplinarity. The focus is on creating educational spaces that foster collaboration, transdisciplinarity, intuition, and active learning (Rendón, 2009). This reunification also reminds us that "ancestral ways of knowing were based on wholeness. Ancient ways of knowing focused on complementarity that exists between two opposites, resulting in a multiperspectival yet unitive view of the world" (Rendón, 2009, p. 134). This pedagogy cultivates personas educadas or well-rounded individuals who possess both knowledge and wisdom.

Rendón (2009) argues that by applying an integrative, consonant approach would attempt to see how the mind and feelings, our knowledge and wisdom, are connected and "how they work together in a natural rhythm that respects their distinctiveness yet appreciate their complementarity" (p. 66). As it connects to Hip Hop aesthetics, "ways of being and doing", the sentipensante pedagogy creates educational spaces that recognizes the connection between 
Western and non-Western ways of knowing and values the individual's quest for knowledge while acknowledging the importance of dialogue and co-constructed, shared experiences.

While Rendón's earlier study on the theory of validation places the responsibility on institutional agents of higher education to create conditions that foster experiences of validation, sentipensante pedagogy takes it further by addressing the goals of how we can privilege the knowledge and wisdom of our students, elicit social awareness around power and privilege in educational spaces, and engage educators through self-reflexivity in examining how our own practices may potentially uphold traditional, racial power structures in higher education.

Given that research has acknowledged the importance and the need for counselors in supporting students in their attainment of their educational goals from the beginning up to degree completion and/or transfer (Barnett, 2011; Hatch \& Garcia, 2017; White, 2015), this calls for an examination of our current college counseling approaches. This begs the questions: How do college counselors "show and prove" for their students? How do counselors show up in these counseling spaces? In what ways do they show and prove or provide spaces of validation for students in educational spaces? Overall, how do these aesthetics of Hip Hop pedagogy help inform our college counseling practices?

Through this conceptual framework, we have described the difference between Hip Hop elements and content versus Hip Hop aesthetics. We have also discussed the importance of "show and prove" as a means of validating student experiences. The last component to this framework is highlighting the importance of the process. This differs from the more traditional approaches to college counseling such as prescriptive and developmental approaches by allowing students to be active participants in the counseling process. It also provides an opportunity for students to engage in self-reflection and make meaning of their own counseling experiences. 
While Astin's (1985) seminal work around student involvement helped provide theories toward student success, it didn't explicitly take into account the different experiences students of color bring. Scholars have also highlighted the disconnect between collectivist cultures, such as those of many students of color, with the schooling cultures that distinguish middle-class individualism (Gosine \& Tabi, 2016). Many institutions have placed more focus on student deficiencies rather than acknowledging and cultivating their strengths, assets, and resources, as well as sources of resilience also known as their "community cultural wealth" (Yosso, 2005). Historically, Hip Hop culture came from a collectivistic culture (Chang, 2006). They manifested in DJ crews, the relationship between the emcee (MC) and the DJ, graffiti crews, and b-boy/b-girl crews. These relationships illustrate the interconnectedness between members of the group and also highlight specific roles each member plays. Democratic, youth-centric, collectivist, solidarity-driven, collaboration is paramount in any sustainable movement towards social justice (Ginwright \& James, 2012).

Given the role that Hip Hop plays within marginalized communities in terms of building community, making sense of their lived realities and exercising resistance, Hip Hop pedagogy can help inform how we can create stronger and more culturally responsive counseling spaces. Museus, Yi, and Saelua's (2017) study on how culturally engaging campus environments influence sense of belonging in college suggests that access to environments that are characterized by cultural familiarity, collectivist cultural orientations, and holistic support might be especially important in providing the conditions to maximize belonging among students in college regardless of racial background.

Gosine and Tabi (2016) maintain that Hip Hop is a form of community cultural wealth that can be used by educators to bridge two "different worlds" in the lives of marginalized 
students: their educational space(s) and their community. The process by which we bridge these two "different worlds" using Hip Hop pedagogy in counseling spaces is through the cipher. How do we operationalize Rendón’s (2009) Sentipensante Pedagogy using the aesthetics of Hip Hop while simultaneously acknowledging our students' community cultural wealth? From a DJ's perspective, how do we bridge those two "different worlds?" One can describe it as fading and mixing between two vinyl records; as this ongoing exchange of stimulus of response, ideas and action, thinking and questioning, that is grounded in contextual experiences and lived histories as illustrated in the figure below.
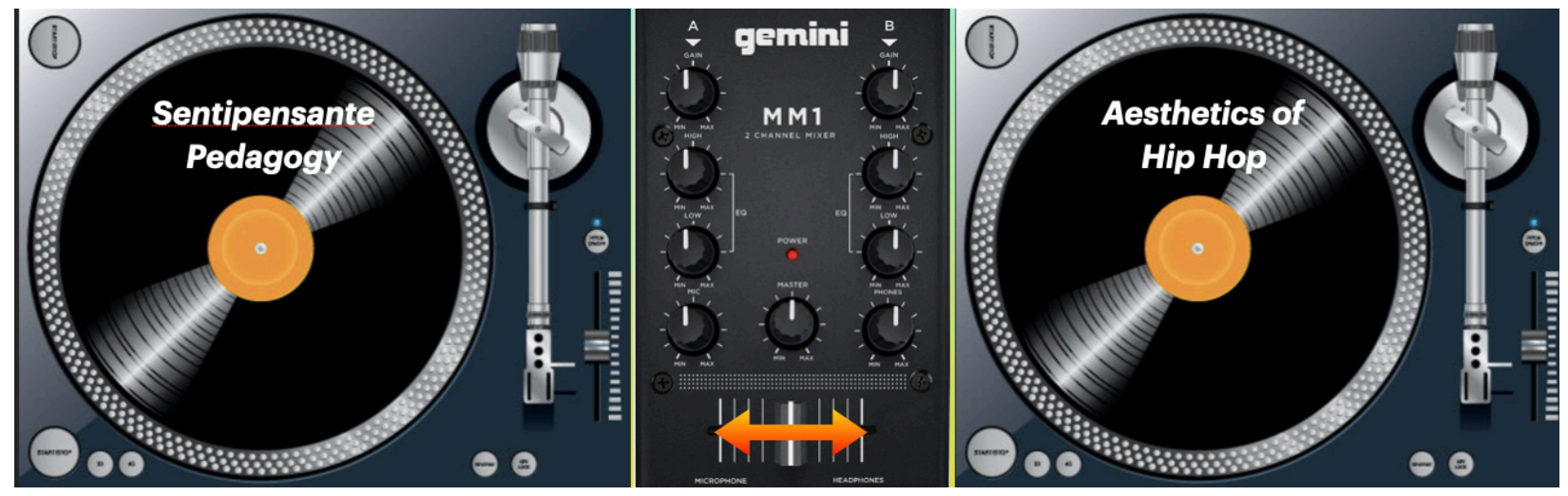

Figure 1. A conceptual framework mixing Rendón's Sentipensante pedagogy with aesthetics of Hip Hop.

\section{Rhythm and Flow}

This dissertation is presented in nine chapters. Chapter 2 reviews existing literature on academic advising/college counseling and Hip Hop based education. Chapter 3 discusses my methods and methodology of portraiture and details my study design in relation to my sample selection, instrumentation, data collection, and data analysis procedures. Chapters 4-7 highlights portraitures of four California community college counselors, Kim, Freas, Rob, and KT. Each chapter describes in detail their lived experiences and relationship to Hip Hop as well as the ways in which Hip Hop has informed and influenced their counseling practices. Chapter 8 analyzes the findings to describe the emerging conceptual framework using Hip Hop in college 
counseling. Chapter 9 will serve as the outro of the dissertation. Within this chapter, I will discuss in the form of the call and response where I suggest recommendations and implications to add, contribute, sample, and advance the work with Hip Hop pedagogy in college counseling practices. I will also discuss how this dissertation journey impacted my work as a college counselor and how it informs my future work in the college counseling field. 


\section{TRACK TWO}

\section{REVIEW OF THE LINER NOTES}

The quest to review literature has been a unique process; a process that was sparked by my attendance at the Greek Theater at UC Berkeley in 2018. I attended the book reading and Q\&A session featuring Questlove of the Roots, one of the most iconic Hip Hop groups of alltime. He had just released his book, Creative Quest, that shared stories and lessons about how to live your very best creative life. In his opening chapter, “The Spark”, Questlove defines the concept of a creative person broadly as "anyone who is making something out of nothing by virtue of their own ideas" (p. 18). During his talk at the event, he shares that "creativity might be in jeopardy because one of the key components of being creative is boredom, silence, and isolation" (Questlove, Creative Quest event, 2018). When his group, The Roots, create new music, they set aside time to get lost in the things that inspire them. They listen to old records to draw inspiration from. They sit with it. They deconstruct it. They talk about what they like about it and they discuss what is missing. Questlove shares through this experience that "your central creative ideas moves with you, and you move through them (Questlove, Creative Quest event, 2018). The Roots goes through this process with every album they create. It helps them better visualize how the completed record should sound. Their creative process is honored and acknowledged in their liner notes.

Liner notes are a huge part of understanding how albums are made and constructed. Unless you are a music junkie or a Hip Hop head, that part of the album may remain invisible to you, the listener. Liner notes are typically printed on the inner sleeve of a vinyl record, $\mathrm{CD}$, or cassette tape. Due to the rise of digital downloads, digital booklets are now being introduced to provide liner notes of the album. Liner notes typically contain sources of 
information about the musicians, lyrics, a personnel list, and credits to other musicians, artists, and producers who were involved in the production of the music. The Roots, in particular, are very intentional in providing historical and social context to their albums in their liner notes. For example, the liner notes of their album, Things Fall Apart (1999), provided information which helped raise public awareness on many social issues that were impacting Black communities. These same aforementioned notes are enclosed in glass at the National Museum of African American History and Culture in Washington DC.

Questlove describes the feeling when he first listened to Hip Hop as "that moment when something hits you out of nowhere, when a work of art carries within itself the thrill of invention, creativity, and discovery (Questlove, Creative Quest event, 2018).” Hip Hop is exactly that; it is an invention and it is history, it is yesterday, today, and tomorrow. It breathes a similar spirit as that of Gloria Anzaldua's notion of Borderlands; that borders and spaces can be shaped and reshaped according to the multiple influences from those who are of that space. When it comes to the liner notes of this research, we will find both contrasts and contradictions, flexibilities and restrictions, and changes and conformities.

In this chapter, I aim to highlight three major threads of literature: historical context and function of community colleges, academic advising and the evolution of Hip Hop pedagogy and education. This study is focused on how Hip Hop pedagogy informs counseling practices by making meaning of the stories and lived experiences of four California community college counselors. To that end, this literature review is designed to describe the foundational principles of Hip Hop pedagogy to create an analytic framework that situates this study within the context for developing culturally responsive college counseling practices. 
The first major thread in the literature provides a brief, historical context around the development of community colleges and the student populations they serve based on the community colleges' open-door policy. The second major thread focused on academic advising aims to explore the various forms of academic advising approaches widely used in the profession of community college counseling. In addition, I have reviewed literature on students' perceptions, attitudes, and satisfaction around academic advising. Further, my review also highlights the impact of academic advising on retention and persistence especially involving strategies such as early intervention activities and academic advisors' availability and approachability to produce positive student outcomes. Finally, the third thread explores more critical perspectives of student development theories and practices that move away from more traditional advising approaches to more culturally responsive practices.

Focusing in this third thread, my review focuses specifically on Hip Hop pedagogy and education. To do this, I explored the historical and contextual explorations of Hip Hop's possibilities in education. Then, building off these explorations, I provide concrete conceptualizations of how Hip Hop has been applied in various educational spaces. I then look at how Hip Hop pedagogy provided positive student outcomes such as higher student engagement, increased sense of belonging, and agency. Finally, I delve into the concepts of Hip Hop aesthetics and sensibilities and its application in classrooms as they have been explored in different studies.

\section{Historical Overview of Community Colleges}

One of the hallmarks of the United States postsecondary educational system is access. The origins of community colleges began as "normal schools" that preceded high schools as institutions of secondary education (Beach, 2012; Jurgens, 2010). These normal 
schools were created in the 1800 's to provide educational training and opportunities for those who wanted to teach in public primary schools (Beach, 2012; Jurgens, 2010). Moving forward, community colleges evolved to address the need to provide additional opportunities for students to earn an education beyond high school. Utilizing this perspective for pursuing higher education, these normal schools became known as the "people's college" (Beach, 2012, p. 4) because they provided educational pathways for many Americans who would not have been able to attend college as a result of academic and financial constraints (Jurgens, 2010).

Community colleges continue to serve a wide range of diverse learners with access to educational attainment of programs such as associate degree programs, certificate, and lifelong learning. After the establishment of the first community college over 100 years ago, the number has grown to 1,051 community community colleges nationwide including 941 public, 75 independent, and 35 tribal community colleges (American Association of Community Colleges, 2019). The mission of community colleges in the United States is focused on three areas of commitment: access, responsiveness to community needs, and equity. More specifically, the California Education Code states that "the primary mission of the California Community Colleges is to advance California's economic growth and global competitiveness through education, training, and services that contribute to continuous workforce development (California Education Code, 1999).”

By directly responding to the community's needs and helping advance the efforts of state and national economic growth and global competitiveness, the community colleges were designed to operate and function with an "open-door" admission policy that provides educational opportunities and access to a diverse student population with an extensive array of needs (Mullin, 2010). Community colleges serve a wide range of student populations ranging from 
low-income students, students from various ethnic and racial backgrounds, students with disabilities, returning working adults, reverse transfer students, recent high school graduates, foster youth, and first-generation students (Kolodner, 2015). Students who attend community colleges do so for a variety of reasons such as lifelong learning opportunities, certificate and degree attainment, pre-bachelor training, career development and exploration, and short-term continuing education (Pusser \& Levin, 2009). According to the American Association of Community Colleges (2019), nearly 50\% of all undergraduates are enrolled in community colleges in the United States. Based on a Fall 2017 enrollment survey, 46\% were White, 25\% were Latinx, 13\% were African Americans, and 6\% were Asian/Pacific Islander students (NCES, 2018).

Although more than half of students who are enrolled in community colleges in the United States are students of color, the open-access model does not prevent or solve the disproportionate rates of retention and graduation for these students. While research around student success outcomes for college students have been focused at four-year universities, research around other conceptual divergences of success for students of color, such as sense of belonging, persistence, and satisfaction have been increasing for community colleges (Museus \& Ravello, 2010; Nutt, 2003). Although college access is provided for all students, especially for those who experience academic and financial constraints that prevent them from admissions to four-year universities, the open-door policy created a surge of incoming, new students enrolling beyond their academic abilities, many who fail or leave the institution entirely (Hasty, 2012). Cohen and Brawer (2003) also argue that students enter and re-enter with various and often multiple goals but not always with clear knowledge of how to accomplish them. As a 
result, students experience pitfalls during the first few weeks of school in community colleges (Hatch \& Garcia, 2018).

Troyer (2015) states that although community colleges have done an excellent job providing access to higher education, access means nothing if it is not meaningful. In other words, access has little meaning if the current educational system, through policies and practices that prepare our traditionally marginalized student populations, results in course failures, lack of progress toward their goal, and low retention rates. The work of community colleges has been impacted by the "culture of completion" which focuses on degree and credential attainment as the primary measure of accountability for colleges. For the last $20+$ years, the national completion agenda focused much of their attention to addressing ways to increase rates of degree completion at community colleges. Today, community colleges are exploring ways of becoming more "student-ready" by closely examining the access and equity on programs, processes, and practices for our traditional marginalized student populations (McNair, Albertine, Cooper, McDonald, \& Major, Jr., 2016). One of the major areas focusing on redesigning processes that impact student outcomes looks at community colleges' academic advising practices with all students.

\section{Academic Advising}

Academic advising has a significant impact and influence on student retention by affecting outcomes such as social integration, institutional commitment, and student satisfaction (Smith \& Allen, 2014). According to Paul and Fitzpatrick (2015), academic advisors' knowledge of degree requirements, as well as their ability to build strong and meaningful relationships with students, produce significant relationships associated with advising and student satisfaction. Research has also shown that successful advising supports student 
persistence in college (Pascarella \& Terenzini, 2005). Many academic advising and college counseling approaches are rooted in various student development theories. For example, Astin's (1985) Theory of Involvement argues that the more involved and invested students are within the institution, the more likely they are to experience better student success outcomes. Building upon his previous Student Integration Model, Tinto (2012) described four conditions which support student persistence and retention. They include: students' own expectations of themselves, institutional support, timely feedback on student performance, and faculty and student engagement. Academic advising has the capability to impact all students by creating spaces of learning and validation that can manifest in multiple ways such as one-on-one appointments, in group settings, in classrooms, and online.

Research has also shown that academic advising and student success are connected (Donaldson, McKinney, Lee, \& Pino, 2016). Light (2001) concluded that "good advising may be the single most underestimated characteristic of a successful college experience." In addition, Pascarella and Terenzini (2005) mentioned that "research consistently indicates that academic advising can play a role in students' decisions to persist and in their chances of graduating" ( $\mathrm{p}$. 404). Academic advisors continue to develop and refine their own advising approaches by staying abreast of current academic advising literature, reflecting on student interactions, and the development of solution-focused strategies and activities that best support the needs of students and that are consistent to their educational goals (Kimball \& Campbell, 2013).

The National Academic Advising Association (NACADA) developed the NACADA Academic Advising Core Competencies Model in 2017 that is intended to "identify the broad range of understanding, knowledge, and skills that support academic advising, to guide professional development, and to promote the contributions of advising to student development, 
progress, and success" (NACADA, 2017). Within this model, there are three major core competency areas: conceptual, informational, and relational. They are at the heart of academic advising and serve as foundational elements for effective advising practices. In accordance to this model:

- The Conceptual component provides the context for the delivery of academic advising. It covers the ideas and theories that advisors must understand to effectively advise their students.

- The Informational component provides the substance of academic advising. It covers the knowledge advisors must gain to be able to guide the students at their institution.

- The Relational component provides the skills that enable academic advisors to convey the concepts and information from the other two components to their advisees (NACADA, 2017).

While this knowledge describes the importance of the role of academic advising, the approaches to academic advising may vary depending on educational background, training, and philosophies.

Prescriptive and Developmental Advising Approaches. Prescriptive advising is one of the most commonly used advising approaches. Crookston (1972) describes this approach as being concerned only with a student's academic and curricular status. More specifically, this approach is often seen as information-based advising where the advisors are seen as experts regarding policies, procedures, degree and transfer requirements, course sequencing, and other institution-specific information. The process tends to be one-way where the advisors provide all of the information while the advisee becomes a passive agent of information. This provides very 
few opportunities for individualized decision making. Because of its lack of student focus and limited scope of advising content, technology has made this advising approach less utilized since more information and procedures can be accessed and shared online (Appleby, 2001).

Advising-as-teaching and learning-centered advising are approaches that emphasize the student learning outcomes in academic advising. This approach is also known as developmental or holistic advising. The advising-as-teaching approach promotes the importance of setting clear educational goals, providing input, modeling, checking for understanding, guided reflections, appropriate closure through reviewing and clarifying key elements, and providing opportunities for homework and reinforcement as key components in successful advising sessions (Drake, 2011). Similar to the advising-as-teaching approach, learning-centered advising also draws on teaching and learning principles such as including clear, reasonable, and positive goals, active involvement, student motivation, high expectations, effective feedback, and reflections. Both development advising approaches, advising-as-teaching and learning-centered advising, require advisors to go beyond information sharing and relationship building to be intentional in assisting with students' cognitive learning development. Because it leads to student growth, development advising is based on a combination of theories related to personal, cognitive, career, and psychosocial advancement. However, because of its focus on psychological and cognitive factors, environmental and ecological barriers as studied through the lens of systems analysis may not be explored in depth.

Other Academic Advising Approaches. Schreiner and Anderson's (2005) work around strengths-based academic advising is grounded on the belief that students achieve greater student success outcomes when they recognize the value of their natural skills and talents rather than their perceived areas of weaknesses. They shifted the focus away from problems to 
searching for possibilities. They hypothesized that advisors who utilize strength-based approaches elicit motivation and engagement in students, resulting in greater confidence and self-awareness in obtaining their educational and personal goals. Similarly, Soria, Laumer, Morrow, and Marttinen (2017) did a study that conducted six focus groups to hear advisor perspectives on benefits they perceived about strengths-based conversations with their advisees. They found that by intentionally and meaningfully drawing out strengths from their students, they were able to lay the foundation of creating positive advising relationships. They also noted that the strengths-based approaches also created enhanced self-awareness and confidence in students. Students felt powerful when they were able to talk about themselves in positive ways, highlighting the importance of amplifying student voices in the counseling process.

Building on the work of strengths-based advising, the appreciative advising model samples, utilizing the perspective of Hip Hop aesthetics, from the social constructivist theory (Vygotsky, 1978), positive psychology concepts (Seligman, 2002) and principles of appreciative inquiry and process (Cooperrider \& Whitney, 2000). Bloom and Martin (2002) connected the concepts of appreciative inquiry to academic advising defining it as "the intentional collaborative practice of asking positive, probing questions that help identify and strengthen a student's ability to optimize their academic performance" (p. 475). In practice, the concepts of appreciative inquiry are operationalized in these current six phases of appreciative advising: disarm, discover, dream, design, deliver, and do not settle (Bloom, Hutson, \& He, 2008). He and Hutson (2018) continued this work by discussing each of the appreciative advising phases using a logic model and mixed methods design to measure the effectiveness and impact of academic advising for a targeted group of international students. Although they did find positive results in the different 
phases for appreciate inquiry, they also proposed that it is not a one-size fit all assessment system. They also highlighted the importance of the learning and growth that students experience during the counseling process, as opposed to the actual end goals such as degree attainment and university transfer. Hutson (2010) conducted research using surveys that measured the impact that appreciative advising had on students enrolled in a first-year experience course. Based on the survey results, students indicated positive ratings for college satisfaction, a sense of belonging, and a deeper understanding and knowledge around campus policies and course expectations.

Students' Perception and Satisfaction of Academic Advising. Research on student engagement and interactions with their academic advisors has consistently shown positive contributions to student outcomes such as persistence and educational attainment (Pascarella \& Terenzini, 2005). These positive contributions have led to higher student satisfaction with academic advising (Allen \& Smith, 2008; Paul \& Fitzpatrick, 2016; Schreiner \& Nelson, 2013). For example, Noel-Levitz (2014) found that academic advising was a predictor of students' satisfaction with their college experience. To deeply understand the ways in which academic advising impacts student satisfaction, it is important to explore the students' expectations around academic advising.

Smith and Allen (2013) sought to understand which advising functions were most important to students in a study they did with 2,100 undergraduates at an urban university around 12 functions of academic advising. They also studied how satisfied students were with the advising that they received on these functions. Within these 12 functions of advising, there were five broad categories: integration, referral, information, individuation, and shared responsibility. Results showed that while students rated all functions as highly important, they 
did not necessarily express satisfaction with these different functions. For example, the mean score of "providing accurate information" in the importance ratings was 5.64 on a 6-point scale $(1=$ not important or not satisfied and $6=$ very important or very satisfied $)$. However, within the satisfaction rates for the same function, the mean score was a 3.87. This was the case for all 12 functions. This suggests that while students found academic advising functions important, their experiences related to these functions did not necessarily indicate satisfaction. While information related to degree requirements and college policies were provided, it is important to assist students in making this advising function meaningful by connecting them to educational goals as well as creating a co-constructed space for students to make informed decisions in their educational planning.

While Smith and Allen (2013) illustrated the importance of advising functions for students, Paul and Fitzpatrick (2016) explored student satisfaction within the context of advising approaches. They argued that the approachability and availability is as important as knowledge of degree requirements in building strong working relationships between students and academic advisors. However, in combination, both advisors' competence and caring behaviors serve as foundational when building trust between advisors and students (Bloom, Hutson, \& He, 2008).

Orozco, Alvarez, and Gutkin (2010) also highlighted the link between trust and relationships, determining that community college students acknowledged the value of having advisors that they can develop a connection with. Trust and building relationships are particularly important for traditionally marginalized and minoritized students of color. Tovar (2015) found that contact with academic counselors had a positive influence on Latinx students' academic achievement and resolve to persist in college. hooks (2000) argued that when marginalized students are moved from the outside to the center of discussions, programs, and 
interventions, everyone feels validated for their differences. However, not all students of color access counseling services. Nearly $50 \%$ of community college students don't access counseling and academic advising services after their initial counseling appointment. Of that percentage of students, nearly $70 \%$ of those students were African American, Latinx, and Pacific Islander students (National Center for Educational Statistics, 2019).

To explore the importance of building trust through collaborative relationships, Paul and Fitzpatrick (2015) investigated student satisfaction with servant leadership-based advising and found positive correlations between servant leadership and student satisfaction with advising. Similar to development advising theories, servant leadership theories focus on the growth and development of their followers (Stone, Russell, \& Patterson, 2004). They surveyed 428 undergraduates at a midsize university in the southeastern United States. The surveys were administered in 10 targeted classes that showed similar demographic characteristics (race, class, and gender) to the overall undergraduate population. Participants were identified as $68 \%$ female and $32 \%$ male, while the majority of the participants were White (59.4\%) and Black (30.4\%). The survey consisted of five constructs of servant leadership: altruistic calling, emotional healing, wisdom, persuasive mapping, and organizational stewardship. With the following five constructs, the participants rated their advisors' servant leadership behaviors using a 5-point Likert-type scale ranging from 1-strongly disagree to 5-strongly agree.

Based on the results, altruistic calling (i.e. "This person puts my best interests ahead of his or her own.") and wisdom (i.e. "This person seems alert to what's happening.") were the best predictors of students' satisfaction with advising. While the findings of wisdom support previous studies that showed that students want advisors who are knowledgeable about degree requirements, policies, and procedures (Noel-Levitz, 2014), students also want advisors to 
extend themselves personally and provide an open and caring advising environment (Paul \& Fitzpatrick, 2015).

Vianden (2016) explored the relationship between student satisfaction and advising using an approach called critical incident technique (CIT). This approach highlights the student voice by asking them a set of questions or prompts that allow them to reflect on the most critical or memorable incident or experience within the context of academic advising. This study explores how academic advisors can act as agents of student relationship management. Taken from a larger study of 157 students, 29 students reported critical incidents that were specific to academic advising. The participants completed an online survey through Qualtrics and responded to four questions related to their critical incidents. Since the participants submitted their results online, Vianden had access to their responses. He used descriptive coding to note expressions of satisfaction and dissatisfaction. Some of the codes included: helpful, unresponsive, unwelcoming, and attentive.

The findings found two definitive conclusions about the 29 participants in the study. Positive advising experiences were related to participants' satisfaction with academic advising. In addition, participants who had positive advising experiences acknowledged that they felt a sense of belonging at the institution. Conversely, participants who reported unsatisfactory advising experiences shared that those experiences discouraged them from seeking future appointments. They also shared that they experienced harm within their emotional wellbeing and felt like they did not belong at the institutions.

Other research has shown that building interpersonal relationships with students as well as having acquired institutional knowledge and high level of advisor responsiveness, is related to students' satisfaction with academic advising (Allen \& Smith, 2008; Paul \& Fitzpatrick, 2016; 
Schreiner \& Nelson, 2013; Vianden, 2016). Educational leaders and administrators must provide training and professional development opportunities for academic advisors and counselors around building genuine and authentic relationships through culturally relevant and responsive practices.

The Impact of Advising on Retention and Persistence. Academic advising is a critical and significant component of students' ability to achieve academic success and personal development (Pascarella \& Terenzini, 2005). The ability of academic advisors to reach students in various ways has a great impact on retention and persistence (Drake, 2011; Hatch \& Garcia, 2018). Hatch and Garcia (2018) argue that an entering community college student's experience can be described as much by the classroom experience as it is by early procedures and processes related to college admissions such as registration, orientation, financial aid, and academic advising. In their study, the purpose was to understand how different kinds of advising activities during the first three weeks for community college students who enroll for the first time relate to their intentions to re-enroll. Data used for this study came from the 2010 Survey of Entering Student Engagement (SENSE) administered by the Community College Survey of Student Engagement (CCSSE). CCSSE provided an 80\% random sample of student responses from 13 community colleges in Florida. Of the 2856 students selected, they were students new to college and not co-enrolled in multiple colleges. Three themes emerged from this study: 1) the relationship between engagement and persistence intentions heavily depended on individual goals, 2) different kinds of advising may matter at different times, and 3) academic and social support networks matter in the short term and long term. These findings suggest that: 1) students are more engaged when they have a sense of clarity with their goals, 2) students respond to advising differently depending on style and timing, and 3) opportunities for student engagement 
should be widely available throughout students' academic journey. This is particularly significant because students who are traditionally marginalized and underrepresented arrive to colleges with a unique set of challenges that impedes their ability to persist toward degree completion and/or transfer (Brooms \& Davis, 2017; Museus, Yi, \& Saelua, 2017; Tovar, 2015; Wood \& Williams, 2013). Wood and Williams (2013) found that interaction and conversation about academic matters with faculty outside of class had a positive effect on first-year persistence for African American men. Similarly, Rodriguez, Massey, and Saenz (2016) observed that Latino men who encountered accessible and approachable members who displayed a sense of investment and authentic care towards them, felt a greater sense of support and the willingness to engage and seek assistance within their community college experiences.

\section{Moving Towards Culturally Responsive Advising and Counseling. As California} community colleges are engaging in conversations and reviewing their institutional data around student equity, colleges have begun to identify equity gaps throughout their institution (Ching, Felix, Castro, \& Trinidad, 2018). The way in which counselors advise and perceive their students can significantly impact the way their students navigate institutions of higher education. While building authentic working relationships with each other, it is equally important for both counselors and students to learn how their own ethnic, racial, and gender identities can influence these counseling interactions. This collaboration in deeper understanding is a hallmark of culturally responsive teaching (CRT).

Gay (2000) defines culturally responsive teaching as leveraging the cultural knowledge, prior experiences, frames of reference and performance styles of ethnically diverse students to make learning encounters more relatable, relevant, and effective for them. This moves beyond what Darling-Hammond (2015) describes as "surface culture." Many colleges and institutions 
have celebrated cultures by hosting Multicultural Awareness events and campaigns that would involve cultural dances, food, and music. While there is value in providing spaces for students to see their cultures represented, the heart of CRT lies in the students' capacity to learn. A culturally responsive approach to advising centers around the co-construction of knowledge between the counselor and students in that it deepens the students' learning about themselves, their goals, their communities, their relationship to education, and the process of critical thinking (Lawton, 2018). In addition to the co-construction of knowledge, other culturally responsive practices include: building on students' personal and cultural strengths, helping students examine information from multiple perspectives, and making the culture of the classroom inclusive of all students (Villegos \& Lucas, 2003).

Although much of the literature on culturally responsive practices centers around classroom teaching, we are slowly seeing more literature focused on culturally responsive advising. Mitchell, Wood, and Witherspoon (2010) found that African American students at a predominantly White institution (PWI) found value in having an advisor who not only provides academic support, but also understands the ethnic and racial implications of being a student of color at a PWI. Lee (2018) used Critical Race Theory to present techniques that can be utilized by academic advisors when working with students of color at PWIs. She argues that to be culturally responsive and critical in our practices, we have to place a specific focus on experiences of racialized oppression, power, and privilege within PWIs into a theory-to-praxis model. She moves further beyond just creating authentic relationships and understanding students' stories and lived experiences. She questions, "How do we become better advocates for our students?" Advocacy-oriented advisors recognize the impact of social, political, economic, and cultural factors on student development and experiences (Lewis, Arnold, House, \& Toporek, 
2003). By engaging with students of color through affirmation, support, and advocacy, we establish safe physical and emotional spaces that encourage student development in a holistic manner while simultaneously acknowledging the varied experiences with structural oppression for students navigating through college (Lee, 2018).

As students' socio-cultural and economical context evolve, it is important to critically look at our existing academic advising approaches and examine how we can help them achieve their educational goals and also shape them to become active participants in their own educational journeys. Critical and poststructural perspectives introduce and reconsider three elements of knowledge that need to exist in academic advising: the role of context, intersectionality, and acknowledgment of individual agency (Jones \& Lazarus-Stewart, 2016).

Context refers to a multitude of areas in which students can be impacted and influenced in their everyday lives by families, neighborhoods, working environments, and current events. In addition, religion, laws, and educational institutions can also play a role in their experiences as well as the power structures that shape them. Crenshaw (1991) asserts that unequal power structures such as racism, classism, and ableism can inform how individuals and social groups function within these various contexts. In practice, advisors can use the opportunity to communicate one-to-one to consider the broader context of racism encountered at educational institutions while providing the amount and type of support each individual need. Addressing contextual factors ensures that students receive humanizing academic advising experiences through which their entire college experience is considered (Museus \& Ravello, 2010).

Coined by Crenshaw (1991), the concept of intersectionality was developed to challenge the notion that a person's identity was defined by one singular dimension and account for the 
complexity that encompasses the lived experiences of people, specifically people of color. Crenshaw also states that an individual's point of privilege or marginalization can shape another's subjectivity and influence their agency and access to capital formation. As we move towards being culturally responsive to the needs of our students, academic advisors have an opportunity to consider how intersectionality can be useful for understanding how privilege and marginality shape and inform each other in how students make meaning of their educational experiences and in the context of their environments (Jones \& Lazarus-Stewart, 2016).

Lastly, critical and poststructural perspectives have also highlighted the role of individual agency in how people understand and make meaning of their identities. Understanding the contexts of how their experiences are shaped along with the understanding of the complexities that make up their identities, students begin to understand how they can become agents of their own change. As practitioners, it is important to create these educational spaces where we are able to foreground students' capacities for resistance and resilience within various systems of oppression.

\section{Express Yourself - Hip Hop's Educational Possibilities}

Growing up in the early 1980s, I lived in a predominantly African American neighborhood in Norfolk, Virginia. I went to elementary school where the majority of students and teachers were African Americans. My sister and I were one of the few Filipinos or Asian Americans, in general, that went to that school. Every morning, my sister and I would walk a few blocks to catch our school bus. After school, these walks home from the bus stop led me to the introduction of Hip Hop.

I remember passing by this green house with kids congregating at the brick steps with music blasting from this oversized radio or boombox as the kids would call it. There was a piece 
of cardboard laid out on the sidewalk where the kids were dancing and spinning on their backs to a genre of music I had never heard of; this type of music now known as Hip Hop. The kids started rapping and taking turns like they were having their own type of conversation. I can't remember what was said but I do remember them spelling their names. I wanted to do the same. "It's the N-A, to the T-E, I'm the best rapper that I can be." I was mesmerized, intrigued, and curious all at the same time. Where did this music come from? This was far different than the music that was playing at home. The sounds of Stevie Wonder, The Beatles, Michael Jackson, and original Pilipino music (OPM) filled our house while my mom would cook our favorite Filipino dishes. While this new music provided a contrast to the music I was used to listening to, I knew I was hooked and wanted to learn more.

Reflecting back on those late afternoons, Hip Hop has grown from the streets to become embedded in the fabric of American culture. It has become a globally-recognized, multibillion dollar industry that has been integrated into many cultural facets such as music, fashion, film, TV, art, politics, health awareness, and education (Chang, 2005; Charnas, 2010; Coleman \& Mansbach, 2014; Flores, 2012; George, 2005; Rose, 1994). While Hip Hop has permeated the entire world as a global creative and economic force, Hip Hop, similar to any culture, has its roots; its own beginnings.

Origins of Hip Hop. While the origins of Hip Hop culture has been highly debated for years, the narrative that has been accepted by scholars, Hip Hop pioneers, and practitioners, is that Hip Hop culture was born in the South Bronx in the late 1970s and early 1980s. Hip Hop culture emerged from the energies and spirit of the Civil Rights Movements and Black Arts Movement. It is very important to note that the name "Hip Hop" and the culture that was created was born at that time; however, elements of Hip Hop such as DJing and graffiti or aerosol 
writing existed much earlier than that, as early as August 11, 1973 (Chang, 2005; George, 2005; Rose, 1994). On this day, the very first party that encompassed the elements of Hip Hop was documented and was hosted by one of the founders of Hip Hop, Clive Campbell, also known as DJ Kool Herc, and his sister, Cindy Campbell, located at the birthplace of Hip Hop at 1520 Sedgwick Avenue in the Bronx. In the spirit of entrepreneurship that is also integral in Hip Hop culture, this community jam served as a Back to School Jam for Cindy to make money to buy new clothes for the new school year. While this date and location is significant in Hip Hop history, a perfect storm of events paved the way for Hip Hop culture to be born from the ashes of poverty, economic disparities, housing displacements, and violence (Chang, 2005; George, 2005; Rose, 1994).

"Broken glass everywhere / People pissin' on the stairs, you know they just don't care / I can't take the smell, can't take the noise / Got no money to move out, I guess I got no choice / Rats in the front room, roaches in the back / Junkies in the alley with a baseball bat / I tried to get away but I couldn't get far / Cause a man with a tow truck repossessed my car."

(Grandmaster Flash and the Furious Five, 1982)

These lyrics come from Grandmaster Flash's song called "The Message" describing the conditions that communities of color experienced in the Bronx Projects. Hip Hop, as a musical genre, has been recognized to have themes that are gritty, authentic, and unapologetic, in comparison to other genres such as pop, classical music, or funk (Chang, 2005; Forman \& Neal, 2004).

The social and economic conditions that plagued the Bronx in New York were directly related to the construction and completion of the Cross Bronx Expressway in 1972, which was conceived by Robert Moses. The result was that a large number of residents, mainly African 
Americans and Puerto Ricans, were displaced from their neighborhoods. Many of the White residents were able to afford to move upstate, known as the Great White Flight. As a result, many neighborhoods that were affected by the construction of the Cross Bronx Expressway were decaying due to low property values, increased gang violence, drug abuse, and poverty. When the Cross Bronx Expressway was proposed to the residents, there were promises that there would be new jobs, fresh food markets, and community kitchens. However, all that was left behind were unoccupied, burned down buildings with spray painted messages that adorned the walls that read, "Promesas Incumplidas" which is translated to "broken promises."

In the 1970s, the South Bronx experienced more than 12,000 fires with over 5000 apartment buildings burned down (Asante, 2008). During Game 2 of the World Series at Yankee Stadium in New York City, ABC broadcaster, Keith Jackson, shared on-air as the telecast showed a view of the South Bronx burning, "That is a live picture, obviously a major fire in a large building in the south Bronx region of New York City. That's a live picture, and obviously the fire department in the Bronx have there, a problem. My goodness, that's a huge blaze." This aforementioned image depicted a time where many parts of the New York City, particularly the South Bronx, were being decimated, largely due to an insurance scheme where slumlords were committing arson to collect insurance money to get out of the fledgling South Bronx real estate market (Asante, 2008).

The displacement of communities, urban decay and plummeting property values, drug use, increased violence, and the formation of neighborhood gangs, were the direct result of institutional racism and classism that created an environment that left many youth feeling frustrated, disempowered, and overwhelmed with the status quo (Cepeda, 2004). Through the 
metaphorical ashes of the South Bronx, Hip Hop was born through the collective efforts of many youth who were coping with the realities that they were living in.

Many Hip Hop historians and scholars credit two major people in contributing to the birth of Hip Hop. The first notable figure was Clive Campbell also known as DJ Kool Herc. He was widely known as the Godfather of Hip Hop and was credited for just playing the "breaks" of the song. Many songs on vinyl records were extended plays, long versions of the song. DJ Kool Herc noticed that when the "breaks" of the song were playing, the dance floor would fill up. He learned how to extend the "breaks" by looping the beat using two identical records and continuously switch between records allowing him to play the "breaks" longer. This technique kept the crowd moving and engaged. After the first documented Hip Hop party at 1520 Sedgwick Avenue in the Bronx, many young people began hosting parties in numerous public spaces such as community halls and neighborhood parks. These parties became known as block parties and community jams. Youth would plug their music equipment to city lamp posts to gain access to free electricity. Given the political and economic climate in the Bronx, Hip Hop became a vehicle and platform by which youth could reclaim public spaces as spaces of liberation and freedom (Forman \& Neal, 2004).

While DJ Kool Herc inspired the creation of Hip Hop culture, Afrika Bambaataa, was credited to be the figure who helped institutionalize it. Prior to his involvement with Hip Hop, he was a gang leader of the street gang, the Black Spades, one of the largest gangs in New York City. After he won an essay contest that earned him a trip to Africa, his perspective of the world changed. When he returned to the Bronx, he believed that he could use his leadership to bring positivity to the community. As a result, he created the Bronx River Organization (BRO) which later became the Universal Zulu Nation. 
The Zulu Nation began to document and chronicle the basic four elements of what was Hip Hop culture. Similar to a qualitative research study, they were observing activities and themes that were happening at the block parties and community jams. They found that the four basic elements of Hip Hop culture consisted of: DJing or turntablism, b-boying/b-girling (also known as breakdancing), emceeing (also known as rapping), and aerosol writing (also known as graffiti writing). Endemic to Hip Hop is this idea of "creating something out of nothing." Sam Seidel (2011) talks about this concept of "flipping something out of nothing" as the creative resourcefulness at the roots of Hip Hop culture. While it can be argued that "nothing" can come from a deficit-based mindset, it also sheds light on the resourcefulness and resilience that many youth of color were exhibiting despite the social and economic challenges they were facing during the 1970s.

Because the South Bronx were filled with burned down, abandoned buildings, it became an artistic canvas for many youth to "throw up" or spray paint pieces as a way to demonstrate identity development or convey messages that were counter to the status quo. B-boying and bgirling, also known as breakdancing, became an alternative to street fights where members of rivaling dance crews from different communities "battled" at various public spaces. While disco clubs were not accessible for communities of color, that didn't stop Hip Hop pioneers such as Grandmaster Flash, Kurtis Blow, and the Sugarhill Gang to create new music utilizing disco grooves. The Sugarhill Gang who arguably released the first Hip Hop song, "Rapper's Delight" used two major disco samples -- Love De Luxe's “Here Comes That Sounds Again” and Chic's "Good Times." These examples of "creating something out of nothing" can be viewed as contributing to the identity of Hip Hop culture. This is also known as Hip Hop aesthetics; 
concepts to describe "ways of doing and being" in the sonic, kinesthetic, linguistic, and visual practices/expressions of Hip Hop (Petchauer, 2011).

The basic four elements of Hip Hop illustrated a form of self-expression and resistance that represented many traditionally marginalized Black and Latino youth (Chang, 2005; Rose, 1994). The culture captures the lives and experiences of these communities of color through the means of storytelling, cultural production (i.e. making beats, creating murals), and language. For over 40 years, Hip Hop has integrated into the mainstream, reaching and impacting a more diverse audience both nationally and globally. Hip Hop has been embedded in the fabric of American popular culture in the form of music, fashion, art, film, social media, and entrepreneurship. As a result, educational institutions of all levels have attempted to utilize Hip Hop cultural practices and artifacts in various informal and formal contexts (Hill \& Petchauer, 2013).

\section{Beats, Rhymes, and Life: Contextual Practices of Hip Hop Based Education}

Embedded in the aesthetics of Hip Hop, there is this notion of "show and prove." Hip Hop culture is performative and participatory by nature. It also encompasses the cultural knowledge and lived experiences of those participating in this culture. Rooted in the principles of critical (Freire, 1970) and culturally responsive (Gay, 2000) pedagogies, Hip Hop based education (HHBE) scholarship provides curricular and pedagogical strategies that connect Hip Hop to effective educational practices. Academic advising and college counseling have been dominated by practices that are either prescriptive and/or developmental. While these practices may be productive for some students, prescriptive and developmental theories lack the environmental and contextual understanding necessary to deeply explore the experiences of 
students of color. Reflecting on the pivotal moments that gave birth to Hip Hop, it is important to examine how these cultural elements of Hip Hop can be utilized in educational spaces.

The following words have been used to describe Hip Hop culture in various educational spaces, texts, and first-hand experiences (Akom, 2009; Levy, Cook, \& Emdin, 2018; Seidel, 2011; Williams, 2009): resilience, resistance, rebellion, revolution, remix, reimagination, and rebirth. How are these words transformed into different educational experiences? What does revolution look like in the classroom? How do you remix traditional forms of teaching and counseling? All of these words embody the idea of dismantling traditional educational practices that can be seen as oppressive and isolating (Harper \& Hurtado, 2007; Lee, 2018) and creating new practices that humanize the student experience. As an approach, Hip Hop-based education (HHBE) explores the different ways in which Hip Hop can be utilized as curricular and pedagogical tools.

Seminal work that utilized Hip Hop pedagogy in classroom spaces provided themes of centering student voices, creating culturally relevant and responsive curriculum, and fostering higher student engagement (Hill, 2009; Morell \& Duncan-Andrade, 2004; \& Stovall, 2006). Morell and Duncan-Andrade (2004) observed Hip Hop music and culture's ability to tap into the students' lived experiences to promote academic literacy and critical consciousness. They found, in their high school English classes, that students were able to engage in critical interpretations between canonical poems and rap texts. Hip Hop pedagogy, rooted in the principles of critically and culturally responsive pedagogy, created educational experiences where students were able to situate themselves within the text. This led to moments of critical dialogue and engagement where students were able to share how the texts resonated with them in a personal and meaningful way. 
Similarly, Hill (2009) created a community of learners within his Hip Hop Literature course that allowed space for "wounded healing." Using ethnography as a research design, he observed, through the practice of "wounded healing", that students were able to share common experiences, challenge each other's perspectives, and produce knowledge. Hill (2009) found that by linking the curriculum to the lived realities and experiences of students, specifically those from traditionally marginalized communities, educators position themselves to hear stories of pain, struggles, and oppression. His insights allow us, as educators, to reflect on how we can "reimagine the classroom as a space in which teachers and students can 'risk the self' through individual and collective storytelling" (p. 291). While this is a powerful shift from traditional forms of teaching, it also requires practitioners to engage in professional development and training that prepares them for the challenges, risks, and potential harm that may manifest from these personal disclosures in the classrooms.

Many of the earlier scholarships of HHBE were very focused on examining text, specifically rap lyrics, that allowed for deeper exploration and critical analysis in courses related to reading, writing, and oral communication (Hill \& Petchauer, 2013). However, HHBE has expanded to other disciplines such as social studies, science, and mathematics. Stovall (2006) suggested the use of rap music to provide context for the humanities and social sciences in secondary curriculum. While much of the perception of Hip Hop has been centered around topics such as misogyny, violence, and drug use, it does not represent the entire culture of Hip Hop. Hip Hop culture, however, has embodied the experiences of black and brown youth where the creative production of music, art, and dance were responses to the injustices and oppressive conditions that were created by urban renewal and disinvestment (Stovall, 2013). By analyzing rap lyrics that depict these types of experiences, students were able to make connections between 
these songs and their own lived realities. The classroom space became a site of praxis where students made sense of their realities and engaged in critical discussion about dismantling systems of oppression such as racism, sexism, and patriarchy. Drawing from tenets of critical pedagogy, Stovall (2013) argues the need to create lessons that engage students in both action and reflection where they can create and construct strategies and solutions to address systems of oppression.

In addition to Hip Hop's applicability to the social sciences, there are very few studies about the utilization of Hip Hop in the math and sciences (Hill \& Petchauer, 2013; Seidel, 2011). Emdin (2010) argues that there is a need to meet students on their cultural turf by engaging them in teaching practices that are rooted in the lived experiences of youth. Part of these teaching practices embodies the understanding of communicative methods that align with the realities of young students.

Emdin (2015) explored the benefits of two Hip Hop pedagogical approaches, co-teaching and call-and-response, as used in an urban science classroom. Co-teaching is a teaching approach that is defined as "two or more professionals delivering substantive instruction to a group of students with diverse learning needs" (Cook \& Friend, 1995, p.25). In this particular study, the student is identified as the professional and expert in the classroom. This shift in power and responsibility to the students allows them to feel a sense of empowerment as well as be able to demonstrate their mastery of the content. Because it is co-teaching, it allows both student and teacher to support each other throughout the teaching and learning experience.

Call-and-response is a spontaneous verbal and non-verbal interaction between speakers and listeners. Through these interactions, the statements ("calls") are punctuated by expressions ("responses") from the listener (Smitherman, 1977). This is a common teaching approach and is 
very prominent in music and dance produced by African Americans. In Hip Hop, emcees engage with the audience through a call-and-response to get them to become active participants of the event. This interaction creates a dynamic that fills an energetic space between the emcee and the participants. In Emdin's (2015) study, this tool was used to review and reinforce science content as well as generating interactive energy that engaged the students.

Emdin (2015) found that the use of these two Hip Hop pedagogical approaches: 1) supported students' understanding of science content and 2) supported students' agency and voice. He also found that when educators are intentional in utilizing teaching approaches that value students' lived experiences and knowledge, they are able to create classroom environments that are rooted in students' culture and reflect their own realities. He also recognized that there are educational narratives that surround students of color around the disciplines of math and science. Emdin acknowledges that by exposing students to Hip Hop pedagogical approaches, he is giving voice and agency to his students in spaces that fosters affirmation and excitement.

Show and Prove: "Crossing New Boundaries" with Hip Hop Aesthetics. Embedded in the aesthetics of Hip Hop, there is this notion of "show and prove." Hip Hop culture is performative and participatory by nature. It also encompasses the cultural knowledge and lived experiences of those participating in this culture. Tajai of the Heiroglyphics rapped in the song, You Never Knew, "In this contemporary maze of methods to floss, we finding trees and trails to blaze, boundaries to cross. We can be found beyond the bounds of reason (1994)." It reminds us that while rap has been the center of many studies in HHBE, "it obscures the ways that youth continue to expand the boundaries of Hip Hop by crafting new products, texts, and practices that fit within the cultural logic and aesthetics of Hip Hop" (Hill \& Petchauer, 2013). 
Hip Hop aesthetics refers to the "ways of being and doing" as it relates to Hip Hop culture. The earlier studies in HHBE contributed significant research to how Hip Hop content can create transformative experiences for students (Hill, 2009; Morell \& Duncan-Andrade, 2004; Stoval, 2006). Hip Hop aesthetics refers to the form by which Hip Hop is experienced sonically, kinesthetically, linguistically, and visually (Petchauer, 2015). What does Hip Hop sound like? What does it feel like? How is it shared? What does Hip Hop look like? Examples of Hip Hop aesthetics include but are not limited to: sampling (Petchauer, 2012), competitive battling, cyphers (Levy, 2018), and space (Mitchell, Wood, \& Witherspoon, 2010). While analyzing content through Hip Hop can be very powerful, examining the various aesthetics of Hip Hop allows us to restructure and reimagine educational and counseling spaces in ways that authentically center the voices and lived experiences of our most traditionally marginalized students.

Sampling is one of the most studied forms of Hip Hop aesthetics in academic scholarship (Schloss, 2004). Sampling is described as a process in which music producers create beats using a digital instrument called a sampler. The producers would take captured beats and recreate the sounds by chopping them up, mixing them, changing the tempo, and manipulating the tone to create new sounds.

Petchauer (2012) implemented and integrated the usage of sampling in an activity for future educators to critically reflect on their previous schooling experiences. The activity consisted of two exercises that had students to pick (i.e. sample) two of the most memorable experiences in their educational journey and explore the meaning of both experiences. Using the sampling method, it was important for students to make meaning for both memories collectively and not separately. The study illustrated cases that highlighted three different domains in which 
students constructed knowledge such as learning about self, learning about schooling environment, and learning about learning. This study also illustrated three different ways students made meaning of their experiences: 1) one experience causing a new interpretation of another experience, 2) students noting a contrast between experiences, and 3) students reflecting on commonalities between experiences.

This understanding of sampling in educational spaces leads educators, specifically within the profession of college counseling and academic advising, to reimagine how we counsel and advise students. In Petchauer's study (2012), he suggests that students' memories and lived experiences are just one set of information we can draw from; that it is also important to understand how students' make meaning of them. It is through this sampling, both weaving and blending both memories and meaning, that students begin to create knowledge. Using Rendón's pedagogical approach of Sentipensante, college counselors can create spaces for students to share their prior academic experiences (wisdom) and have students make meaning of these experiences (knowledge). Counselors can provide insights (wisdom) that can help inform students on how they can take their newly constructed knowledge to create new ways of being and doing. These interactive exchanges of wisdom and knowledge between counselors and students models the Hip Hop aesthetic of sampling. Counter to more dominant counseling approaches such as prescriptive and development models, utilizing sampling in our counseling spaces can transform students from being passive recipients of knowledge to active participants in their college journey.

Similar to sampling, the Hip Hop aesthetic of freestyling describes the process in which an emcee creates lyrics and rhymes spontaneously in the moment that directly reflect their immediate environment or in dialogue with another emcee or emcees. Freestyle's marked 
distinction reflects a cultural authenticity that differentiates real MCs from fake rappers (Peterson, 2006). Within educational spaces, specifically in English and Language Arts classes, freestyle is widely used as a Hip Hop pedagogical tool to elicit "improvisational intentionality" (Dyson, 2004). In an earlier study that used the aesthetic of freestyling, Rice (2003) found that utilizing a "whatever-based intervention strategy" in his English class allowed students to set aside their inhibitions about formal writing practices and write without fear of reprisal and judgment. This "whatever-based" strategy allowed students to write in any form or structure of their choice. Through this strategy, Rice was drawing from students' community cultural wealth by allowing them to express their thoughts freely without feeling restricted and judged. It permitted them to write as themselves and center their own experiences as primary text.

While freestyle as an aesthetic is most widely studied as written form, it can also lead to learning more about how freestyling can be used linguistically specifically in counseling spaces. College counselors can utilize the practice of freestyling as a way to engage students to think and explore college and career decisions without judgement. Freestyling, as a counseling practice, has no structure or boundaries. There are no right or wrong answers. Drawing responses from "if" questions is a popular pedagogical practice. "If you can design your own classroom, what would that look like?" "If you can go to any school in the world and money was not an option, which school would you go to?" Responses to these "if" questions on the surface level can engage students in a non-traditional and engaging way. However, reflecting deeply within these questions, counselors can address topics such as the impact of classroom environments and financial aid such as grants and work-study programs.

To create the space where sampling and freestyling can exist, another Hip Hop aesthetic that emerged from Hip Hop scholarship is the cypher (Emdin, 2016; Hill \& Petchauer, 2013; 
Levy, 2018). The cypher is "the quintessential space in which people create Hip Hop." (p. 24). The cypher describes the process by which information is transmitted within a circular, cultural space. Within Hip Hop spaces, these cyphers are highly codified yet unstructured practices usually in the forms of rap and dance (Emdin, 2016).

Levy, Emdin, and Adjapong (2018) explored how the cypher can be implemented within a group work setting to engage in healing-centered practices with high school students. In conjunction with another Hip Hop aesthetic around the concept of space, Levy redesigned his counseling space at a South Bronx High School to include a studio space where students can use DJ instruments, write rhymes, and produce songs. Levy's intentionality to create a space that is relevant to his students' lived realities and culture, allowed for authentic relationship building to exist.

Moving away from more traditional therapeutic practices, this study explored how the Hip Hop cypher is applied in group work settings. This study began with a group of eight participants composed evenly of male and female students. The purpose of this group was to use the Hip Hop lyric writing process and the cypher to provide students with the opportunity to express and examine a wide range of emotional obstacles they were facing. They met for a total of 15 meetings.

With access to studio equipment, the group set a goal of creating an emotionally themed Hip Hop mixtape. Students collectively chose a theme that they could relate to and engaged them in a discussion where students shared their personal experiences and thoughts. Based on their selected theme, students wrote and recorded each song. Because of the nature of the topics, discussions between students were very emotionally charged. 
To ensure a safe and brave space that allowed for sharing and reflecting, students established cypher norms that maintained accountability for themselves and each other within the context of group work. The cypher norms consisted of: 1) everyone stands at an equal distance from each other in a circle, 2) everyone has a chance to share, 3) all voices have equal value, 4) praise is awarded to individuals when they share, and 5) equal support is provided to participants when in need (Levy, Emdin, \& Adjapong, 2018). When these norms are not practiced, students hold each other accountable. For example, when the cypher (circle) got too close or someone was crowding the space, group members would yell, "Hold the circle!" They would also recite a rhyme like: "Before we move forward and get any hyper, take two steps and open up the cypher!" These practices of accountability allowed for the restoration of balance and created a space where students felt validated and heard.

The study found that utilizing expressive methods of healing allowed students to feel mutually supported and participate in a setting where they experienced a greater sense of belonging and validation. Levy observed that the cypher was a cathartic space that led to the universalization of feelings. He found when students rhymed about a particular topic, other students would rhyme about similar experiences. Whether the rap content was positive or negative, he noticed that the group became a community of individuals who genuinely cared for each other. When healing-centered practices are not accessible for communities of color or are seen as carrying negative stigma around mental health, the Hip Hop cypher provides an alternative that honors and acknowledges their lived experiences and culture (Ginwright, 2015).

\section{It's Bigger Than Hip Hop: Impact on Student Engagement and Sense of}

Belonging. Research has illustrated the impact on student engagement and sense of belonging using culturally responsive and relevant practices serving students of color (Brooms \& Davis, 
2017; Museus, Yi, \& Saelua, 2017; Tovar, 2015; Wood \& Williams, 2013). Studies have shown that Hip Hop can increase student engagement and foster spaces that allow students to experience an increased sense of belonging (Hall \& Martin, 2013; Sulé, 2016).

Hall and Martin (2013) examined the impact of Hip Hop pedagogy on African American student engagement and retention at a historically Black American university. They conducted a case study approach where they examined the teaching practices and student interactions in the classrooms of one African American faculty member at a historically Black American university. In addition to the faculty participation, the students were also asked to complete a questionnaire responding to questions related to their engagement with the use of Hip Hop in their classes. They were specifically asked how Hip Hop pedagogy in the classroom impacts their learning experiences. Based on the 120 student responses, two themes emerged from the data: 1) the role of pedagogy and 2) the role of the faculty. Within both themes, there were also sub-themes. Within the theme of the role of pedagogy, four sub-themes included: 1) culturally relevant, 2) socially relevant, 3) interdisciplinary, and 4) academically rigorous.

The first sub-theme of cultural relevancy was observed through teaching practices that connected Hip Hop culture to the indigenous roots of Africa. One of the ways these connections were made were through the use of essays that articulated how the history of Hip Hop reached further beyond the birthplace of Hip Hop. The faculty member also incorporated an African tradition of call and response into his class lectures to elicit reactions and responses similar to how an African American preacher would do during a Sunday mass. These spirited approaches to teaching traces back to the roots of Africa.

The second sub-theme that emerged from the role of pedagogy was social relevancy. The Professor would intentionally integrate issues of social relevance into his class lectures to 
generate conversations around social justice and empowerment. Given Hip Hop is seen as a culture that is unapologetic, fierce, and adopts a "don't mess with me" mantra, it parallels the movements such as the Civil Rights movement, where African Americans fought relentlessly for equal rights. By including experiences that students can relate to, they begin to feel they belong in the space and that "it gives them a voice (Hall \& Martin, 2013, p.99).

The last two sub-themes found that the role of pedagogy was interdisciplinary and academically rigorous. Students found that in their English class, they learned about other disciplines such as history, sociology and psychology. The findings also revealed that Hip Hop culture is discussed through the lens of cultural hybridity. Hip Hop culture blends African cultural patterns with Western European culture. Hip Hop also doesn't operate within a vacuum. It cuts through layers of politics, governments, laws, mental health, and economics. Through this intentional approach to interdisciplinarity, the English class was observed as academically rigorous. Another way that the faculty member increased the academic rigor while privileging Hip Hop scholarship, he incorporated works by African American scholars and assigned additional scholarly readings.

Several of the sub-themes reflected the tenets of Critical Race Theory (CRT) where students were able to share their own stories as it relates to the curricular content taught in class. It created a learning environment that allows for critical thought and dialogue when examining the class content. Students expressed that they cared about the subject matter because it directly related to their cultural and social experiences.

The second theme, the role of faculty, had two sub-themes that included: 1) classroom climate and 2) knowledge of the subject. Students shared that the classroom climate was laidback and flexible. They also expressed that the classroom experience was very interactive and 
animated and noted that they were positioned at the center of the dialogues. Students felt validated and were highly engaged. This description of the classroom space is very similar to the graffiti element of Hip Hop in that it represents a transformation of space. What used to occupy a particular wall is now transformed into a wall that conjures thoughts, emotions, and feelings through lettering, colors, shapes, and messages. Mitchell, Wood, and Witherspoon (2010) critically examines how social relations structure the production of space on a college campus. They called attention to the relationship between race and space and how these social structures impacted students of color during their academic advising experiences.

The second sub-theme of the role of faculty is the knowledge of the subject. Hall and Martin observed that students found it valuable for the faculty to understand the subject matter as it directly relates to their cultural and social lived realities. While most of the students' responses conveyed that it was important to have an African American faculty member, some noted that knowledge, not race, mattered most. This is a profound finding because this notion of "keeping it real" is an ongoing debate between Hip Hop scholars and practitioners on who can utilize Hip Hop pedagogy in their classrooms. According to the U.S Department of Education, about $50 \%$ of the public student population are students of color, while nearly $80 \%$ of publicschool teachers are white. Adjapong (2017) argue that, although teachers may not identify with Hip Hop culture as their students, it does not prove to be a limitation of utilizing Hip Hop pedagogy. He views this as a strength that encourages teachers to position themselves as a student of students' culture. Irby and Hall (2013) also points out that "keeping it real" can be stifling in the advancement of Hip Hop-based education. If this is an approach that can interrupt white privilege within teacher education, then it would prove valuable if white educators are provided an opportunity to learn about the praxis of Hip Hop based education. 
The Hall and Martin (2013) study confirmed that Hip Hop pedagogy can impact African American student engagement when the content is culturally, socially relevant, interdisciplinary, and academically rigorous. They also noted that students in the study cared about the content because it represented stories and experiences that they could all relate to. The classroom climate also allowed them to have their voices heard and validated. Given all of these conclusions, it would be worthwhile to explore the impact of Hip Hop pedagogy on graduation rates.

Museus, Yi, and Saelua (2017) argue that when studying the success of students of color, we must look beyond the traditional measures of success such as completion and graduation rates, grade point averages, and number of units completed. They assert a need to examine other measures of student success such as sense of belonging, student engagement, cultural wealth, and cultural integrity. How might these conceptual divergences help educators to understand how we can best serve our traditionally, marginalized student populations? Hip Hop pedagogy has been shown to create classroom spaces that increase student engagement through culturally and socially relevant curriculum (Banks, 2017; Hall and Martin, 2013; Hall, 2017; Seidel, 2011).

Sense of belonging as another unit of success has been shown to demonstrate increase in college retention and persistence rates for students of color (Gurin, Dey, Hurtado, \& Gurin, 2002; Hurtado, 2007). Historically, Hip Hop culture provided a platform for communities of color to engage in the different elements of Hip Hop as a means of cultural and social solidarity. It brought people of various neighborhoods in New York City together to voice out their concerns over the multitude of social and economic disparities that were impacting their communities. From this pain and struggle, Hip Hop as a platform provided them with a sense of belonging; a sense of oneness. 
While most of the educational research on Hip Hop pedagogy has focused on K-12 settings, there has been a growing body of research that falls within the context of higher education (Henry, West, \& Jackson, 2010; Petchauer, 2012; Rodriguez, 2009). To understand how the phenomenon of Hip Hop culture is experienced by students at an institution of higher education, Sulé (2016) drew from phenomenological epistemology. She interviewed 19 students who were affiliated with campus Hip Hop organizations or campus Hip Hop related topics. The population was predominantly male ( 15 total) but the group was racially and ethnically diverse. The interviews lasted 90 minutes to 2 hours in length and discussed topics such as earliest memory of Hip Hop culture, educational goals, transitions to high school and college, social memberships, campus climate, campus experiences, and their participation in Hip Hop. She found that students experienced a feeling of mattering as well as learned about the processes of connecting with others.

Sulé's (2016) study identified three sub-themes that are manifestations of sense of belonging: 1) self-expression, 2) empathetic mattering, and 3) counterspace membership. Selfexpression was experienced by students in three distinct ways. Students reported that they felt a sense of spirituality where Hip Hop provided them with experiences of catharsis. Hip Hop represented something bigger than the mundaneness of everyday existence (Sulé, 2016). Another way that Hip Hop promoted self-expression in this study was in the form of counter-storytelling. While many stories rooted in dominant narratives silence the experiences of racially marginalized groups, students found, through counter-storytelling, the ability to use their language and stories to dismiss and interrogate normative conceptions of their lived experiences (Solorzano and Yosso, 2002). These two sub-themes that describe self-expression as contributing to increased sense of belonging demonstrate a harmonious relationship between 
spirituality and counter-storytelling. Rendón's Sentipensante Pedagogy (2009) represents this relationship as unifying both wisdom that students bring in and the knowledge that they have cocreated in these educational spaces. The final way that self-expression was manifested was in the form of emotional release. Students defined their college experience as stressful and full of anxiety. They reported that, through Hip Hop, particularly through raps and dance, their stress and anxiety levels decreased.

Sulé's (2016) study also found that sense of belonging emerged through empathetic mattering. One of the most profound findings is how Hip Hop serves as a conduit to illustrate how others matter. Storytelling was also at the center of this experience as students were able to make meaning of the experiences of others that have perceived cultural similarities and differences. Sulé (2016) argued that Hip Hop culture can facilitate intercultural capital by allowing students to share about their own lived experiences as well as examining how other stories from students of varied backgrounds resonate with them.

The final manifestation of sense of belonging is one's membership in a counterspace. Counterspaces are used to describe physical locations where underrepresented students seek self-affirmation and social support (Solorzano, Ceja, \& Yosso, 2000). Examples of counterspaces in Sulé's (2016) study include: student organization meetings, dance battles, Hip Hop conferences and workshops. Drawing from these observations, counterspaces can be used to help inform how educational spaces can engender forms of interactional diversity and equity. Counterspaces are not limited to physical spaces. They draw upon Hip Hop aesthetics; "the ways of being and the ways of doing." While creating counterspaces that intentionally design culturally relevant curriculum is an important part of integrating HHBE, it is also about the feelings and emotions that students experience in those spaces when engaged in Hip Hop 
pedagogy. As Petchauer (2015) describes, Hip Hop aesthetics is how we are moved sonically, kinesthetically, linguistically, and visually.

Conclusion. Through this literature review, we have explored the history of community colleges and how academic advising has been operationalized traditionally in higher education. We have examined the various academic advising approaches and their impact with student success outcomes such as retention and persistence. Then, we delved deeper into the educational possibilities that Hip Hop can provide through its historical and cultural contexts. We also described the various ways Hip Hop has been conceptualized in educational spaces specifically in the K-12 settings. We finally looked at how Hip Hop education has entered in scholarship related to higher education through topics such as student engagement and sense of belonging. The next chapter on the methodology of this study will describe how we will examine Hip Hop aesthetics and its application in college counseling using Rendón's Sentipensante pedagogy as a theoretical framework. 


\title{
TRACK THREE
}

\section{METHODOLOGY}

\author{
Heiroglyphics \\ Hip Hop is vintage \\ Invented in days back \\ Rekindling in ways that many thought was lost \\ In this contemporary maze of methods to floss \\ We finding trees and trails to blaze \\ Boundaries to cross \\ We can be found beyond the bounds of reason \\ Or earthbound, heatin' up the Coliseum \\ (Tajai of Heiroglyphics, You Never Knew, 1994)
}

Hieroglyphics is defined as designating or pertaining to a pictographic script, particularly that of the ancient Egyptians, in which many of the symbols are conventionalized, recognizable pictures of the things represented (Random House Unabridged Dictionary, 2019). It can also be a figure or symbol with a hidden meaning. Additionally, hieroglyphics is also used as an adjective to describe something that is "hard to decipher or hard to read." Emcee Tajai Massey of the Bay Area Hip Hop group, the Heiroglyphics, wrote and performed this verse in the 1994 song, You Never Knew, and vividly describes the landscape to which research can be a process that involves "reflexive, messy texts" where "we find trees and trails to blaze, and boundaries to cross." As I explore the lived histories and experiences of four California community college counselors, I need a tool that will navigate these messy texts that are contextual and openended. Through in-depth examination of their experiences, a diversity of perspective of coding, and an organized means to analysis, this qualitative study allows for "multiple truths" (Abes, 2009).

My research on how Hip Hop pedagogy informs counselors' practices necessitates a methodology that could capture the many layers that are embedded in counselors' lives, motivations, life histories, and beliefs. Numbers regarding retention and success rates for 
students of color in community colleges paint an alarming picture. Community college completion data shows that $27 \%$ of white men enrolled earn a certificate or degree or transfer within three years after entering. The number significantly drops to $17 \%$ for African American men and 15.4\% for Latino men (National Center for Educational Statistics, 2015). More significantly, a staggering 5\% of African American men who attend community college parttime (i.e. enrolled in 11 units or less) finish or transfer in three years. These numbers do not change drastically as we look at six-year rates for students completing a bachelor's degree within that time frame. While these figures can be attributed to a number of factors, research has supported Light's (2001) assertion that, "good advising may be the single most underestimated characteristic of a successful college experience" (p. 81). For example, in a review of attrition and retention studies, Cueso (2003) linked academic advising with student success and argued that strengthening academic advising programs exerts a positive effect on student success. Additionally, Pascarella and Terenzini (2005) noted that "research consistently indicates that academic advising can play a role in students' decisions to persist and in their chances of graduating” (p. 404).

Given these research findings, drawing conclusions utilizing retention, persistence, and student success data does not tell the whole story. It is essential to discover the "aesthetic whole." To facilitate this process of research, I selected portraiture as my methodology, which has many shared elements of phenomenology and narrative inquiry. In this section, I will discuss how portraiture is an appropriate methodological approach to examine how Hip Hop aesthetics are operationalized to help inform college counseling practices. In addition, I will explain further how features of portraiture such as voice and relationships highlight the importance of Rendón's (1994) Theory of Validation and Yosso's (2006) model on Community 
Cultural Wealth. I will then explain my participant selection process, data collection, and data analysis utilizing portraiture as a methodology. Lastly, I discuss the generalizability or transferability of anticipated findings and potential study limitations.

\section{Methodological Purpose}

\section{Moving from a Bad Rap to the "Search for Goodness"}

In examining the "aesthetics" of Hip Hop pedagogy operating within college counseling, using the method and methodology of portraiture made sense because portraiture focuses on this "search for goodness." This is an attempt to illustrate what might be considered "good counseling" in the midst of human imperfections. Lawrence-Lightfoot and Davis (1997) call this the search "for what is good and healthy (p. 88)." While there are more current studies that are assets and strengths-based, previous literature regarding retention and student success of students of color in higher education were largely focused through a deficit-oriented lens. This can also be seen in the prescriptive approach of college counseling where counselors assess what's wrong with the student and provide the necessary prescription or solution to address their needs. Given that research shows that effective college counseling is integral to student success, deficit frameworks impede relationship building and reinforce low expectations which inhibits help seeking behavior (Coronella, 2018; Perez Huber, Huidor, Malagon, Sanchez, \& Solorzano, 2006). Brooms and Davis (2017) studied peer bonding and faculty mentors supporting Black males' persistence in college and found that deficit frameworks make navigating college difficult for Black males.

Similarly, Hip Hop culture has experienced deficit frameworks that often paint this culture as hypersexual, violent, drugs-laden, and misogynistic. Hip Hop culture was born out of the socio-political and economic conditions that plagued the Bronx in the early 1970s. It was a 
response generated by youth resistance and rebellion to the oppressive structures that afflicted many Black and Brown communities (Chang, 2006). Since then, Hip Hop as a culture, particularly within rap music, has become a multibillion dollar industry due to the profit-driven commercialization of the culture. However, a byproduct of its wide availability is concern about excessive violence, misogyny, and substance abuse found in the lyrics and imagery (Travis, 2013). While these concepts of violence, misogyny, and substance existed before Hip Hop culture was created, mass media has highlighted the proliferation of songs with lyrical content that spoke to these concepts presenting Hip Hop culture from a one-dimensional perspective. What's lost from the culture as a result of commercialization and corporatization is what made Hip Hop so vibrant and impactful; it was an act of resistance and expression.

Despite these viewpoints on Hip Hop culture, there has been greater emphasis within academia on how Hip Hop can be used to address personal growth (Emdin, 2010; Travis, 2013), increase student engagement (Emdin, 2010; Hill, 2009; Morell \& Duncan-Andrade, 2002), address community inequities (Emdin, 2010; Petchauer, 2011; Seidel, 2011), and catalyze therapeutic interventions (Levy, Emdin, \& Adjapong, 2018; Travis, 2013). Findings from these research studies have shown developmental themes of self-esteem, resilience, growth, and community. Here, we are moving from a bad rap to the "search for goodness."

Portraiture's focus on an expansive search for goodness, as opposed to a prescriptive and developmental approach to identifying what is bad and wrong, takes on significance, importance, and relevance in an education reform context that narrowly defines "good" counseling. In the case of California community colleges, institutions have been tasked to evaluate and examine current policies and practices with students. More specifically within college counseling, many community colleges have interpreted "more support" for students as requiring more counseling 
appointments. However, according to the Community College Research Center (2013), community college counseling is often characterized by: a) high student-counselor ratios, which result in rushed counseling sessions; b) no assigned counselors, resulting in receiving little to no information and long waiting periods for counseling; c) little to no follow-up for new students after they complete enrollment; and, d) fragmented connections to programs and services. Through portraiture, this study attempts to emphasize the importance of enhancing the quality of counseling, not quantity. It also asks the question of community college counselors who utilize Hip Hop pedagogy in their counseling practices, "What is good here?". Equally important, this process also "captures contradictions and disrupts romanticization -- highlighting imperfections, vulnerabilities, and the strength, weakness, and complexity of character" (Lawrence-Lightfoot \& Davis, 1997, p. 9).

Portraiture attempts to tell the stories of people who do not have "voice" in the realm of academia. The portraiture method also rejects flat, stereotypical explanations for student success or failure. To capture the richness and distinctions of stories, they are told through the energies of both the researcher and the subject. Lawrence-Lightfoot further describes how portraits are:

Shaped through dialogue between the portraitist and the subject, each one participating in the drawing of the image. The encounter between the two is rich with meaning and resonance and is crucial to the success and authenticity of the rendered piece. (LawrenceLightfoot \& Davis, 1997, p. 3).

Portraiture's focus on goodness aligns with Rendón's (1994) Theory of Validation and Yosso’s (2005) Community Cultural Wealth model. Validation theory works with students as whole human beings. While Astin's (1985) Theory of Involvement and Tinto’s (1975) Theory of Student Integration contributed mightily in the scholarship of student development theories, they don't explicitly explain how environmental and ecological factors impact the college experiences 
of traditionally marginalized students. The notion of "wholeness" aligns with one of the core elements of portraiture - seeing the "aesthetic whole."

In addition, both validation theory and community cultural wealth model embrace and acknowledge the importance of students' personal voices and experiences. Portraiture, with the use of phenomenological interviewing, allows me to focus on stories and lived experiences and gain a deeper understanding and underlying structure of a particular phenomenon. The use of Rendón's Theory of Validation and Yosso's Community Cultural Wealth model within the methodology of portraiture allows me to understand more deeply how these theories are informing counseling practices with traditionally marginalized students.

Abes (2009) challenges the traditional notions of student development theory as trajectories that predict and explain. She also challenges us to move away from subscribing to monolithic beliefs that one student development theory is a "one size fit all" approach that speaks to the multiplicity of students' lived histories and experiences. In her work, Anzaldua (1999) described a borderland as a third space that is neither one land nor the other but a new space that is a "both/and" location. This borderland is an environment where individuals fluctuate between two discrete worlds, participating in both and wholly belonging in neither, "none of them 'home,' yet none of them 'not home"” (p. 528). Rose (1994) also argues this point around style, aesthetics, and Hip Hop principles as a "potential blueprint for social resistance and affirmation (p. 87)." As we engage in this research, it is important to dismiss this notion of landing on one theory or approach to predict or to explain and rather be open to multiple theories and concepts that speak to the myriad of student experiences.

The methodological choice of portraiture also speaks to this notion around decolonizing educational research. Similar to many different types of culture such as Hip Hop, research is 
relational to contexts. Westernized research practices often require methods that can produce results that can be seen as practices that are tried and true. However, to understand the complexities of culture, it cannot be measured in terms of objectivity and neutrality. This study is looking at how the lived experiences of college counselors who are engaged in Hip Hop help inform their own counseling practices with students. While their experiences and their counseling pedagogical approaches may differ than that of more traditional methods of academic advising, it does not mean it is less effective. Battiste (2013) argue that Eurocentric science seeks principles that are universal; that all information is open to disproved. However, in doing so, when engaged in this type of research philosophy, the stories and experiences that are found in research loses its meaning and its ability to touch and inform practices. Similar to Hip Hop culture, portraiture takes on an unapologetic approach by studying the various contexts that makes up the lived experiences of our participants.

\section{Turn It Up: Voices Amplified through Hip Hop Aesthetics}

I remember sitting in my dorm room and I'm blasting "If I Ruled The World (Imagine That)" by Nas and Lauryn Hill through my mini Bose speakers that my parents gave me as a present when I first moved into the dorms in the 90 s. I was reciting the hook of the song at the top of my lungs reflecting on what it would look like if I really ruled the world. Imagine that. The beat was knocking or so I thought when the beat became mismatched with the actual cadence of the song. Someone was pounding on my door. I opened the door and it was my resident advisor (RA); his face beet red. He shouted, "Can you please turn down that noise? Why do you listen to that garbage anyways? Do you even know what they're even saying? It's just noise." 
It wasn't until I was teaching a Hip Hop college success course many years later when I understood how profound that moment was for me. I was in class sharing with my students my all-time favorite Hip Hop songs. The majority of the class either didn't know some of the songs I mentioned, or they did not like it at all. So, I asked the class who they were listening to. Responses were: J Cole, Kendrick Lamar, Young Thug, Drake, Lil Wayne, Cardi B, Drizzy, Logic, Future, Migos, Lil Yachty, Lil Uzi Vert, Smokepurpp, and others. There were plenty more that I didn't recognize. I could not bear to listen to most of the songs they were listening to. A part of me wanted to tell them to "turn it down" just as my RA told me many years before. However, rather than having them "turn it down", I asked them what was about these songs that resonated with them. While most of them admitted that the beats were what they liked the most, they could relate and identify with the rap lyrics. They felt that the rappers were expressing similar experiences, thoughts, and feelings as they were. By "turning down the music", I would essentially be turning down their experiences. I would perpetuate the same oppressive conditions by marginalizing my students and rendering them "silent and voiceless." Hip Hop culture is about amplifying youth voices and expression. It was born out of the revolution and resistance in response to the socio-political and economic conditions that ravaged New York City in the early 1970s (Chang, 2005). Hip Hop is about "turning it up."

Similar to Hip Hop, the element of voice in portraiture is paramount. Similar to Hip Hop culture, there are a multitude of voices that are utilized in portraiture. While rapping in its literal sense exerts and manifests the sounds of voice, the other Hip Hop elements such as b-boying (breakdancing), graffiti art, and DJing, elicit voices in different, varied ways. Through each element of Hip Hop, the artistic expression provides "voice" by sharing messages and stories through their visual and auditory storytelling. Lawrence-Lightfoot and Davis (1997) provide a 
wide range of voices utilized in portraiture, framing a portraitist's voice as: witness, interpretation, preoccupation, autobiography, and in dialogue. In exploring these sets of voices, I will attempt to draw connections of Hip Hop aesthetics as ways to engage in this methodology of portraiture. Hip Hop as a culture and as a pedagogical approach naturally embodies these "voices".

In utilizing Voice as Witness in exploring the work of community college counselors engaging in Hip Hop pedagogy, I will observe and take notes as a discerning participant observer, intentionally gathering details of behaviors, expressions, energy, language, tone, and other various factors. In the same spirit of Hip Hop, every move, every action, every word, and every beat are informed by a set of beliefs, values, histories, lived experiences, and ideas. This notion exemplifies the Hip Hop aesthetic of kinetic consumption. Kline (2007) refers to the idea that "Hip Hop is meant to be felt and not just seen and/or heard." It also elucidates that affective and emotional experiences are valid and critical ways of knowing the world and building knowledge.

Voice as Interpretation will manifest in both in the field of study as well as deeper, more formal data analysis. This will be my attempt to make meaning of the data. It is an opportunity for me to move from being distant as Voices of Witness to one that utilizes abilities in the form of observation, analysis, and improvisation. Improvisation or "freestyling" is a form of Hip Hop aesthetic that allows me to create meaning that is thoughtful and discerning.

The Voice of Preoccupation refers to the knowledge and perspectives I bring into my research. This will include my own personal understanding and knowledge around Hip Hop pedagogy in counseling practices as well as the theoretical frameworks that support this as a culturally responsive approach to counseling. This speaks to the Hip Hop aesthetic of 
"sampling." Karimi (2006) describes the idea of sampled consciousness as a way that people who are socialized into Hip Hop culture construct their identities by sampling different experiences: education, stories, and observations. The individual takes these experiences and makes them part of their overall worldview. Lawrence-Lightfoot and Davis (1987) believed that the researcher is defined by these experiences inside and outside the researcher's discipline. As a result, I bring my total self to the research.

"Sampling" also shows up in the Voice as Autobiography where it recognizes the importance of my own positionality and life history as situated within the research study. What is the significance of my role as a college counselor who utilizes Hip Hop pedagogy in my counseling practices? How do I "sample" or select stories that can build space for constructing knowledge and highlighting perspectives while simultaneously ensuring that my autobiography does not become the main portrait?

To address these important questions, I turn to the Voice of Dialogue. With this voice, I situate myself purposefully in the center of inquiry as a process that constructs meaning of the data. While Lawrence-Lightfoot and Davis (1997) talk about the symmetry of voices - my voice and my participants' voices - the Voice of Dialogue also acknowledges the "asymmetry" through the Hip Hop aesthetic of "rupture." Rupture refers to a break in a flow or the intentional disruption in flow (Schur, 2009). For example, a DJ uses two copies of the same records to manually deconstruct a beat down to its basic parts and then artfully reconstruct them into a new form appreciated by listeners (Petchauer, 2015). Similarly, the Voice as Dialogue seeks to balance participants' perspectives by placing them in dialogue with each other. This process ensures a collective process of meaning-making that allows participants to take part in the data analysis. 
Portraiture provides the methodology that allows us to travel through traditional disciplines, approaches, and perspectives while delicately weaving ethnography and storytelling to capture the complexities of the human experience. It provides us with the method in "finding trees and trails to blaze"; highlights "boundaries to cross"; and may shed light on what we find is "beyond the bounds of reason." It allows us to give life and voice to those who have been traditionally marginalized in these academic spaces.

\section{Research Aim and Research Questions}

This research aims to explore in depth how specific California community college counselors make meaning of their lived histories and experiences within Hip Hop culture and how these experiences have shaped and informed their own college counseling practices with community college students. This study also emphasizes the need to bring awareness to the developing best practices of college counseling as an integral part of Hip Hop education. Equally important, this study also adds to the body of research that only represents $8 \%$ of studies that look at academic advising and college counseling practices in community colleges (Townsend, Donaldson, \& Wilson, 2004). The majority of research within this field has focused primarily on predominantly White institutions (PWI) at the four-year university level. A move towards a college counseling framework rooted in culturally responsive pedagogy is not intended to replace, dismiss, nor reject the existing approaches to academic advising and college counseling but rather to inform another counseling pedagogical approach that authentically attempts to reflect the needs of historically neglected and traditionally marginalized students. 


\section{Research Questions}

1. What are the life stories and experiences of community college counselors who engage in Hip Hop pedagogy?

2. How does their lived experiences and their understanding of Hip Hop shape and inform their college counseling practices?

\section{Study Design}

I employed phenomenological interviewing using Seidman's (2006) three-interview method to explore three areas: contextualization, apprehending the phenomenon, and clarifying the phenomenon. To address the research questions, I interviewed four California community college counselors for a total of three interviews each. The first interview focused on their life histories, educational experiences (i.e. K-12 experiences, college experiences), and their personal experiences with Hip Hop. The second interview focused on their current occupation. We explored their roles and responsibilities as college counselors at a California community college. The last interview focused on the connection between their Hip Hop lived experiences and their current work in counseling. In addition, phenomenological interviewing approach was an opportunity for participants to make meaning of their experiences. The length of the interviews varied between 60-90 minutes with about 3-7 days between each interview. All of the interviews were conducted at a private location where the participant was comfortable (i.e. office, classroom, home). These interviews took place from September - December 2019.

\section{Sample Selection}

Because there is little research done on community college counselors engaging in Hip Hop pedagogy in their counseling practices, the search for counselors to participate in this study may be difficult. To assist in helping me find participants, I used a snowball sampling method. I sent emails and social media messages to personal contacts I knew who were involved in Hip 
Hop education. I also reached out to college counseling listservs to identify people who could inform me of other counselors who may be utilizing Hip Hop in their practice. In the communication to locate and identify counselors, I provided these specific criteria related to this study. College counselors must have a Master's degree in Counseling, have worked as a community college in California for at least 5 years as a full-time faculty, and have explicitly utilized Hip Hop pedagogy in their counseling practices. College counselors and academic advisors who only have a Bachelor's degree were excluded from this study. In addition, counselors who practice Hip Hop pedagogy who work at 4-year universities were also excluded. After my outreach, I was able to identify 11 counselors throughout the state. I sent them an online pre-survey (refer to Appendix C) to respond to questions that directly corresponded to the criteria above. In addition, I also asked them if they practice Hip Hop in any of the elements (i.e. emcee, DJ) as well as their definition and understanding of Hip Hop pedagogy.

As a result, I identified four California community college counselors who met the stated criteria as well as those who actively and explicitly utilize Hip Hop pedagogy in their counseling practices. Below is a list of the participants of this study:

\begin{tabular}{|l|l|l|l|}
\hline Name & Title & Institution & Department \\
\hline $\begin{array}{l}\text { Kimberly } \\
\text { Davalos }\end{array}$ & Promise Scholars Counselor & Skyline College & Counseling \\
\hline Adam Freas & $\begin{array}{l}\text { EOPS Counselor \& Faculty Equity } \\
\text { Coordinator }\end{array}$ & $\begin{array}{l}\text { Sacramento City } \\
\text { College }\end{array}$ & $\begin{array}{l}\text { EOPS } \\
\text { Counseling }\end{array}$ \\
\hline Ken Times & General Counselor & $\begin{array}{l}\text { Sacramento City } \\
\text { College }\end{array}$ & Counseling \\
\hline $\begin{array}{l}\text { Robert } \\
\text { Alexander }\end{array}$ & General Counselor & De Anza College & Counseling \\
\hline
\end{tabular}


Kimberly Davalos will be referred to as Kim in this study. She is currently a Promise Scholars Program counselor at Skyline College and has been in the field of college counseling for 8 years. She is one of the faculty instructors for the CIPHER Hip Hop Learning Community where she teaches a course titled, "Community Engagement and Leadership." She served as the Associate Director for Rock The School Bells, an annual youth Hip Hop conference, for two years. She is also a writer and author of her published book titled, Delilah's Daughter.

Adam Freas will be referred to as Freas in this study. Freas is a name that he is referred to as a Hip Hop emcee. He currently works at Sacramento City College as an EOPS Counselor and Faculty Equity Coordinator. He has been in the field of college counseling for 14 years. He is also one of the founders of a non-profit organization called Low End Theory Collaborative that works independently and in conjunction with other organizations to provide customized academic programming, professional career development, and community-based event planning services within the framework and approach centered around Hip Hop culture. He is currently an emcee in a Hip Hop collective called Bap Notes.

Ken Times will be referred to as KT in this study. KT currently works at Sacramento City College as the counselor and coordinator of the UMOJA Program. He is also one of the founders of the aforementioned non-profit organization called Low End Theory Collaborative. He has been counseling in the field for 12 years.

Robert Alexander will be referred to as Rob in this study. Rob currently works at De Anza College as an academic counselor and instructor. He teaches courses such as Human Sexuality, Career and Life Planning, and Life Skills for Higher Education. He has been in the field of counseling for 14 years. In addition, he is also the author of his book titled, Can't Let 
Nobody Ride My Bike, a personal narrative of his life living in Oakland described through the lens and soundtrack of Hip Hop.

\section{Instrumentation and Data Collection}

I used an interview protocol that consisted of questions exploring the following areas: life histories, occupation, educational experiences, Hip Hop lived experiences and pedagogy (refer to Appendix D). The instrument consisted of 30 interview questions that addressed four areas over a course of three in-depth, semi-structured, and one-on-one interviews. The gaps for each interview per participant ranged anywhere between 3-7 days. The gaps between each interview allowed me to listen to the recordings more closely, take notes of what was being said and how it was being said (i.e. tone, volume), and write down any clarifying questions I had so I could address them during the follow-up interview. The interviews were recorded on my iPhone as well as my iPad tablet. All of the participants had a lapel mic to ensure that the captured recording was crisp and clear.

The first interview focused on the participants' life histories, their academic and counseling experiences as a student, ranging from middle school to college, and their geographic locations of residences. The second interview consisted of questions around the participant's current occupation, their understanding of college counseling, their roles and responsibilities as a college counselor, their motivation in becoming a counselor, and their counseling philosophy. The final interview looked at the following areas: the participant's relationship to Hip Hop, their definition of Hip Hop pedagogy, what informs their counseling practice when engaged in Hip Hop pedagogy, how their counseling philosophy connects or supports Hip Hop pedagogy, and what meaning they created from these experiences. The last two questions in the final interview provided me with in-depth understanding around participants' understandings, 
ideas, beliefs, and experiences related to college counseling and Hip Hop pedagogy. Other data sources included: field notes, data memos, initial reflections, performances, classroom observations, and examples of their work such as lesson plans and published works.

\section{Data Analysis Procedures}

To do efficient and effective data analysis, there is a need to wallow in the data (Glasser \& Strauss, 1967). In this study, portraiture is framed using phenomenological interviewing by focusing on lived experiences and gaining a deeper understanding and underlying structure of a particular phenomenon. During the interviews, to ensure accuracy of reported statements, I utilized multiple forms of recording devices such as a smartphone and tablet. I also used a lapel mic to clip onto the participant's shirt to ensure clarity in capturing the audio. Also, by recording on a smartphone and tablet, I was able to directly store all of my interviews onto my hard drive. This allowed additional security as there is a passcode needed to access them. In addition to these advantages, having these digital recordings on file allows for smoother transfer to a transcription service which I used to transcribe all of my interviews. Throughout the process of conducting interviews and reviewing transcriptions, I wrote data memos that allowed me to keep a journal of how I made meaning of their experiences and stories, drawing connections to the literature review, and identifying emerging themes. While I did not personally transcribe any of my interviews, I listened and read each transcription multiple times.

I utilized in vivo coding to identify emergent themes found in my transcribed interviews and data memos. This method is appropriate for this research study because it prioritizes and honors the participant's voice. In diving deep into my participants' lived experiences and stories, I found many instances where participants had experienced their voices silenced and marginalized. My chosen method enhanced my ability to keep their voices alive. Strauss (1987) 
defines in vivo as "in that which is alive" and as a code that refers to words and phrases that are "terms used by participants themselves" (p. 33). It also used to describe how the researcher "sits and rifts through interview transcripts, observational narratives, field notes, documents, and Impressionistic Records in search for patterns that will order and scaffold the narrative", a process involving a deeper level of analysis (Lawrence-Lightfoot \& Davis, 1997, p. 189).

I approached my data analysis through different levels: 1) Identified how Hip Hop was woven into participants' lived experiences, 2) Identified their participation within Hip Hop, 3) Identified how Hip Hop informs their counseling pedagogy and teaching practices, and 4) developed portraits based on emergent themes. I used the software NVivo to analyze my data. My initial number of codes totaled 71, which was then whittled down to 24 codes. NVivo analysis utilizes instinctual analysis meaning that there are no set number of codes. I was able to capture different types of codes allowing me to create in-depth portraits such as imagery, symbols, poems, and metaphors that provided more richness in the description and interpretation. During this process, I wrote data memos regarding development of my analysis which included deeper understandings of certain themes, new themes, and areas of coherence and rupture. While some researchers may caution the overdependence of NVivo coding due to its simple, safe, and secure methods, moving back and forth between my notes, interviews, and data memos, allowed me to continue to refine and hone more conceptual and theoretical levels of analysis and insight.

Portraiture also recognizes that, in this process of data analysis, the Voice as Autobiography consisting of my own familial, cultural, developmental, and educational background may emerge. From a Hip Hop aesthetic perspective of Voice as Witness, I engaged in kinetic consumption in that I related to the intellectual themes of the work. To address this, I 
provided the opportunity for my participants to review my interpretation and my analysis of the data to ensure accuracy and authenticity. In my aim to employ trustworthiness in this process, I am reminded by Lawrence-Lightfoot's reference, "the articulation of early presumptions does not inhibit or distort the vision; rather it is likely to make the lens more lucid, less encumbered by the shadow of bias" (Lawrence-Lightfoot \& Davis, 1997, p. 186).

\section{Role of Researcher}

Portraiture cannot be accomplished without developing a working and trusting relationship between the portraitist and the participants. Hip Hop pedagogy also builds off this idea of relationship building and collectivism. One of Hip Hop's strengths is the ability to create these authentic relationships internally and externally. Internally, the various elements of Hip Hop thrive off the relationships with each other such as the relationship between the DJ and the emcee (MC) or the interconnectedness between b-boys and b-girls in a dance crew. In addition, the different elements of Hip Hop also feed off the energy and connection from external stimuli such as the MC performing to a crowd or a graffiti artist's relationship with different canvases such as brick walls, subway trains, and white walls.

Comparable to the culture of Hip Hop, portraiture rejects and dismisses the traditional notion that a researcher should establish a minimally impactful and distant relationship with participants. Alternatively, portraiture leans heavily on a level of intimacy to engage an authentic, complementary relationship between the portraitist and the participants. To honor the "empirical, ethical, and humanistic dimensions of research design, as evolving and changing processes of human encounter" (p. 89), building authentic and meaningful relationships are necessary and required in order to gather data and offer genuine interpretative frames of analysis (Lawrence-Lightfoot \& Davis, 1997). Relationship building further concretizes this notion of the 
portraiture's search for goodness while ensuring that there is empathic regard for participants' perspectives.

The participants of my study included people I know as well as people I do not know. One of the participants is a colleague who I work closely with in my capacity as the Executive Director of Rock The Schools Bells and is a colleague within the Counseling Division at the community college where I work. Two of the other participants are colleagues who are doing similar work at different community colleges in Northern California. The last participant is a counselor I have not met but was recommended to me by other colleagues as a counselor who is doing significant work in counseling using Hip Hop as a pedagogy. Given the wide range of personal and professional familiarity I have with the participants, I worked to develop a safe and brave space for trust and openness to exist in our conversations. It was also necessary to define boundaries with respect to the research study. Because this study explores their histories and lived experiences, I also worked to ensure clear communication and highlighted the importance of confidentiality.

\section{Strengths and Limitations/Delimitations of the Research}

This study included a small number of participants, drawn from a snowball sampling method. Because there are a limited number of participants that align with the criteria of the study, the counseling experiences of the participants may not be generalized to the experiences of all counselors. It is also important to note that three of the participants have worked with me in spaces that implemented Hip Hop pedagogical approaches. Also, all of the participants are located in Northern California due to convenience, so their counseling experiences may not be similar to those in Southern California due to the varying processes, practices, policies, 
legislations, and pedagogies that exist throughout many different community colleges in California. 


\title{
TRACK FOUR
}

\section{KIM DAVALOS}

\author{
there is no \\ absolute truth. \\ there is yours. \\ there is mine. \\ right and wrong \\ do not matter. \\ what matters is \\ do they align \\ together.
} (Davalos, 2019)

This is a poem that will soon find its home in Kim Davalos' future release of her second self-published book. When you absorb each and every line, you experience a sensation that signifies meaning to our very own complex realities. They evoke the spirit of Gloria Anzaldua's words from her book, Borderlands/La Frontera in that it speaks of the uncompromised marking of a space and identity. There is no absolute truth. It's not an either/or but rather a both/and. When I first met Kim in 2012, she was in her last year as a graduate student in the Master's Program of Counseling at San Francisco State University. I was invited to be their keynote speaker for their inaugural Counseling Student Association (CSA) Symposium. After my presentation, the department chair quickly introduced us and said, "You two need to meet. You both share the same love and passion for Hip Hop.” With graduate students awkwardly hovering around us, we quickly exchanged numbers and scheduled to meet another time.

In the ensuing years that followed in her involvement at Skyline College, Rock The School Bells, and the CIPHER Hip Hop Learning Community, I have witnessed her growth and transformation as a counselor and an educator. I am also equally impressed on how she finds harmony with the numerous roles she embodies. If you visit her Instagram page, @kimdavalos, 
you will read the following description. Poet. Photographer. Professor. Pinay. Counselor. Creative. She is the daughter of Floyd and Delilah. She is the author of her self-published book of poetry, Delilah's Daughter. And not to mention, she will work for coffee.

We have had a number of conversations around the definition of counseling. While there have been some noticeable shifts in the approaches of counseling such as strength-based and appreciative advising, the dominant and traditional forms of counseling practices remain to be prescriptive and developmental. When counselors function utilizing these approaches, it can be very stifling and constraining for students all at the same time. When students perceive that they have no input in their educational planning or that their cultural wealth is not acknowledged in these counseling spaces, they feel voiceless and invisible. There are moments of confusion and ambiguity. Counseling approaches that do not center students' voices and experiences perpetuates the racial structures that continually produces the experiences of systemic oppression for many students, specifically our traditionally marginalized and invisibilized students of color.

These conversations are part of the reason why she describes herself as a poet, photographer, professor, Pinay, counselor, educator, and a creative. How might these different parts of her identity help inform each other? How might her counseling skills impact her ability to do her photo shoots? How might her poetry provide a platform for her to explore her sense of identity? If we limit ourselves to singular entities of our being, then how can we help our students see the power and harmony of their intersecting identities? There is no absolute truth. What matters is that they all align. We both agree that it starts with us. It is up to us to create the conditions and environment that acknowledges our students' whole self. So when she builds with her students, she identifies herself as a poet, photographer, professor, Pinay, counselor, educator, and a creative. But for me, I call her Kimdizzle. 
“Kimdizzle" was a nickname I gave her a few years ago. I can't remember when but it was during a year where we were asked to do presentations, spoken word events, classes, and keynotes. Whenever and wherever you saw me, it was more than likely you saw Kim. She was also part of the Rock The School Bells team and was heavily committed and involved with the planning. So when we were doing all of these projects together, I got to learn more about who she was while engaging in curriculum development, program planning, grant writing, and performing. Kim was down for anything and everything. She was always up to the challenge. She was also the type to take a nontraditional and spontaneous approach to things. "So what if we do it this way?" or "Let's hit them with this." Sometimes, we would present in a way to intentionally elicit certain reactions and responses. She gets bored easily and she will be the first to tell you that whatever she produces is never good enough or not at the level she wants it to be. She admits that she can be "a little extra." Her family thinks she's just extra.

In the 1990's, the term "fo shizzle" became common language in Hip Hop. It means "for sure" or "for real." Someone could say, "That shizzle be off the hizzle fo' rizzle." In translation, it would mean, "That shit be off the hook for real." The term -izzle would signify something “extra." While Snoop Dogg popularized the term "fo shizzle" in the late 90's, it was the legendary E-40 from the Bay Area who actually coined it in 1996. People in the community knows me by Nate Diggs during my days doing spoken word in the mid-1990s. So it was natural for me to create her a nickname because we were building and collaborating so much during those years. So the nickname "Kimdizzle" was born. It was a homage to the Bay Area and it also represented her as a person who was always down and about the work. But most 
importantly, it was that dose of "extra" that she would put on anything and everything that she was involved in.

\section{THE POLITICS OF S P A C E}

Fridays after 3pm at Skyline College feels like a ghost town. The college situates itself between Daly City, Pacifica, and South San Francisco where it is located near Sweeney Ridge Trail that overlooks the Pacific Ocean on a nice, sunny day. But today was like any other day at Skyline College where the thick blanket of fog slowly maneuvered its way onto campus, painting a gloomy picture of ghost towns like those old black and white western films that my Pops used to watch. I'm in the "old" CIPHER office, Kim's former office, setting up the tripod, iPad, and all of the recording equipment for this interview. With the door slightly ajar, I can hear her footsteps, her black short-heeled stilettos tapping the gray carpet of the Learning Communities wing of Building 4. Kim opens the door, breathing slightly harder than usual and says, "Sorry, I'm late. I just had back to back appointments non-stop.” I replied, "All good Kimdizzle!" Kim works as a full-time counselor for the Promise Scholars Program at Skyline College. The program operates on a caseload approach where she works with 150 students very closely from the moment they start college, all the way to degree completion and/or transfer to a four-year university. She moved from the "old" CIPHER office in Building 4 to the next building over in Building 2 where the Promise Scholars Program is located. Most of her office belongings have already been moved to her new office which isn't technically an office in the traditional sense. Over the past summer, they gutted an entire computer lab and transformed it into six counseling offices for Promise Scholars counselors. All six offices have these sliding doors with frosted glass so you can only see silhouettes of people who were congregating in the space. Separating the offices were these thin wall contraptions that went from the floor to the 
ceiling. But these weren't fully formed walls because there are tiny gaps that separate the top of these makeshift walls and the actual ceiling. That means that every conversation in the six offices can be heard. They remedied that the best way they knew how — playing lo-fi Hip Hop music. When you visit the Promise Scholar counseling offices during the school day, three things immediately attack your senses: 1) the soulful, chill, lo-fi Hip Hop beats, 2) the calming lavender scents emitting from an aromatherapy oil diffuser, and 3) the cacophony of multiple voices emanating from the six counseling offices. While they are trying their best to navigate codes of confidentiality, all of the counselors know that this space cannot be the permanent space. But as with any space at any institution, space can be hard to find. Space is political. Kim lets out a huge sigh, "I miss this office. I mean it's a real office." She glances around to observe the remnants of her old office. As I am putting together the tripod, she sits on the chair that is directly in front of the tripod. Behind her is a burgundy colored accent wall with ten photo frames of posters from the last ten years of Rock The School Bells with titles that read, “Sky's The Limit”, "Takin' It Back”, and "K.R.E.A.M.” As she swiveled her chair to the left, there was a small side table with a turntable on top with vinyl records tucked underneath. Then she says, "Those would never fit in my new office," as she points at the two large, black storage units that housed all of our Rock The School Bells and CIPHER materials, merchandise, school supplies, graduation stoles, packs of water, and other random items. I joked, "those storage units are bigger than your actual office." We both shared a joyful laugh that quickly turned serious. She asked, "So, what are they going to do with this office? Where will CIPHER be?" Kim had moved into the Promise Scholars building during the summer so there were no conversations regarding where CIPHER would be located. I have been advocating to keep the space for CIPHER but the administration had other plans in mind. One thing I was adamant 
about was that CIPHER needs a space just like every learning community that has a space in the Multicultural Building. Kababayan has two offices. Puente has two offices. ASTEP, our UMOJA learning community has an office. Our First Year Experience (FYE) has an office. We are clear that we want to make sure all of the other learning communities keep their offices. We just don't want to be left out. Our CIPHER students who are primarily students of color are being left out. The Administration hears us and deeply understands our position and situation and they promise to work together to find a solution.

When the word "promise" came out, we let out another laugh. That word prompted two initial thoughts. I said, "It's funny how they move you to another office because you are part of the Promise." But it also reminded me of a passage in Can't Stop, Won't Stop by Jeff Chang where in the late 1970s, black and brown families were being displaced due to the construction of the Cross-Bronx Expressway and moved to dilapidated areas in South Bronx where burned down buildings were barely standing. One picture that caught my attention was a man sitting on a chair with concrete rubble surrounding him. Behind him on a large strip of cloth was a written message that read, "Falsas Promesas." False promises. Back then, communities of color were fighting for their spaces, places where they can call home. They were promised jobs and better housing but none of those promises were delivered.

While not to the extent of those experiences in South Bronx in the 1970s, our CIPHER community was experiencing this loss of home. While we are both upset about losing the space, we both understand the importance of space no matter where we are located or what office we are operating from. Space is not always about the physical. Space is also about the energy. It is how we enter the space and what we bring to the space that represents the stories and experiences of the students we serve. This is, by no means, a new fight. Communities of color 
in higher education are constantly and unapologetically fighting for space for many years. We both nodded our heads in agreement and I say, "Yes, the politics of space."

\section{GENERATION OF RECLAMATION}

As the video camera sits on the tripod, Kim gets up and gently swerves it to the left to provide a more creative video angle shot. Just like a photographer and a counselor, she understands the importance of angles and perspectives. She sits back down and adjusts her black blazer above her white "Women Are Sacred" t-shirt. This t-shirt has so much meaning to her. She writes in one of her Instagram posts:

if you remember one thing about me, remember how damn hard i ride for womxn. womxn of all kinds, from all walks of life, evolving + becoming their full selves through all transformative narratives + identities. all shapes, all sizes, all shades, all sexy, all S A C R E D. i believe at my core in the feminine power, perspective, + energy that this world needs so much more of.

And as if the ancestors embraced her with the powerful words of "women are sacred", she rolls her shoulder, tilts her head slightly alternating from left to right, and confidently lets out a soft breath. She replied, "I'm ready." And on that cue, I pressed the record button on all of my devices.

Bridging from our conversations about space, I was very interested in her lived experiences and stories growing up. Kim grew up in Stockton, California, which is also known as Historic Little Manila. While the history of Filipinos in Stockton runs deep, she remembers that the Filipino community had already been dispersed at that point in the mid-to-late 90s. The Bay Area, at the time, was experiencing a recession, especially during the period between 19942000 forcing many Bay Area residents to move to cities such as Antioch, Pittsburg, and Stockton where houses were much more affordable. This evolving demographic shift created a portrait of Stockton that was vastly different than the pictures she would see from the Historic Little 
Manila. This would have a profound impact on her sense of identity growing up in

Stockton. She remembers vividly:

So when I was in Stockton, I grew up mainly around Blacks and Latinos and some Southeast Asians, but particularly, a lot of my best friends were Blacks and Latinos and a lot of that also came from...the recession was about to hit, kind of like what's happening again right now and so a lot of communities of color, particularly in the East Bay were being forced out of their homes, and so they were going to places like Antioch, Central Valley to Stockton and that's kind of where I think the demographic of my friends came from because a lot of them came from the Bay Area from outside of the area. So I grew up in a time of Stockton when it was at least in my area which was one of the better areas was actually really diverse and so yeah, Stockton, to me, was very much like a melting pot of different ethnicities and cultures and in particular, my mom also taught down in South Stockton where she had a lot of Latino students and families. So with that I actually grew up as the only one of the only Filipinos in my crew.

While her mom taught at South Stockton, Kim grew up in North Stockton where it was known to be a nicer and safer area than South Stockton. She adds:

My parents wanted a better life for their kids. That's why they made the sacrifice to move up north. So the bad parts of Stockton are South and East Stockton. East Stockton still is a place where you just don't touch. South Stockton, I feel like, it's starting to improve...that's like the downtown area. And now it's dope to see that there's kind of this generation of reclamation as I call it happening in Stockton right now.

This concept of "reclamation" manifested during a recent photoshoot she did with two collaboration creatives, Brown Papaya, a digital magazine for Pinays and BRWNGRLZ, a jewelry company that also coincidentally released a product line titled, "Reclamation" which was inspired by this photoshoot. As all of the women discussed the vision and direction of the photoshoot, they asked each other these questions: "What does this photoshoot mean for us?" and "What are our experiences of being Pinay?" Kim recalls someone saying, "This is like a reclamation process.”

Mass migration of Filipinos to the United States began in the early 20th century during the period when the Philippines was a territory of the United States. The Immigration Act of 1917 permitted Filipinos to immigrate to the U.S. with limited restrictions. This wave of 
immigration was also known as the manong generation where many of them immigrated to states

such as Hawaii, California, and Alaska, to work as laborers in the sugar and pineapple

plantations, fish canneries, and farms.

The most recent immigration wave came after the passing of the 1965 Immigration Act

where Filipinos began arriving in the U.S. for education, work, and also to escape the political

regime of President Ferdinand Marcos who placed the Philippines under martial law in

1972. While many of the Filipinos who immigrated from the earlier waves were primarily

laborers, many of the immigrants after 1965 were professionals such as teachers, nurses, and

lawyers.

Kim is a third-generation Filipino-American. Her family's experiences from one

generation to the next has had an impact on how she articulates her understanding of her

identity. This notion of "generation of reclamation" allowed her to reflect on what it was like to

be a Filiipino-American throughout these different generations. She explains further:

So what I think we mean by the "generation of reclamation" is, at least, I can speak to my own experiences with my family and how I identify the generations. I identify my Lola, my grandma as first generation of coming to America. Then the second generation is my mom and dad, and then I identify as third generation Filipino-American. So with the first generation, it was a lot about the identity of being an immigrant to America and the idea of survival. The second generation was almost the idea of acculturation and becoming American. And then the third generation, with my generation now, is at least for my family and my brothers and I, on neither side were we taught the language, and so we were also not really taught or brought up in this kind of idea of like these Filipino households. We actually wear shoes in our house. In my nucleus family, we don't identify with the idea of taking shoes off. We're very American for whatever reason.

To reclaim something implies that there is something to claim back. It also can mean that there is something missing that's creating an empty void. Acculturation can create a loss of identity. While Filipino parents utilize this practice as one of the ways to quickly assimilate their 
children into mainstream America, it can also create an identity experience that can be both complex and confusing.

Kim describes her earlier years in middle school as a time where she didn't feel like she belonged. Many of her friends were white until she got to high school where she found her sense of belonging. She loved to run and joined the high school track team and immediately connected with her teammates who were predominantly African Americans. One of them, Deborah, eventually became her best friend. They had similar interests such as dancing. Kim grew up doing jazz dancing throughout middle school and Deborah performed at her church. Their love for dancing eventually led them to creating a step group called "So Sweet." They both became involved in student leadership and government and organized many of the school rallies. Kim remembers, "And then we started to do all of these rallies and Deb and I would do the choreography for it and we would teach everybody and from that. I don't know. It's like I got this street cred at the school, right?"

Because of their success in organizing rallies through dance, they all decided to join Black Student Union (BSU) to continue to do school-sponsored activities. During her senior year, Kim was nominated and voted in as the BSU President. She recalls:

So, in my senior year, our older friend was leaving and graduating. She was going off to college and we needed a President and we only have the meeting of, okay, who wants to nominate who and everybody nominated me just because the fact that I think that I'm organized at leading things already and it wasn't necessarily about like color or race or ethnicity. It was about the fact that you just felt like 'We know you."

Ethnic identity development is primarily the result of racial socialization practices influenced and impacted contextual factors such as neighborhood factors, parenting styles, and educational experiences. In Hip Hop, artists have produced songs about how their hometowns have shaped and informed their understanding of identity and culture such as "Virginia" by the Clipse, 
"Welcome to Atlanta" by Jermaine Dupri featuring Ludacris, "Black and Yellow" by Wiz Khalifa, "Born and Raised in Compton" by DJ Quik, and "Crestside" by Mac Mall. Kim's involvement in school activities and her connectedness to her set of friends allowed her to make meaning of what Stockton has taught her in regard to her identity development. She explains:

I think the big theme that threads through my background is the idea of like what we call, right, and there's a buzz word of intersectionality or multicultural, right, which is Hip Hop. Stockton really taught me to grow up in a time in Stockton and at my school with friends that were just all embracing and accepting. To be a Pinay who didn't understand her own identity and culture, I didn't have resources at the time to understand it. To be welcomed in my other friends and cultures helped me to have a sense of identity that helped to keep me grounded and feel like I got a sense of belonging and I think that's what Stockton really taught me is, one, just pride in where you're from. Stockton has taught me that the idea of just true true genuine diversity and embracing everybody for who they are and no matter where they're from just is all open arms. It's all love.

While she learned through her high school experiences about the importance of celebrating diversity of all cultures, she finds herself in this continued search of self of what it means to be a Pinay. She further expands on her definition of the "generation of reclamation"; that it is our responsibility to understand the history because it is rarely taught in our American education. It is also about reclaiming our native language. She expresses that while we may not have the time or ability to learn about our ancestors' dialect, at least "learn some terms here and there." Even though she had wished that she could have learned much earlier on what it means to be FilipinoAmerican and specifically, as a Pinay, she doesn't blame her Lola or her parents, aunts, and uncles. She acknowledges that they all had their reasons; however, she didn't want her upbringing to deter her from learning her history. Kim adds, "I think it's a reclaiming from the system, from society, what it means to be a brown woman." The catalyst for reclamation is choice and its level of importance to an individual. Kim explains that no one doesn't necessarily needs to learn their ancestral roots or their native language. People have a choice if they want to learn. They have to see value and importance in this learning process. 
Kim reflected on what was the catalyst of wanting to learn more about her Filipino history and culture and she immediately attributed it to Hip Hop. She then adds, "I think Hip Hop Ed specifically." In addition to being a counselor for the Promise Scholars Program, Kim also teaches the Community Engagement and Leadership (CEL) course for the CIPHER Hip Hop Learning Community where students in the class work on projects that address social justice issues impacting communities of color. One of the units in this class covers the birth of Hip Hop and its relation to the social, political, and economic conditions that marginalized communities of color in the 1970s. This deeper understanding of Hip Hop history allowed Kim to "come back full circle to herself." She explains further:

Because I first got into Hip Hop Ed and Hip Hop culture because it was the idea of diversity, and then when you get into the culture and seeing that, at the core of the values is indigenous roots, knowing your history, believing in social justice, which ties to all those things...to be an intersectional advocate for others, then I would learn about African-American, Black history and Latinx history, then it came then back full circle to myself. Like now I have to understand myself and what it means to be FilipinoAmerican.

She recalls finding two black and white photos of her mother, Delilah, at her parents' house in Stockton. The first one depicted her as the moon goddess, Mayari, based on the Filipino mythology. She was the goddess of revolution; a deity of the moon. Her mother had a glimmering crescent moon that was positioned on top of her head with intricate jewelry that hung right above her eyes. Geometrical cut-out shapes were placed symmetrically across her face, alternating between diamonds and triangles.

The second picture resembled the attire of the Maranao Princess. The garments were ornate, decorated with metallic threads of embroidery, sequins, pearls, and beads. Her mother's back was arched straight, her eyes peering down as if not to make any eye contact with anyone. Her fingers positioned as if she was going to snap her fingers, while three sets of beaded 
bracelets sliding down her wrists. Her black hair flowed down past her shoulders onto her silky black garment. She was the Maranao Princess in the singkil dance.

Both pictures of her mother came from a time when she was part of the Luzviminda Dance Company led by Artistic Director Voltaire Gungab in Stockton during the 1970s. The name, "Luzviminda", is derived from the names of three islands - Luzon, Visayas, and Mindanao. Kim recalled that when she attended a Parangal Dance Company performance a couple of years ago with her parents at Skyline College, she remembered being amazed of how many former dancers from the Luzviminda Dance Company who are current teachers of the Parangal Dance Company knew and remembered her parents. Voltaire Gungab, who was also in attendance, said to Kim's mother, "My moon goddess." Her mother humbly responded, "That was a long time ago." Kim would also find some of her mother's pictures in historical books and newspaper articles.

In the same way these photos were stored away, the experiences of her parents performing for the Luzviminda Dance Company was also not shared with her during her middle and high school years. She wondered why but she understood. She said, "And I think for them, it was an experience they had for a year or two years in high school, and then they just stopped because they were so focused on working and raising their family and surviving."

Combined with her experiences growing up as a young girl from Stockton along with her current work with Hip Hop Ed, she has become a fierce intersectionality advocate for her students, reminding them of the importance of deepening their understanding of their intersecting identities. She recognizes that to ask her students to learn their histories, she had to model it too. She shares, "Because the idea that as an educator, I have to understand myself to be able to be in connection and communication and ethically and do it all in the right ways to communicate with others outside of my own upbringing and culture." She understood that to "know herself," she 
needed to "know her history." And through this understanding, she acknowledges her place and commitment of being part of the "generation of reclamation."

\section{SHOW AND PROVE: MORE THAN JUST SCHOOLWORK}

Experiencing this discovery of critical consciousness and ethnic identity development with Kim, it injected a sense of curiosity of how she made meaning of her place and space in education, from the K-12 system, college, and graduate school. Without hesitation, she blurts out an extended and drawn out, "Yeah", with her eyes gazing towards the ceiling, seemingly recollecting those moments vividly. There were two quick themes during elementary school and middle school that seemed to sum up her educational experiences - being told to be quiet and the acknowledgement of doing well with her schoolwork.

Kim described moments when she was told to be quiet. This really impacted her tremendously because she felt, at the time, she was being singled out for talking. She would recall her teachers saying, "You need to stop talking out of place and there's no socializing right now." Kim could not understand why "she" had to be quiet. It wasn't until years later that she understood these experiences. She said, "As an Asian American girl, I get put into the stereotype that I am passive, submissive, and my worth will be found through affirming these characteristics and achieving academically."

Achieving well in school was something that came natural to her. She would recall moments where her teachers would comment on her academic abilities. Kim adjusts her voice to sound like her teachers and sarcastically imitates them, "Oh, wow, you finished your math problems so fast. You're like Speedy Gonzalez or like oh, you do so good in writing." While she was acknowledged academically, she knew that she was "much more than just schoolwork." 
Kim adjusts her position in her chair and begins to reflect on a couple of moments in high school that really stood out to her. These two moments also began to shape her understanding of self within the context of time and space. Where does a young woman of color fit in as a firstyear student in high school? Who will she become? What kind of relationships will she build throughout her high school journey?

She begins by sharing about Mr. Conklin. He was her history teacher during her freshman year. He was also the yearbook advisor for the school. To her surprise, he had asked Kim to join yearbook during her sophomore year. Typically, the yearbook class consisted of juniors and seniors. As she is sharing this memory, her body perks up, reminiscing of the source of pride she was experiencing during that time. She shares:

He saw so much potential and creativity in me and leadership, that he brought me on which I will always remember because I think that like one of those things that are a recorrection, right, like 'oh people see me for other things than just schoolwork or they see something in me and in general. And then I'm in this space with all of these older people which you know in high school, it's like, 'I'm cool' and that was a time where my social skills started to improve.

For the first time, Kim felt like she was actually seen in an educational system where expectations and stereotypes can render students invisible; that they are limited to what Nigerian novelist, Chimamanda Ngozi Adichie, would describe as "the danger of a single story." Kim states that, "To be seen by an educator is such an important thing for students."

But to be seen can take on multiple perspectives. Kim recalls a vivid negative experience during her senior year when she took her one advanced placement (AP) class in high school. It was an AP US History class taught by Mr. Gillig. She remembers him clearly saying, "Oh, you know I'm surprised you're in this class because most of you and the people you are with don't take AP classes." Kim let out an incredulous laugh like she still couldn't believe he had said that to her. At the time, she expressed that she didn't necessarily have the language to articulate what 
had happened, but she knew that it was absolutely wrong, especially coming from a teacher. While Mr. Conklin saw potential and creativity from Kim, Mr. Gillig saw her differently through the lens of race and academic abilities. Kim processed his statement as, "Students of color don't take AP classes. AP classes are for smart kids so therefore students of color aren't smart kids." She remembers distinctly that when the first exam was scheduled, she wanted to prove him wrong by studying as hard as she could. As a result, she aced the exam and more importantly, she proved her point.

All throughout her K-12 experiences, Kim felt as though she was always having to "show and prove"; that she was just more than someone who can do schoolwork. However, it did put a great deal of stress and anxiety on her as she was trying to navigate her way through education. Kim takes a deep breath and exhales slowly as she replays the memory:

I think going through K-12, I think that's why I had a lot of angst. I feel like I dealt with a lot in middle school to high school with mental health issues. That's when I started cutting. That's when I started learning about depression because I think it was literally the fact that I didn't know how to express myself and, you know, take risks and be a part of conversations and be acknowledged and feel like you had some kind of worth and from being, whether it was actually intentional silence or just not being or like being overlooked. I think that there was resentment and anger there. So I definitely felt it. I was conscious of feeling suffocated or silenced or not.

As we fast forward to today, she explains that, unfortunately but not surprisingly, she still experiences moments where she has to continue to "show and prove." She makes a gesture to her black blazer. "I have to wear this. These glasses too. And the heels so I can be seen as a professional and not as a student or someone not taken seriously." I nod in agreement as I too experience these microaggressions that are disguised as "harmless" comments for looking like "one of the students." We have had these conversations many times and sometimes, my counseling intuition wants to validate her experiences and say, “Don't listen to them. They're not on your level." While I felt like I was making her feel better, I soon realized later that I was 
engaging in unintentional toxic positivity. So, when the conversation comes up again, I listen. I

listen, not only with my ears, but with my heart. Kim shares:

I absolutely feel like I have to show and prove as a woman of color and as a Pinay. Every single day. Every second of the day. It happens everywhere, but mostly work. Not so much within student to student interactions or doing the "groundwork" but more so at higher-ups meetings or colleague to colleague, especially when they're not women or of color themselves. The safe haven I never feel like I need to show and prove is actually within Hip Hop and Fil-Am spaces.

For someone who has been experiencing this notion of "show and prove" all her life, I asked her, "How do you navigate through these experiences? How do you practice healing? As a counselor, what do you tell your students who are going through similar experiences?" And as a poet, she seeks refuge and healing through words. To young women of color, she shares these two poems: \\ These words serve as reminders to herself and to those who resonate with these experiences that \\ they are the authors of their own narratives. There is an aura of this raw and unapologetic \\ energy; not giving anyone permission to shape her becoming. She knows who she is. As I
} reflect on these poems, she is truly Kimdizzle. 


\section{LOST ONES: I'M NOT BLACK BUT I'M NOT WHITE}

Once in a while to disrupt our daily activities, our group of colleagues who I also call my close friends, would play this text game called "Top Ten." Someone on the text thread starts the game by texting, "Name the top 10 Hip Hop artists of all time." There were about five of us on the text thread. We would start with \#10 and work backwards until we get to \#1. We each took a turn. The tricky part was that we don't know what each of us would respond. Someone might take our answer, or someone may place a Hip Hop artist at a particular number like placing Tupac at \#5. Tupac at \#5? That is completely blasphemous in the Hip Hop world. But that's what makes this game so interesting because we were all coming from different perspectives and criteria on what represents an artist as one of the best. For this particular thread, I don't remember the actual order but I do remember the top five being: Nas, Kendrick Lamar, Lauryn Hill, Notorious BIG, and Tupac. I believe Missy Elliot, Jay Z, and Common were other artists on the list. We would do all types of "top tens."

Then, it was my turn to select a "top ten" category. I texted, "Name the top 10 Filipino R\&B artists/groups in the Bay Area of all time." Immediately, the text messages lights up with comments such as "I got this", "Ohhhhhhh", and "Awww damn!” Pinay. One Volce. Drop n Harmony. Premiere. Then there was a pause. A long pause. Someone texted, 'Kim, it's your turn." She responded, "I don't even know who these groups are." I jokingly responded, "How could you not? You're from Stockton!” She texted back, "No, really I don't even

know. Someone texted back, "Not even Jocelyn Enriquez? Those were the days." For Kim, it clearly wasn't, and I honestly don't think we even completed the top ten text thread.

I still remember that text: "I really don't even know." This text transported me back to my conversation with Kim about her college experience at San Diego State University 
(SDSU). This part of her educational journey really made her realize her place in society as a woman of color. She describes San Diego as the city and school as a place that was predominantly White. She remembers, "It was notoriously known -- I don't know if it is anymore -- as the party school with a lot of sororities, fraternities, that Greek life. And a lot of White folks with a lot of money." She recalls thinking to herself, "like that was what I was trying to avoid when I was living in Stockton." Now here she is in San Diego, surrounded by "whiteness" and now she's starting to realize that she's literally seeing the color of her own skin. Kim shifts her body in a way that in some ways reflects her uneasiness that she was experiencing during that moment of realization. She recollects, "Now, it's like, I feel like I'm lower class. I don't feel like I don't have the money and I feel like I'm brown." Coming from a high school where it was diverse and being part of a tight group of friends who were predominantly African Americans, this gave her a huge culture shock. The color of her skin in Stockton was not an issue; it wasn't even an afterthought. But in San Diego, it was everything. Despite feeling the initial shock of being lost and miles away from home, she knew she needed to find her community. She reflected back to her high school experiences on how she was able to connect with other students of color. The first thing that popped into her mind, "Step dancing!" Where does one find step dancing? She excitedly says, "In the Greek life!" So, she thought maybe she should join a sorority. Given that her best friends in Stockton were African Americans, she figures, "Well, I just look into a black sorority because of my high school experience in Stockton.” During rush week at SDSU, she made a concerted effort to connect with some black sororities. Then, Kim proceeds to share this vivid memory of that day during rush week.

They're all lined up. I go to the black sororities and I'm going to the tables. They're talking to other people, you know, they're trying to recruit. I'm there waiting; reading 
their table materials and they never talk to me. They never talk to me. I even say hello and they're like "oh, what's up" and then still don't acknowledge me. And now for the first time I realized, not only did I realize the color of my skin, I realize also, 'oh wait, I'm also confused' because now people of color don't like each other right away. Like, oh, yeah, I'm not black, but I'm not white.

So, within the same breath, she recalls a moment immediately after that experience. As she walks away from the black sorority table, she can hear voices from another table encouraging her to come over. Kim glanced over and saw that they were Filipino student clubs and organizations. But because of her experiences growing up, she didn't identify as Filipino either. She politely smiled and walked away.

As she shares these memories, you can almost hear the pain and confusion latched on to every word. In that very moment, she realized that she was very lost as a student of color on campus and in education. Where does she fit in? Where does she find her place? At this moment, I'm starting to feel really bad about the text game and how I was jokingly getting on her for not knowing any Filipino R\&B groups or artists. I begin to get a deeper understanding of how much her friends in Stockton were so profoundly impactful in the development of her own identity as a woman of color. She reveals to me this powerful reflection in a phone text:

The fact that I didn't grow up being exposed to Filipino R\&B groups or artists, my role models and examples of powerful women, the closest thing I could latch on to were always these incredibly black women in Hip Hop and the arts -- Lauryn Hill, Beyonce, Maya Angelou, and Nikki Giovanni. Like yeah, now I have awareness of my Pinay identity and a dope sisterhood through things like Entrepinay. But before I had any of that language, identity, or community of my own people, it was all about my black sisters. Deborah, Ashley, Xiomara, BSU in high school. They took me in. They TOOK. ME. IN. And held me; taught me their culture and values and slang. When my own Filipino community couldn't. So even more than Beyonce and Lauryn Hill, those women and family are Hip Hop to me. And they're the reason why I do the work.

Being completely invisibilized by the black sororities really impacted Kim as she struggled to make sense of this experience. She's beginning to wonder who she is at this moment in time. Self-doubt begins to creep in as she was still dealing with the fact that she was rejected by 
all of the UCs. Her self-doubt and her feelings of invisibility led her to experiencing impostor syndrome. She distinctly remembers, “Like I'm really lost. I don't have any sense of belonging in the educational system. But I have so much to prove because I know I'm smart and I got to get A's and I got to keep on excelling. I just feel like a lost one.”

\section{GETTING HER PH.D.: PLANNED HAPPENSTANCE + DESTINY}

good thing i am many women. good thing i cannot be one thing.

While only two sentences, this short poem written by Kim, signifies such a profound message. Being a Pinay and a woman of color in general, there are many expectations that are heavily rooted and maintained through White, patriarchal ideologies such as the type of job one should pursue, the role they play within the family, and how they should carry themselves in public. This poem declares as a woman of color, she is more than the gender and cultural expectations that tries to box her in. There is not a single story that can define who she is and who she will become. For Kim, that's a good thing.

Her journey towards her profession in college counseling does not travel in a straight line. It reminds me of listening to lo-fi Hip Hop where there are moments of the boom-bap beats followed by soothing sounds of piano keys and strings. In between these beats, there is a smooth flow which then gets interrupted by quick, rapid snare beats that purposefully hits on the upbeat. The texture of the beat is muffled representing the lo-fi, gritty sound. This story of her journey starts with a simple question, "When did you know you wanted to become a counselor?" Kim laughs out loud and responds, "People always ask me that. How did you know you wanted to go into this? I told them I didn't [ever] really know?" What Kim knew was that the journey toward the counseling profession was unorthodox. 
Reflecting back to her time at her undergrad at San Diego State University (SDSU), she was having a difficult time adjusting to her new surroundings. She felt very homesick and lost. She elaborated more about her struggles in adapting to this new campus community:

I realize I'm very lost as a student of color on my campus and in education and that's where my mental health took the hugest dive. But I was also dealing with the idea of had already gotten rejected from all UCs because I thought I'd go to UC Berkeley somehow in my head. Cuz I knew it was for, [I knew] I was creative [but] I got rejected from all UCs. I got into San Francisco State and San Diego but having is also dealing with this idea of I guess it was like my experience of imposter syndrome. Like I'm lost, I don't have any sense of belonging [in this] education system and [in] this campus, but I have so much to prove because I know I'm smart and I got to get A's and I got to keep on excelling in education.

For her to navigate these next two years at SDSU, she knew she needed help. Fortunately for her, she was very aware about the benefits of personal counseling because her then-boyfriend's parents were both therapists. She also drew from her K-12 experiences and knew if she didn’t address her mental health issues, it would be detrimental to her well-being.

Similar to many college students, Kim changed her major about four times but eventually landed in Psychology because she was dealing with mental health issues and wanted to learn more about how to cope with these challenges. She initially enrolled into SDSU as a Hospitality, Tourism, and Management (HTM). She perks up from her chair and leans forward like she's about to tell me a secret:

I wanted to be a journalist. I wanted to be the next Lisa Ling [and] then I wanted to be a fashion editor [kinda] like a magazine like Vogue or then I wanted to be I was still going to say [like in] all my presentations, I wanted to be like Jennifer Lopez from the Wedding Planner because I wanted to be an event planner.

I recall being at numerous events and conferences where Kim would share with me what aspects of the events she would change or make better. She was a natural event coordinator. She proclaims that she has "high expectations", a mindset that she alludes to when she talks about working with her students. 
While being part of the Psychology program, she also sought personal counseling from Psychological Services. Through this experience, she had the opportunity to meet her first mentor who informed her about a job announcement that was looking for residential advisors and academic mentors. She eventually was hired on as an academic mentor where she assisted students through peer advising at various colleges throughout SDSU. During the last two years, she was hired on to become the assistant to the supervisor of the academic mentorship program where she details the impact of those two years:

So I became her assistant and she became my mentor for my last two years. [So] through her mentorship, I think cuz she's a Latina woman of color, highly educated. She was in her thirties like she's been my first example of like 'I can stay here.' I can do this cuz I was thinking of dropping out. I just wanted to go home but through her mentorship and then I reached out and got some help with counseling, Psychological Services. I think it was really saving me and then I think I found a niche of friends, a small group of friends through the academic mentorship.

This mentoring experience had such a profound impact on Kim. She felt like she was also making an impact on others, specifically students she has worked with in her academic mentorship role. She explained that in her role as an academic mentor, there were many similarities that resemble college counseling. While she was creating meaningful mentoring experiences with her students, she shared that she cannot recall having any impactful college counseling experiences:

Because I think I just didn't know. It's not that I didn't trust the higher education system. [It's] like the faculty and staff and counselors, they just weren't accessible. They were really hard to find and it was intimidating to even try to go out especially since I had this lost sense of identity to go to a counselor. And from that, I like just figured I can find it. I have the autonomy within myself to do it. So I literally had no college counseling experience because then I became academic mentor for my second year so they trained us. So academic advisors at different colleges trained us on how to become advisors. So then I just use my training for myself. Yeah, that's why I became a college counselor.

Within the context of norms and expectations around counseling in Filipino culture, counseling is often seen as taboo. If there were issues and problems that were existing within the family, 
they were traditionally dealt and handled within the familial space. Given that Kim is thirdgeneration Filipino American, the cultural norms and expectations around counseling was not necessarily reflective of what has been generally practiced in traditional Filipino culture. She explained:

Education was valued in my family, but how to navigate the system was not well known to me. It wasn't discouraged nor was it encouraged to go seek counseling. It was the message to me was just go to school and just go if you want to have a college experience because it's important. That was about it. And graduate in four years.

Through her experience Psychology program and her job as an academic mentor, she was slowly finding her purpose. While she didn't find counseling, counseling found her in the form of these experiences. Kim lets out a sigh of relief as if she were reliving the moment. "I think this is where planned happenstance and destiny for me comes in.” During her last two years at SDSU, they opened up a new minor in Counseling.

Kim was struggling with what she wanted to do when she graduated with her Bachelor's degree in Psychology. She was afraid of the recurring narratives of folks who earn Psychology degrees; that it was too broad and that it would be difficult to find jobs after college. So when the Counseling minor was offered, she was hopeful that this was going to be an educational opportunity that can potentially guide her towards a direction. She remembers scanning through the course titles and descriptions that spoke about social justice, multicultural competencies, and feminism. As she is explaining more about the program, her voice increases with excitement. She recalls attending the Open House and seeing so many women of color that looked like her. She was hooked. She was inspired. It was all planned happenstance. She enrolled into the minor and was able to see the light at the end of the proverbial tunnel. She shared what this particular moment meant to her: 
So I ended up enrolling into the minor and that's what I think prepared me to be very young in our graduate program and again, like a still wasn't like that moment of 'I know I want to do college counseling.' I just knew I liked it. I like the topics and I knew, my academic mentorship my role. I was basically doing college counseling. I knew I can do it. I enjoyed the idea of helping people figure out classes, liked color coding things and figuring it out. And I also like the idea of storytelling and social justice for my minor.

This educational experience propelled her into her decision of applying to graduate school. The bitter taste of not getting accepted into the UCs stayed with her and provided her with the added motivation to "show and prove." All throughout her educational journey and even currently in her professional career, she feels like she's constantly having to "show and prove." But when she was deciding to apply to graduate school, a big part of her knew that she was capable of accomplishing great things. "I was getting to the point of really believing and knowing how smart I was." She was also inspired by her mom who earned her Master's degree online while raising three children.

While she began to feel a sense of belonging during her last two years at SDSU, she knew that she wanted to come back home to the Bay where she applied and was accepted to the Master's Program in Counseling at San Francisco State University. When she reflected back at the question, "When did you know you wanted to become a college counselor?" She responds, “I didn't ever really know. I just always gravitated to what felt right but felt like good to me. That it felt like I was true to myself. I guess it was just destiny.

\section{THE MISEDUCATION OF KIM DAVALOS}

When one hears the question, "When did you fall in love with Hip Hop?”, you can't help but think about Rick Famuyiwa's theatrical ode to Hip Hop with his movie, Brown Sugar, a film that paid homage to many of the great emcees that graced the mics such as Big Daddy Kane, Common, De La Soul, Pete Rock, Method Man, and the Roots. The MC stood for "master of 
ceremonies", "mic controller", and "movin' the crowd." When I asked Kim the same question, she pauses, reflects, and then responds:

I can't pinpoint exactly when but if we're going to attribute Hip Hop to be a relationship, I would say Hip Hop was the childhood friend that I never knew was going to be the "one" until I was older. Just like Brown Sugar. It really is because it was always around in high school. It was there. It was just there. Hip Hop was there. My relationship to Hip Hop in high school and in college was all about having fun. It was a good time. It was the friend that was chill. We always had a good time together. Always around. We got each other. We love the same parties. We love the same music.

Similar to the film Brown Sugar, this was a love story between Kim and Hip Hop.

Reflecting on her earlier memories of Hip Hop, she proudly talked about the time where her step group, "So Sweet" actually competed at the West Coast Apollo and won for the Youth Dance category. She also recalled during practices and track meets that she would get hyped off Lil John's Get Low and R Kelly's song, Remix to Ignition. She begins to sing, "to the window to the wall." Understandably, she quickly stops short of singing the next line and lets out this big smile as if she was transported back in time to 2002. She explains that these were some of her first cemented memories in really identifying her love for Hip Hop. She also shared, "This music brings me together with these people that I feel a connection to.” For someone who has battled this notion of invisibility throughout grade school, Hip Hop placed Kim front and center, especially during her senior year when she became President of the Black Student Union.

And just like a dusty old vinyl record that skipped, Kim ruptured her own flow. "I'm sorry. Let me backtrack. Lauryn Hill was always there. I think in high school, she was the one most that was there because the album, The Miseducation of Lauryn Hill, actually was with me in middle school. And then the Unplugged album came out when I was in high school." That Unplugged album inspired Kim to write one of her earlier spoken word pieces, a piece that she has performed on numerous occasions. Like many of her poems, this poem didn't have a 
title. Not having a title allows the readers to form their own opinions and interpretations and not be guided in a particular direction. It was a poem that tugged at Kim's soul and with her pen, she wrote a remix to The Miseducation of Lauryn Hill that found home in that album.

if my consciousness could exist in an album it would build home in

The Miseducation of Lauryn Hill.

seeking refuge in the suburbs of her new

jersey block lessons

and exploring the concrete for the answer of

love fell through the cracks.

$\mathrm{i}$ am sure there is a rose soon to grow from

there.

certain there is a young colored girl from

small town stockton to grow from there.

she is

memorizing every rhyme and dope line

of a black beauty queen one-of-a-kind.

a young girl who at the ripe age of nine

learned that can be both colored and

female.

all disheveled, rough, frizzy

and still refined.

guided early on by this walmart bought

walkman

and one cd she found and stole from her big

brother's bedroom floor.

(don't tell him that)

listening to the lyrics as if they were

flowing through an iv.

to keep her dehydrating body alive.

This verse allowed us to see this coming-of-age story of a young Pinay from Stockton understanding the strengths of her intersectionalities through this album. Her poem also creatively weaves in the numerous songs that made up the album, similar to the old 1990s love songs mixtape where we used to create messages to our crushes using the song titles.

that this album isn't just music to me. it is the remedy to Every Ghetto, Every City, Miseducation is the Ex-Factor to Everything that is Everything. 
and when Nothing Else Even Matters.

she is there.

lauryn is there.

telling me that When It Hurts So Bad,

when it hurts so bad, it tends to feel so

good.

This album was the development of Kim starting to become a young woman of color; growing into her own critical consciousness. It also became her bible, her book to study. It became her understanding of the difference between "going to school" and "getting an education" as she articulates in the conclusion of her poem.

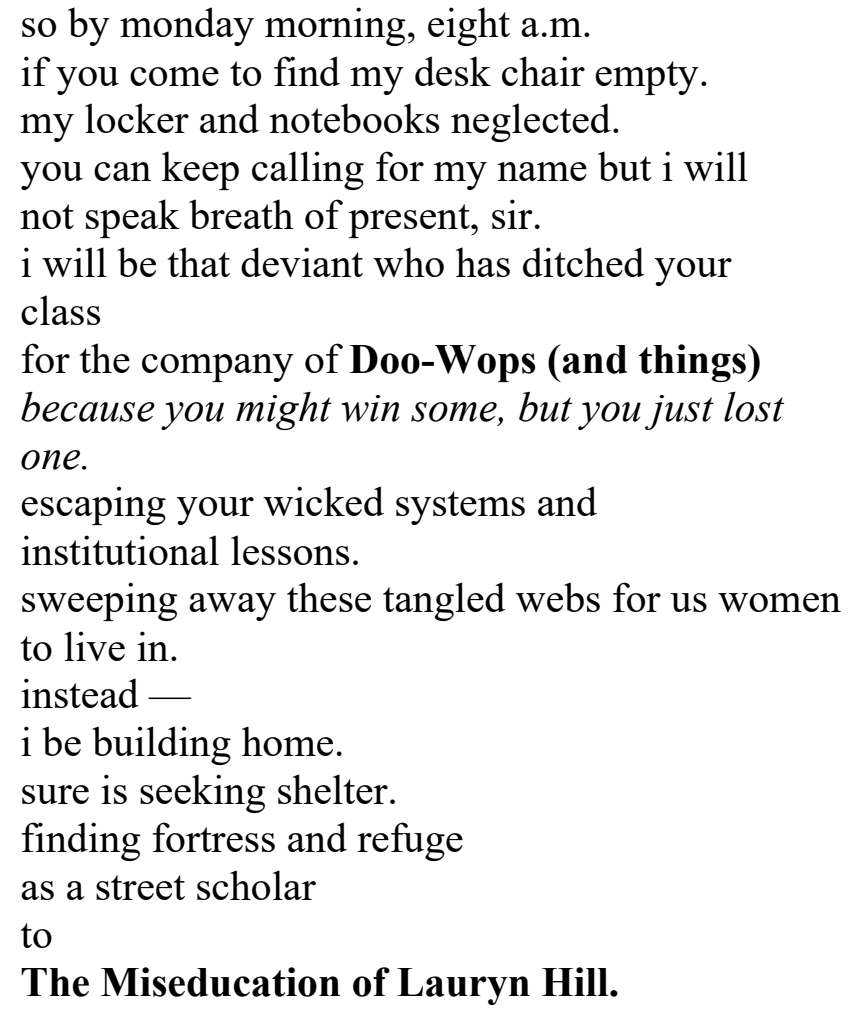

While Lauryn Hill centered and amplified her experiences, Kim began to explore Hip Hop more deeply while she was in undergrad at San Diego State University. She was getting exposed to artists such as Atmosphere and Murs. From there, she began to dive deeper into her exploration of Hip Hop from Chicago and the East Coast, listening to emcees such as Common and Nas. Initially, in high school, the catchy beats and the memorable hooks are what got her into Hip 
Hop. Using her relationship analogy, Hip Hop was just there; a friend to hang out with. It was nothing more; just strictly platonic. However, while she was in college, Kim really started to listen to the songs beyond just the beats and catchy hooks. She replied, "Wow, oh, Hip Hop is more mature than I thought. It's more conscious." She soon realized that Hip Hop had something to say. Through these aforementioned artists, she was able to learn about their life experiences through their songs. Hip Hop was personal, emotional, and real. For Kim, Hip Hop was going somewhere and, in that moment, she experienced a parallel moment. "I'm becoming more aware of my own identity. Oh, Hip Hop and I are on the same path together."

While Kim and Hip Hop were just friends in high school, through her college experiences and thereafter, her relationship with Hip Hop has become more than just a friendship. Kim explains, "I think this is a lifelong partnership together. And that was [towards] the end of graduate school and into the beginning of my career. So now, we're fam, we're in it for the long haul."

In any relationship, there are going to be many ups and downs. There will be moments of evolution, stagnation, and transformation. We learn and re-learned how to adapt and adjust. Hip Hop culture, like relationships, experienced a wide range of changes and evolution ranging from the party rocking moments, to the sociopolitical consciousness of the 1980 s, to gangster rap, to Afrocentric soulful rap, to auto-tune, to mumble rap, and many other aesthetical changes. While many Hip Hop heads, scholars, and artists may disagree with the content, style, and aesthetics of Hip Hop today, this constant evolution in Hip Hop has been able to carry and push this culture forward and elevate it to new heights. This is what draws Kim to Hip Hop. She explains in this passage why she loves Hip Hop:

It's the grittiness. It's the unforgiving [unapologetic-ness]. It's the... I don't even know if that is a word, but we don't care because you [get] what I'm saying kind of thing. And it's the fun of it. It's the color of it. It's the life of it that I love. It's just being able to be yourself. And sometimes it is the duality of the critical consciousness of it. And the other 
side of I just give a fuck anymore. I just want to have a good time and just live my life. And let's just all have a drink and go dance. But also, you could also be conscious and aware and woke at the same time.

\section{BROWN PAPER BAGS}

It was one of those rare sunny days at Skyline College in the middle of October. I ran into one of my colleagues who was known to rock Aloha button-ups and dope rhymes. He said, “If the sun keep on shining, I'm gonna keep rockin' my Aloha shirts." We both laughed and I gave him our customary fist bump. I traversed across campus through the main quad where the students of the Associated Students of Skyline College (ASSC) were hosting their student club and resource fair. One club was selling Tea Pumps milk tea to raise funds for their trip to Southern California. The Financial Aid staff were giving away free popcorn and pizza for students who filled out surveys about financial aid awareness. Then I saw the Engineering Club challenging students with a Physics riddle that involved gravity. Music filled the air as one of our students from the CIPHER Hip Hop Learning Community was serving as the DJ for the event. There was so much energy emanating from this quad. This quad is uniquely designed in that if you stood at the center of it, you can hear conversations and sounds from every inch of the quad. One of my students came up to me and said, "Your shirt is as loud as this quad." I was wearing a bright pink Aloha-type shirt that had bright yellow pineapples and green palm trees. I even had the pink and grey Adidas shoes to match. We were both laughing. Amidst the symphony of sights and sounds in the quad, I noticed Kim walking towards Building 8 clutching three paper bags and immediately disappeared amidst the crowd of students who were just getting out of classes.

Minutes later, I found myself on the third floor of Building 8 where Kim was teaching her College Success class for the Promise Scholars Program. Her classroom was at the end of 
the hallway located in one of the larger classrooms. As I walk closer, I can hear the lo-fi Hip Hop beats emanating from her with its noticeable thumping but muffled bass levels and intermittent vinyl record scratches. I enter the classroom and immediately notice Kim placing the three brown paper bags on a table in front of class. The students quickly stopped in the middle of their conversations and asked, "What are the brown paper bags for? What's in them? What do you have planned for us today? Did you bring us lunch? Maybe, there's alcohol in them!" Laughs and chuckles filled the room along with the lo-fi beats that have occupied the space. Kim turned down the music and proceeded to give them instructions. There was no attendance taken; no announcements made. She jumped right into it. She divided the class into three work groups and provided them with the directions. "Each group will receive a paper bag. Each group must choose their name. You will have ten minutes to create a collage that represents college success. Please open your paper bags. Your time starts now.”

\section{HIP HOP FEMINISM}

Transported back to our second interview, there was a noticeable shift in energy from Kim from talking about her lived experiences to talking about Hip Hop pedagogy. There is an excitement in the air as if we've been waiting years to declare the powerful impact Hip Hop pedagogy has on counseling practices. She clasps her hands together, rubs them together, and replies, "I'm ready." When I asked her about how she defines Hip Hop pedagogy, she immediately responded, "To who? Students? White faculty?" I nodded my head to give her permission to answer it however she wanted to. She expressed, "Oh my gosh, that's so tough. If we're talking about Hip Hop pedagogy, this is a practice and educational practice that is about people in the youth." I found the difficulty of her answering the question both interesting and validating. Often times, as Hip Hop educators, we experience some tension regarding answering 
that question to anyone who may not be familiar with Hip Hop and its culture. If one is not familiar to Hip Hop culture, then to explain how it is operationalized in educational spaces may be too abstract for them. If it is too abstract for them to understand, we run the risk of those in academia of not understanding the power and impact Hip Hop has on youth and students. How do we explain it without losing Hip Hop's wholeness and integrity? People may reframe and critique this question as "Why are you dumbing it down?" After processing more on the question, she replied:

Students. It starts with the students. If I have a student in [a] CIPHER Counseling 100 class and explaining Hip Hop pedagogy, I would say, it is a teaching practice that is going to meet your impact of how you identify yourself as my student. I would say it is about being relevant, having a good time, and finding creative means to help students become more critically aware of their world and themselves. That's how I would say to students.

After she shared her response, she immediately perked up and said, "You know what? I would actually say the same thing to academics at a conference, maybe add more academic terms such as culturally relevant pedagogy." However, her development and understanding of Hip Hop pedagogy came from the unlikeliest of places. While she acknowledges Freire as the foundation of her understanding of critical pedagogy, it was bell hooks who allowed her to make sense of Hip Hop pedagogy.

For me my own unique spin on, it would be, I always refer back to bell hooks. She kind of is the one that makes Hip Hop pedagogy makes sense for me. Because Hip Hop pedagogy and Hip Hop culture is more male dominant. There are these nuances in [the] history of misogyny and patriarchy. So as much as I love Hip Hop, that was the part I couldn't understand being identified as a female woman of color. And so bringing in the ideas of bell hooks and more radical women of color helped to make sense of how there's a lot of connections, and then that it is very much integrated into Hip Hop pedagogy.

When she was at San Diego State University and San Francisco State University, she had taken many women's theory and feminism classes as both part of her Counseling minor and on her own. Even with this newfound knowledge, she still felt a sense of uneasiness. "But that 
didn't quite make sense. A lot of critiques with feminist work is that it's still dominated by the white narrative by white feminists. So then it no longer made sense to me. But Hip Hop pedagogy itself didn't make sense either." Then she lifted both of her hands and drew them together to create an interlocking fist. She explained, "And then for me, I blended the two together, and that's where they came together. So, the feminist framework of equity, at the heart of the framework, is exactly what I think Hip Hop pedagogy is trying to practice and then so I blended them together."

Coincidentally, the term "Hip Hop feminism” was coined by Joan Morgan who just recently released her new book, She Begat This: 20 Years of the Miseducation of Lauryn Hill." Very much of what Kim was expressing her own understanding of Hip Hop feminism, Morgan and many Hip Hop feminists utilize Hip Hop culture as one of the primary points of departure to put a spotlight on social issues such as racism and sexism as interlocking systems of oppression. In her poem, The Miseducation of Lauryn Hill, Kim speaks about her growing into her own critical consciousness and understanding deeply the power of her intersecting identities.

\section{GOT HOT SAUCE IN MY BAG -- SWAG!}

When I created the CIPHER Hip Hop Learning Community in 2014 after 7 successful years coordinating the Rock The School Bells Hip Hop Conference for middle school and high school students, I recognized a need to think through what it means to have the CIPHER Hip Hop Learning Community. What would our classes look and feel like? One thing that was very clear to me and the other CIPHER faculty is that we did not want to recreate the same educational experiences many students of color have experienced in K-12 settings.

Fast forward to 2019, here we are in the old CIPHER office hashing out what we have learned throughout the process of building a meaningful and intentional educational experience 
for our students in both the classroom and in our counseling appointments. When we engage in conversation with other educators about transforming student experiences, sometimes you may hear someone say, "Well, I have this strategy in my bag of tricks." For Kim, it was much more than having tricks in her bag. In the words of Beyoncé in her song, Formation, "Earned all this money, but they never take the country out of me, I got hot sauce in my bag, swag." What makes a person authentic defines who they are; illustrates their own swag. Adjusting herself in her chair, she then explains how she defines the word swag:

Swag is a term that it's almost like umami. Right, like it is a unique flavor that you can't describe. SWAG is something that's not definable. You just have it and that's like the idea of all the layers like what makes Nate has swag. It's [this] idea [that] allows for an educator to make it their own. You have these core principles almost like you need sneakers you need pants you need a top but you make it what you want it. You choose what those layers are going to look like and the idea that but you need to dress yourself as well and know what your statement in your fashion is or who you are when you show up in a room to be able to expect that from your students as well. And then that's when you're going to connect to each other so yeah, that's the best way I can explain it.

Swag draws again this aesthetic of Hip Hop - to "show and prove" and "keepin' it real." Beyoncé explains that you can't take the "country out of me." Learning from her experiences in counseling, Kim understands that Hip Hop pedagogy is more than just analyzing lyrics from playing Tupac Shakur in your classroom. She replies, "It is much more complex and nuanced. It's an art to be a Hip Hop educator." To create transformative change, she acknowledges that we, both students and educators, cannot be passive recipients anymore. She believes that we need to center our students' voices and experiences. We need to upset the setup. We are more than just counternarratives; that we are the narrative.

After years of counseling and deepening her knowledge utilizing a blend of feminist theories and Hip Hop pedagogy, she created a framework called SWAG. SWAG has been at the center of how our counseling and teaching approaches are practiced with our CIPHER students 
and students in general. Prior to her breaking down the acronym, SWAG, I commented,

"Because, you know, Filipinos love their acronyms." We both laughed knowing that she also refers to me as the "King of Acronyms." "So what does SWAG stand for?", I asked. As the metaphorical drum rolls escalates into a fever pitch, she explains the SWAG framework.

So, SWAG framework is an acronym for four different components of counseling and teaching, but specifically to counseling that we practice within Hip Hop Ed and CIPHER. And it is a four-piece component, and a two-part layer reflection also. So, we got layers to this. To go into it, [the] breakdown of the acronym $\mathrm{S}$ is the sense of self. So, that's the idea of who am I; in all the various intersections of who I am. I am, as I described in our first interview, right? I'm Female, I am cisgender, I am Pinay, I am middle class, I am XYZ. That as much as I'm Kim and I'm Filipino American. I'm Kim, I'm a woman. So, it's the sense of self, then that goes into when you have a [sense] of yourself and your history.

In this frame, she discusses that there are two layers to the SWAG framework - one for counselors and the other for students.

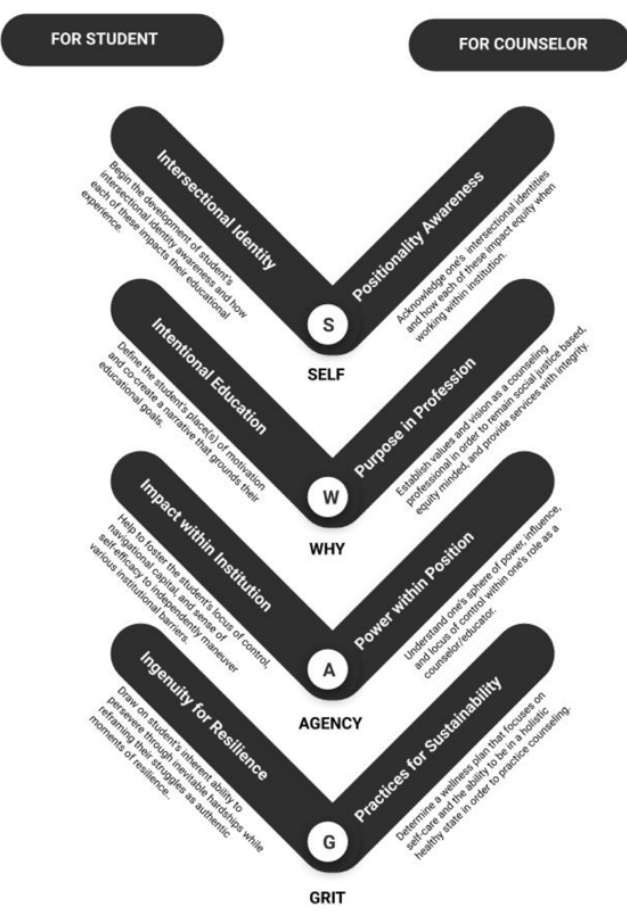

Figure 2. SWAG counseling framework. Adapted from Davalos \& Nevado, 2020. 
As she's explaining it, she's referring to the role we play as counselors. How do we enter our educational spaces? How do we hold ourselves accountable for our own actions? How do we sustain ourselves in a profession that is always giving? When she speaks about her sense of self, how does her intersecting identities impact her counseling space? She points to her black "Women Are Sacred" t-shirt and shares:

I like it because it stands for my feminist ideas. The blazer because it just looks fly [and]I like black, I look more professional, but taking a little more seriously because I look younger so it sets me apart as a professional and then I wore high heeled boots just [because] I like high heels. But it makes me confident as their instructor to come into the room but I wore jeans still to be more casual. It's very intentional what I choose to wear because it shows the values I have. But it also makes me set apart as their facilitator and a professional, but in a way that's welcoming and in a way that makes me confident because again SWAG is about us too.

She continues on with the SWAG framework:

The $\mathrm{W}$ is [when] you can understand your motivations for why you navigate the way you do in your life and why you want to strive for this educational goal, this career goal, this creative project. What is the intention behind everything that you do? What is your why? The A is agency and advocacy. So, when I can understand myself, and I can understand my intention, I will come across what we call these systems of oppression. I will come across pushback and challenge. Where do I find the skills and self-efficacy to voice my stance in this? How do I work these systems to be an entrepreneur; an Entrepinay and to make my money or to get my point across and make my goal? How do I work these systems?

Kim admits that sometimes she may fall victim to the sheer number of students she has in her caseloads. She would often describe her typical day as a Promise Scholars Counselor as "a day of back to back to back appointments." With just only 30 minutes with each student, it can be extremely difficult to strike a balance between building genuine rapport with the student while attending to their appointment needs. She shares that we easily go down that "academic advising road" where we just provide them with advising information such as transfer and degree appointments. The "W" in SWAG reminds her why she is in this profession. It reminds her the importance of building authentic relationships with her students. Her own lived experiences are 
direct examples of how she felt as a student when a teacher invested in her. Her "why" extends beyond her counseling professional life. It also includes her work as a writer, poet, Entrepinay, and a photographer. When she deeply understands her purpose both as an educator and a creative, she can also articulate her own processes with her students as they are navigating their own academic and life purpose.

The "A" in SWAG also is rooted in her experience growing up as a student. During her K-12 and college experiences, there were many instances where she felt invisible, silenced, and marginalized. In order for her to advocate for herself, she had to understand her own intersecting identities and find power in them. In addition, she needed to find her purpose and intentions. Together, she can draw the courage and power to allow for her voice to be heard. If we cannot advocate for ourselves, how can we advocate for our students? Kim added, "How can we teach them the skills to navigate these systems of oppression if we, ourselves, cannot?" She then proceeded to share about the "G" in SWAG:

It's still going to be hard to do at the end of the day. How do I take care of my ability to sustain through this work? How do I take care of my ability to make sure my business, my job lasts 20-30 years without burning out and without quitting? And you can even get into the mental health part of that how do I not kill myself, to not give into addiction, to not give in to a toxic relationship. I think we're in a time where just educators allowing us to understand our own narratives. And I think that whole piece of allow and this idea of sustaining work, and us not being getting burnt out because of the way our socialpolitical, culture and environment is right now. That whole idea of the self-care piece, and sustaining ourselves as educators as well as having us look at ourselves again which I found for myself in theorists like bell hooks.

We both agreed that this part of the SWAG framework was the most important but least practiced component of our work as counselors. The irony of this profession is that it is described as one that is giving; it also can be very unforgiving to our minds, body, and soul. We often place our students before our own well-being that we tend to forget to practice selfcare. Kim freely shares, "I always find myself sick, with low energy towards the end of each 
semester." Unfortunately, this is a common narrative for many educators who are invested in transformative and innovative practices in teaching in counseling. The beautiful part of this SWAG framework is that it ties all of the elements together. A counselor's sense of self, their purpose and intention, their ability to advocate for themselves, and their ability to sustain themselves through self-care, allows them to create their own SWAG. While Kim may find challenges in operationalizing SWAG in systems that structurally oppress our ways of being, she doesn't buckle under the pressure. Her SWAG is what makes her accountable to herself but most importantly to her students. This poem she wrote truly embodies what the SWAG framework represents:

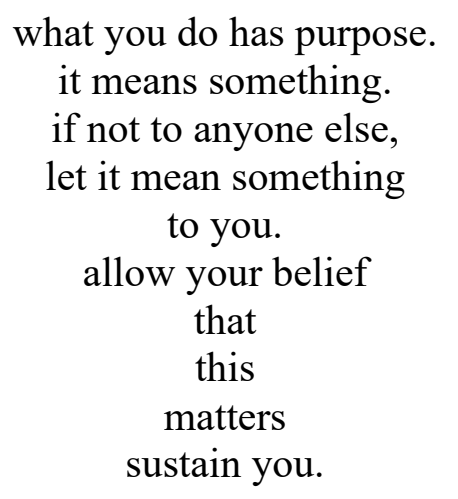

Through this SWAG framework, counselors can deeply reflect on their own practices by examining their own intersecting identities and how each of these identities impact their work with students. The SWAG framework really sets itself apart from other counseling and student development theories where the focus lies on how we can theorize ways to increase student success outcomes from the student perspective. However, if our students are relying on us as counselors to help co-construct their educational experiences to achieve their goals, it is very important for us to "check ourselves." Kim adds:

The duality of it is that, this is a practice that we do with our students within our counseling appointments and in class. But also the idea that it is something that we have to practice for ourselves. And that is in the foundation of all these different theories that 
create Hip Hop Education; that the student is the teacher as well, and the teacher is a student. So, in that way, we have to remain all accountable in our community and in our classrooms and office spaces with our students.

The SWAG counseling framework from the student perspective naturally created four student success outcomes we wanted to ensure in our counseling spaces with students. In her counseling role within the duration of the semester, Kim co-creates counseling experiences with her students to elicit these four outcomes: 1) understanding sense of self and identity, 2) understanding purpose and their "why", 3) developing skills for self-agency and advocacy, and 4) developing self-care practices. In order to do this, she creates the space for their voices to be heard and for their experiences to be centered in her appointments. This allows her to understand each student's version of SWAG. Kim also purposefully puts it out there clearly with students. She explains:

You say SWAG to a student and they know exactly what you're talking about. When I explain to them what SWAG means within counseling, they immediately feel welcomed. You can see the students become more invested in the conversation. And the students say things like, 'They really listened to us. And you really want to know me.'

\section{CAN I KICK IT? AESTHETICS OF HIP HOP}

Hip Hop has endured many changes throughout the years in terms of its aesthetics. Hip Hop has felt and looked differently every year and there lies the beauty of Hip Hop. It is never one thing. It can go from boom-bap beats to airy synthesizers and auto-tune. It can go from baggy jeans to skinny jeans with holes in them. It can go from bald, shaved heads with a Yankee

hat to match to dyed red hair with beads in them. Nevertheless, Hip Hop has proven to show that there is no standard in aesthetics. While there are constant debates on what real Hip Hop is and what it should look like and feel like, it will always continue to evolve. As educators who practice Hip Hop pedagogy, it is important to be culturally relevant and responsive to today's youth and students. Kim is highly aware of this when she engages with her students every 
semester. In teaching her college success class, there are several aesthetic choices she makes in creating a welcoming community environment.

I come in and turn on my Bluetooth and I play what is the relevant music to the youth right now and also what I love. Because again, it's still about me as an educator, and I love Chance the Rapper's new album. So, I've been playing Chance the Rapper. I start playing in class students coming in probably confused so then that's what I have the PowerPoint up that has a nice aesthetic to it. A funny GIF with it and then rap music is playing and they're probably confused about what's going on.

Hip Hop is about creating energy and a sense of mystery where students are anticipating what's going to happen next. At musical concerts, artists draw their energy from the audience which begins an exchange of energy between the artists and the audience. Similarly, Kim draws upon this energy using music and relevant GIFs in her Powerpoints. She also adds that energy is also derived from purposeful movement:

The way I go about it, too, is the nuance part that you can't define and that's the art of it, is how the engagement, the dialogue. I can't quite give a formulaic definition of that, but it's a way that I see the students. It's the way I move through the room. It's the way I catch on to the words they're using and start to use those words as well. The slang that they use. The jokes that I know are relevant to them in social media and mainstream media right now.

She would add those slang words, GIFs, and memes in future Powerpoint slides. By utilizing this simple strategy, she is centering their voices and experiences. In many educational spaces, our students are forced to conceal their true selves to fit in a system that wasn't designed to acknowledge their stories. Another way she has created visual aesthetics in her class is through the development of her syllabus. Hip Hop has always been about creating spaces, products, and ideas to be more visually appealing. While many institutions have policies on what needs to be on the syllabus and how it should be structured, Hip Hop gives us permission to redefine how we can communicate differently with our students. How can we make our syllabi more visually appealing while clearly providing the necessary information about the class itself? This reminds 
me of Yvette DeChavez's poster that says, “Decolonize Your Syllabus." The poster was a response to her white colleagues who said that her syllabus was "too ethnic" and that it was missing white authors. Kim draws from this energy and then takes out her colorful syllabus and explains:

That's another aesthetic that we have right is the way that the syllabus looks. So, syllabus I have here. It just has color. And then I even put down here different... because I'm teaching a Counseling STEM class. So, it has different scientists, mathematicians, engineers of color and that also identify within the LGBTQ+ community as well. That's the visual side of Hip Hop Ed allows me to be welcoming and bright but also let me show representation of the different intersections of who you can be in this field. And then it's silly even goes like this, all colorful and all that.

She flips the pages, showing me the various content. There were different colors. There were images of people of color. There were different font sizes with different borders and boundaries. It was visually appealing. It made you want to go through the pages like a magazine. That's what it felt like. In one of the pages, there was a noticeable blank area. She points at it as if she was writing with an imaginary pen:

So, the Counseling 100 Community Commitments, so you see what I put it on there, not just writing it down on a piece of paper in the classroom. And what I do is, their first activity in the class is on their syllabus. So, I will leave this blank because it's the idea that they're going to create the community commitments. And so what I do is then I break them up into different groups and then I have them discuss with each other. One introduced themselves to each other based off of the prompts that I had them answer on the question. And then I start out with the prompt question to them like, "In your groups discuss what is an example or experience you've had of oppressive, toxic, negative experiences in the classroom with peers and or teachers. So define for me what a bad situation will look like in your classrooms." And then they share that with each other, and then we share it out in the class.

Kim is providing a space for her students to share their experiences. Rendón, as explained through Sentipensante Pedagogy, shares that students are bringing their own wisdom into the classroom. While many students may not see their own experiences as wisdom initially, they begin to feel a sense of belonging and validation. Kim continues to share this experience: 
Then I tell them, 'Okay, now that we can all recognize and acknowledge what are the ways that we don't feel good, and we don't feel free and comfortable. Now, give me what your utopian ideal situation is." And this is where then that students get to co-create the space with me. And I tell them this, "You tell me what you want me to be like as your instructor, and what kind of classroom you want to create in here."

This co-creating of space is a huge component of Hip Hop pedagogy. To create this moment, she engaged students into a cypher, another Hip Hop aesthetic. It created an experience where everyone was sharing how they would like to have their classroom shaped and created. With their different backgrounds and experiences, how can they all breathe into existence together? Kim jumped into the cypher:

It makes me think of, I think of this academic term. It's co-generative dialogue drawn from Dr. Chris Emdin's Reality Pedagogy. It is CIPHER to me. It is a back and forth exchange of energy and ideas. And that is the concept is as we go back and forth more and more, we're going to improve together and evolve together in our experience, talents, and knowledge for this subject, or this topic, or this art.

The ability to create a space that honors their voices and experiences can have such a profound effect on how students will navigate within the class. Kim replied, "They would say things like 'Oh, I have a voice. Oh, she wants to hear from me. She wants to know who I am and what I've experienced."' For many of her students, it took time for them to adapt and adjust. They may have spent a great deal of their lives where their stories and experiences were never asked about. Hip Hop can do that. It can create another Hip Hop aesthetic - rupture, in their academic journeys. Rupture is the intentional interruption in music, art, and writing. It breaks away from the norm to create new ideas, art, and stories.

While much of the research looks at the impact of Hip Hop in classroom spaces, Kim also describes how the aesthetics of Hip Hop pedagogy plays out in her counseling appointments. And it begins with space. Kim glances around her old CIPHER office and remembers how important it was for her space to represent her students. She elaborates further: 
I think that's what I try to do with my office space is I'm always trying to find pieces. It's about being relevant to our students. I'm always bringing in new artwork or new things, new stickers. Even the littlest thing that I could put up in my office is an invitation to students. It goes back, I will say to the "A" in advocacy and agency. It invites them to control the counseling session by being able to use, "Oh, I like that sticker." I know I have cultural capital about that sticker. And that makes me confident enough to ask my counselor a question about what do they know about that? Because I know something about that. And then that could shift the whole counseling appointment. Little moments like being attuned to the things that students love to talk about.

Reflecting on her current space in the Promise Scholars office, her office can carry multiple conversations. When you enter her space, you can see two floating shelves. At the top level, you can see a spray paint can colored in all gold, a wooden Rock The School Bells boombox piece, a gold metal piece that spells the word, FRESH, and a vinyl record of Lauryn Hill's The Miseducation of Lauryn Hill. Situated below on the second shelf, there is a small portrait of Chance the Rapper encased in a black frame, a cactus that she got from a Mexican vendor, a miniature Hindu statue, and a Frida Kahlo book adorned in red and yellow flowers. At the center of the second shelf, she has a quote that reads, "You have the same amount of hours in the day as Beyoncé." Draped down from both shelves, she has her gold and black CIPHER graduation stole that she wears at every Skyline College graduation. On one side of the stole, there are the five elements of Hip Hop that includes knowledge. On the other side, the word, CIPHER, is embroidered in a classic graffiti lettering that was created by one of our former CIPHER students. This is just the left side of her office where students can see them and engage in conversation with Kim.

Kim reflects on a conversation she had with her student who happened to glance at one of Kim's posters about love. They began to talk about their current relationships. She shares:

Students are all about their astrology. So, that's something that I've learned more about. And then like just yesterday, students talking about their relationship. And then I talked about, "Oh, what sign are you?" They love signs and so we start to get into what their costar is and what their birth chart is all the stuff. So it's like a little moments like that. 
It is amazing to hear about how the intentional use of space can conjure up conversations that are deep and personal. Similar to processing art at museums, graffiti artists also known as aerosol writers create graffiti murals that allow consumers to create interpretations of what they are seeing and experiencing. In one of my Hip Hop spoken word pieces, one of the lines goes, "We are the writers that sprays on walls, carves on classroom desks with textures and colors, not only to be seen but also to be heard." Kim's office space is creating the same experience. When educators ask how Hip Hop pedagogy is practiced in our counseling approaches, this is one of the ways we can achieve it.

Storytelling is one of the major pillars in critical pedagogy; to be able to lift and honor students' lived experiences and narratives. Being in tune with what our students are sharing is very much like DJ's being in tune with their audience. If the dance floor clears up, it is the DJ's responsibility to get them back on the floor. Otherwise, they have lost the crowd. Kim nods in agreement and adds:

So much of a DJ too right and DJ to a counselor is nonverbals. So, DJs have to also watch body movement. How are they dancing? How was the energy of how many people are coming? The physical energy that you can see when your students are in a counseling appointment, are they crossing their arms? Are they looking away? How do I know they're engaged with me? And then it's a sampling. Well, let me try this. Okay, they're not, they don't like that. We try this. I'll bring up an astrology sign. Oh, they love that. Okay, let me play more of that. That's for sure.

Kim begins to shift the topic to discuss one of her random observations from work one day. Part of this observation is rooted in her understanding around the history of institutions of higher education where colleges were created to increase the industry of labor workers during the early part of the century. She elaborates further:

And then I'm walking [onto] campus, just see all these huge lines of all these students of color trying to get into the bus. [It] made me think about how education can be seen as a tool of liberation but through our American system, it's used as a way to really still 
oppress a lot of communities of color. So, I'm just seeing this right, I'm thinking also, all the students think that they're coming here to better their futures when it almost looks like they're packing into this bus like sardines. But often, if we don't have these more radical practices coming a lot from educators of color or say, queer educators of color. They're going to become just another part of the system.

Often, scholars question Hip Hop's ability to produce student success outcomes. Hip Hop is about the rupture; it's about creating a remix. Within the context of counseling practices and student success, Hip Hop pedagogy challenges us to rethink about how we are defining success. Kim continues her story about the students getting on the bus:

So, what I see with the way we practice with Hip Hop Ed is that my value is okay if these students are going to be here, and in the spaces that I can be in with Hip Hop Education, I can liberate them then. Are they awake? I don't want say woke, are they open? Are they aware of what is going on in their world? Because maybe I can, as one educator solve the inequitable injustices and means of access that they might have within their family, the jobs they get, the income. But are they free in their minds to be aware of every choice that they're making in their life? Can they want to better themselves to get out of those toxic relationships, or to create boundaries in their life? So, all a very long answer to say that the outcomes I've seen with our students is that they are liberated, they're awake. They are hungry to continue their education, and they feel they can really do whatever they want. They're not just even prescribed to these means of this is my major, this is my career. They can do whatever they want, and they can be creative with what they do with their lives.

Through the intentional creation of her space, her purposeful way she develops her syllabus and class content, and her ability to create a space where students can co-construct their educational experiences, she's providing them with the tools to be critically conscious. Students begin to understand their own power within their intersecting identities. They begin to develop and own their own SWAG. While high GPAs, increased degree completion rates, and high retention and persistence rates can be solid student success measures, it doesn't capture the complexities of success of how it's defined across different races and ethnicities. Much of what is shared about the power of Hip Hop pedagogy cannot solely be measured by statistics but by stories and 
personal narratives. While there is very little research around the impact of Hip Hop pedagogy

on counseling practices, Kim shares her students' responses to their experiences:

Using Hip Hop pedagogy directly ties to students' successes because you create a community, you create a family. And when students aren't doing well at an institution, or things happen outside at home, they retreat back to family, right? Whatever that family is defined as. They go to what is safe, where they're protected, and where they're seen and understood. And within the practices and the nuances of all the different ways we do Hip Hop Ed, what we're doing is creating a new home for them, as Janice would say, and a new space for them. So then when life gets hard, it's almost the opposite. Now life's getting too hard out there. Can I kick it in your office and "Oh, I'm always like a student." Okay, well, can I just hang out here? They don't want to leave. A lot of our CIPHER students that go on to graduate and transfer, keep coming back or keep hitting us up, staying in the group chats and checking in with each other because it becomes a community. It comes to place. So it creates a loving environment for them.

Just like the song, "Can I Kick It?" by A Tribe Called Quest, Kim and both inhaled a breath of fresh air. "Can I kick it?" "Yes, you can!” Hip Hop pedagogy creates an educational experience for students to feel like they belong and that they matter. The birth of Hip Hop was born from this notion of giving voice to those silenced and visibilizing the invisible. It created a space where youth and students can engage in critical and creative dialogue through cyphers. Sense of belonging has been a major research topic in higher education for many decades specifically with students of color. While past research examined numerous ways to increase student success from the student perspective, there has been extensive movement to investigate how institutional structures, practices, and policies have negatively impacted student success. Hip Hop pedagogy allows us to create rupture, sample between stories, re-examine how we can construct our space, and allow our students to co-create their experiences through cyphers.

\section{BROWN PAPER BAGS PT. II}

The students dove into their brown paper bags to begin sorting out the contents. While they were sorting the contents, each group began their own cypher and started to express 
different collage ideas in how they defined college success. As I walked around the class, I noticed that each group had different contents. The first group had a magazine, a pair of scissors, glue, tape, cardboard paper, and markers. The second group had a magazine and markers. The third group had cardboard paper, tape, and markers. Then, they began to define roles on who was going to do what. They only had ten minutes so there was a sense of adrenaline rushing through their veins. While Chance the Rapper was playing, you can see the laser-like focus that all of the groups were showing. The first group seemed to have a nice groove - one person cutting pictures out of a magazine, while another was gluing pieces onto the cardboard paper. The second group was actually using their paper bag as a canvas for their collage since they didn't have any cardboard paper. They were also carefully ripping out pictures from their magazine. The third group didn't have a magazine, so they assigned one of the student artists to draw images, words, and phrases that symbolized college success.

Kim finally yelled, "Time's up." She asked all of the groups to present their collage to the entire class. Once they delivered their presentation, Kim and I voted to see who had the "best" collage. While they all demonstrated key components to college success in their collage, we selected the third group that had just a cardboard paper, tape, and markers. Kim, then, informed the class that they all had different contents in their paper bags. Immediately, you can hear the groans and moans from groups that had limited materials. I heard students say, "That's not fair! We didn't have scissors. Magazines? We didn't have one, so we had to draw." However, Kim reminded them that the third group still had the least materials and still was able to produce a cohesive and creative collage representing college success.

After processing the activity, she played Kendrick Lamar's video, "Alright”, as a way to introduce the topic of the four "I"'s of oppression. She showed a slide that illustrated the 
different forms of oppression and how they interacted with each other. There were two interlocking rings titled "Individual" and "Systemic." The four different forms of oppression are individual, interpersonal, institutional, and structural. They were all positioned within one or both rings. Individual oppression was inside the "individual" ring, while institutional and structural oppression were housed inside the "systemic" ring. Interpersonal oppression was linked between both rings to show the relational impact between the individual and systemic oppression in terms of impacting one's interpersonal being. Each form of oppression was clearly defined on the presentation slide. Once she felt that they had some grasp of the concepts, she then asked them, "What does individual oppression look like as a college student?"

For many students, this was the first time they were introduced to these concepts. When they began to share their own experiences and stories related to racism, gender roles, and sexism, you can feel a sense of energy that was filling the room. There was a sense of validation of the feelings and emotions they may have been experiencing throughout their academic journey. Having access to this language and now moving towards being critically conscious, it sets the stage for Kim to provide new learning experiences that will equip them with the tools to address these systems of oppression. I also found that the paper bags were symbolic. When the student joked about whether or not alcohol was in there, I found that to be a profound statement. Paper bags are often associated with concealing or hiding something such as alcohol, drugs, or money. Our students of color who arrive at our institutions often feel like they have to conceal their authentic selves for various reasons. Similar to the second group who used the paper bag as a canvas for the collage activity, how can we redefine students' experiences so that they can feel safe and brave to be themselves in an institution that was not originally intended for students of color? Through this activity, I can clearly see that Kim was facilitating an 
educational experience where they are developing their own authentic swag through the various aesthetics of Hip Hop pedagogy. So if we intend to transform our college counseling practices and break through these brown paper bags, Kim reminds us:

$$
\begin{gathered}
\text { you are } \\
\text { your greatest } \\
\text { revolution. }
\end{gathered}
$$




\section{TRACK FIVE}

\section{ADAM FREAS}

\section{IBTIHAJ}

I'm staring at a sea of cars in front of me, sitting idly in a mid-week traffic jam when my phone rings. Through my Honda Pilot BOSE speakers, my sister asks, "What's your landmark?" We always seem to ask that question whenever we want to know how far we were from our destination. We got it from my Pops, a military man, who spent over 25 years serving in the U.S. Navy. When we would be out with friends, he would make us check in every hour to let him know our landmark. These were the times before cell phones so we literally had to find a pay phone or ask our friends' parents if we can borrow their phone. I replied, 'I'm heading towards the San Mateo Bridge." She quickly replied, "San Mateo side or Hayward side?" "San Mateo side," I responded. She then said, "Okay then. You and Charles, get your dinner." Before I could utter a word, she hung up.

This is going to be a long drive to Hercules. The traffic on the San Mateo Bridge was slow moving and it didn't help that two of the three lanes were open. I've driven this route at this time several times before, so I knew this was only the first of many traffic jams throughout the Bay Area. I've already visualized my drive to Hercules. The first major traffic area would be the San Mateo Bridge, then it would be the 238-880 merger near Castro Valley where the palm trees of In and Out Burger would wave at you, enticing you with a quick visit for a doubledouble Animal-style burger with well-done fries. Then it would be Highway 80 where you can see the bright yellow IKEA sign in Emeryville. The last traffic area is normally located near San Pablo Dam Road in Richmond, California. For some reason, people want to wrap around that curve near San Pablo Dam Road really fast knowing that that area was prone to 
accidents. Despite knowing that this drive would take more than an hour, I was still on that teaching high from class earlier that day.

The lesson of the day for my CIPHER College Success class was centered around identity and intersectionality. I had my students listen to the song, "Ibtihaj", by Rapsody, from her third album titled Eve. My students learned earlier that week that Rapsody's album Eve, consisted of tracks that were titled after Black women who Rapsody identified as influential and inspiring. Tracks included: Michelle, Oprah, Nina, and Aaliyah. So naturally in our discussion in class, students asked the question, "Who's Ibtihaj?" Without answering, I played the "Ibtihaj" video and immediately the room was filled with the grimy basement sounds of the Gza's Liquid Swords sample. Given that Hip Hop is still young in comparison to the other musical genres, you know you're old when a Hip Hop song you grew up listening to is now being sampled by today’s Hip Hop artists.

After the students watched the video and did their own research online through their laptops and cell phones, they learned who Ibtihaj was. They learned that she was an Olympic medalist in fencing. What they also learned was that she was a woman. She was an African American woman. She was a Muslim African American woman. She was a Muslim African American woman in a sport that was accessible traditionally for the elites and were dominated by men. My students read excerpts from Ibtihaj's book titled Proud: My Fight for an Unlikely American Dream and learned about the many struggles she had growing up in a sport that did not accept her. They began to understand how her intersecting identities resulted in experiences that made her feel inferior, undervalued, and marginalized.

Then, students started to make those connections on their own as they began to see themselves in Ibtihaj. They spoke about their experiences in middle school and in high 
school. They expressed about the unresolved harm that impacted their ability to see themselves as smart, worthy, and capable. However, within this community of learners, in this cypher that they have created with each other, they have found refuge in each other. It was one of those moments in teaching that reminds you how important our work is with our students. Hip Hop gave me the platform to facilitate these necessary conversations of hope and healing. I let out a proud sigh and before I knew it, I was one exit away from my sister's house.

\section{LIFT YOUR FIST}

My alarm was going off when the bedroom door cracked open letting a stream of light creep in from the hallway. I was squinting my eyes trying to see who it was. I heard my brother-in-law's voice, "There's coffee downstairs for you." I turned off my alarm and the clock read, "6:17AM." I went to get myself ready, preparing for what was going to be another long drive to Sacramento, California where I would be interviewing Adam Freas, an EOPS counselor and Equity Coordinator, at Sacramento City College. The drive to Sacramento, the California state capital, was going to be really thick in the morning commute. There was no way I was going to drive to Sacramento from San Mateo in the morning so sleeping over my sister's house in Hercules the night before seemed like the best idea especially since I needed to be at Adam Freas' class by 9:00am the following morning.

As the sun was rising, its rays painting the sky in yellow and orange strokes, I was out of the house by 7:00am with my brother in law's freshly brewed coffee in my hand. I decided not to put any creamer because I wanted the espresso to go straight to my veins since my trek to Sacramento City College was estimated to be about an hour and a half drive. I put on some Nipsey Hussle and I was on my way. There's nothing like starting your day with some black coffee and a little bit of Nipsey. Just like Nipsey's album title, this drive is going to be like a 
"Marathon." And just like a marathon, I knew deep in my bones that after today’s interview with Adam Freas, there will be moments of pain, struggles, inspiration, and celebration.

After what seemed like forever, I finally exited 12th Avenue toward Sacramento City College. As I drive closer to the campus, you can immediately see Hughes Stadium, home of the Sacramento City College Panthers. The building was huge with bleachers painted alternately, gold and cardinal red. I work at a community college but I have never seen a football stadium that large for a California community college. Sacramento City College, in general, is considered a large community college serving nearly 25,000 students each year. I parked my car on the third floor at the college's parking garage and headed towards the Business building where Adam Freas teaches his College Success class.

His classroom was located on the second floor where students congregated outside of the classrooms, sitting on the wooden benches. Other students sprawled out on the floor, sitting on the green carpets. The building had an old but nostalgic feel to it; its smell reminiscent of dusty old books in the library. As I approached his classroom, I started to hear muffled beats emanating from the walls. You can slightly see the papers pinned on the bulletin boards shaking with the beats. I said to myself, "This has to be his classroom." The closer I got to the classroom, the more profound the beats became. I placed my hand on the doorknob, turned it, and opened the door. Just like turning the volume dial up in my car, the beats of the music got louder. It was a refreshing way to enter the classroom. I felt invited into the space. I felt like I came home.

Immediately, I was drawn to the front of the class, where a DJ was playing music. I nodded with the beats while smiling from cheek to cheek. As I walked closer, I immediately recognized the DJ as he was a good friend of mine who goes by the name, Mic B. I gave him a 
head nod so not to disrupt his musical flow. There were a couple of students in the room vibing to the beats while entertaining themselves on their cell phones. While the students were scrolling and swiping right and left on their phones, Mic B, was modeling the same movements on his Pioneer DJ controller. I thought to myself, “There's an actual DJ in the classroom!” The beats continued to fill the air of the classroom as more students started to file in and take their seats. I walked up to Adam Freas, most notably known in the community by his last name as Freas, and we gave each other daps and the "homie hug." He says, "Yeah, my man, Mic B, is one of the students in the class." I was inspired by the fact that Freas' provided Mic B with an opportunity to showcase a part of his own identity as a DJ to build community in his classroom.

The class was about to start so I made my way to an open seat next to Mic B. As desks were occupied by mostly students of color, Freas, a Caucasian male standing 6' 2", positioned himself in front of the class decked out in his gray button up shirt with a gray hat to match. Moving from left to right in his Nike running shoes, his arms gestured in an outward motion like an emcee rapping at a show. He provided a recap of the last class and how the concepts of the word "dope" were going to connect with today's topic. He pointed around the room at all of the large white post-it notes. Each of the post-it had a title that read, "Synonym of Dope" but they each had a different reflection question attached to it. Freas explained to the students that they were going to engage in a cypher at each of the different post-it notes. He explained the concept of the cypher by comparing how information is shared and received in classroom spaces. Freas elaborates:

From an educational standpoint, the teacher is in the front of the class teaching while students are receiving the information. In a cypher, everyone stands in a circle sharing ideas and stories with each other. But if someone from the outside sees a cypher, they wouldn't be able to tell who the teacher is. 
He, then, instructed the students to make their way to different parts of the room and respond to the different prompts that were listed on the white post-it notes. As soon as Freas provided the last part of the instructions, without hesitation and on cue, Mic B drops the beat at the right time. The chords of the keyboard introduced us to the song followed by the familiar boom bap sound that made the whole room nod their heads in unison. With its soulful and jazzy energy, I immediately heard Guru's voice and knew that we were being treated to some Jazzmatazz Street Soul. While students were busy writing their responses to the prompts, the hook blasted through the room, commanding our attention:

To all my people, just lift your fist

Seem like it ain't no peace, no justice

How you want it, the bullet or the microchip?

Either way you got to lift your fist; we get it down like this

To all my people, ball up your fist.

The song, "Lift Your Fist", was released twenty years ago in 2000; yet the content of the song still resonates today for many communities of color. The lines that stood out to me the most were from Guru's first verse. He raps:

Garments bloodstained, face bruised and battered Our eyes reflect the agony, of dreams that were shattered And they love it, when we wild out and kill our own But the greater responsibility, yes, is still our own.

I look around the room and see all of Freas' students. I imagine them to also be my students. I read their responses on the post-it notes while the song continues, and I am struck by their honesty and vulnerability. I wonder if any of the students are soaking in the lyrics of "Lift Your Fist." Nevertheless, this song reminded me again how powerful Hip Hop can be in these educational spaces. I peered towards Freas' direction and he gave me this look, his lip curled up and his eyebrows scrunched while bobbing his head to the music. He was feeling it. He was 
feeling the energy from both the beats and his students. And with that, Guru hit us with his last line, "Me and the Roots, word up, we takin' over. To all my people, just lift your fist."

\section{FREAS' INSTINCTIVE TRAVELS AND THE PATHS OF RIDDIM}

As I reflect back on that class, I remembered leaving curious as to what informed educators, particularly college counselors, to utilize Hip Hop in educational spaces. In addition to being a college counselor and faculty equity coordinator, Freas is also the Executive Director and co-founder of the Low End Theory Collaborative, also known as LET-C. LET-C is a nonprofit organization that collaborates with other organizations to create educational and professional development experiences that are centered and rooted around Hip Hop culture. Also, the name Low End Theory Collaborative paid homage to one of the greatest Hip Hop groups of all time, A Tribe Called Quest (ATCQ). So, to deeply understand the origin story of Freas, I also drew inspiration from another classic album by ATCQ, taking readers through Freas' instinctive travels and his paths of riddim.

Freas grew up in South Florida in Fort Lauderdale in Broward County. The city is north of Miami and about 5 miles west from the Atlantic Ocean. He lived in a neighborhood called Lauderdale Manors. South Florida, essentially, was the tropics. It was always hot and humid. Freas laughs and says, "I think I maybe owned one pair of pants, you know what I'm saying, as a kid, because it was shorts all year round." The neighborhood was predominantly communities of color. Freas expanded, "I'd say probably a mix of African American, and then Caribbean, so like Haitian, and Jamaican, but then you had Puerto Ricans, and Dominicans, and folks like that. Predominantly, I'd say, African American and some of the island folk from the Caribbean.” 
Freas recalls being one of two or maybe three White families in his neighborhood. When asked what it meant to be one of the few White families, he responded:

I mean, it was a very unique, for me, at least, perspective. It's like, what you grow up in you see as the norm, because that's what you grew up in. You adapt and understand that to be the normal thing. To be in a diverse space is the normal kind of experience I assume everybody has, until you move out into other spaces, and you realize, not everybody does $\mathrm{X}, \mathrm{Y}, \mathrm{Z}$, or this isn't common.

Freas was defining his reality despite what the rest of the country was experiencing when it came to race relations in America. Not only did living in Lauderdale Manors provided him exposure to different communities of color, it also provided him with a musical aesthetic that was created and blessed by those communities. Freas beautifully articulates this reflection:

The beauty of that experience, I mean, I've been shaped in so many ways just from the music, the tapestry of music through that neighborhood. I commonly refer to going to sleep at night and the reggae bass lines that you would hear from multiple streets away, you don't even know what the song is, but you could hear that 'riddim'. You basically, I go to sleep to the reggae bass lines consistently. Not having a reference of that's reggae music, you know what I mean? Just knowing that that's part of the aesthetic that I was raised in.

While he was immersed in the musical aesthetics of his neighborhood, music was also rich and prevalent at home. Freas remembers his Pops playing different types of music throughout the day ranging from jazz, classical, and reggae music.

Up north in New York City, Hip Hop was just coming out. He shared a memory when Hip Hop was introduced to him. He talked about an older kid named Otis who would always come out with a boombox. He described Otis as this "kind of mysterious cool kid" who really didn't like kicking it with the younger kids. Freas remembered that Otis was also on house arrest with an ankle monitor that was strapped onto his creased-up Lee's jeans. He adds, “There was a vibe about him. This cat, he's cool. He's a cool dude." He would always hear cars drive down the street playing "Egyptian Lover" and other songs that painted this new reality of Hip 
Hop. When you are from a particular space for so long, you tend to embody that space. As one of the few white kids in the neighborhood, the embodiments of this space deeply shaped his lived experiences in his neighborhood. He further reflects:

That's how I think those two experiences, growing up in that neighborhood, just the reality and exposure of having that diversity of people, but then, also the musical aesthetic, and just cultural norms, and experiences, from diet, and food, and stuff, plants a seed to how you travel and see spaces as you move forward. I think I was a little more invested, either consciously or unconsciously, in that component of Hip Hop, in terms of how race is engaged and how I fit into that equation, as a white person.

Hip Hop culture centers the lives of traditionally marginalized communities through the various elements of Hip Hop. It gives voice to those who have been silenced and positions communities at the core of its culture. Freas explains, "As I immersed myself in Hip Hop, that is a very raceconscious genre, in terms of rap music and just the culture itself centers the discourse around race." He leans forward, lets out a laugh, and says, "The work that we do with Rock The School Bells? It's like critical race theory over a cadence, you know what I'm saying? It's critical race theory to a beat."

When he got word that he and his family were moving to California, it didn't really bother him as much as he thought. It was going to be a temporary move and he would be right back to South Florida. He remembers his friends jokingly saying, "You're moving to California. It's just like Florida, right? It got beaches. You'll be good, man." He has been part of this neighborhood for his whole life so he convinced himself that nothing is going to be like South Florida. He adds, "Wherever I go can never replace what I'm grounded in. This new kind of whatever, it could be the greatest thing waiting ahead for you, but it's not home. It's not home. It's not that. No matter where we go, it's not going to be home."

You can tell based on Freas' voice that this transition was going to be huge and that he would need something to ground him and anchor him. Hip Hop was that anchor. "It's like that 
blanket for the baby kind of thing that they hold onto. I think a part of it was finding my own identity in the music or in the culture, in Hip Hop." Being immersed into Hip Hop culture while growing up in South Florida, allowed him to acquire the navigational skills to experience these travels instinctively while being able to travel in his own paths of riddim as a White male in Hip Hop culture.

\section{BALL IS LIFE}

It was 1987 and Hip Hop was evolving into a new direction, leaving behind the old school Hip Hop of the late 70s and early 80s. The Billboard Charts that year showcased a number of songs from classic albums such as Eric B \& Rakim's Paid In Full, Public Enemy's Yo! Bum Rush The Show, Boogie Down Production's Criminal Minded, and LL Cool J's Bigger and Deffer. While most of the rap songs that played on the radio that year came from the East Coast, there were also a few emcees from the West Coast that were also making noise. Ice-T came out with is noteworthy album titled Rhyme Pays, and songs such as Eazy E's "Boyz N The Hood”, NWA's “Dope Man”, and Too Short's "Freaky Tales." These West Coast rap songs introduced the world and painted artfully through words the realities of what was happening in Los Angeles and Oakland, California. Freas recalled the moment when he first moved to Stockton, California, that same year when Hip Hop was experiencing this new evolution in music:

Stockton was a diverse, unique space as well. Very working class. It's, I don't know, I don't even think Stockton can figure out its identity. It's a mix of, the outskirts are rural and farming kind of types, but then you get in the city, and it's like, nah, it's like gang culture. A really unique and weird space. This was late ' $80 \mathrm{~s}$, at this point. It's the beginning of...well, it was more primed for it already, but I got out here, and gangs, and all that stuff was a little more prominent out here. Eventually gangster rap started bubbling. It popped in Cali much faster. Yeah, just absorbing all that new landscape was an interesting shift. 
Part of adjusting to new surroundings is finding a community that shares the same interests as you. For Freas, it was the game of basketball. Basketball was something he loved to play dating back to his life in South Florida. When he reflected back to his elementary days, he shared, "School is not my thing. I loved sports. I loved hooping. Yeah, I'd rather be playing in the streets than studying vocabulary words or whatever."

So when he moved to Central Stockton, basketball was something that provided community for him. Freas attended Stagg High School where they were also known as the Delta Kings and Queens. He described the school as "pretty diverse." He elaborated with more detail:

The high school I went to, so, Stag, at that time, was a pretty diverse, even though it was central, it was an interestingly diverse high school, versus all the other ones, where it's like, the South side [schools] were just predominantly Black and Brown. Then, the North side [schools] were predominantly White. They'd be White, and Asian, and a little Brown, you know what I mean? The private ones were predominantly White. Stagg was this weird blend. Again, pretty diverse, but it had South side cats and North side cats, you know?

While his high school was seen as one of the more diverse schools in the city of Stockton, much of his educational experiences was insulated in the world of being an athlete, especially as a basketball player. Freas described this reality as "You just hang out with your teammates, and you hang out with the cats that ball, and you just ball. When you're at home, you're calling cats to ball. You're at school, like lunchtime, you're seeing if the gym is open. It's like, that's just what you do."

As he was talking about playing hoops, I can hear the excitement throughout the tone of his voice. He reached back into his bank of memories and shared a poignant time in high school that really resonated with him. He recalled when his high school basketball team was in the finals of a local tournament. At this time in his life, Freas was really getting into Hip Hop and 
remembered always being worried about what music the gym would play during warmups. $\mathrm{He}$ explained, "That was the shit I would always think about. The experience, to me, it was like, it was just something about the beat, right, and the energy of all the crowd." So, he approached the teacher who was running the music and asked, "You mind if we play this?" Freas asked him to play Public Enemy's “Can’t Truss It." The teacher asked, "Well, there's no cussing on it, right?" As Freas was reflecting on that memory, he let out this laugh and said, "I told him, there's no cussing in it. I'm thinking, you play it loud, you ain't going to really understand Chuck D anyways, in this thing, right?"

Freas begins to paint this picture of the song playing as the whole basketball team is running onto the court for their warm-ups. He recalls vividly that moment:

This joint is like with the balcony, people looking down, so all the students were up, sitting up there, predominantly students of color from both schools. You could hear the, you know, "You Can't Truss It." Starts off with the little, the nonviolent little verbiage or whatever. When that beat drops, yo, that whole balcony was just rocking. They was like, "Yo." They felt it, you know what I mean?

Freas enunciated the word, "Yo", so profoundly that it felt like I was actually in the gym hearing the hard beats by Public Enemy reverberating throughout the place. His basketball team won the championship game for the local tournament but despite winning it all, that moment of the "balcony rocking" was more important to him. Freas places his hand underneath his chin and continues to reflect, "At the time, I couldn't articulate it, but I know that was the thing, where they felt validated in the space. I was like, 'Yo, this is us,' in a space that it's not really about us. The beats and the folks rocking to it was like, that fed me more."

There were so many layers that were created at that moment in time. Not only did this moment validate the experiences of communities of color but where it was played made the 
moment that much more powerful. It was a moment that demonstrated this notion of antiestablishment; the idea of how people should show up in spaces. Freas elaborated further:

It was like the establishment. So the adults and the officials of the space were, in most cases, were there but also not accessing that moment of celebration and community, which is another layer to me. I feel like growing up and I feel like youth still to this point, there's this framing that what they show up lacking, you know what I mean? And are forced to kind of acclimate, assimilate to kind of adult standards and the BS that exists within that.

This is such a wonderful illustration of how Hip Hop can find its way to disrupt the status quo, occupying spaces with governing rules and policies that are not necessarily made for communities of color. Freas, in the midst of an emotional high, replied, "That moment made us feel extra good about ourselves." It was a moment that said, "We are here and you're going to know that we are here."

Freas played on the basketball team all four years in high school. He remembers the coach asking him, "Where are you thinking about going after high school?" Playing hoops was all he knew and the only reason why he thought about college was to just play hoops. Shrugging his shoulders, Freas expressed:

That's why I went to, so, I ended up going to community college and hooped. That was really it. That was the only reason I thought about [college]. I still wasn't thinking about grades, like, "I have to get my grades together." Nah. I'm thinking about just hooping, like, I've been doing well enough to hoop up to this point, meaning grade-wise, so I should be good to go at the next wave.

Freas transferred locally to Delta Community College in Stockton, California to continue playing basketball for the college. However, his time playing hoops at Delta didn't go as he would imagined. He played the first year and ended up quitting later that same year. You can see the struggle painted on Freas' face as he's explaining his experience:

In my mind, I was blaming the coaches. I was like, "Yo, this cat," blah, blah, blah. I was coming up with all kinds of shit. I remember the day I quit, my car broke down at the house. I was about to go to practice, broke down. It wouldn't run. This is the '90s, so you 
ain't call Uber or nothing. Like, fuck it, I ain't making it to practice. The next practice I go to, I'm about to pay for not going to practice. I'll have to run extra. Just like, man, you know, fuck this, man. I'm done.

As he continued to process, he shared what he was experiencing during the same time when he quit playing for the basketball team. With his voice strained and the words tinted with pain, he recalls:

At the time, my pops was out of the house. My brother was full-on dealing with addiction issues. That cat was homeless. You know, as a parent, they were back and forth in terms of, "All right, you can stay. You seem like you're moving in the right direction. You're out." Out was like sitting in his car in front of the crib, you know what I mean?

And as if Freas was transported back to those moments, there was a noticeable pause. You can feel the uneasiness of the pain fill the air. Freas continued to reflect, "At the time, you just kind of rolled with it. Man, I see my brother sitting out front, bugged out, or he's living in the house and you're trying to sleep but he's in the next room, bugged out."

At the time when he quit the basketball team, he didn't point to his issues at home as the reasons why he quit. He asked himself, "Why the fuck did I back out on hoops? I lived and breathed hoops. I balled. That was all I did. I could just shut it down on a car breaking down?" But as he grew older and processed this experience much more deeply, he was able to clearly articulate what he was really going through at the time. Clasping his hands together and leaning back in his chair, Freas replied:

I imagine, just the inability to process what that does to a person, then, you start pivoting out of shit for reasons that aren't really rooted in why you think you're doing what you're doing, like the stress and weight that comes with that. I was just dealing with being in my mind, I assume, being the man of the house, because my pops wasn't there. My brother was bugged the fuck out. At that time, you got a cat talking out the side of his head, you think, man, I got to protect my mom. What's going to happen? I don't know.

There was the tone in Freas' voice that was shrouded in resignation that this possibly was the end of his hoops career. How can he move on when he spent the majority of his educational career 
playing ball? While the professional and institutional opportunities to play ball didn't present itself for Freas, it did propel him to a whole new experience that would further give him a deeper purpose. So in a strange, unassuming, and indirect way, the saying "Ball is Life" has transformed into "Ball Gave Life." In this newly remixed version of this saying, his love for hoops had unintentionally created a trajectory in life that would lead him towards higher education, but more specifically, towards Hip Hop education.

\section{FINDING REFUGE IN HIP HOP}

Freas experienced a vast majority of his academic life playing sports so it would be interesting to hear and learn about how he navigated throughout college. Freas immediately responded:

Yeah, well, that was the thing. I didn't tap into any support. That's what I think was the biggest issue. I didn't really tap into any support. I didn't go see a counselor or [anything]. I didn't do anything. I just kept it moving. Just like, "Nah, I'm going to figure this shit out," which was probably the issue from the jump, right? Like, "Nah, I got this. I'll be all right. Yup, I'll be alright. I'm going to figure it out." It's some, also, some male norms, some patriarchal kind of framings of how men are supposed to be.

There is significant literature that suggests that male students who don't seek help, ask questions, and identify male mentors, are more likely to experience difficulties in navigating institutional systems. In the case of Freas, his idea of "figuring it out" is directly linked with adapting a mindset that was rooted in Hip Hop. His voice started to rise and increase in volume as he explained further as to what he meant about this Hip Hop mindset. He replied:

I mean, it wasn't a...shit, it's still a battle, to this day. I mean, I think I found refuge in Hip Hop and in the narratives in there, because I think about, what's Hip Hop? What's that? Why's that different from rock? Why is that different from any other genre? Because they're telling stories, too. They're not telling a consistent story of struggle. I mean, there is struggle. There's a little heartbreak and that kind of stuff, but social struggle, and just the layers that exist in all those kind of dynamics, right? Whether it's financial, or race, or just the history of things, or identity struggle, and all that shit, acceptance. Just the constant conflict, right? 
As educators who engage in Hip Hop pedagogy in our counseling practices, we are often questioned as to how Hip Hop explicitly changes the way we counsel or teach in our classes. Freas explains that it's about explicitly naming the oppression. Hip Hop is unapologetic, intentionally loud, and in your face. It is a musical genre that is race and class conscious. While storytelling is a common component in academic advising and college counseling, the courage or knowledge to unearth the oppressive realities our students face can be found absent in these counseling spaces. Freas continues:

Hip Hop always problematized shit in a way that was always counter to the comfort of the norm, which I think that was another level of made me gravitate to it. That's why I think punk and Hip Hop cats, from the jump, were always this mix of like, man, fuck the standard. There's something that's not right about it.

Practices, policies, and rules that are developed as standardized, prescriptive, and traditional in educational spaces can be viewed as problematic and harmful for students who are often marginalized and minoritized. He concluded his overall thoughts by saying:

As you go through your own process of dealing with your own internal conflicts, and trying to figure out what's the next step, you find things to lean into that help you process and make sense of the world. If you don't know how to tap into resources, the human resources, in this case, I tapped into Hip Hop more. It had already been something I was into and loved, but I got further into it.

During his academic journey at Delta Community College, he was working part-time and venturing more into his music. While he wanted to go back to school in Florida to attend the University of Miami, he couldn’t leave his mother who was trying to support his older brother. Instead, Freas transferred to Sacramento State University to major in Communications with an emphasis in Media and Film. He imagined, "Yo, I'm going to be writing. I'm going to write for films. I'm going to write for my life because I'm afraid of a day job like Common says." 
When he transferred to Sacramento State University, he attended one of those orientations for transfer students. The person who was leading the orientations instructed students to meet with an advisor to get their educational planning started. In the midst of all of the orientation madness, Freas overhears students talking about AA degrees. As he was about to continue the story, Freas laughs embarrassingly and sighs, "Oh my." Then he proceeded to share the story:

All of the transfer students are coming in. I go talk to the person. Like, "Hey, I just met with a student. They were talking about an AA degree. How do I sign up for that?" They're like, "AA degree? That's only at the community colleges. We don't do that, here." I'm like, "Okay." I just tried to play like I knew.

We both laughed hysterically. Underneath the laughs, there were some truths hidden within this particular experience. We both agreed that we're sure that there were other students who had similar experiences. Freas, at the time, began to question whether or not he received his AA degree? Did he finish his degree? Did the college forget to send his degree? But he quickly shot that idea down as he knew he most likely didn't complete his AA degree requirements. While the other students were sharing about their AA degrees, Freas avoided any further embarrassment and said, "I forgot to sign up for that."

While this experience highlighted his lack of ability to connect with resources at that time to be more effective, efficient, and productive, Hip Hop teaches him to keep going. Drawing from the title of Jeff Chang's book, he embodied the "can't stop, won't stop" mentality. Freas elaborates further:

That was my resource, again, was, I always felt like Hip Hop was a resource that always gave me an answer, always gave me some guidance of things to think about. It wasn't like I was like, "Alright, Ice-T, tell me what's next," right? It wasn't like, "Tribe, which class should I take in the fall?" It was like, they gave me shit to contemplate. They also honored just that struggle of the process of dealing with any conflict, just processing it, and persevering, or just processing it, and just honoring that as a process, or just recognizing it and naming it. All that shit happens in Hip Hop or in rap music. 
Hip Hop provides listeners and artists a means by which we can learn from each other's stories whether they are rooted in struggle, pain, or happiness. It also allows Freas the permission to make mistakes and fail so that he can work on finding ways to persevere and search for solutions.

Hip Hop also allows us to name the oppression. It allows us to speak and project loudly how we are affected within systems of oppression. While Freas speaks about how he could've done better to navigate college systems, he also points out that, in hindsight, it could be a systemic issue. He explores this more deeply and expresses:

Maybe it was just because I didn't feel like there was a system. Something wasn't right with the framing of how this shit works. Maybe that was a part of the reason I didn't feel comfortable to go in and talk to folks, even though I had all the privileges tied to me. I show up as a White, heterosexual male and like I had the green card. I had the pass to get into anything, the VIP shit. Still, for some reason, I never reached out to really lock in with folks, in terms of guidance and resources in that way.

While Freas acknowledges that his intersecting identities give him power and privilege, it further highlights the struggles and challenges that marginalized and minoritized students of color experience in obtaining guidance and resources in educational spaces. Students want help but what Freas is suggesting is that the structures in place may not allow the knowledge and resources to be accessible for those students.

\section{ACT YOUR AGE NOT YOUR COLOR}

Freas shares a photo of where he grew up in South Florida. His house was surrounded by a metal linked fence that encompassed a huge front yard with circular stepping stones that led directly to the front door. Different types of trees, especially palm trees, congregated around his house, providing the welcomed shade during those hot, humid summer days. You can see clear blue skies sprinkled with white fluffy clouds. The brightness almost made you feel the Florida 
heat emanating from the picture. This is where young Freas grew up and this is where he would get picked up in the morning to head 30 minutes away to a magnet school called Eisenhower Elementary School and then Nova Middle School, thereafter. Both schools were located in Davie, Florida, a huge shift from where Freas lived in Lauderdale Manors. Freas unravels this reflection as he explains:

Then, my folks ended up getting us in a magnet school where we get bused out of the neighborhood. That's another interesting thing, is, so, all the kids that were getting bused out of my neighborhood, so I'd pull up to this campus that was a very, still diverse, but it had kids from other places, like Hollywood, which was a little more affluent, at the time. It was in Davie.

Davie was about 30 minutes south from Lauderdale Manors while Hollywood, Florida was located 30 minutes south of Davie. Hollywood is known for Hollywood Beach where the Hollywood Beach Boardwalk was located. Tourists around the world would also visit Hollywood to experience places such as ArtsPark at Young Circle, the Arts and Culture Center of Hollywood and the Anne Kolb Nature Center where the city's aquarium was located. This was far different than the neighborhood that Freas have grown up in.

Kids were being bussed into Eisenhower Elementary School from various cities and neighborhoods of South Florida. Freas remembers clearly and points out:

Anyways, you pull up, or, at that time, they have tables in the lunchroom, when you're waiting for your bus. You all sit at your table for your bus or whatever. It was clear, there'd be the black tables, white tables, you know what I mean? I'd be at these black tables. To me, that was like, whatever. This is my neighborhood. These are the kids, you know, some of them I know, most of them I know, whatever.

Freas noticed this but didn't really have the words at the time how to articulate those experiences. However, it really didn't bother him as much then as he saw himself as part of this Black community because it was the reality he grew up in. He, then, shared another example of an interaction with other White kids from Hollywood he befriended at school. 
I be like, "Hey, can you come spend the night?" They're like, "Nah, why don't you come spend the night over here?" I realized later, like, yo, they never wanted to come spend the night at my house. I had to think about it. I was like, I wonder why that was, you know what I mean? Kind of an interesting thing, that they never wanted to come over to our house. At the time, it was like, "Whatever. Yeah, cool. I'm not tripping."

Those early experiences really didn't make much meaning and impact until much later on when he started to really engage in conversations around whiteness and white privilege. Freas talks about how it was not as apparent to him then as it is now. He begins to talk about these mental connections as his face and voice are tinted in exasperation:

Then, it connects dots to reflect back to those things I talked about. I said, I got a list of them, of just how white people or whiteness impacts the daily experience of folks. When it's people that you really care about and have a true feeling for, it just baffles you that shit...Like, fuck. Then, it's just like, it connects dots. When you hear it enough times, you start to realize, like, damn. Common's saying, "I was told to act my?" What'd he say? I was told to act my age, not my color. Color, yeah. I was always told to act my age, not my color.

This moment of realization provided him with a deeper understanding that his experiences with people of color as a White male was very different than other White people he has engaged with. "It's just wild to think about how cats have to deal with other people's perception of a person based on their color." The phrase "act my age not my color" was popularized by Lisa Delpit in her book, Multiplication is for White People. She discusses how if African Americans fail to acknowledge and recognize their ability to learn and to be successful, then they would continue to carry on the stereotypical views that they are damaged goods and cannot be expected to succeed (Delpit, 2012). Delpit challenges teachers to understand their own roots to help them better understand the children in their classroom. By doing this, it centers their students' experiences while pushing their assumptions and biases to the peripheries of the classroom space.

In Common's song, “Book of Life”, he raps: 
I may not be the darkest, brother

But I was always told to act my age, not my color

Not knowing that my color, was out of the original

So now I sing the new negro spiritual

It goes, get up, stand up

Stand up for your rights

Get up, stand up

Don't give up the fight

It's like, how can you understand the pain

When you never had to stand under the rain?

When it rains, it pours

And it about to come down hard, thank God

I found you.

There is a danger when White educators use the mindset of colorblindness and meritocracy

because it dismisses the realities, lived experiences, and knowledge that students of color bring into the educational spaces. Freas adds to this realization and promptly shares, "Because when you get further in the scholarship around [whiteness], we begin to notice how often we as white folks just do the dumbest shit. Our defaults are always so blind to our natural moves and then are baffled why folks of color don't respond in a positive way."

In addition to his role as an EOPS Counselor at Sacramento City College, he also serves in the role of Faculty Equity Coordinator where he engages in work around the impact of Hip Hop-based education on privilege, identity, and the countering of whiteness in higher education. He adds to how whiteness plays out even when institutions are addressing equity gaps in higher education:

A simple thing, like, I was just in a meeting, and they were talking about "We need to have an emphasis on global climate issues on the campus. That should be our theme for our next convocation," kind of thing. Okay. I'm already thinking about speakers. Pop, pop, pop. [And they say] hey, check out this video of Greta, the little girl. [Folks be] like, "Okay." We've been doing this for years, but we do these workshops. We do things on campus. [But] nobody shows up. I'm like, "Well, let's look at your whole list. So far, you got all white people that you just showed up with. Was that intentional? Tell me about that." You know what I'm saying? 
Freas brings up what can be commonly phrased as just "checking off the box." Whether it's addressing diversity, equity, social justice, or inclusion topics, the intentionality by which it is facilitated and operationalized has to be examined and interrogated. Otherwise, equity events and workshops without deep self-reflection are merely just activities. You can feel Freas frustration emanating as he continues to share further:

That's their norm. These are people that are showing up, like, yeah, equity is super important. I really care about my Black and Brown students. Those come out of their mouth right before or after they just ran off a list of all these White people that are going to come in and tell us about climate change and validate that. I was like, "we decided to play the video of this girl." I was like, "Man, I felt like there were some native voices telling this exact same issue." I mean, can we run a Standing Rock video or something? But that's the one that you are going to champion to show and get us going, right?

Even when institutions are engaging in work around addressing equity gaps, there is a need to counter whiteness; to engage in more reflection and reflexivity, in order to include the voices and experiences of those who have been historically silenced and invisible. Freas acknowledges his positionality clearly in the context of the overall equity work that has been happening at his college:

That shit, I would notice those kinds of things throughout my life, just being in the spaces that I am in. There's not a singular kind of thing to say, because I grew up in a black neighborhood, that I'm more anti-racist than anybody else. Nah, nah. That ain't even it. I was lucky enough to be exposed to experiences and perspectives by friends and folks that I've just, spaces that I've felt comfortable in, that I think has prompted me to look at it a little more critical than the average white person. It just pushed me further to do the work, not that I'm anywhere further than anybody else.

\section{REMIX IS IN MY DNA}

Mad Libs is a phrasal template word game where you create stories, often comical and nonsensical, by entering words in the blank spaces. It was one of those childhood memories

Freas and I both commonly shared. Freas excitedly elaborates:

I used to smash Mad Libs. I used to come up with the most off-the-wall, like, that was, to me, the exciting part, is come up with the most extreme, probably the most weirdest shit 
that I can imagine. I'm like, "Ma, look at this." She probably like, "Boy, you need some help." I'm definitely like, what's next? I'm always on the beyond. I'm always like I'm not the trees. I'm looking at the forest. I'm looking at the bigger thing.

This idea of thinking beyond or reflecting on what's next has always been a part of his identity. Mad Libs really resonated with him because he created and recreated stories that elicit different responses and experiences. Growing up at a young age, Freas would sing along to music and ask, "What if we sang it this way, and in this direction, or added this note, and sang it a little differently? The remix has always been in my DNA."

However, in school, those moments that sparked his creativity and interests were very few in between. In speaking about a Sociology class he took, Freas reflected:

I loved that class. It wasn't even really about the professor, just the topic. I was excited to come back and talk about stuff. It was never anything that hit me enough to make me want to remix it. I don't want to remix bullshit. I want to remix shit that I'm inspired by, you know what I'm saying?

For Freas, school was not inspiring to him at that time and would describe it as "a wack joint." Education didn't hit him like a classic Hip Hop song where he would "absorb it, appreciate it, and live in it." Freas lived and breathed Hip Hop and while he was struggling to figure out what he was going to do after he obtained his Bachelor's degree from Sacramento State University, he knew Hip Hop would be there to guide him as it has done many times before. He expressed, "Alright, you got this far. Go ahead, keep on moving."

Sacramento State University had these listening rooms called the Terminal Lounge where students can hang out and listen to music, watch music videos, and play board games. Freas remembers his time working there:

They had these rooms, with beanbags or whatever. You control the light, the volume. Then, the attendant has, at that time, had CD players. We had a whole catalog of stuff, or you could bring in your own joint, and you'd be like, "Hey, you guys got that new Tribe? Yeah, put that on," and then, I'd just put it on. They'd get to hang out in a room for the whole album. They could study. They can take a nap. They could just bug out, chill. 
While working in this space, he was working with a co-worker who happened to have a Hip Hop

band. His co-worker's band needed a keyboard player and Freas recommended his

roommate. Through planned happenstance and the love for Hip Hop, the universe

aligned. Freas retells:

I was now fully in the band, at this point. We was rocking, doing recording, into it, MCing, in the culture, on top of the fact that the cat I would connect with at work, who was the bass player, this cat was part of the Zulu Nation chapter in Sac. They were already doing all kinds of other shit. We were doing, like, we did a Free Mumia rally on the capitol steps, like Hip Hop for Mumia. We was doing some real righteous shit, looking back on it.

There was this energy that you can sense from Freas as he is telling this story. These Hip Hop experiences are creating spaces of knowledge production where students like Freas were able to develop their own critical consciousness and share their own stories. Freas nodded in agreement and replied, "School was like, yeah, I can get you done, but you're not going to get my true heart and energy in it."

Freas began to pursue creating new experiences through Hip Hop at Sacramento State University. In hindsight, this is his first foray into remixing his own education, creating experiences that would teach him more about building community and understanding self than many of the classes he attended. He takes us through memory lane:

We started hosting B-Boy jams on the campus. We created a Hip Hop club, just to get access to the facilities. How do you get a room? Well, you can pay for it, or if you got a club, you can get it for free. Okay, cool. Beats, Rhymes, and Culture. Boom. We got a club. Free room. We was doing B-Boy jams. We was bringing out BAM, brought out Grand Wizard Theodore. We brought out some legends. Yeah. We was doing some things, using our academic keys to bring the community in, which was, I mean, when you do it, you just do it. You ain't thinking about, like, wow, we're a power in the community, and we're bringing Hip Hop to the campus. We're like, nah, fuck that. We're just using this space because we want to go out and do some dope shit. 
Hip Hop events at educational institutions were primarily intended to provide space for students to engage in self-expression and build community with each other. These Hip Hop events were often student-led and research has shown that students view Hip Hop spaces and organizations on campus as important to their engagement on campus (Petchauer, 2010).

As Hip Hop educational events have become increasingly common in educational spaces such as Rock The School Bells at Skyline College and various community colleges, the Hip Hop Ed Conference at Columbia University, and the Show and Prove Conference at UC Riverside, Sulé (2016) suggests that Hip Hop should be seen as a cultural artifact in higher education through the lens of its therapeutic function. The B-boy jams are dance battles that are structured where participants compete against each other to outmaneuver each other through a combination of dance moves. Dance has been commonly seen as a practice of self-care. These spaces provided participants with means to express themselves, to build community, and in some cases, collectively heal.

In addition, Petchauer (2010) also adds that faculty should pay more attention to these events as they may inform them about the lived experiences of their students not just as observers but as institutional agents who can address students' needs in more meaningful and intentional ways. Freas, like many students, is part of student-led movements across the nation that placed Hip Hop's value prominently in the center of higher education. This understanding of Hip Hop and its impact on education would become clearer for Freas during his short, but impactful tenure in the Windy City of Chicago.

\section{DROPPING G.E.M.S.}

The wind is howling through the blistering thin air of Chicago. It's hitting your face like a hundred sharp icicles poking at your lips. Specks of snow sit atop your beanie, eyelashes, and 
any facial hair you may have. You can hear the snow crunching underneath your black Timberland boots as you walk on the snow-covered sidewalks. Your earphones are blasting the very best of Chicago's Hip Hop while simultaneously serving as your earmuffs. You inhale the cold air slowly and exhale in a gust of white, smoky, and frigid air. This is a typical day in the city of Chicago. Chicago is no joke when it comes to the winter. I lived there for about four years while my Pops was stationed at one of the instructional centers in North Chicago when he was part of the U.S. Navy. Freas, who lived in Florida and California for most of his life, quickly found out how unforgiving Chicago's winter can be for people who can't stand the cold. Freas vividly recalls his first winter in Chicago. Shaking his head slightly, he shares:

When I walked into this building, one day, at the school, one of the schools I was working at in Chicago, on the west side, it's fucking snowing and all that shit. I walk in. Custodians are like, "Hey, Cali, what's up? You're lucky, man, it's a light winter." Bruh, it's 15 below zero outside. Do not tell me that shit. I'm out of here, man. Out of here.

Upon receiving his Bachelor's degree in Communications at Sacramento State University, Freas was trying to figure things out. He wasn't trying to work at Enterprise or Hertz. He found a job listing in Chicago looking for former college athletes to work for the AmeriCorps. Freas chuckles and recalls, "Yeah, I played a year of ball. Will I still qualify, right? They're like, yeah, yeah. I think it came down to like, yeah, we need bodies, bro. You did intramurals? You're in, dog." We both laughed out loud. Nevertheless, Freas decided that a change in scenery would work for him. What would Hip Hop say to him? "Gotta keep it moving." He joined the AmeriCorps, which is a network of national service programs that provide opportunities for members to commit their time and service to address critical community needs such as increasing academic achievement, mentoring youth, and fighting poverty.

Moving to a whole new city meant that he would have the opportunity to immerse himself in the Chicago Hip Hop scene. Prior to the drill scene, a popular Chicago Hip Hop style 
today inspired by Southern rap, Chicago is well known for its jazz and soul- based sampling and conscious lyricism with its influences initially from the East Coast. Artists such as Common, Kanye West, and Lupe Fiasco helped put Chicago on the map. While there were East Coast influences, you cannot deny the West Coast influence on rappers such as Twista, Do or Die, and Crucial Conflict, where rapping in double or triple time over the heavy, funky, synth-driven beats were undeniable. The Chicago Hip Hop scene had something for everybody. Freas kept his writing game up and was getting connected with folks in Hip Hop in Chicago. However, his experience at the school he had worked at through AmeriCorps really changed the game of education for him. Freas dives in and reflects:

A big piece of like, I would always be traveling spaces, checking out Hip Hop shows out there, and trying to, I don't know if I connected with a bunch of the local cats, but that part, I think I started cultivating more of my understanding or investment in education, like the different spaces I was working in out there, and seeing the impact of that.

He continues to share about his experiences working with youth in the public schools and how these experiences became the impactful education he was lacking in his own educational journey. Freas' face lights up as recalls these pivotal experiences:

I realized I'd be more empowered by the youth, and then, reflecting back, like your question, was there an educator that motivated you or empowered you? It's like, nah, but now, I reflect on my friends and other students. They were more empowering, more guiding to me. I'd learn so much more from them. I'd learn the ins and outs of the system and space by the peer, colleagues, and supervisors, or whatever, like this is where this happens, or this is how we used to do it, or whatever. The real game is from the students. I think that was just a continuation of how I navigated spaces.

How we learn about navigating spaces is about understanding the norms and expectations of those spaces. I remembered a friend sharing a story about going to his local barber shop. He entered the barber shop and looked around. He saw all but one chair being occupied by customers. He locked eyes with one of the barbers who was cutting another customer's hair. They both gave each other a head nod and the barber put up one finger. My friend 
mouthed, "One hour?" His barber nodded in agreement and my friend sat down and picked up one of the magazines. Another customer came in and yelled, "Are there any appointments?" Everyone turned their attention to this new customer and within seconds, went about their business seemingly ignoring him. The customer was confused. He spotted the barber at the end of the room sweeping the floor and noticed that there was an empty chair. He walked up to the barber and asked if he was free. The barber put his broom down and proceeded to get the new customer in the chair. Then, the whole room started laughing. The customer was bewildered, and the barber told him, "Don't pay them no mind. They're just messing around." My friend was able to navigate the space because he understood the discourse that came from this barber shop. He has been going to this barber shop for years and adapted to the culture of the space. Without even uttering a word, he was able to communicate with his barber about getting a haircut. He also shared the reason why the whole shop was laughing. He said, "You never want to get your hair cut by someone who has an empty chair. It's usually empty for a reason." We both shared a good laugh because there was definitely some truth to that.

While this was an example of a space where understanding norms and expectations are important, Freas also cautions us that norming to the space, especially in higher education, can be problematic. He adds, "You start to get into this routine of autopilot as an educator. The students will pop you out of that shit, if you're really rocking with them." This statement was important because there was a condition - "if you're really rocking with them." Students can push back, resist, or even not show up when they feel that educational spaces are not representing their lived experiences. Many educators respond in various ways; while some don't respond at all. When students' needs are not being responded to, students begin to feel silenced and invisible. These exclusionary practices begin to have a direct impact on students' self- 
esteem and their ability to engage throughout the campus (Nadal, Wong, Griffin, Davidoff, \&

Sriken, 2014; Museus \& Quaye, 2009). Freas vividly remembers a profound moment that left

him speechless:

I remember one day [at] one of the schools, that west side school I was working with, all the kids in my little tutoring session, all the kids in there were Puerto Rican and Mexican, and maybe a few Black kids, but it was like no White kids. These cats came up to me and said, "Mr. Freas, we got a question. Are you Puerto Rican or white?" I said, "Really? Why are you asking that?" He said, "Well, we got a poll going between a group of us. Some of us think you're Puerto Rican, and some of us think you're White. We want to know what it is."

Freas motioned both his hands in front of him to emphasize the point. That question left him in disbelief and then transformed later on into this moment of realization. He expressed:

It was like, because the only white people that come to our neighborhood are police. I was like, damn. I mean, you want a gem dropped on your ass? Bow. There you go. They just like, "Yo, check this out. I got a question. Here. Take that gem with you while you got it."

These kids were dropping gems. Gems are knowledge acquired by lived experiences. Freas became a part of his students' realities. Their questions allowed them to create new knowledge that not all White people are police officers. Rendón (2009) discusses the value of the individual's quest for knowledge through means of acknowledging the importance of dialogue and the shared construction of meaning. This blending and construction of knowledge has the elements of Hip Hop by way of sampling. This moment provided Freas with a deeper sense of purpose. He continues to share:

That shit just sat with me, like it blew my mind. It was moments like that when you really see the, I guess, you really feel it, versus you can read about it, you can talk about, like, "Okay, if you're going to be working in these spaces, you're going to really impact these students." Okay, I get that. You ain't telling me nothing brand new. When students peel that layer back for you, you get a true sense of what that means. That was my springboard into the educational trajectory. 
As an emcee, there's nothing more exciting than dropping bars that gets the crowd all excited. There's something about that energy that feeds your soul. With Hip Hop continuously flowing through his veins, these educational experiences began to add new nourishment to his soul. With a breath of fresh air, Freas added:

That was kind of the continued trajectory of my, now, amplification or even investment in education and seeing something I really want to be in. That's the want to remix shit, and do extracurricular stuff, and be passionate about things. Yeah. I mean, it was a blend of now finding a topic that spoke to my own, and challenged me around issues that I needed, but then also, find a community. Again, continuing to learn more from my peers, the other students.

This is the beginning of the remix in education. With his lived experiences and knowledge he had acquired in school, there was a sense of harmony that was manifesting. He was able to blend what he loves in Hip Hop into a new passion in education. What made this even more beautiful and inspiring was this was the result of youth and students dropping gems on him. As youth today would say, "IYKYK. If you know, you know." Freas, as a true emcee, keeps his ears open to the pavement because gems are being dropped and gems are about "growing and enriching minds through stories." For Freas, that was the game changer.

\section{FUCK THE BULLSHIT, GET DOWN WITH THE REAL REAL}

In the 2012 documentary, The Art of Rap: Something from Nothing, Grand Master Caz stated, “Hip Hop didn’t invent anything. Hip Hop reinvented everything." Hip Hop pedagogy, developed from the field of critical pedagogy, is utilized in educational spaces to validate and challenge norms and expectations that define and inform students' experiences. The act of inventing and reinventing is inherently Hip Hop and Freas saw the community colleges as a place and space to drop the remix on teaching and counseling. Freas reflects about his choice in working at community colleges as opposed to four-year universities: 
I think at that point I realized I wanted to have an impact, and I saw out of the gate community colleges were a space, and at least how I saw it, even though it might have not been designed that way, as a space that basically anybody could show up and change the trajectory of whatever the hell they're dealing with. It's open access, right? And I'm like, "Man, that's where I need to be." Universities are cool. I had some great experiences in universities in different ways, shapes, and forms. But that community college space, there's something about that, right? That space, anybody can come in there, right? And the populations were going to be more, well, depending on your campus, would be more an alignment of kind of the worlds that I was hoping to be a part of and helping shape.

Drawing from his own experiences, he knew that community colleges were always going to be there no matter what. However, what happens at the community colleges plays a huge part in creating a sense of belonging and engagement for students. Freas gravitated towards college counseling because he saw the immense value in developing strong and authentic relationships with students. He delved in deeper and shared:

I realized I don't do well with the bullshit talk. I don't like the fluff talk and just talking to people just to like if you meet the president of a campus, asking them about their golf game and shit like, ah, that ain't my thing. But that real talk, that, I resonate with, and I really being entrenched in somebody's authentic self, that, to me, the counseling piece really activated that part that was already me.

For many students of color, asking for help or seeking support services can be extremely difficult especially if their prior experiences were negative (Mitchell \& Rosiek, 2005). Students can sniff the "bullshit" especially if institutional agents are seen as inauthentic or untrustworthy (Lee, 2018). Culturally responsive advising and counseling requires us to operate from our authentic selves especially if we are asking our students to do the same. Freas expresses the importance of providing spaces of affirmation and validation:

And so counseling allowed me to help to activate that more, that side of me more that say, "Yeah, this is a place where you can allow people to engage." You can help engage folks to want to access that authentic self and then honor it, right, because the space, much like I was learning from the students, the space doesn't honor it. And so if I ask them to tap into it and see the beauty in it, I got to also work on how this space welcomes and affirms and values that authentic voice that they pull up, or that maybe they already showed with it, which is dope. 
The counseling spaces are where some of Freas' critiques come into play. While culturally responsive and transformative counseling is necessary to help close equity gaps in education, he acknowledges that traditional forms of counseling still serve as the dominant form. These traditional methods can be seen as "good intentions" but it doesn't address the whiteness that permeates the methods within college counseling. Freas shares his critique specifically within the context of physical space:

And so that, they created all kinds of new, man, how do I remix this shit, that innate thing, right, and that Hip Hop in me is like, yo, any space I go into, like, "Naw, man. This place is bullshit." Man, we can have some beats going. Visually the shit looks wack. I wouldn't want to be here.

Freas engages once again through the idea of the remix. How might we transform the students' counseling experiences by transforming the physical space? Mitchell, Wood, and Witherspoon (2010) suggests that the counseling spaces are examples of reified racial spaces where there are significant material and psychological consequences in the ways students of color experience schooling within the context of counseling.

The Vision for Success for the California Community Colleges (2020) emphasizes that all community colleges will make sure that students from all backgrounds succeed in reaching their educational goals and improving their families and communities. The goals of this vision include: increase the numbers of students transferring to a University of California (UC) or California State University (CSU); increasing the numbers of students earning degrees and certificates; and reducing the number of unnecessary units many students are taking to get their degree and transfer. The framework for achieving the goals of the Visions for Success is Guided Pathways.

While educators are deeply committed in making sure the goals are met, it is equally important to assess and evaluate how we are going to accomplish these goals. Part of this 
assessment is also critiquing current systems, policies, and practices that are contributing to the equity gaps in education. Freas adds to the conversation:

It's like, how not only just we teach, but how they experience and then always because the students have always taught me, I'm always on the critique of us versus critique of them. That's the biggest thing. There's such a natural thing the further I get into education of measuring students, judging students, critiquing students, making remarks about students. Rarely is it looking at us, measuring us, evaluating us, critiquing us. If it is, that's shit does a quick pivot right back to the students, right?

Freas sees immense value in utilizing the framework of Hip Hop within a broader system such as examining institutional structures and systems that negatively impacts traditionally marginalized and minoritized students. It also serves as a cultural framing; a means of checks and balances. Freas embellishes further:

And so that's where I think I've really, really found my groove in the space is that it's a space that's constantly in need of a remix. They keep dropping wack music. And I got to remix that. I got to keep remixing the space and finding the dope producers on campus to help the remix, right? Wherever I went, Hip Hop came with me. Any pivot I made, Hip Hop was part of that equation. It was always able to, whether it was a network, whether it was the cultural kind of framing, whether it was the music, whether it was the community, always offered a guide, a link, some insight in any move I made, right?

The "dope producers" Freas is referring to are the people in educational spaces who are about reimagining and remixing the ways we serve and assist our students. Education, as described by Freas, has been a "wack joint" for many years. But to be able to move and change systems, it takes a community of folks. It takes a movement to turn a "wack joint" into a classic hit song. P Diddy once said when asked about working with the late Notorious BIG, "I am not in the music industry just to produce music for just today. I want to produce music that's going to outlive me; that will have a lasting impact." Freas talks about the importance of connecting with folks who are down to do the work. He leans forward and expresses emotionally:

I think there was a natural piece about just who I am that's like, all right, I love the authentic narratives, and moments, and conversations, and the authentic; the worth of any individual. But then it's Hip Hop, there's, "Nah, fuck the bullshit." It helps cultivate that 
part of who I already was to help activate it in a way to say, "Nah, don't waste time on the bullshit. Get down with the real. Get down to the authentic, the thing that's really going to connect with folks" All right? No time for fools. No time for the wack. What's the real work? And so when you get in that space and you identify people, not even just Hip Hop. You also identify the folks that are about that work much faster, right?

Freas acknowledges that working to remix the way we serve our students can be challenging and that it can feel like "you're a single push." But when you begin to identify with colleagues who draw energies from Hip Hop culture, even if it starts with a small group, it begins to become a space of solace, a space of refueling, and a space of care. He adds, "And not just self-care, but community care, right, that recharges you and helps you, and reaffirms what you do." This is extremely important for Freas because the work to dismantle educational frameworks rooted in white supremacy and other forms of dominant ideologies, can be a very insurmountable and daunting task. It can feel like a lonely path. He shares, "But unless you've got something else that you can anchor yourself in to help weather the storm and push through to find the purpose of what you're hoping to do, you might get lost in that shit." Hip Hop is about firmly placing your flag into the ground and letting folks know that this is where you're at. Hip Hop provided Freas the voice and presence that said, "Fuck the bullshit, let's get down with the real, real."

\section{STEEL SHARPENS STEEL}

Understanding ways to increase student success in higher education has been an ongoing discussion for many decades. There are hundreds of conferences, workshops, and professional development opportunities around the world that are geared towards addressing different segments of student success such as retention strategies, classroom pedagogies, mental health awareness, learning communities, usage of technology, and counseling practices. I have had the privilege to be able to attend numerous conferences nationwide and learn from many scholars and experts in higher education. 
While sharing the work around Hip Hop education in various conferences can be exciting and liberating, it also can be a very difficult and frustrating experience especially when engaging with educators who do not necessarily identify with Hip Hop culture. There are also others who understand Hip Hop culture but have a very limited and narrow understanding of how Hip Hop can be utilized in educational spaces. Freas shares a common example where he attended a meeting where other educators were interested in how he utilized Hip Hop in his college success class. As Freas shares this example, he changes his voice to emulate the voice of another person:

So we introduced the class, teaching this class, a college success class with a Hip Hop cultural emphasis. Even in support where folks are like, "Ah, yeah, that sounds interesting. So maybe at the next meeting, you could tell us more about it, right?" And we get to that meeting, they're like, "Are we going to be like, rapping the syllabus?" Or they'll be like, "Is it going to be a dance-off?"

This view of Hip Hop pedagogy is very commonly made as it highlights the performative aspect of Hip Hop but dismisses the aesthetics that make up Hip Hop pedagogy. One of these aesthetics centers around this notion of "keeping it real" and authenticity. Freas elaborates further:

And so I think the one piece, and I think it might be an era thing in the 90s, but I think because it was a prominent component of the era of like some authentic, keeping it real shit. And not that that component isn't still part of today's culture in some way, but because it was such a prominent flag of the '90s, that being authentic in itself is part of that pedagogy, right?

In reflecting back at that meeting around how to utilize Hip Hop pedagogy in college success classes, Freas expresses the importance of authenticity even if you do not identify with Hip Hop culture. He adds:

You ain't got to be a head to do that. You don't have to be a Hip Hop cat to do that. And that's the thing I try to offer to colleagues. It was like, "Yo, here." Like, "Oh, I'd love to do something like you're doing." I'm like, "You should do it." "But I don't do it." Perfect. Be authentic about that. Say it up front. 
Freas is open to colleagues utilizing Hip Hop pedagogy in their practice just as long as they are authentic and genuine. Hip Hop is about keeping it real and being authentic. Not all counselors can identify with Hip Hop but most of them can identify with authenticity.

There is also a growing tension within Hip Hop scholars and educators in terms of who can practice Hip Hop pedagogy in the classroom and within counseling. On the one hand, you have folks argue that the practice must be strictly within the arms of those who truly identify with or practice in Hip Hop culture. However, on the other hand, others feel that the narrative of "keeping it real" can stifle the ability to disrupt the whiteness that dominates teacher and counselor education programs (Hall, 2017). If we truly want to lift up Hip Hop pedagogy as a counter and alternative to what's being practiced in higher education, then we need to integrate curriculum and pedagogical trainings at these teacher education and counseling programs. It cannot be overstated that those who are not of the culture can create problematic situations when their intentions in utilizing Hip Hop in their practices are inauthentic. However, if counselors', specifically those who don't initially identify with Hip Hop culture, intend to co-construct meaningful and intentional educational experiences with their students and they want to truly learn how to engage their students through Hip Hop pedagogy, who truly holds the power to prevent them from utilizing it?

Another aesthetic of Hip Hop pedagogy is this notion around sampling and blending counseling strategies and effective practices. Freas' voices begin to ramp up with excitement and expresses:

And so the pedagogy goes beyond just like when folks think about pedagogy, I think the natural reflection is about the actual unveiling of it, right? But before that, I think the cipher with colleagues where if you're lucky enough to be connected with other Hip Hop heads, whether they're counselors, instructors, there's a thing in Hip Hop, you know that steel sharpens steel shit, right? 
Hip Hop, by nature, has always been competitive. While each element of Hip Hop allows people to express themselves in their own creative and personal ways, it is also a way to let other people know who you are and what you represent. In Hip Hop, you always have to stay ready because someone is going to outperform, outdo, and outmaneuver you. If you win, you don't stay complacent. You're already thinking of your next move. If you lose, you reflect on what didn't work and build something new. Hip Hop is also about "being a student." You are constantly learning and adapting. This, too, is indicative in the ways we engage with other educators when it comes to Hip Hop pedagogy. It's about that "steel sharpens steel." It's about how we can continue to be better at our craft in counseling. Freas excitedly expands:

So if you come with some fire, I'm not just going to sit back and let that happen without trying to come with some fire too, right? And so it pushes back on that common, I think, approach of being on cruise control, right? Like, "Oh, I've been teaching this class for 10 years, so shit just goes." Right? But when you're around heads that are like, "Yo, I was thinking about doing this, like, "Man, I wouldn't even be on that shit. But, damn, this cat just pushed me."

This piece reminded me of our conversations between our different chapters of Rock The School Bells - Skyline College and Sacramento City College. We would attend each other's conferences to support but also to be inspired in the various ways we create and cultivate spaces that honors our youth and students through the elements of Hip Hop culture. There is this level of friendly competition that stems from Hip Hop culture. While both conferences achieve its goals in providing spaces for expression and the acquisition of tools to become agents of change and critical thinkers through Hip Hop, we're constantly finding ways to raise the bar and push the envelope of what educational spaces should feel like and look like. The beauty of this competition within Hip Hop education is that it is rooted in love and community. Freas jumps in and adds, "If you ain't got it, you're garbage. And, I mean, that carries on to the now. It's like, 
'Yo, Nate just dropped. Share this shit. KT just shared this shit. Yo, what am I doing?' Internally I'm now thinking, I got to get my game up."

Reflecting on Freas' earlier story about how his colleagues had this narrow view of how Hip Hop pedagogy is operationalized in a college success class, it reminded me of what my colleague would say when it comes to participants attending workshops, conferences, and other professional development opportunities. My colleague would express loudly and clearly, "People fetishized so much on the methods that they don't understand the why." How do you use Hip Hop in your counseling practices? To truly arrive at the answer, one must understand why Hip Hop should be utilized in counseling practices in the first place.

A crucial and critical part of pushing each other to refine and sharpen our counseling practices is the engagement within the cipher. Before any unveiling of counseling strategies and effective practices, the cipher has to take place. The cipher can be seen as the "meeting of the minds." It is a conversation that engages in reflection and reflexivity. Drawing from Freas' innate need to remix, the cipher is a process that fuels and sustains him. It pushes him to be better. Freas motioning his hands before him like an emcee adds:

Because I know these cats are dope and they're coming with some more cards on the table, like some new shit, it's pushing me, right? But it's also a call like, "Yo, [you all], get that." And what's your response? How are you going to come back? You going to just take it and then copy it? Right? I was just listening to an interview of Rakim. He was like, "Yeah, you know, when cats bite my style, I kind of take it as like I've done something right because they want to emulate it." They want to emulate it. But if you're a head, you can't settle for that shit, right? Not that we can't share resources, because you might be like, "Yo, I do this." I'm like, "Man, that's dope. I'm going to take it, but I'm going to flip it."

Freas summarizes what he identifies as essential components to Hip Hop pedagogy - the cipher, competition, and the call and response. Each component requires critical conversations that critiques and interrogates the dominant narrative and status quo. These are the aesthetics that 
make up Hip Hop pedagogy. It moves beyond what people see and experience on the surface. When educators begin to understand that it's more than just reciting rap lyrics or playing music videos, then they can begin to envision Hip Hop's value and application in the counseling profession. Freas reflected back to how he communicates with educators who are non-Hip Hop heads:

Yo, take it. But understand it and experience it through your authentic self. Of course this one-size-fits-all shit doesn't work. Hip Hop doesn't work that way. There's a format that you could look at, be like, "Oh, that's how DJ Premier is doing it? All right. I'm going to take this and flip it, but I'm going to do the scratches differently, or I'm going to do sample drops without a scratch.

When Hip Hop pedagogy infiltrates into the scholarship of college counseling, Freas reminds us that your authentic self has to drive everything that happens. He elaborates further, "You can't be faking the funk, number one. Two, if you're authentic in it, then you're going beyond you, meaning you're tapping into the authentic sources that are in the culture." This is a very profound moment because to be Hip Hop doesn't necessarily mean that you have to be a practitioner of Hip Hop, meaning that you engage in at least one of the elements of Hip Hop. What this potentially suggests is that to be Hip Hop is to be your authentic self and that your authentic self can be drawn from the energies and culture you come from. That is Hip Hop. The aesthetic of Hip Hop by which this happens is through this idea of sampling. Freas adjusts himself in his seat and descriptively shares:

So this is back to the sampling piece, right? Folks that are jazz heads be like, "Ah, what's this rap shit that is taking samples? They're not even musicians. They're just taking a song and then putting it on its head." Nah, samplers are doing that shit and chopping it up to where you don't even know. If you're dope, you're sampling from what you've got this whole crate in the room. The room is a crate of records, dog. You got to pull from that crate. And the dope shit is you don't have a random crate. You got a crate with the fucking gems in it. You got the fucking Roy Ayers in there. You got the JBs in there. You got the Grover Washington Jr. Joints. You got the obscure Brother Sly Family Stone unreleased joint. You got some random weirdness, bangers that become cultural standards, right, that lives in your crate. 
This is a powerful description of what college counseling looks and feels like when engaged in Hip Hop pedagogy. The random crates refers to the different approaches and theories that are related to student development. One theory doesn't fit all students. Hip Hop is about taking samples from various theories and pedagogies that would address the different needs our students come in with. Hip Hop forces us to look at student success differently, far beyond just completion rates and GPAs. Hip Hop also holds us accountable to be knowledgeable about our students because each student has gems of their own. How do we create a counseling experience that allows us to acknowledge their wisdom and knowledge that they bring into the counseling space? The most valuable component of sampling is that you have to have a deep understanding of the music to be able to blend and remix to create new classics. Freas concludes his thoughts emphatically:

The challenge is who's the cat, who's dope enough to take that crate and flip it to where it's now become a classic, classic meaning not your colleagues coming back to be like, "Yo, that class you're teaching, man, it's fire." Nah, it's the students that leave with that shit feeling like my voice was up. I was heard. I was used as part of the track." That's Hip Hop pedagogy because it takes what it has and makes something out of it. That's what it is. That's the root of it. You are taking what you got. You don't need nothing else. You got the dopest shit right here. And you're going to flip it into something that folks have never heard.

Hip Hop as a culture is constantly evolving the same way that the educational landscape is evolving. In Hip Hop, there’s a saying that goes, “A hit song today ain’t a hit song tomorrow." Staying relevant can be a challenge because you have to be in tune with what's going on in the world. However, when engaged within a Hip Hop mindset, you're going to find a way, keep it moving, create a remix, and always stay ready. As educators, if we are going to engage in transformative change and address equity gaps in education, it is absolutely necessary to stay fresh and relevant. 


\section{SYNONYM OF DOPE}

Transported back to Freas' classroom, I followed the hypnotic beats of Little Brother all the way to DJ Mic B. DJ Mic B had on this black Kangol with a blue t-shirt with Grandmaster Caz’s quote, “Hip Hop didn’t invent anything. Hip Hop reinvented everything.” Behind him, there was a white paper taped on the white board. Like all of the other white pieces of paper that were taped, the heading read, "Synonym of Dope." Underneath this heading was a rap verse from Little Brother:

Every now and then I gotta ask myself

Do you really want to win or just look good losing?

Students began to gather around him to engage in a conversational cypher that reflected their own understanding of the quote. One student yelled, "It's about priorities!" Another student walked up with diamond-studded earrings shining bright and said, "I ain't about that losing. I always win, win, win." The whole group laughed out loud and they all recited, "Win, win, win!"

I started to make my way around the classroom where groups of students were congregating next to other pieces of white paper. Each piece of paper had a different prompt. The prompts were: What is one thing that someone else would say is fresh about you? What is one thing that someone else would say is fly about you? What needs to happen for you today for the day to be considered a success? Share one thing you are doing today that contributes to your happiness. Students began to write their responses on a large, white butcher paper next to the assigned prompts. I remember watching a girl with her long black hair with burgundy tips, slowly and somewhat painfully writing her response to the prompt of what success looked like for her today. When she walked away, her response tugged my heart and soul. She wrote, "hopefully to find a reliable car." Two lines above her response, someone 
wrote, "having something to eat today." Many of the responses displayed so much courage and vulnerability. While pain and struggles were often shared, there were also opportunities for them to shine. They were able to express themselves in ways that they define as fresh and fly. Some of the responses included: my wisdom, my memes, my sense of humor, and my patience. I really appreciated watching them share about themselves and their experiences. However, it made me wonder where this concept of "synonym of dope" came from.

Freas later provided more context around how this activity was created. He shared:

In discussing success, I wanted to engage students around the language they use in high frequency to acknowledge and to celebrate. This topic was preceded by a discussion around the importance of their cultural capital and the knowledge assets they currently hold. Part of this was explored through affirming that language used at home or with the crew, which should be as important as any new terminology they may gain in their experience in college. So, in attempt to model the words I use for acknowledging celebration, I gave the example of "dope", a term I grew up using in various stages of being a head, and offering different ways I implement the word "dope."

Students often find it difficult to navigate educational systems when their culture is not aligned with that of the institution. How students present themselves at home and in their community may counter the educational discourses of what it means to be a college student. Students begin to lose their sense of self and may impact their ability to experience a sense of belonging. By honoring and acknowledging their wisdom and lived experiences, Freas is helping students to understand how knowledge, power, and authority can be redefined in this classroom.

Because the word "dope" was a word that Freas would traditionally use to acknowledge praise and celebration, he asked the class what are their synonyms of "dope". They responded with words such as fly, fresh, success, happiness, and motivation. At that moment, my mind exploded and I began to put the pieces together in terms of the activity. The context provided me with so much clarity and I started to experience this "steel sharpens steel" moment. My thoughts were racing and brainstorming ways I can adapt this activity. Freas created a classroom space 
where he engaged his class in collective sharing where he was able to acknowledge the importance of their language in an educational space that historically dismisses it. He eloquently adds:

This collective sharing, which is being invited through the use of their own claimed language, can serve as a mental health check in, a recharge or realignment towards the celebration of their worth, an invitation to the now, and the opportunity for students to see they are not alone.

I remember one student clearly not because she had this bright yellow top but because she was staring at the responses on the paper. She stood there long enough for me to notice since many of the students would write their responses and move on. She stood there with her crossed arms, motionless. I knew I had to approach her. I stood next to her and asked, "What are your thoughts about the responses you're reading?" She took a deep breath and she replied, "People be keeping it real. I thought my life was hard but some people are really going through it. It definitely puts things into perspective."

While many students experience classes as passive recipients of information, Hip Hop pedagogical approaches engage students in critical thought and active participation. Learning should be an emotional process because when you feel something, you begin to build your thoughts around it. I recently saw a post on Instagram of a colleague who said, "The best thing you can ask a student is: What do you think?" Freas created a classroom experience where students felt like they belong; that their thoughts and experiences matter. He utilized their language as part of their prompt questions. He has created safe and brave spaces where they can collectively share. He has co-constructed a class where it was positionless highlighting that students are teachers and teachers are students. His use of Hip Hop pedagogy moved the students from the periphery into the core like a dope emcee performing at a Hip Hop 
concert. And I thought to myself, "This is dope. 


\section{TRACK SIX \\ KEN "KT" TIMES}

\section{BELIEVE}

I cracked my window of my car to let in the cool breeze to keep me awake during this early morning commute to Sacramento as I am on my way to meet with Ken Times, also known as KT, for the first of two interviews. The traffic was flowing smoother than usual so I was making good time. I decided to take a detour and exited to stop by Safeway to pick up some flowers. I got to Safeway and walked through the sliding doors and saw the floral section immediately. There were vases of red and pink roses, pots of purple orchids, and a variety of packaged bouquet of flowers. I was never good at selecting the right flowers for the right occasion, so I stood there staring blankly at the flowers. I thought to myself, "What would Pops like?” He would say, "Don’t get me any flowers." I laughed to myself because that's exactly what he would say. But I was going to get some flowers anyways so if he had to choose, what would he pick? I was between the bright, yellow sunflowers and the bouquet of mini carnations that were red, purple, white, and yellow. When we lived in Virginia, we had sunflowers growing in our backyard. It was there since the previous owner but it was nice to see them growing and giving life to our backyard. But my Pops was also simple. He was the type of guy that would rather be in the background. He would think that those sunflowers are too much. So, I opted for the mini carnations. They were simple and small. It didn't draw too much attention; something I know my Pops preferred.

I placed the flowers in the front seat and played a little Beres Hammond to get my juices flowing. A few miles have passed, and I begin to see signs of Dixon, California. That was my going to be my quick pit stop before I make my way up to Sacramento. I exited Midway Avenue 
and turned right passing up a fruit stand that was selling apples, oranges, pears, and avocados. I headed straight down this two-lane road where on both sides of the road, you can see rows of fruit trees and bushes. I finally reached my destination as a huge concrete sign welcomed me that read: Sacramento Valley National Cemetery. I drove in and turned left on the roundabout and parked between flagpole \#5 and \#6. That was my landmark because that would lead me straight to my Pops. The cemetery early that morning was peaceful and serene. All you can hear were the birds chirping and the water fountain that was splashing in the background. The grass was filled with the morning dew. I popped my trunk and took out another pair of shoes because the ones I had on were some all-white Vans. I put on my other shoes, grabbed the flowers from the front seat, and went to the area where they stack of green, plastic flower holders and garden pruners. I took out the mini carnations and cut the stems short enough to fit in the plastic flower holder without tipping over.

I walked towards my Pops resting place. The tombstones were all of the same size and were arranged in perfect rows and columns so finding his tombstone can be somewhat challenging. It's been three years since he passed away but it still feels fresh like the flowers I'm holding and the morning dew I was standing on. I found his tombstone and it reads:

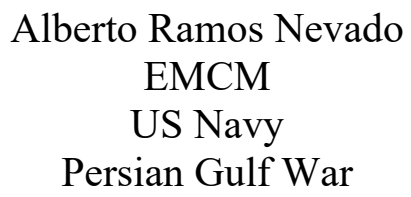

October 22, 1951 - September 25, 2016

I also noticed a penny and a dime on top of his tombstone. A penny symbolizes that someone passed by and a dime represents that they have served together in some capacity. The coins comforted me because it meant that he wasn't alone; that people were there to keep him company. I drove the flower holder's stake into the ground and positioned the flowers left of this 
tombstone. I told him about my son, Darius Jayden, and how much he was growing. I told him that DJ loved math like him. I told him about how I was almost finished with school and that it has been the hardest thing I've ever done in my life. School never came easy for me so there were times where I didn't believe I was capable of succeeding. After all of the academic struggles I've experienced in my life, it's hard to believe that I was actually going to get my doctorate. But my Pops always believed. In 1999, when I graduated with my Bachelor's degree in Psychology from San Francisco State University, he gave me a graduation card. He wrote on the envelope and addressed it to Dr. Nate Nevado. I still have that card with me to serve as a reminder that he'd always believed in me and that I should too. Twenty years later, that dream will come true for him. He always wanted a doctor in the family and soon enough, he will have his first.

Sometimes, you just need that one person to believe in you. That might be the one push you need to get you over the hump. This final semester is the most challenging so visiting him gave me the extra boost to keep going and keep grinding. This degree is not only for me; it's for my family, for my community, and for my students. Pops continues to remind me as I do with my students - believe strongly in others so they may believe in themselves.

\section{FRONT AND CENTER}

$\mathrm{KT}$ is this larger than life, gentle soul of a human being. He's an African American male in his early 50s that has the energy of our youth. Maybe it's the Hip Hop in his soul that keeps him fresh and active. There's an aura to his presence that comforts you when you share space with him. I arrived at his office where he coordinates the UMOJA Program. He gets up from behind his desk and we both clasps each other's hands and pull in for a "homie" hug. $\mathrm{He}$ suggested that we should meet somewhere else since students were constantly coming in to see 
him. He locked his office and we headed towards the library where he was going to try to secure a study room. We walked outside and I immediately felt the nice warm November breeze. It's the middle of the month and approaching winter and it's still warm in Sacramento. We walked to the library which was a building over from where his office was located. The library's entrance was grand as it stood on six pillars supporting these beautiful arches. The front was an architectural beauty. It reminded me of buildings you would see in Rome or Athens.

We entered the library and veered left to walk upstairs to the second floor. As we arrived on the floor, I immediately saw the featured collection of books. The title of the collection was "Rap and Hip Hop." There was an open book that sat on top of a wooden book holder. On the left side of the page was a black and white picture of the $\mathrm{Wu}$ Tang Clan and on the right side of the page was a quote by them that read, "All the Wu were street dudes living in the projects. We definitely came in crazy. We took the good things and the bad things and put it into a musical form. Some people live that same life. For those who haven't lived that life, they can live it through us." I was moved by that quote by the Wu Tang Clan because it was a reminder of how powerful Hip Hop songs are in terms of sharing narratives that were real and authentic. It gave those who have never experienced that life, a glimpse of what it was like living in Staten Island, New York. Rap is like poetry over beats. Situated around this open book were several other books that encapsulated Hip Hop from various lenses such as music, sociology, history, and literature. Titles included: Somebody Scream, The Message, Blowin' Up, Hip Hop America, The Rap Yearbook, Beats, Rhymes, \& Life; Raw, and Breaking Bread. The library chose to highlight rap and Hip Hop as the monthly exhibit because November is considered Hip Hop History Month. While many Hip Hop scholars and practitioners argue that the birth of Hip Hop happened in August 11, 1973 when DJ Kool Herc and his sister, Cindy Campbell, threw a Back 
to School Jam, other believe that Hip Hop culture was born on November 12, 1974, a year after the Universal Zulu Nation was formed and created by Afrika Bambaataa. Whether it is August or November, Hip Hop's place in history has been recognized nationally and globally.

I motioned towards KT with a head nod indicating to him that it was dope to see this collection front and center in a library where historically, Hip Hop has been in the background and in the periphery. KT reciprocated and hit me back with a head nod of his own. We walked through the aisles and finally made it to one of the study rooms that were tucked in the back. It was a small room with three chairs and a small circular table. Amidst in the room, the acoustics of the words and sounds reverberate against the walls. As KT takes his seat, I handed him the lapel mic to clip onto his grey short sleeve button shirt. I attached the end of the cord into my iPad and asked him if he was ready. He glided his hand over his scruffy chin and then leaned back in his chair. He takes a small breath in, positions himself front and center, and says, "Let's do this."

\section{MUSIC IS MY EXISTENCE}

KT was born and raised in Sacramento, California where he first lived in

Meadowview. However, it was at Greenhaven where his family solidified their roots after years of struggling and saving to move out of Meadowview. His mom was a nurse and his pops worked at McClellan Air Force Base as an electrician. He has a brother who is three years older than him. He remembered vividly that they were one of two African American families within a five or six block radius. It was during the mid to late 1970s, at the heels of the Civil Rights Movement and Black Panthers Movement, when they were living in Greenhaven at that time. KT wrote in a follow-up email:

Having lived in the neighborhood since kindergarten, of course I was entrenched. I made fast friends as a little kid with the other little kids at school. With friendships formed at 
this age - many of the biases that would later show up were not prevalent. These biases became prevalent as I grew. Kids started to reflect the views of their parents, families, friends, and groups, and conflicts emerged. I can remember not being welcomed in the houses of some of my friends - not being invited to some birthday parties.

On the other hand, KT mentioned the love that his family would receive from the families of other African American families in the neighborhood. With a glowing smile on his face, he mentioned, "There was a sense of kinship and protection. This was where the dynamics of my family life could show in complete safety in terms of language, food, music, and culture." Despite being one of the few African American families in the neighborhood and racial separations became more prevalent, KT's parents always made sure that Africa was in their lives. KT elaborated:

I mean, not explicitly, but we always had African pieces in our house. We always had books about Africa in our house. But pops wasn't like, "Oh, you need to read this, or you need to do that, or you need to do this." It was just always there.

He also recalls several African goods such as artwork, statues, shields, and clothing; some of which are also displayed in his current house. He shared about a wooden statue that stood about 4 feet tall holding a walking stick or spear; while his other arm was broken off of the statue. He added, "It was a statue that represented a standing African guard, masculinity, and perseverance. To be honest, I was scared of it for a long time. It always seemed as if it had more power in it than meets the eye." KT's words began to paint a visual of a bust of an African woman wearing a head wrap representing this aura of unpretentious magnificence. He was reminded of the scent of burned incense and the sounds of African drumbeats.

Then, KT lets out a hearty laugh as he recalls dinner conversations between his mom and pops who had their own stances when it came to politics. His mom was a staunch Martin Luther King, Jr. supporter while his pops vibed more with Malcolm X. Like a true Hip Hop head, he was able to draw inspiration and knowledge from both Black leaders. Education runs deep in his 
family as his grandmother was also an educator in a one-room school teaching kindergarten through 8th grade. His family would always implore that education is the key. KT's voice booms a little louder as if he's conjuring the words of his ancestral, spiritual guides:

To validate your struggle or to help support you in your struggle. Know how to express yourself in this lane even though you might live in this lane. That duality has been a constant, you know what I mean? So it's something that I've really learned to value today. When you work with students of African descent or you work with students of color there's something about the language that you use and the mannerisms that you show that let them know you're authentic and that you're not faking it. That you have some of what they have in them. You know what I mean?

Hip Hop pedagogy draws from culturally responsive and relevant practices where it places students at the center of learning and power within educational spaces (Gosa and Fields, 2012). It also moves the student's voice towards the center valuing the language and knowledge they bring into the space. Having knowledge of oneself and access to education was something he learned very early on from his family. It is very clear that family was such a monumental influence on KT especially within education. However, his family also impacted him in another way that would forever define his existence.

KT's mom was from Atwater, California, a small town in Merced County, that was situated along State Route 99. Looming over the town, you can see a huge water tower with the name, Atwater, scribed in all capital letters painted in black. Beyond that, very few people knew where Atwater was. KT reflects, "I always say Merced because not too many people heard of Atwater. That was country living. That's where my mom's family was from. So I was always there. Summer times I'd be there for a spell. Just raised around that. So I knew country." You can feel the warmth in the room as he's reflecting upon his upbringing. KT extends his arms and motions them back towards his heart and shares, "It brought me closer to my roots. That's where my elders were. So I could sit with my elders and learn about the family history." The area that 
KT's family settled in was essentially built by his family members. He draws upon this history that has been shared down to him by his mom. He wrote:

My grandmother lived in a house where her neighbors on both sides were her brother and sister - and their families. It was pretty simple living - many on that side of the family grew up in agriculture related jobs, working as migrant farmworkers or related work (trucking, processing plants, raising animals to sell, etc...). My grandmothers generation's grandparents had experienced slavery in the south. All this to say that the living was pretty simple - very communal among families - as kids we moved freely through a variety of relatives houses that were in walking distance.

Know history, know self. No history, no self. This was something I've heard countless times when I was taking Ethnic Studies during my undergraduate program. On his pop's side of the family, they were from Ohio. He was one man in a family with six sisters. He was the oldest and when his pops passed away when he was young, he became the man of the family until KT's grandmother remarried. Within the depth and breadth of his family lineage, what really connected both sides of the family was music. KT recalls vividly:

The thing that was constant was music, man. I feel like we always had dope music around the house and that's what started it for me, man. My mom is heavy in the gospel singing at choir and kept us in church. Then my pops was just, man, he had all the wax of James Brown and just, he had some funky shit. So, the mix of those two things, man. When you listen to gospel, it's something, it sounds so much, you can hear the influence of the blues, right?

As he was sharing this quote, I can almost hear the funky James Brown beat hop as KT articulated each word. The funky joint continues to hit as he expresses more about the musicality that existed in his family memories. He adds:

So just the music man, it was something I always remember that was just the basis of my existence was music. I can't play. I mean I played violin. I played trumpet for awhile but didn't really keep up with it man. But I always kept a love for music. Always had a piano in our house. My brother played various instruments. He played saxophone [and[ the alto horn. I had a room next to his and then he played bass. He plays bass now. So my room was next to his, so I heard him teach himself how to play bass. So now when I hear bass lines from 70s music, funk music, early 80s I just know it right off. You know what I'm saying? 
I knew by hearing KT speak about music that it was a huge part of his identity. He described that he would literally hear in his sleep bass lines that his brother would play. Music was in his bones and his soul. Music was part of his existence and those bass lines that continuously played in his mind would eventually lead him to a new love called Hip Hop.

\section{STAND ON THIS CULTURE, IT'LL BE THERE FOR YOU}

Funk in the late 1970s and early 80s was huge in the community but for KT, that was all his cousins and his older brother. Hip Hop was his. He has seen it come into play and has witnessed the evolution of Hip Hop since the beginning all the way until today. He remembers clearly when the Sugar Hill Gang came out in 1979 with the hit song, "Rapper's Delight." While that song swept the nation and introduced Hip Hop into the mainstream, KT heard a song from the Fatback Band, titled, "King Tim III (Personality Jock)", which was rapped by the lead vocalist, Tim Washington. In many Hip Hop debates, people would argue that this was the first Hip Hop song ever recorded, six months before “Rapper's Delight." Needless to say, this was not new to KT. He was a huge music aficionado.

Hip Hop, in particular, got him hooked. KT is smiling from cheek to cheek as he recollects:

Just thinking about that stuff makes me smile because that was the motivation. That was the thing that kept me going. I always wanted to have the dope beats. I didn't have a car to ride in at the time like that, but I always wanted to have the dope beats. I had a boombox. Right? That's how you represented, you brought your boombox out. So I was always known as a cat who just had music.

KT later emailed me a picture of his first boombox. It was a red, Realistic Radio Shack, 8-track, $\mathrm{AM} / \mathrm{FM}$ radio that had two speakers. He remembered saving up enough money to run to the Radio Shack and buying it. "I was hyped," he yelled. Not long after buying his boombox, his pops gave him an 8-track recorder and then began to make his own mixtapes. 
KT would have everything from funk music to house music, and Hip Hop. He would recall meeting his cousin from Chicago at a family reunion held in California - that cousin who is now known as Hip Hop producer, Dug Infinite, would share music from the Midwest. These were one of the few experiences that allowed KT to capture the essence of different musical genres. KT leans forward and excitedly shares:

One of my cousins would come with music. Be like, "Oh man, I need to hear this. I need to get this." Come with that house music. So I heard that house music. People from the Bay area be bringing up the Too Short tapes. You know what I'm saying? Literally bringing the Too Short tapes up. I'd have a fifth or sixth generation, Too Short man. It sounded like shit. But I loved it. I rocked the hell out of it.

Wherever music would be, KT would find it. Whatever was going to get the juices flowing, KT had to have it. In addition to getting his music through records and tapes, reel to reel, or live music, he was also getting influenced by radio. There wasn't a black station in Sacramento that was on 24 hours a day. It wasn't until September 1992 when San Francisco's own 106.1 KMEL became an all Hip Hop and R\&B station. So, prior to 1992 in the Bay Area, Hip Hop music would only be played during a short stint during the day. KT remembers, "We had a station called KPOP that played some Hip Hop around 3:00pm in the afternoon."

An extension to his love for music was his ability to share his knowledge with other kids. KT chuckles to himself as he recalls one of his earlier memories:

There's a few white funkateers out there that have me to blame for that, that they are familiar with the P-Funk. One of my best friends, man, I met this cat in first grade and we met over music. He was singing a song that I knew and I was like, "Man, that's a cool song." We're together to this day, that's my man, 20 grand. He's a DJ and has a massive music collection. So, he's a part of a lot of my childhood because we were salt and pepper basically. We were a white dude and a black dude that got along and we rode that wave.

Acquiring knowledge and a deep appreciation of music was huge for $\mathrm{KT}$ in his earlier years growing up. He expressed and enunciated each word to emphasize the importance of music. $\mathrm{He}$ said, "Music was all throughout. That just got me through. It's still the thing I say it's the most 
dependable thing in my life. It's music." Spirituality is very important to him and his family, but in terms of music, it served as a compass, a guide to how he views and navigates the world around him. KT elaborates further:

But looking back, it taught me a lot about the lies and the hypocrisy that's out there. You know what I mean? As I started to realize those things, Nate, the music was right with me. You know what I mean? The music was validating what I was learning or the hints of things that I was learning on my own. So that music just validated things for me in terms of being different. You don't have to be what the stereotype or what the model is of who they think you are. Those are the things, man. I mean those are the pillars that shaped my life.

He recalls experiences in elementary school where he noticed a distinction between him and the other Black kids that were being bussed in. Because he was one of the only Black kids that were part of that neighborhood, the other Black kids saw him as different. KT expanded further in an email he sent me:

I was going to school with white kids, Asians and others from the new neighborhood. We could ride our bikes to school because it was close to our new home. Other kids, mostly kids of color, were catching the bus to school, and there lied a distinction. Although we looked the same, there was that distinction related to where you lived, how you arrived and left the school on a daily basis, and who you hung out with. So, I felt connected to and at the same time, disconnected from each group in a way. I wanted to be with folks that looked like me, but I also wanted to show the other kids that they were no better than me.

In addition to which neighborhood kids were from and how they traveled to get to school, his educational experiences also fed into the distinction between KT and other black kids. While he wanted to show, in other ways, that the other kids weren't better than me, his involvement in a gifted program furthered the divide. He elaborated further:

The "gifted minds" program (GMP) in elementary school fed the division and distinction that I mentioned earlier. Most of the kids in the GMP were white or Asian. So at the points in the school week, when teachers would call for the "GMP" students to go to another room - that proved to create more of a divide between me and other Black kids at school. 
Despite the perceived distinctions between him and other Black kids, the unifying force that bonded KT with the other Black kids was music and its culture, particularly Hip Hop culture which has its roots from Black music culture such as soul, funk, and R\&B. He also expresses that even in relationships, he has found music was what got him out of arguments. He laughs and shares, "It helped me calm down before I say something stupid, you know what I mean? Or do something stupid." Music, in general, elicits feelings and emotions. There is also an instant psychological connection between songs and events. KT described moments when he would listen to Switch, a funk and R\&B band, and wrote lyrics from songs such as "I Call Your Name" and "There'll Never Be" and sent them as letters to girls at school. He emailed me about it and said, "I felt like my game was tight!"

As KT struggled to understand the perceived distinctions between him and the other Black kids, music provided a common bond that allowed each other to feel connected and to feel valued. Sulé (2016) speaks about this notion around belongingness through empathetic mattering. When you add the social, political, and economic context into the mixture, being Black is being Black. No matter what neighborhood you're from, how you traveled to school, or what classes you are taking, you begin to understand that you are no different than the other person. Hip Hop culture becomes that bind that highlights the similarities of the sociohistorical lived experiences that KT and other Black kids were experiencing during that time. Through these set of experiences, he has found that music grounded him and provided him a space of harmony. As if he's delivering a sermon, KT professes:

So music was always a place for me to hide out, to celebrate, to contemplate, to learn. Even as a child, man, my parents didn't always get along the best and there were some tensions in the house, but music was right there for me. I saw that in terms of even when my parents weren't getting along, what they would retreat to is their music, you know what I mean? So that was ingrained in me. "Y'all stand on this culture." Because really 
that's what it is. It was more than music, it was culture. You know what I mean? Let it do its work. Stand on this culture, it'll be there for you.

KT leaned on this culture through and through. Whether it was making tapes or bumping albums on his pops' huge speakers, music was always with him. He turned to Marvin Gaye, Switch, and KRS-One for inspiration and for answers and they always delivered. KT learned very early that life was just like music. And with that, Marvin Gaye's voice sings, "Just like music", as Erick Sermon raps on his song, "Music."

To relax my mind, so I can be free And absorb sound that keep me 'round Doin my thang, constantly with no worries Peace to Keith Murray (just like music) To keep me flowin and keep me goin And keep me growin, and keep me the $\mathrm{E}$ from knowin What happens out there, is not my concern You wanna die it's not my turn (just like music).

\section{A PLAN IS A POWERFUL THING}

"You got to go to college." This was a phrase that has been reminded of him all of his life. Now that he graduated from high school, there was no other decision to make other than go to college. There was no choice in the matter. KT reflected back to that moment, "My pops didn't graduate. He graduated high school but didn't go to college. So he was like, 'You need to go to college.' My mom? She did college, nursing school, and got her Master's in Business."

So KT made his way to Cosumnes River College in Sacramento. He had a couple of friends from high school that were there so it gave him a sense of familiarity. While he knew folks there, navigating through college felt like he was on his own. Not in the sense that he was alone; but more about how he felt empowered to navigate college freely and on his own terms. The curricular content during his K-12 experiences were prescriptive, structured, and 
intentionally created by design and never felt like he owned his education. As a result, he took it upon himself to define his own college education.

Hip Hop, in many ways, had to do a lot with his new mindset. He expressed, "The cultural capital I possessed in Hip Hop culture and Black music served as part of my badge of honor." The Hip Hop artist who significantly impacted his own understanding of self and identity was KRS One. With excitement booming from his voice, he added, "I mean just the Teacher. BDP, Criminal Minded. When that came out, it was like a fringe record. My man KRS on the cover looking out the window. I think I knew that picture before I knew that picture of Malcolm X." The evolution of KRS was in line with how he was evolving in terms of his African and African American consciousness. The cultural capital he acquired through Hip Hop allowed him the freedom to choose which classes to take such as African American history, psychology, and sociology. While that experience bolstered his growing independence, he also felt that he lost track of direction.

Similar to many first-time college students, he floated around taking courses; some of which he knew he had to take, while others he wasn't as sure of. He floated around the community college system in Sacramento from Cosumnes River College, to American River College, to Sacramento City College, and back around again. He changed his major 3-4 times. He did this for about 5 years. Karp and Bork (2012) found four distinct themes that impact students' ability to persist and succeed. They argue that while the demands and expectations placed on community college students may differ based on their social and ecological positions, they found that students needed support in the following components: academic habits, cultural know-how, balancing multiple demands, and help seeking. KT repeated, "I just kind of floated around. I was an alright student but I just floated around." 
It wasn't until his fourth year in college when he saw a college counselor besides the initial counseling appointment when he first got to college. He laughs out loud incredulously and yells, "In my fourth year!?" He shared his counseling experience and let out a sigh:

So I had a fairly good counselor there, but her views I didn't really agree with in terms of the direction that I wanted to go. And I think more so back then, they were really looking at, "Let me help guide you to something that you could be successful at," as opposed to, "What do you want to do, and how can I help you be successful at that?" Right? So I mean, my community college experience is extensive.

Although KT spent 5 years in the community colleges, he expressed that his experience was invaluable. This was an experience he shares with his students all of the time. He also shared that even though he didn't agree with his counselor's views of the direction she felt he should go towards; he found the agency to "go out and do it himself." He started completing his requirements even though he would change majors and eventually was able to transfer to California State University of Northridge also known as CSUN. CSUN was located in the valley in Southern California near Los Angeles. With his voice slightly tinted in disappointment, KT expressed, "I really wanted to go to UCLA, but didn't have the grades, didn't have the dollars, and didn't have the knowledge. You know what I'm saying? Now knowing what I know now as a counselor, I could've got there somehow." No dollars, no sense. I nodded in agreement because I, too, wanted to go to UCLA, but like KT, I didn't acquire the knowledge and the cultural know-how to get the information I needed to get to UCLA.

CSUN wasn't really his vibe. KT spent a year at CSUN and mentioned that he probably grew more in that year than any other year of his life. KT shares this reflective perspective:

I was working. I worked in the library. I held some other odd jobs, and I was providing for myself. I had my own spot, so I had to keep the spot clean and be wary of things that I didn't really need to be wary of living in my parents' house. But with that came added responsibility and added opportunity, right? So I learned the consequences of some things, right? Of going a little bit too hard, I learned the consequences of that. And I was there... My parents said, and they made that very clear, at some point that if you're going 
too hard and you need to straighten up. If we're paying, then this is what you need to produce, and at this level.

Afterwards, KT let out this laugh and said, "So when I moved back to Sacramento, I came back to where I knew it was safe for me. Sac City was a safe place for me right down the street from the pad. And when I moved back, there was kind of a renewed spirit of now I'm ready to get back out in terms of making a move." The shift in energy and voice was very apparent as he was sharing this reflection. His voice rose with every word he delivered. He shared, "But I came back this time with something different. Not long after I came back I had a plan, and a plan is a powerful thing."

\section{BY ALL MEANS NECESSARY}

By any means necessary. This was a quote that was popularized by the civil rights movement through a speech given by Malcolm X at the Organization of Afro-American Unity founding rally in 1964. This quote also inspired the album title by one of KT's influential artists of all-time, KRS One. The album title was a modification of the actual quote, "By All Mean Necessary" which depicts a young, KRS One looking out of the window holding an UZI in his right hand on the album cover. He is wearing a white and black hat, black sunglasses, and a black coat with white sleeves. Stitched on the left side of his jacket was the letters, "BDP", which stood for Boogie Down Productions. On the right side of the album cover was the album title, "By All Means Necessary." The album's cover art is a homage to the iconic photo of Malcolm X peering through his window while holding a M1 carbine rifle. Drawn from the energy and spirit of Malcolm X, KRS One's album addressed social issues such as government and police corruption, safe sex, government involvement in the drug trade, and violence in the Hip Hop community. The album's social commentary and politically conscious efforts brought 
light to many of the social, political, and economic issues that were plaguing Black and Brown communities.

When KT returned to Sacramento during his one-year stint at CSUN, he had this renewed sense of energy. This energy grew stronger over time as he was surrounded by like-minded individuals that all were really coming into this time of critical consciousness of who they were as Black men in America in terms of their ancestry and their heritage. Along with his own cultural and familial roots and understanding of African American history and culture, Hip Hop enhanced his understanding on a deeper level through the words and messages by KRS One, NWA, Public Enemy, and Eric B \& Rakim. They were speaking to his experiences which proved to become pivotal in his next chapter in his academic life. He rechannels this experience:

And his [KRS One] trajectory at the time really influenced what I was going through, right? We always had Africa in the house growing up, but it just wasn't like something that was pushed on me, right? So at that time, just being influenced by all of these things, I realized it was all of these things, but initially I felt it was the music. But as I looked around, I saw I had all these other influences, right, that are saying the same types of things. So when I got back to city, man, many of my crew, we were on a mission. We decided we were going to transfer to Howard on the East Coast.

So in 1991, KT and four other friends packed their lives in a U-Haul and drove cross country to Howard University in Washington DC. He leans forward with joy written on his face and shared:

I was telling this story the other day. We picked up one of my men in Alabama, and it was there that I got the call from my mom and she said, "Hey, you got a letter from Howard, you got accepted. We're going to need to talk, because you really packed up your life and went out there and didn't have an acceptance letter?" I was like, "Yeah, I went on faith."

And that's a part of KT's story. He was aware that he was going to encounter struggles along the way but he knew that he would survive that too. Hip Hop was his compass and his guide. While he went out there on faith, he knew he had to do this on his own terms - by all means necessary. 


\section{HIP HOP IS A WAY OF LIFE}

Yo, Hip Hop is a way of life. It ain't a fad, it ain't a trend.

Not for those of us who are true to it.

It's reflected in our slang, in our walk, and in our stance; in our dress and in our attitude.

Hip Hop has a history, an origin, and a set of principles including rules and regulations that a lot of these new kids overlook nowadays.

The music itself acts as a safety valve on society. If there was no Hip Hop music, there would be much more chaos in the street than we have now.

It's our way to release tension, to let out the frustration that young people face in the world today. Over the years Hip Hop has evolved to represent what is happening now; the reality of street life.

Rap is the oral expression of this; the tool, the literature. Hip Hop is the lifestyle, the philosophy, and even the religion if I may.

Just as Jazz has had its own culture, rap music has its own culture which we proudly call Hip Hop.

Although the music and lifestyle is now propaganda-ized by the media, and is now exploited by big business, it will still remain -- for some of us -- as the raw essence of life.

These are the spoken words from the great emcee, Guru who is part of the legendary Hip Hop duo with DJ Premier called Gang Starr. His fluid streams of thought layers perfectly over the boom bap beats, piano chords, and strings that make up his track titled, "Jazzalude III: Hip Hop As A Way of Life" on the album, Jazzmatazz Volume 2.

This way of life was so prevalent in the East Coast especially in 1991. KT further reflects, “"91, man, Hip Hop was the ruler. Yeah, it was the ruler. And I was on the East Coast and I was in the belly of it. I mean, there were emcees all around me, mad Girbaud jeans. Everybody was just...the environment was saturated with the culture, right?” KT was heavily steeped into Hip Hop culture but his move to the East Coast really amplified Hip Hop's impact on his life. He leans back in his chair as he replays this memory:

And that's where it was like, "Hip Hop is a way of life." And somewhat before that, but really at that point, that's when it just took off and Hip Hop became much more important to me as a culture. We were already heads by that time. But to be in that environment out there, it just took it to a different level. And we were all pushing to graduate, you know what I'm saying, but we were all just so heavy in this culture. So it really became like one unified direction. We want to advance what we know and love in the culture. And plus 
we want to advance educationally, right? So that's where the spirit really came of Hip Hop and education being symbiotic, right?

The more he was into the culture, the more he wanted to learn about it. It was very reflective of his childhood where he was the first to kick game or share knowledge about a song, album, or artist. He then adds:

And I started to learn more about it as a culture. I always looked out for, "Oh, have you seen Flashdance? They got a break dancer in there." Or, "I'm watching Star Search, they're going to have such and such breaking on there this week." You know what I mean? So that was always the word around the way. "Did you see this, or did you see this, or such and such is coming on?" Or, "PBS is running this special on Hip Hop." So that was the thing.

As Guru shared in his spoken word piece, "Yo, Hip Hop is a way of life. It ain't a fad, it ain't a trend." Trends come and go all of the time. Hip Hop was destined to keep going but for that to happen, it had to be represented boldly and loudly front and center. So, for KT, it was important to remain knowledgeable of the culture because he recognizes that his understanding and willingness to engage with the culture is what's going to sustain it. It was also important for him and many folks of color to see themselves as part of the cultural narratives of America. This understanding also helped inform the way he related to students. He explained his connections:

And that really morphed into the call saying, "Well, what are you listening to? What are you rocking right now?" And so even when I talk to my students now, I'm like, "What you slapping? What's in the headphones?" And students have said, "Nobody's ever asked me that before. What am I listening to? An instructor's never asked me, or gave a damn what I was listening to." Right?

College counseling is about understanding the contextual realities that our students experience. With Hip Hop, we are able to draw these stories by asking a simple question such as "What's in the headphones?" A simple question can elicit such rich and powerful responses that we may never get if we don't ask. Reflecting on these experiences, KT saw the symbiosis between Hip Hop and education. As a college student at Howard University, the relationship 
between Hip Hop and education helped inform the way he learned in college. Reminiscing on his college experiences, he recounts:

And it really got me through school, because once I could start relating my assignments and my mission to Hip Hop, it just kept my interest, right? So I'd be taking history and thinking, "How does this relate to Hip Hop? How did this event influence this, that influenced somebody that was an MC, or a dancer, or a DJ, or an artist?" Right? So that just kept me involved with it, right? And that just carried on, that carried on through my undergrad, through grad school.

While immersed in Hip Hop culture, Howard also offered a space where he cultivated a deeper sense of his historical and cultural roots. When he was in Sacramento, he was involved with the All-African People's Revolutionary Party. He soaked in the knowledge by reading literature, participating in movements, and meeting people with similar philosophies and values. With KRS One and Public Enemy blasting out messages from his boombox speakers, he soon realized at Howard University, everything that he was learning and reading all came to life. He paused, reflected deeply, and let out a sigh. He remembers vividly, punctuating every word to let me know that this experience was so important to him. He shared:

And then when we moved out there, it just went to a different level. I started actually meeting people who were producing literature that I was reading, right? I was walking on hallowed ground on campus from great minds, right? So part of the music influenced that, you know what I mean? And it was the time, that time in history, or that time in my history that was just so influential in me gaining my consciousness of who I am, right?

These were the musically ingrained moments he remembered most and made him reflect how much it influenced him throughout his education. It was a respite. It was a motivator. It was a counselor. He added, "It was a soundtrack, right? Man, yeah, it was a soundtrack." People can connect important events in their lives to a song whether it was their first dance, their first kiss, the first time they drove a car, or when someone broke their heart. Songs became chapters of our lives. KT shared an example, "That Chronic album, man. When we were in DC, we lived in a 
house with three stories, man. Every story was rockin the Chronic album, every story. They

called that house the Cali House, because it was like that."

That feeling that Hip Hop gave him, KT sees the same look in the eyes of his

students. His ability to capture and be attuned with his students' experiences allows him to

counsel and advise his students in a deeply personal and meaningful way. He explains:

And I see it in the eyes of these students now, you know what I mean? Same look.

Sometimes it's the same red eyed look, right? And I'm like, "Look, I know what it is. So time and a place." That's my thing with that, it's a time and a place. I'm not telling you how to live your life, and students respect that. So nobody ever really told me that. I had to determine that on my own, or suffer the consequences. So now my experience helps me be compassionate and empathetic with students. You know what I mean? But I don't want to be a dictator, you know what I'm saying? So I'm real careful about how I do what I do, and what I do. There's a time and a place for me to really be. These are the guidelines. These are the walls you got to stay in. And then there's a time and a place where you just got to open it up, right? I tell my students now, "Know when to get turnt, and know when to turn it down."

In the Spring of 1994, KT graduated with his Bachelor's degree in Business

Administration. During the three years while he was at Howard University, Hip Hop has always been with him, from the moment he stepped foot onto campus all the way to his graduation day. With a huge grin, KT slightly pounds his fist on the table and vibrantly recollects:

Our graduation theme song was Cash Rules Everything Around Me at the official graduation, right? So to say that, it was like, man, you know, you're used to hearing that other graduation music. We marched in to that song during the graduation procession of Howard University's School of Business. Yeah, it was bananas, right? And just the spirit of that, man, we had at that time the commencement speaker was Colin Powell. We almost booed this cat off the stage because it was like at that time and probably now, we ain't trust that cat. You know what I mean? He was in the belly of the beast. So, I mean, just that atmosphere of being at this prestigious university, but being so down and so rooted in the culture, right, and being so vocal, like, who boos their commencement speaker?

And that's Hip Hop. It's unapologetic. When systems of oppression try to turn you down, Hip Hop gives you the permission to turn it up. It makes them feel your presence. Hip Hop is a way of life and as Guru says, "it still remains as the raw essence of life." 


\section{FROM LOW END THEORY TO PRACTICE}

In 2013, I was invited to present our work with Rock The School Bells at the Hip Hop Education Think Tank III at the Schomburg Center for Research in Black Culture in Harlem, New York. The theme of the conference was "Legacy Building: Cultivating a Global Cipher from the Streets to the Classroom." I was part of the lightning round where I had ten minutes to provide a quick overview on the work we do with Rock The School Bells. I remember all I can think of was I was on the same lightning round with Easy A.D. of the legendary Cold Crush Brothers who are pioneers to the culture of Hip Hop. Easy A.D. was presenting on the importance of Hip Hop and healthy lifestyles through his work with the Hip Hop Public Health Academy. The Hip Hop Think Tank was filled with scholars, practitioners, educators, and artists from all over the country sharing, building, and collectivizing in the spirit of Hip Hop and education. While engaging in necessary dialogues in professionalization of Hip Hop in academic spaces is important, it was also equally important to build and break bread with other Hip Hop educators in spaces that brought us to the birthplace of Hip Hop in New York City.

Prior to arriving in New York City, one of the homies from Rock The School Bells Sacramento found out that there was A Tribe Called Quest (ATCQ) listening party for the classic album, Midnight Marauders, hosted by Jeff "Chairman" Mao. Chairman Mao was a prolific music writer whose articles can be found and read on Redbull Music Academy (RBMA) and Ego Trip Magazine. Writers and DJs would host listening parties in NYC called Classic Album Sundays at secret locations throughout the city. To find out where the listening party was located, you had to stay tuned on Twitter that day. Some of the homies received the tweet to the secret location and texted it to everyone. It was in Brooklyn at a bar two blocks away from the Brooklyn Bowl. 
I was in downtown Manhattan in the SOHO area when I received the text. I hopped on the A train from the Canal Street Station towards Hoyt-Schermerhorn Street Station where I then hopped on the G train. I tapped on iTunes on my iPhone and searched for Midnight Marauders by A Tribe Called Quest. I selected “Award Tour” to kick off the 45-minute train ride towards Brooklyn. I got off the train at the Nassau Avenue Station and made my way to Wythe Street for another 10-minute walk towards Brooklyn Bowl. I didn't know exactly where the listening party was, but I knew it was near Brooklyn Bowl. I stopped by a nearby bar called the Whiskey Bar where the 2013 NFC Divisional playoff game between the 49ers and the Panthers was playing. I sat on a fire hydrant with a Notorious BIG sticker on it while I watched Colin Kaepernick throw a pass to Anquan Boldin for a first down. I laughed to myself because the last time I was in New York City and the 49ers were playing was in 2012 when they played the New York Giants in the NFC Championship. I was watching the game with a Filipino Hip Hop crew called Deep Foundation and they were giving me a hard time after their Giants beat my 49ers.

After watching for about 15 minutes, I continued my way towards Brooklyn Bowl. I immediately saw the arrow sign with blinking lights that pointed towards Brooklyn Bowl. I surveyed the area trying to find the potential secret location. I went across the street where empty warehouses became canvases for aerosol writers and street muralists. The walls were colorful and vibrant with shapes that were sharp and jagged. The lettering on the walls range from bubble letters to wildstyle while some walls had stencil art and different throw-ups. It was a photographer's dream. Then I noticed a gray van pull up and parked across the street. A guy with a fedora jumped out of the van and popped his trunk. He pulled out a dolly and stacked DJ equipment a crate of records on top of it. I said to myself, "This has to be the secret location." Within minutes, the homies arrived and confirmed that this was the secret 
location. We entered through a side door and walked down a narrow and dark hallway. Once we got to the end of the hallway, it opened up into a small lounge area where there were a few tables and seats. There were also a couple of couches but those were already occupied. We found seats towards the back near the bar. The needle dropped onto the vinyl as the music was bumping fairly soft. Chairman Mao grabbed hold of the mic and welcomed us all into the space. He played the whole album from beginning to end, starting with the "Midnight Marauder Tour Intro" and concluded with "God Lives Through.” Throughout the evening, what I remembered most was 1) the homies from Sacramento were hardcore ATCQ heads and knew every line of every song on that album and 2) hearing the homies chant, "Turn it up, turn it up" because the sound was not bumping with the respect that it should deserve. Nevertheless, the heads were nodding and smiles were extended from cheek to cheek. There's nothing like that feel good music with A Tribe Called Quest.

In looking back, ATCQ was significant and monumental for KT and his homies from Sacramento. It was ingrained in everything that they do. I remember KT and his crew would do workshops at Rock The School Bells Hip Hop Conference with titles such as "Lyrics To Go" or "Verses From The Abstract." They were heavy into ATCQ and 90s Hip Hop in general and they wore it hard on their sleeves. Inspired by ATCQ, KT and his crew of Hip Hop educators became known as the Low End Theory Collaborative.

Low End Theory Collaborative also known as LET-C emerged out of KT's experiences in his graduate counseling program at Sacramento State University. To be in community with other men of color in a graduate counseling program is uncommon; much less, men of color who all engage in Hip Hop culture. The basis of the formation of LET-C is grounded in Hip Hop 
culture activated in higher educational spaces. It also became a way of life and how they

approach their own personal and professional path in higher education. KT adds:

And it was through LETC that we really started to apply aspects of Hip Hop culture to our formal education and to our educational goal. Right? So that's just the dance of trying to get in somewhere and fit in, right? And so with LETC and with our focus, that was what set us apart, right? And then we started doing some things, doing some counseling things on the side, working with former felons, and working with social service agencies with Hip Hop as our base.

Hip Hop has a way of connecting folks who identify with Hip Hop culture. There's an aesthetic and aura that makes the embodiment of Hip Hop transparent to folks. In other words, when you see or hear folks of Hip Hop culture, you just know. Hip Hop has a presence about it that is unique and endemic to the culture from the language we use, the way we dress, and how we carry ourselves in different spaces. You just know.

KT shares about LET-C's connection to an adjunct instructor who identified with Hip Hop culture that also ran a social services agency called Wellspace. He elaborated further:

He gave us an opportunity to work through that agency, doing some counseling with some former felons. And those were the first real gigs that LETC had. And our first project with him was called The Bridge. And we had a picture of the Brooklyn Bridge on there, and it was just Hip Hop based from the start. So these cats would come from halfway houses and meet with us for an hour and a half, two hours a session. And when we saw the power in it, these cats were coming through the rain on a bus, having to walk blocks to get to us. But they were coming every week, and they loved it. Part of what they loved was that we let them be who they were. You know what I mean?

This was the first professional experience where KT witnessed Hip Hop's potential in educational and social services spaces. He added, "All right, so now I see the culture as a tool that I can use professionally. More than just motivation, but I can actually utilize this professionally." This led to a natural transition into redesigning his college success course at Sacramento City College utilizing Hip Hop pedagogy as the base. 


\section{BRINGING THAT FLAVOR}

"What is this Hip Hop emphasis? Are you guys rapping in class? Do you just listen to music? These are questions KT has heard numerous times when he shares with other educators about utilizing Hip Hop pedagogy in his classes and counseling sessions. Initially, KT didn't understand pedagogy but when he was able to understand that it was how you teach, it made much more sense to him. All throughout his life, Hip Hop has been a part of his DNA since the birth of Hip Hop. KT provides an example of how he specifically practices Hip Hop pedagogy. He expressed, "It could've been as I was thinking of assignments, or how I delivered the exam, or even in language I use in explaining it, or the references I use in explaining it." Hip Hop was much deeper than just the performative elements of Hip Hop. There was an aesthetic that was endemic to Hip Hop such as the language he was referencing to. One of the aesthetics of Hip Hop KT shared was the freestyle component. Counter to most traditional and prescriptive forms of teaching and counseling, KT allowed the energy of the space to provide directions. KT reveals this practice of freestyle:

So part of it is the freestyle aspect of how I teach, right, because Hip Hop enacts and reacts, right? So, to me, my classroom and my counseling space is a manifestation of that. So I want to make sure that when I talk about Hip Hop pedagogy, it's not necessarily readily apparent at all times, right? Because, like I said, it could've been in how I developed the assignment or how I speak to students when I'm counseling.

Freestyle is Hip Hop's version of improvisation. It's not planned. It's the ability to read the energy of the room and respond accurately and empathetically to the needs of our students. Hip Hop also calls for an exchange of ideas; a cultural dialogue between students and counselors. This exchange is defined as the cypher with the intention of creating co-constructed spaces where knowledge is valued and shared among the participants. KT details:

There is a cipher effect, right, in terms of just even the way I do my syllabus. I don't give my syllabus out until I have student input. What do you want to get out of the class? So 
this is not just me pontificating from the front. You have a say in this from the jump. That's what Hip Hop is. You can always write your own rhyme to a beat. You don't have to ask nobody unless you want to put it out.

Hip Hop places the students' lived experiences and knowledge front and center. Hip Hop firmly plants students at the core; however, students who have experienced traditional ways of being and doing embodies the traits of what it means to be a student in educational spaces. In most cases, students are passive recipients when it comes to learning (Hall, 2011). Kelly (2019) shares in her study that when students were given the power and authority to determine what their assignments and projects should be, they grew exasperated and asked her if she can tell them what to do.

While Hip Hop is participatory and performative by nature, KT is very explicit that educators do not need to be Hip Hop practitioners to be able to practice Hip Hop pedagogy. However, living the life and the culture is viewed as a prerequisite to practicing Hip Hop pedagogy. KT expanded more:

I'm not an emcee. I'm not a dancer. I don't do graffiti. None of those traditional aspects, but I lived the life. I lived the life and the culture. So I think that comes through in how I teach. And I know it comes through in how I teach. I know it comes through in how I counsel students. It comes through with how I interact with students on campus, comes through with how I interact with my community.

What $\mathrm{KT}$ is suggesting in this passage is that to be able to practice any pedagogy, one must come from a place of authenticity. Specifically with Hip Hop pedagogy, given that Hip Hop was rooted in the experiences of Black culture, there is a reluctance to allow folks who do not identify with Hip Hop culture to be able to approach their classes or counseling sessions through the lens of Hip Hop. However, Hall (2017) demands that Hip Hop based education (HHBE) should be integrated into teacher education programs and by extension, to counselor education programs to provide opportunities to gain new knowledge that can counter the existing 
traditional forms of counseling and teaching. There will certainly be tensions and contradictions that can come from this demand but it is certainly a step towards how we can best serve our students.

Hip Hop pedagogy through the aesthetics of freestyle, the cypher, call and response, and keeping it real, allows us to re-examine our own counseling practices through critical selfreflection. How can counselors be more intentional and meaningful with our students? How can we begin to engage students to co-create their educational experiences? Through Hip Hop pedagogy, KT has been putting in the work. Like a breath of fresh air, educators expressed to KT and his crew in LET-C about their work with students, "Thanks for bringing that flavor."

\section{PEACE, LOVE, UNITY, AND HAVING FUN}

Hill and Petchauer (2013) challenges us to look at Hip Hop as not just content or product but ways it can be utilized for educational purposes. Furthermore, how can we look at Hip Hop as a cultural form that produces new ideas, epistemologies, and dilemmas that can inform college counseling practices? More importantly, how does these nontraditional forms of counseling impact academic outcomes, specifically with Hip Hop pedagogy. Given that most institutions of higher education measure successful student outcomes based on grade point averages, percentage of degrees completed, persistence rates, and countless quantitative evidence, it doesn't clearly address the impact of opportunity gaps between students of color and those who represent the status quo. Museus and Ravello (2010) suggests that we look at other conceptual divergences of success that can produce other forms of academic success outcomes such as validation, cultural integrity, and sense of belonging. Within these divergences, KT describes his approach to creating counseling spaces for students that are humanizing and student-centered. KT elaborated: 
So as you were talking about Herc and Bambaataa, and those founding fathers, it's up to us to keep that alive, right, in concept, and then in how that's used in the classroom as educators, right? That's up to us to keep that alive. But this is where we base from: peace, love, unity, and having fun in terms of just a guideline, that was never meant to be a guideline for education. But if we look at it and the way that I look at it is those are the things I base my pedagogy around, right? What do we need to do to have peace? Right? And peace, a lot of times, is going to require change, change from the status quo. So, to me, change is revolution, so I teach about revolution. Love is like that. We just got to love each other. You know what I'm saying? And what do we got to do to love each other and love ourselves? We got to work on ourselves.

Hip Hop is about how we show up in these spaces and provide validating experiences for our students. This is within the spirit of Hip Hop; this idea of show and prove. KT expressed, "It's that revolutionary love; that critical love." It is the recognition of our own power and privilege that may impact the ways our students respond and react to us. To create these validating spaces, there is a need to enact critical listening; the ability to understand how you listen based on your own privileges and how your interpretations and lens impact the way we understand and make meaning of our students' experiences. KT's energy rises with every word spoken, he continues:

Yeah, exactly, because that's part of your own self development. So, to me, that's all Hip Hop too. That's all part of the culture. It's part of cultures in general. But in particular, it's part of the Hip Hop culture. But you have to draw that out. You need to be able to see through that lens, right? Everybody's talking about equity lens now. You need to be able to see through that lens. And you need to be able to hear correctly. Your grandma might not hear Hip Hop like you hear Hip Hop, but if you act as the interpreter, then she's going to understand somewhat, especially if you have a knowledge of how she lived in her era, right?

When counselors are engaged in self-reflection and reflexivity, they allow themselves to be fully immersed and invested. One of the most paramount things about Hip Hop is its close attention to building authentic relationships. Hip Hop is relational. Whether you are an emcee, a DJ, a dancer, or an artist, your performance or your art is communicating with someone. KT leans forward, clasping both hands and continues:

The relationships that I have developed with students and people that I work with in the community around the culture, right, and utilizing the culture, I know students on a 
different level than a lot of other counselors or a lot of other instructors, right, because we share this common interest. It just informs the way our relationship is going to be because when we start at a common place, then we establish some trust. And once we have trust, then we can help students move from A to B. Really, because if you don't have the trust, then you're struggling to get them to believe that what you're trying to teach them is valid because they're used to sitting in a classroom and letting stuff float by.

Show and prove. How do we show up in these educational spaces and how do we create validating experiences for students to feel a sense of belonging; that their presence in college matters? Rose (2018) discusses how problematic when educators lean on this notion of "keeping it real" while demonstrating a lack of understanding or willingness to meet students where they're at. One of the educators in her study parallels this phenomenon to a rap verse articulated in the rap song, "Feel It in the Air" by Beanie Sigel. It states, "Man I read between the lines, your handshake ain't matching your smile." Woods and Williams (2013) describes the various barriers to success for many male students of color in colleges that include lack of sense of belonging, lack of culturally relevant curriculum, and inauthentic academic experiences with faculty members. To address these barriers, KT expresses the importance of relationship building with students rooted in authenticity and trust founded on his counseling approach with Hip Hop pedagogy.

While KT has found success in utilizing Hip Hop pedagogy in his counseling practices, he also acknowledges that there are also challenges. He shares about his students' struggles in finding similar educational moments that they had experienced in his class. They would say things such as: "I wish all of my classes were like yours." "Where do I go next?" "Where can I get that same feeling?" KT breathes in a deep sigh and expresses, "So now it's on us to bear the responsibility to prepare students in that world where they won't get the same feeling." Drawing back to the Hip Hop aesthetic "call and response", using a critical Hip Hop lens can help with the agency building that's necessary for our students to acquire the tools and skills to navigate 
oppressive structures within higher education. To do this, we call or name the oppression that impacts our students and facilitate a cypher for students to respond by discussing possible strategies on how to navigate those structures. The call and response, this back and forth dialogue, allows the ability for both counselor and students to co-construct knowledge. KT elaborates further in the importance of the student voice saying:

That it's not always going to be like this, and recognize this as an opportunity, and take advantage of it that you have a voice in here because next semester, you're going to be in a class where you don't have a voice. And an instructor may not want to hear your voice even if you don't have a voice. And an instructor may not want to hear your voice, even if you do have a voice. So we need to kind of prepare you for that. It's not all like this. So when you have it like this, take advantage of it. But that's where I wish we had more to offer in terms of this in the way that you can get through this whole system.

But at the end of the day, students will remember how much you made them feel about themselves. For KT, it starts with authenticity; staying true to yourselves. Hip Hop lives and breathes in KT; it's in his bones. Encapsulating everything he knows about his experiences utilizing Hip Hop in all facets of his personal and professional life, he continues to lean on the philosophies of the Universal Zulu Nation - approach relationships guided by peace, love, unity, and don't forget -- having fun. 


\section{TRACK SEVEN \\ ROB ALEXANDER}

\section{SOUL FOR REAL}

It was one of those cold and dreary November days where everyone seemed to be under the weather. The campus was filled with the sounds of coughing and sniffling. Even though it's typically cold at Skyline College in late November, the rain made the cold weather a little bit more unbearable. The tips of my fingers felt frozen as I clumsily tapped on my iPhone. I was texting Rob Alexander, letting him know that I'll be there in a few hours to do our first interview. CIPHER Hip Hop Learning Community were wrapping up our 5th Annual Holiday Bling Vendors Fair at Skyline College. I thought to myself, 'I'm exhausted. I'm feeling sick. Why did I schedule this interview today? There's going to be traffic going there.” I certainly didn't plan this effectively. I sighed to myself and left it to the universe to grant me more strength and energy to head to De Anza College in Cupertino, California. I went back inside of the building as the winter chill started to bite at my dry lips.

As I opened the doors to Building 6 where Holiday Bling was being held, I immediately feel and hear the energy that was emanating from the event. My student who goes by the name of Lil Vibey was putting it down on her DJ equipment. When Saweetie's song, "My Type”, started playing, all of my students were gathered together into a human ball of energy and started chanting, "That's my type, that's my type." The place was packed with students and faculty as they were enjoying the music and live performances while getting some last-minute holiday shopping done. I made my last rounds to purchase from our local vendors and by the end of my shopping spree, I was carrying a couple of bags of holiday gifts I plan on giving to friends and family. I bought some Hip Hop inspired enamel pins from Surreal, Hip Hop posters from 
MixerFriendly to add to my office walls, CBD oils for aches and pains, coloring books from ColorHerStory, unique jerseys from Animeish Apparel, and some dope Pasifika prints from Afakasi Prints. There's nothing like giving gifts that are unique and meaningful especially if they're purchased from our local vendors. Six of our vendors were our very own CIPHER students so witnessing them throughout the event filled my soul. You can see the confidence building inside all of them and the sense of validation it gave them. This experience assured them while being an entrepreneur can be tough, they knew this is the journey they wanted to embark on.

As I walked around, I gave my gratitude to all of the vendors for making it out despite the dreary and gloomy weather. Simone Hufana who is the entrepreneur behind the inspirational coloring book titled ColorHerStory, reciprocated the gratitude. She was sharing with us about her recent experiences that challenged her as a woman of color in the field of business and entrepreneurship and how it impacted her mental health. We appreciated her courage and vulnerability to share with us how much those experiences impacted her and how she has transformed those negative experiences into badges of courage and hope. Simone responded, "I thank you and what you do with the CIPHER Hip Hop Learning Community. Being here really filled my soul. Please invite me back anytime.” I thanked her and gave her one of those long, extended hugs knowing that we both needed it. Despite how sick I was feeling and how cold it was out there; her words gave me the fuel to embark on this long drive through the thick traffic to De Anza College.

As I was driving to De Anza College, it was pouring rain and Siri had me jumping on and off the freeway instructing me that I can save three minutes here and four minutes there. I decided to just ignore Siri and stayed on the freeway despite the cars moving like molasses. An 
hour later, I finally arrived at De Anza College and parked at the staff parking lot in front of the Student Services building. I texted Rob that I was there and he texted back, "I'll be down with your parking pass." By then, the rain had stopped thankfully and headed towards the front of the building to meet him. I've never met Rob but recently I had purchased his book titled, Can't Let Nobody Ride My Bike, where his picture was on the back. The book was an Oakland narrative and Hip Hop soundtrack about his life's experiences. The picture in the front of the book had four African American boys on their bikes which were brightly colored and decked out with multicolored mags. One boy was bare chested staring at the person who took the picture as if he was letting the readers know that they were about to go on a literary adventure through Oakland.

Then, I saw a tall African American male, roughly six feet tall, heading towards the glass entrance. He was wearing a blazer and matching slacks while his brown shoes clapped against the concrete floor. He opened the door and he immediately knew it was me. He yelled, "Nate?" I walked towards him and without skipping a beat, we gave each other daps, pulled each other in, and gave each other the "homie hug." I never met him but for some reason we naturally did it. It was instinctual and cultural. He handed me the parking pass and I quickly went to my car and placed it on my dashboard.

When we walked back inside the building, Rob adjusted his eyeglasses and said, "Man, it's an honor to finally be meeting you." I nodded in agreement and replied, "It's been a hot minute." Rob and I have some mutual friends that worked at De Anza College. Three years ago, De Anza College became the third community college to host Rock The School Bells. Everytime I'm at De Anza, there is always this sense of pride and humility knowing that Rock The School Bells is now a major part of the fabric of De Anza College. Rob has been hearing about Rock The School Bells for some time now. We entered the elevator to head up 
towards the Counseling offices. He said, "I am honored to be part of this research study. I really appreciate what you are doing with Rock The School Bells and Hip Hop education in general.” I humbly replied, “All good. Just trying to document the great work we're doing within Hip Hop education."

We arrived on the second floor of the building and walked through the empty lobby. The counseling services were closed for the day. The only person in the area was one of the custodians who was going to each office emptying trash cans. Rob's office was directly ahead of us where his door was slightly opened. We walked in and he situated himself on his chair while I was getting all of the equipment together. He turned to his computer screen to find the campus WiFi login and code. While he was doing that, I glanced around the room and noticed the various items he had on the walls. Directly in front of me, he had those mini banners from Fresno State University and UC Santa Barbara. Right below it, there was a Stanford sign taped with a San Francisco State Gator flanked to its right. This was truly a college counselor's office. I looked to my right and I saw a UMOJA graduation stole pinned on the wall. The stole had a black background that was adorned with red, black, and green stripes with letters and symbols embroidered in gold. The word and symbol represented by interlocking links stands for "unity." The UMOJA Program at De Anza College and many colleges around the nation is based on an African-centered philosophy that enables students to see themselves within a positive historical and cultural context.

Situated behind me on the back wall, front and center, was a poster that depicted hand drawn images of women of color. The woman in the middle had a dark complexion with a yellow and white hijab. The other two women were on both sides, closely embracing her. The sentence on the poster read, "We all belong here. We will defend each other." It was such a 
beautiful and powerful poster that were filled with so many vibrant colors. Immediately, I began to imagine myself as a student in Rob's office where I'm surrounded by these posters and banners. It was a place that said, "I belong and I can make it to any of these colleges. And Mr. Alexander is going to help me get there." Nothing is impossible. And, of course, as I am imagining this, I glanced at a picture of a young Stephen Curry that was posted in front of me. He looked like he was only 15 years old. But despite Curry's small frame and short height, he overcame all odds and proved his doubters and haters wrong that he belonged in the league. He became a two-time Most Valuable Player. He became a three-time World Champion. He was a true Warrior. Anything is possible. When I snapped out of my imagination, I reflected how students can potentially experience a sense of belonging and hope just by immersing themselves in the aesthetics of Rob's office.

Rob is a college counselor and instructor at De Anza College. He teaches courses such as Human Sexuality, Career and Life Planning, and Life Skills for Higher Education. He has been at De Anza College for more than 12 years. Having released his book about his personal life and having been in the "counseling game" for more than a decade, I was eager to learn more about his lived experiences. Rob swivels his chair towards me after locating the WiFi login and password and said, "I'm ready whenever you are." I've been ready.

\title{
FROM THE CITY OF DOPE TO THE CITY OF HOPE
}

\author{
City of Dope, I call it Oak \\ Can't be broke, selling coke \\ Fat ropes, shattered hopes \\ Fresh cars and all that dope \\ Baseheads keep the trade alive \\ Nobody know about a 9 to 5 \\ Everybody's just trying to survive
}


You need a gun, can't use those knives

You got a bullet? Well just pull it

And if you trip, get pistol-whipped

By a psycho maniac sick in his head

want to be a gangster, now he's dead

His brother took over, ain't no sweat

Bought a new drop-top white Corvette

Now he's buying keys, making G's

And all the girls say "Won't you please

Take me" In the City of Dope

In his book titled, Can't Let Nobody Ride My Bike, Rob starts every chapter with a Hip Hop verse from an array of Hip Hop emcees. This verse was from the song, "City of Dope" by Too Short. Rob replied, "Too Short, in my mind, was kind of the godfather of Oakland Hip Hop. And just a living legend, you know what I mean?" This particular verse set the stage for his third chapter, eloquently painting the drug scene in East Oakland when he was growing up. But while the drug scene was rampant, he shared some vivid memories growing up in East Oakland on 78th Avenue and Hillside. Rob leaned back in his chair, clasped both hands together and started to rub them together. You can tell by looking at him, he was being transported back to the 1980s. He expanded by sharing:

[I] grew up in East Oakland 78th Ave [and] Hillside which was [a] five-minute walk away from Eastmont Mall. And it was the end of the opioid epidemic but the beginning of the crack epidemic. My community was very close knit, I had neighbors, my friends' parents could babysit us, my friends' parents could also discipline us if we were just getting out of line, my best friend's father was a coach, a basketball coach, football coach for Youth League.

The crack epidemic hit Oakland real hard in the 1980s. It was actually ranked 7 th among 232 U.S. cities based on a study released by The Rand Corporation. Eerily similar to what happened 
in the Bronx in the 1970s, Oakland also experienced a high rate of cases involving arson that was attributed to the warfare between drug gangs. While drugs were routinely sold on over 100 street corners in East Oakland, Rob found ways to avoid the traps of "making that dough." One of the ways he avoided that lifestyle was that he had a close set of friends who had each other's backs. "We were close knit. We were friends. We capped on each other. We would have a little freestyle; little sessions like that. None of us could really rap that good, but we tried. It was more like rapping just to cap on one another." We both laughed and he proceeded to say, "We were jumping on one another, playing the 'dozens'. That's what we tend to do in Latino, Filipino, and Black communities. East Oakland is my home. I love it and that's a large part of why I bought a house out there.”

Rob also attributed his ability to avoid the drug dealing lifestyle by being active in sports. He and his friends all came up playing basketball, football, and Babe Ruth baseball. Rob also had the opportunity to participate at Camp Hardaway. Tim Hardaway was one of my favorite basketball players growing up. He was part of the Run TMC era where the Golden State Warriors had Tim Hardaway, Mitch Richmond, and Chris Mullin. When I was with my cousins, I would be the shortest player on the court so I emulated my game after Tim Hardaway. Hardaway came out of the University of Texas-El Paso (UTEP) and had this basketball move that was called the UTEP two-step. Rob shared:

We went to Camp Hardaway. I met Brian Shaw, Jason Kidd, Hook Mitchell from Mosswood. I wanted to be a hooper. When I was in shape, younger, that sports is one of the reasons why I stayed clear of selling weed and selling drugs because I knew every school has a policy where you've got to have a minimum GPA, over 2.0 and my father and coach Bruce, which I wrote about in my book; they wouldn't allow me to slip and go down that path.

The path. As counselors, we are very interested in our students' paths; where they came from and where they see themselves going. But at the time, Rob, as a young African American 
teenager, had only two options. Two paths. Motioning to two fingers, Rob added, "The

environment we lived in, we never really looked at education as a way out. Either you was playing sports or you sold coke, you sold dope." Just two paths. I was interested in how these paths were shared to him because it is a common narrative I've heard in various spaces, particularly for African American males. Rob then responded:

One of my childhood friends who's no longer here, Marcel Scott. He was the first person that showed me that you can make money selling dope. I believe we were around 12 years old and he was younger than me, which was the ironic part, but I remember being with him one afternoon and I was trying to talk to him because he had recently dropped out of middle school. I asked Marcel why he had done it and he pulled out a stack of money and it was the most money that I had ever seen, with 50s and 20s on the top. He wasn't playing around. And prior to that, we looked up to the older D boys because they were their own bosses. They were the ones in the hood getting money. So, I was attracted to them. I'm not going to sit here in front.

When you have access to that kind of money at a young age, it can definitely influence how you make decisions, especially if you are financially struggling. How can middle school compete with all that money, I wondered. Rob continued, "We didn't have a whole lot of engineers, doctors, people that were going into environmental science or any of these careers nowadays. They weren't doing that in my neighborhood. The people that was getting money, they sold dope." Rob's reflection reminded me of an excerpt in the final chapter of his book when he, too, was wondering why one of his friends made the choice in dealing drugs.

I still liked Manny and wished that we were friends, but was not happy with the decisions he was making. I tried to look at it from Manny' point of view. What if my back was against the wall? What if my mother struggled to raise me and my siblings? What if I knew a way to help my mother with the bills even though it was illegal? Nope, I still wouldn't do it, too much at stake. I care about my life and future. When did Manny stop caring?

I noticed the struggle that was written on Rob's face as he was trying to make sense of Manny's decision. I had a feeling that perhaps Rob was feeling like he could've done more for him. In his book, Rob mentioned that if he and his friends didn't get on Manny about stealing a super 
soaker at the mall, maybe Manny would be still around. Unfortunately, Manny became another statistic. One of my favorite rappers of all-time, Nas, had a song called, "I Can" that was intended for the youth to hear to disrupt the narrative that they were limited to this idea that they can only become athletes, drug dealers, or rappers.

I know I can

Be what I wanna be

If I work hard at it

I'll be where I wanna be

I know I can (I know I can)

Be what I wanna be (be what I wanna be)

If I work hard at it (If I work hard it)

I'll be where I wanna be (I'll be where I wanna be)

B, b-boys and girls, listen up

You can be anything in the world, in God we trust

An architect, doctor, maybe an actress

But nothing comes easy, it takes much practice

However, it takes more than just practice. Having role models was vital in his survival within Rob's community. While many youth in East Oakland looked up to the D boys as role models because they had all of the money, cars, jewelry, and street cred, Rob reflected on the importance of mentorship. He shared:

But I feel like men of color, we need many mentors. I hate to use cliche terms, but it takes a village. It really does. Because folks could get easily distracted and if you see somebody getting money, that could be appealing. But it takes somebody else, somebody going down a positive route, getting money to influence that change.

Rob witnessed how material wealth easily captured the minds of many young black men in his community. This often led to behaviors of hypermasculinity where you had to present yourself in a way that projects bravado and power. When you had the money, women, cars, and jewelry, you commanded power and respect. Rob adds, "There's a bravado, especially if you're from the ghetto. There's a bravado that we carry, like don't show no softness. Don't be weak. Don't let people see you cry in public.” 
Rob knew in his bones that young black men can't continue this vicious cycle if they wanted to survive and rewrite the narratives. There were many mentorship programs in Oakland that really reached them. There was the OK Mentorship Program that empowered black men and boys to transform their communities. There was also the Brother to Brother program. Rob continued, "They also had a male mentorship program at Oakland Technical High School that you could get into that could change your life for the better, positively influencing your life." Despite the community's efforts to counter the negative experiences that were destroying their communities, the commitment for change had to come from the individual. They had to want it. Rob elaborated more:

You could tell somebody, "Hey, do this." Or, "Let me introduce you to such and such." You could tell somebody that until they're blue in the face. But until they own their own life and until they want to stop fronting, they're doing the [stuff] that is either going to get you shot or in prison, it's not going to happen. They have to take ownership of their lives, basically.

Rob bought his house in East Oakland on the 98th. He's about five minutes away from his mom where he grew up on 78th. Given how Rob depicted what life was like in East Oakland, I was very curious as to why Rob bought his house there. Rob loves East Oakland. He loves his community. He even started his nonprofit organization called The Hood to Higher Education Organization that exposes youth of color to college options while building on their own cultural awareness through critical literacies. As Rob continued to share, you can hear the pride peeling off every word he speaks:

Oakland is a melting pot of culture, liberals, and revolutionaries. Oakland is where I cut my teeth in terms of sports and growing from a boy to a man. I experienced a great childhood and love being reminded of it when I come home. I could go on and on about my love for Oakland. Home of Tom Hanks, The Black Panthers, Mayor Ron Dellums, The Pointer Sisters, Ricky Henderson and so many others. My city is so diverse and I love it here. 
His lived experiences also helped inform the way he wanted to raise his four

children. He shares, "I got four kids. I got three boys and one girl. One is twenty years old; the others are 18 and 17, and then I hit the reset button and got a six-year-old. In particular with his three sons, growing up in a community where drugs and violence were prevalent, Rob was able to instill hope and compassion in them. He explains:

First of all, their dad is a college advisor. So, I've laid into them their whole lives that they've heard me preaching the importance of education. I know that young boys, in particular, boys of color can be influenced if they don't have somebody strong in their lives or if they don't have somebody that shows them that they love them. I read articles that if you hug a boy of color, this brings down anxiety, this reduces stress. Just a simple act of giving somebody a hug. You know what I'm saying?

I definitely know what he was saying. I thought of Manny and all of the folks in his community that were impacted by drugs and violence. I thought of my own homies who died from violence and drugs and those who were sent to prison. He adds:

And I'm trying to tear down those barriers. I've lost people. I've lost loved ones, I've cried in front of my sons. I've cried in front of my family members. I show them that I'm vulnerable. I have the ability to be vulnerable in front of them because I don't want them to feel like they can't have a moment of weakness in front of me.

So, as a parent, Rob wanted to avoid all of that. He wanted to create a life with his children in the community he was raised in. There was no running away from it; he was going to approach it head-on. He loved East Oakland and he loved his children. Deep down inside, there are these visions of East Oakland transforming from the City of Dope to the City of Hope.

\section{WRITES OF PASSAGE}

Rob's family came from the East Coast by way of Washington D.C. His father made the move to Oakland in the Bay Area to pursue his writing career. His mother was the librarian for James Lick Middle School in San Francisco. She transferred to Frick Middle School in Oakland and finished her career as the librarian at McClymonds High School. Education was something 
that was ingrained in him at an early age. His father as a writer and his mother as a librarian, it was destined that words would follow him throughout his life.

However, living in East Oakland, made it difficult for Rob to navigate living a life of drugs and violence or pursue a life in education. But his mother wasn't going to allow the decaying city to dictate her son's life trajectory. Rob lets out a hearty laugh and said:

My parents took me out of the neighborhood elementary school, Parker Elementary. My mom did her homework straight up. She knew that Parker Elementary wasn't the best school for me. So, we drove to a different elementary school that really wasn't too far, but they had a higher ranking. They had a higher educational report card, score card. So, I went to Grass Valley Elementary, where I had really good teachers.

At Grass Valley Elementary School, he experienced his very first African American teacher, Ms. Carpenter. She believed in him and was one of the first people who saw that Rob had a talent in writing. Rob liked to write but it needed to be honed in. With her guidance, it prepared him for middle school where he had his first two African American male teachers. He remembered them so fondly:

I had two African American male teachers, which is rare, Mr. Green and Mr. Onyeador. Mr. Onyeador taught Geometry and Mr. Green taught Art. And his classroom was decked out, Nate. He would have Prince posters, he'd come in there and we'd be playing music. And one of our major assignments was to put together a model car. So let's say using muscle cars, let's use high-performance type vehicles and you could buy a Chevy Nova model or El Camino or Chevelle, what have you, and we'd put together in a class with super glue and we just had so much fun doing it.

This memory from middle school stood out to him because until he went to college, that was the last time he had African American male teachers. Not even in high school. Rob went to Skyline High School also known as the 'Line. He motioned with his hand a roller coaster action and said, "Education went up and down for me. I was still being influenced by the "hood. I still was in my "wannabe" days. I had one foot in the "hood and one foot in academics." Anytime someone refers to the word, "wannabe", it conjures up this idea that you're trying to be someone 
else because you don't want to show your true self. This was also known as a survival tactic. He shared in his book, Can't Let Nobody Ride My Bike, a vivid story about how his friend hid his schoolbooks in a pizza box as they walked past the D boys in front of a liquor store on MacArthur Boulevard.

If the older homies saw us studying or carrying books, they would pick on us and we would never hear the end of it. It was weird that way in the "hood. You almost felt trapped. If you tried hard enough in school, they would call you a "sucka" or a "mark."

Going to school wasn't cool. It was already hard enough to live in the neighborhood. But to have a reputation that you like school and enjoy reading and studying meant that you aren't one of us. If you aren't one of us, you were outcasted. This type of experience causes anxiety, high stress levels, and symptoms of post-traumatic stress disorder (PTSD). PTSD can manifest from these various experiences of toxic masculinity leading to destructive forms of self-harm. "One foot in and one foot out." It was the dance of life for many young black men in the "hood.

Skyline High School was the home of the Titans. Its logo is either a picture of a Titan or a capital "T" encased inside a circle. The bright red and white colors of the school pops at you from a distance. Skyline High was very diverse. Rob elaborated, "I would say a little bit more than half was African American, Latino, Filipino, and Pacific Islander. We had a large Pacific Islander population at the 'Line and we would joke because most of them played on our football team." The teachers at the school were also diverse but Rob somehow managed to not have a single African American teacher in high school. He never understood why. He explained, "Based on your interests, based on what level you were in English or Math, you might get them, or you might not. And I wasn't fortunate enough to get them in high school. [That] might have been the reason why I started to lose a little bit of interest in school." In Hip Hop, it's all about relationships. The relationship between the artist and listener. The relationship between the 
beats and the verses. The relationship between the art and music. Is there harmony existing within these relationships?

Just like a preacher in church getting ready to deliver their sermon, Rob's back straightened up and he proceeded to provide his understanding about how teaching is all setup. He leans forward and explains:

The way teaching is set up, we're talking about Teach For America. Another popular one I believe is AmeriCorps. We don't really promote teaching in the Black and Brown community like it should be. And because of that, there is a lack of teachers of color, especially men of color that are teachers. That needs to be revved up. If in urban areas promoting teacher credential programs, then those numbers would go up. They would.

They certainly would. There are intentional efforts in teaching credential programs to integrate culturally relevant and responsive pedagogical approaches to teaching. It calls for placing the lived experiences of those who are traditionally marginalized at the center of the work. If we have more men of color in educational spaces, it can potentially provide opportunities of counternarratives for young black men to experience. Then realism begins to take over as Rob continues:

But the fact of the matter is that those who gravitate towards teaching tend to be white women. And there's no knock on white women at all. There's a lot of research that supports this. For men of color, we look at the teaching profession as something that is feminine. It's emasculating because a lot of us have been conditioned to think that a teacher's role or teaching position is catered towards women. And a white woman at that. From many of my educational experiences, leading up until now. But if we were able to rev up and promote in our own communities, the importance of having an instructor like me, when you see somebody that looks like you, that's what we would go on some places. That's where it would take off.

\section{THE FISH THEORY}

Rob eventually graduated from high school despite some of the deficiencies that showed up in his grades. But Mom, as always knew best. With the life of East Oakland becoming more accessible for Rob after high school, Rob's mom felt that it would be a good idea to get out of 
Oakland. Rob decided to go to a Historically Black College and University (HBCU) called Southern University in Baton Rouge, Louisiana. The beautiful thing about the African American community was that they were tight knit. It felt as though if one of the kids made it to college, it was a huge thing. This definitely showed up in the church community. Rob replied, "The church gave me a $\$ 2000$ scholarship. They had fish fries and they raised money for ten of the youth that were going away to college. I was one of them; one of the recipients.” As he was sharing this memory, my mouth started to water for some fried fish and hush puppies.

Rob found himself at Southern University as a young 18 year old student, thousands of miles away from East Oakland. Southern University was known for their famous football games against their rival, Grambling University. These pigskin battles were also known as the Bayou Classic. Rob was in the thick of this new southern culture. You can sense the energy emitting from Rob as he vividly shares:

Just to be honest, just keeping 100 with you, I was out there chasing girls and stayed in the dorm my first semester. Second semester, I split a two-bedroom apartment with my homeboy from high school. We both went out there and we were splitting like $\$ 600$ rent, which was unheard of. I had a little job at Subway and was partying. Really we actually formed a West coast clique out there in Louisiana, so we would have what's called West Coast parties, this is 1996 .

1996. This is the year that Tupac Shakur passed away after being shot at a stop light on East Flamingo Avenue in Las Vegas. There was a pause in the air as if we both knew a moment of silence was required.

Tupac was a living legend in the world of Hip Hop. You know if an artist is legendary when your music outlives you. No matter who you are, what generation you are from, chances are you knew or heard of Tupac Shakur. I remember during my most recent trip to the Philippines, I visited the Taal Volcano, one of the smallest volcanoes in the world. At the center of the volcano, you can witness the beauty of the steaming lake that inhabited the volcano. Our 
travel guide was wearing a Tupac Shakur t-shirt with the title, All Eyez On Me. Tupac was his favorite rapper of all time despite never stepping foot on U.S. soil. Hip Hop was everywhere, and Tupac was loved in the Philippines.

Tupac was also well-respected and admired in the South. As a matter of fact, Bay Area Hip Hop was loved in the Dirty South. When Tupac passed away, there was a sadness that swept the world. I remember being in shock and disbelief. Rob added, "So just imagine ten cats from the West, from LA, the Bay, Seattle, we were just all West Coast. When 'Pac died, we threw a West Coast party. It was all out in the yard with bandanas and our shirts off. Just riding for 'Pac."

Although he was enjoying the time of his life, a part of Rob felt remorseful and guilty. Rob shrugs his shoulder and explained:

Being from the West Coast, it was like shooting fish in a barrel, man. I took advantage of a lot of situations that I shouldn't have and my grades suffered. And even though I went on academic probation, I had a chance to even rebound from that because my GPA wasn't low like that, but the fact that I was blowing money that people had invested in me, my community invested in me, my family invested in me.

His grandfather sent him money. His church sent him money. Berkeley Mount Zion sent him some money. And he felt he was wasting all of that. Being at an HBCU, he also felt he missed a valuable opportunity to deeply learn about his history and culture. He reflected on one of his classes:

It was a seminar class. One of our assignments was to name all the countries in Africa. They gave me some blank African maps, they gave us like a week to study and we had to come back and name all the countries in Africa. So, it was assignments like that where I should have taken the bull by the horns. Sometimes you gotta fail to succeed.

Soon enough the guilt of not succeeding and squandering the community's money began to weigh heavily on Rob's mind, body, and soul. He had all of the structure of the HBCU and the support from his community but as Rob explains, "It wasn't matched with maturity." When 
times grew tough and his soul started to take a beating, he always knew he could turn to his mom. He remembers his conversation with her:

My mom has always been an angel on my shoulder. She's still here. She's my sounding board too. So, I had that tough talk with my mom and she was like, "Baby, you ain't doing so good out there. You want to try to come home and get it right at the community college?"

With the out-of-state fees adding up, it just didn't make financial sense to continue. He took a deep breath and said, "I was just too young. Just immature, I was chasing girls. I mean, it was like shooting fish in a barrel. It was easy." With how this educational system is set up for students of color, particularly young men of color, it reminded me of the Big Fish Theory. The first time I've ever heard of this theory is, quite honestly, from a Hip Hop album titled, The Big Fish Theory, by Vince Staples, one of the most notable rappers of today. I have also been fascinated by the thought process behind album names and this particular title intrigued me.

While I cannot be $100 \%$ sure of what this theory represents, it does represent some truth in how people of color, specifically African Americans, are seen and valued in society. The theory argues that fish only grow to the size of their tank. So the Big Fish Theory applies to a set of people who are capable of doing big things but are trapped within the limits that society has placed on them. Similarly to Rob's quote around the two paths that young black men only have in life, the theory argues that once labels are placed on people and have been systematically ingrained in them to believe these labels, those who are oppressed by them may not be capable of growing past these labels. Essentially, those who have been traditionally marginalized have been swimming in small fishbowls. However, Rob was determined not to be stuck; to be confined into a fishbowl that society has created for him. He reflected on what his mom said and made the decision to go back to the Bay and "get it right." 


\section{COMING FULL CIRCLE}

“Gotta get my mind right" was Rob's mantra as he came back home. While he enjoyed his experience at Southern University, he knew he was capable of more. He reflected on the time when the greatest NBA player of all-time, Michael Jordan, was cut from his Junior Varsity (JV) high school team. Jordan was hurt and angered but he turned those emotions to motivation, grit, and pure ambition. You never know what the outcome is if you don't try. Just like Michael Jordan, Rob got back up and enrolled at Chabot College in Hayward, California. He completed some college units so he didn't need to start from scratch. This is where he met one of his mentors, Patrice. Rob lights up and shares:

She was the one that put the fire to me. She told me what I needed to do to finish my GE to get up out of there. Number one, because the first step to get a Master's is first getting a bachelor's degree. And I would tell her straight up, I was like, "I want to be like you." I want to be a counselor. And she told me what to do. She was one of those people, she did gentle push kind of thing. She was deliberate. She was intentional, she always had a message. Every time I went to her office, she maximized our time together because she was popular. Good counselors are going to be popular. You know what I'm saying? If you're solid, you're going to have a following.

Effective counseling requires a humanizing experience that is intentional and deliberate. It requires us to listen with purpose and meaning. It is a very similar experience when you are listening to a classic Hip Hop album. Some of the great albums have tracks that have been weaved seamlessly sharing a meaningful, cohesive story. It doesn't feel fragmented or rushed. Effective counseling, specifically culturally relevant and responsive counseling, feels just like a classic Hip Hop album.

After Chabot College, he transferred to San Francisco State University. Like many students, going from a small community college to a large university can be very stressful and anxiety provoking. There were more people, extensive information around policies and requirements, and cultural changes from one campus to another. These conditions impacted 
Rob's first semester. He shares, "My grades were going up and down. And being in these big lecture size classrooms, it wasn't conducive to my learning style. I thrived better in smaller classrooms." For him, smaller classrooms were more intimate. It felt more like a community.

As a result of not immediately adjusting to a four-year university, Rob found himself on academic probation after his first semester and had to take an online college success class. There was no way that his experience at Southern University was going to repeat itself. Fortunately for him, he was surrounded by a great community of peer advisers. During the group sessions, the staff really liked how Rob was interacting with other new transfer students. This moment in his academic journey became one of the many pivots that deeply informed his life and career trajectory. Rob remembers how that moment impacted him. He excitedly shared:

When I got to San Francisco State, I had a community of peer advisers. Michael Ritter was this white dude. Bita, Shoshone, Indian dude. And they started up a Peer Advisor program. So, that was my first taste of being out in the field and working with students that were like me because I worked with other transfer students. And I was able to explain to them some of my roller coaster ride type experiences. When you go through something, if you fail at something, you're a good advocate for telling people what not to do kinda thing. You know what I'm saying?

I nodded my head in agreement. I always believed that our experiences are our greatest teachers. As counselors, it allows us to utilize our own stories to connect, uplift, and give meaning to students who may identify and relate with you. I've learned over time that my mistakes became my badges of courage and vulnerability. I no longer see them as mistakes but rather a means of taking risks to learn about our own capabilities.

As a result of these group counseling sessions, Michael Ritter made Rob a peer advisor. He led workshops on sexually transmitted infections, how to protect yourself, and dating tips and strategies. He was enjoying every minute of this. Despite all of what he has 
experienced as a student in education, he knew that he needed to be "that dude." He recalls that one moment when it all clicked:

That's just like if you go to a meeting, there's [always] somebody that is recovering and he or she is able to give advice to the newbies. Like this is how you could not fall off the wagon so to speak. Like this is what you need to do to manage your time, this is what you need to do and there was somebody at San Francisco State and was like, "Hey man, you're low key good at this. You might want to consider this as a career option." So it came full circle man.

\section{PAID MY DUES}

After receiving his Bachelor's degree in Psychology, Rob was ready to take on the world. As if we were in a comic book script, I could see all of the conversation bubbles as Rob rattled off some quotes he heard when he graduated. "Get your bachelor's degree, Rob. You're going to blow up. If you get your bachelor's degree, the world is yours." Well, the world wasn't his as he quickly learned. Today, many would argue that the Bachelor's degree is the new high school diploma. Similar to many college graduates, Rob had a difficult time trying to secure a job using his Psychology degree. He found out that there were a lot of graduates out there that had similar degrees; all fighting for the same jobs and positions. You can sense Rob's energy dissipates as he reminisced back at that moment. It felt like a tiny, punctured hole in a balloon and the air was slowly seeping out. He recalls:

So, I worked at Federal Express as a package handler for a couple of years. I did some odd jobs. I tried to DJ. I wasn't that good. I bartended and I was a swimming pool manager. I was a lifeguard for the city of Oakland and the money was coming in slow and it was very seasonal. Being a pool manager, you make [the] most of your money during the summer. During the fall and winter, the money was slow.

Rob found himself in another pivotal moment in his life. As he did with his mom when he was at Southern University, Rob reached out to his mentors from San Francisco State University and Chabot College. Through their mentorship and guidance, Rob was accepted into the Master's 
Program in Counseling at St. Mary's College. Around this time, he also became a father to his

first child. Motivation was certainly at its peak. He elaborated further:

Yeah, I got hungry. I got hungry again. When you work hard labor jobs and odd jobs, you're like, "Okay, either I could do this for the rest of my life or I'm going to make a change." So, St. Mary's took me when I was at the peak of my motivation. I had already had the Southern experience. So at that point, I knew what it took now. The motivation was high and like I said earlier, I took ownership of it. My Master's thesis was Career Counseling for African American students. So, the more specialized your education is, the more it speaks to your mind and your heart, you're going to do well. You're passionate and passion can definitely drive your educational experience for sure.

Fast forward to today, after years of freeway flying, working at institutions such as the College of Alameda and Los Medanos College in Pittsburg, California, he has established his professional roots at De Anza College for the last twelve years. Making meaning of earning his Master's degree and getting a full-time, tenured counseling position, he simply replied, "I paid my dues. When I recognized that I came in with a rich culture and rich history, that's when I took ownership of my education." Reflecting on the song, Paid My Dues, from the late, great

Nipsey Hussle, Rob's academic journey embodies every word from Nipsey's hook:

Now it's a possibility that I can come from nothing to having it all

Now it's a possibility that I ain't gonna have it all and fall

But I stand tall

I've been down for so long, you really want a chance so

I done paid my dues, my dues, my dues

I got to go, up to the top.

\section{IT'S UNFILTERED}

1979 was the year that the Sugarhill Gang came out with their hit song, Rapper's

Delight. While it was not the first song to include rap lyrics in a song, it is widely known to be the first rap song to put Hip Hop on the map. When they appeared on the Soul Train in 1981, it propelled Hip Hop to mainstream status. Prior to the Sugarhill Gang, Hip Hop began to manifest as a culture through art forms that antagonized the status quo such as b-boying (i.e. 
breakdancing) and aerosol writing (i.e. graffiti). These various art forms later became the elements of Hip Hop culture. Flipping through old Hip Hop articles and news clippings, you can see images of young teenage boys wearing Kangol hats, large belt buckles representing Puerto Rico, and shelltoe adidas with burgundy fat laces. This was on the East Coast in New York City where Hip Hop was born. While Rob's family was from the East Coast, it wasn't until he was in Oakland when he learned about Hip Hop. Rob shares, "[We] had to base everything on what we saw in the movies. So pop and locking, break dancing, that all came from the movie Breakin'. Breakin' 1 and 2, Breakin' 2 was actually Electric Boogaloo with Ozone and Turbo, and I was just addicted."

Prior to the birth of Hip Hop, the West Coast had its share of historical contributions to Hip Hop. Poppin' was known in Oakland. Robottin' was represented in Richmond, California and struttin' emerged in San Francisco and San Jose. All of these different and unique street dance styles were inspired by the Boogaloo dance style that came from Fresno, California. So while Hip Hop didn't make it to the West Coast in the early 1970s, the arts and dance culture was alive and well. Rob flashes back to one of his earlier memories of Hip Hop:

We would always go to the Eastmont Mall, and we used to have this big event called The Gong Show. It was a spin-off off of the original Gong Show that was on TV, but the Eastmont Mall would have for local artists. So cats would come up there and either kick a freestyle, or it could be something that they had written. So it was writers, rappers, singers, and they might do a cover song from like Anita Baker or Chaka Khan, that type of thing. Or they would kick some original stuff. So these all tied into my early experiences. Because Eastmont Mall was an earshot away from my house, I would walk there. I would walk to the mall and just get immersed in what was going on in The Gong Show. Cats was break dancing right on my corner, on the corner right outside of my house. So I gravitated towards that. And my group of friends, our age group, we saw so much that we got our own cardboard, and we started tagging on our cardboard, our own turf. And this is what I've done. It was unfiltered.

Many Hip Hop enthusiasts may argue that Hip Hop today isn't real Hip Hop; that it is a culture that has been culturally appropriated and commodified to financially capitalize on its rewards 
and universal appeal to young people. When the general public defines Hip Hop, they naturally define it as rap music. It is also possible that rapping or emceeing became the face of Hip Hop because it is free and accessible to anyone. You can rap anywhere and anytime. While Rob acknowledges the importance of knowing the different elements of Hip Hop that provided the foundation of the culture, he cannot dismiss the power and impact of rap music. Rob adds, "It was new. It wasn't trying to fit into the genre of other musical genres. It was its own thing. It was street. It was gritty. And I was hooked like a junkie to drugs.”

Hip Hop started to hit its strides in the early 90s when artists and groups like A Tribe Called Quest, Nas, Jay-Z, Outkast, and the Wu Tang Clan came out with their seminal albums. Their success and inspiration came at the heels from rappers and groups such as LL Cool J, Run DMC, NWA, and Public Enemy. Aside from NWA and Outkast, most of these notable artists came from the East Coast. But that didn't mean that the West Coast, specifically in Oakland, was sleeping. It was wide awake with their loud, gritty bass lines and rhythms. Rob was excitedly nodding his head and quickly jumped into the cypher:

Oh, yeah, man. Rapper Father Dom was somebody that emerged from it. This young MC named Plan B. Plan B was a local legend. God rest his soul, he lost his life. His life was taken away far more earlier that what should have been. He lost his life to violence, Plan B. The Delinquents, the Luniz, Too Short, Dangerous Dame. Dangerous Dame wrote a love song. It was popular, it was called I Call Your Name, where he was kind of sprung on this girl, but the girl kind of moved away, or left without notice. So Dangerous Dame was big. Yeah. Too Short kind of pioneered. He opened the door for a lot of Bay Area acts, like Father Dom. MC Pooh, also known as Pooh Man. Rapper Ron and Ant Diddley Dog was, they had this group called The Bad-N-Fluenz. You heard of good influence, well, these cats called themselves The Bad Influence.

1990 was also the year when a former Oakland A's batboy by the name of Stanley Burrell took over the Hip Hop scene, both locally and nationally. We all know him as MC Hammer as his most famous song, "U Can't Touch This" blasted on every radio station, boombox, and walkman. Opening with Rick James' sample, "Super Freak”, Hammer would fill out concert 
venues performing on a stage with bright, flashing lights and intricate funky choreography with hundreds of background dancers. And everyone remembers those trademark Hammer pants. Rob laughs out loud, recalling, "I had some Hammer pants. I tried to typewrite across the stage or across the living room floor. Yeah, man. Oakland and the Bay Area had such a rich culture." I couldn't help but imagine Rob typewriting across the floor and suddenly stopping on a dime shouting, "Stop! Hammer time!" That year was a memorable year for many kids growing up at the time. I remember at our Filipino family parties, all of the cousins took turns trying to do their best impression of MC Hammer. This song wasn't just huge locally and nationally but it also took the world by storm. It was the \#1 song in 1990 in New Zealand. It went double platinum in Australia. While it was \#1 on the weekly charts in the US, Hammer's most famous song finished $\# 55$ by the end of the year. This would be a recurring theme for Bay Area Hip Hop. You can see the disbelief and frustration written all over Rob's face as she shares:

They just, they spit with fire, man. They just, in my mind, it was no competition to them dudes. And I wanted to see them. I wanted to see local dudes blow up on the international level, but some made it, some didn't. But Bay Area, Bay Area Hip Hop is my heart.

I totally agree with Rob in that the Bay Area had so much Hip Hop talent. We had the Luniz, Souls of Mischief, Del the Funky Homosapien, RBL Posse, Paris, San Quinn, Rappin’ 4-Tay, and Mac Dre. And we can't forget the Ambassador of the Bay, Mr. Charlie Hustle, E Pheezy, 40 Fonzarelli, most recognizably known as the legendary E-40. Bay Area Hip Hop didn't really need the Billboard Charts or Clear Channel to validate their contributions to Hip Hop. Just go to any club, venue, or house party, and you will never see the "dance floor empty" when songs from E-40, Mac Dre, or the Luniz congregate the air space. Bay Area Hip Hop was for the people, by the people. It was raw. It was gritty. It was definitely unfiltered. 


\section{BEATS}

I remember doing a collaborative keynote with Kim Davalos at San Francisco State University titled, “The Metamorphosis Factor", for students in the Master's Program in Counseling. The keynote was a mixtape between Kendrick Lamar's To Pimp A Butterfly and Lauryn Hill's The Miseducation of Lauryn Hill. In my piece, I talked about an experience about a counselor telling a young student to turn down his music. I remembered her saying, "Turn it down. Why do you listen to that noise?" One may argue that the choice of music is an extension of one's own identity and experiences. By describing his music as "noise", she is sending a message to him, intended or unintended, that his identity and experiences are not valued. As a college counselor, I am always interested in the music that my students are listening to because it gives me the opportunity to explore deeper into the lives of my students. The beauty of Hip Hop arts and culture is that it doesn't leave you entirely. Not everyone becomes a professional emcee, DJ, or a well-known graffiti artist. However, it becomes a part of our lived experiences and our identity. It represents the beats that reside in our soul.

Transporting back to Skyline High School, Rob shares some Hip Hop memories:

There'll be cats, six or seven cats form in a circle, and they would kind of be roasting each other, you know. They might be rapping about a stain on your shirt, or somebody else might be fluent about your run-down shoes, your shoes look run-down, or your shoes are outdated. And I tried my best to get in, to keep up with them. So we would just rock it that way. Now, I like hip hop, you know what I mean? But I never really fancied myself as one of the best rappers, you know. Freestyle cyphers usually be spontaneous, and like I said, it was high school, early college. We could be in a car, and you know that part in most songs, where they finish rapping, or the chorus is done, and after kind of the end, it's just kind of playing the music.

Rob pounds on the desk imitating the beatbox sounds that they used to do on lunchroom tables. I can imagine the silverware rattling on top of the tables. I see kids tapping on the sides of empty 
milk cartons while students were reciting rhymes over beats. Rob continues to share as he softly pounds the table to continue the beat:

Well, my high homies would kind of come in, or I would come in and try to rap. Yeah, those were fun days. It's like when you're younger, I feel like it's less inhibition. You know? You're not caught up in, "Oh, does this sound good?" Or, "Does this word rhyme?" You just kind of go for it. And to me that's the essence of Hip Hop. And I feel like I lost some of that, just that daredevil willingness to kind of just go for it and just jump into something.

Hip Hop at its core is about amplifying the experiences of those who are traditionally silenced, ignored, and invalidated. There is this unapologetic spirit to Hip Hop proclaiming that "we have arrived and we're here to stay." However, Rob brings up an interesting observation around the willingness to "go for it." What informed Hip Hop culture 40 years ago has definitely evolved today and may perhaps change the way we approach Hip Hop. But what changed? Rob shares his opinion:

I feel, in my mind, I feel like there's more of a stigma nowadays, to where people can become embarrassed over something silly? You know? Where back in the day, you try stuff. And you fail that stuff, sometimes you succeed at stuff. Nowadays, we're caught up, and like many adults, and I can't speak for everybody, this kind of a sweeping statement. It's a generalization where adults are kind of caught up in the 9:00 to 5:00, we're trying to be professional. And sometimes that just spills over to everyday life. I'm just less willing to take that risk and just start off kicking a flow than I was when I was younger. I'm not going to say I matured out of it, because that's insane. Your creative process, you should never mature out of that. But, just caught up in work, man. Work, and family stuff, you know.

Rob brings up an interesting statement and while it can be seen as a generalization, there are some partial truths hidden in it. Today, we are inundated with information in real time, 24 hours a day. We are bombarded with streaming TV, social media, and digital technological devices that are readily accessible through a simple touch on the screen. Regardless of what TV show you watch, what meme you find entertaining, or an Instagram post you found inspiring, we are constantly informed and re-informed about what we value and what we currently believe in. At 
the root of it is this idea around success. What is success? What does it look like? How does this definition of success impact and influence what folks say, do, or feel about

themselves? This is counter to what Hip Hop is all about. Hip Hop continues to be the rupture that disrupts the status quo. It is a reminder that there is still a richness in understanding our own history and culture. Rob sums it up eloquently about a conversation he had with his father:

Like my dad, he would rather listen to an album on a record player, vinyl, compared to Spotify. And I'm like, "No, That ain't..." I would challenge him. "That ain't the same sound." He's like, "No, sonically, it's not the same sound. There's a deeper groove when you listen to vinyl. There's a richness that emanates from an album, from a record being played on a record player. From that record, when that needle touches that album, it sounds different." And to me, that's how I look at old school Hip Hop up until now. There's a richness to that, you know what I'm saying? And we can't continue to get away from that richness, otherwise, we'll have to change the name of what this music is being called, man.

Despite the advances in digital technology, nothing can replace genuine authenticity. While there are no words, the beats represent a lived experience, a story, or a particular feeling or mood. In a world where we are accustomed to swipe right or hit the next button, the deep understanding and appreciation of the beats challenges us to listen with purpose and meaning.

\section{RHYMES}

While Hip Hop has evolved as a culture over the years, its evolution is what keeps it sustaining. There have been countless debates on what is considered real Hip Hop or what is the golden era of Hip Hop. One thing for sure is that Hip Hop is a culture that knows no boundaries, inviting creativity, innovation, and freestyle to shape and mold the culture for many generations to come. Although the construction of Hip Hop culture was born in America, its roots are indigenous allowing this culture to be practiced and understood universally. As a Hip Hop enthusiast and aficionado, Rob witnessed the transformation of Hip Hop over the last 30 years. For Rob, when it comes to rap music, it always starts with the pen. Rob expands further: 
My opinion is in the '80s, your penmanship had to be tighter. I feel like nowadays, you can kind of come out with a gimmick, some people will say a fad, and that fad or gimmick could be very popular, and you could sell. You could sell a lot of records just by pure virtue of that fad or that gimmick. When you sell a lot of records, you don't feel like you have to work on your lyricism. Do you know what I'm saying?

This was definitely one of the major discussion points when Hip Hop enthusiasts engage in debates about the essence of real Hip Hop. When rappers come out with fads and gimmicks such as dance inventions or creation of new slang, does it make their music any less real? Does capitalism dictate and determine what is played on the radio thus influencing what rappers write about? How much creative input does an artist have when putting out music? However, when it comes to good music, fads and gimmicks can come and go, but the lyrics and rhymes can be timeless. Rob extends further about the importance of lyricism:

So when we talk about cats like Eric B. And Rakim. Rakim, his rhyme pattern was different than Run-DMC. Right, Run-DMC's rhyme pattern was different than the Sugarhill Gang. So lyricism has evolved. But at the same time, people try different things, lyric-wise. So if I could paint the picture, like there are different kinds of poems. When you're writing the poem, there are different stanzas and different styles you can write to. It's the same thing with rapping. Eminem kind of changed the game, because he was able to combine a lot of words into a short space of time, bending words, flipping different syllables. Ludacris is the same way, where he would enunciate a certain part of a word to make it connect to another. So, to me, that's the brilliance of it. It's not the gimmicks. They're saying, "Okay, this is my style." And in Hip Hop, the more styles a person can have, the more tools that you can have in your tool shed, the better lyricist that you're going to be.

Hip Hop, particularly rap music, was about the shock factor. If you can get a crowd excited by your wordplay or if your words just annihilated another emcee in a rap battle, you would receive instant credibility about your lyrical prowess. Today, especially in the age of social media, where access to videos and streams are obtainable, there has been a shift in how the shock factor is achieved in rap music. We are constantly bombarded by texts, tweets, push notifications, ads, and the list goes on. A recent study found that the average human attention span has dropped from 12 seconds in 2000 to 8 seconds today. People crave new information every day that our 
attention span gets shorter and we become very selective of what we want to see and hear. Armed with this information, many music corporations such as Times-Warner and Clear Channel strategize to explore what consumers crave and want. Speaking with the expressions of hope and helplessness, Rob replies:

So a Blueface, these cats, they can come out, and they can glorify gang violence. They have tattoos on their face [and] they can do all of that. It's gimmicky. It's a fad. The main reason why you're selling records is because people want to see tats on your face and your dyed green hair. If that's the case, we're at a lost cause, you know what I'm saying? When was the last time a new artist came out and had break dancing behind him? Or their DJ could scratch. You know what I'm saying? Scratching always needs to be embedded in Hip Hop, because that was one of the things that changed the game, you know what I mean?

Part of my work with Rock The School Bells is to educate and inform our youth about the history and culture of Hip Hop. It was born out of resistance and the struggle. It was the voice of the youth who were experiencing oppressive social and economic conditions in their communities. However, the corporatizing and commodification of Hip Hop culture have shifted many young minds from learning the historical roots of Hip Hop to chasing the financial wealth gained from it. In addition to Rock The School Bells and other educational conferences, artists have played a significant role in keeping the art of lyricism and storytelling alive. Rob gesturing with both hands shares:

And that's why people will say the J. Coles, the Kendricks, the Big K.R.I.T.s, these guys are going to stand out, because they know that there's an inherent thing in them that they know; that they've got to keep it true to what the culture intended them to do.

Hip Hop will always evolve but it is also important to have artists such as those Rob mentioned above along with others such as Vince Staples, Ruby Ibarra, Bambu, and the Roots that can provide that balance to ensure that integrity and history of Hip Hop culture is maintained and always remembered. 


\section{LIFE}

$08 / 05 / 2019$

Hip Hop + Hoops (9:43AM):

Yo! Did you see the tweet about the list of the Top 50 Best Rappers of All Time by The Brew Podcast?

Nate (9:45AM):

Nah, let me check it right now.

Hip Hop + Hoops (10:06AM):

What were they thinking? 'Pac at 15? Eminem at 28? LL Cool J at \#46?! This is blasphemy!

Nate (10:07AM):

Who are these guys anyways??? Are they for reals?? Joe Budden at \#3??? Joe

Budden??? Over Biggie, 'Pac, Eminem, Kendrick??

Hip Hop + Hoops (10:08AM):

Do these cats even know their Hip Hop history? What criteria did they use???

Nate (10:09AM):

Not sure if I should take this list seriously 'cause these cats be crackin' jokes all of the time. But

if they really think this is the top 50, their Hip Hop credentials should be immediately revoked.

Hip Hop + Hoops (10:10AM):

LMAOOOOOOOOOO. I'm gonna make my own Top 50.

Nate (10:11AM):

I only got time to do my top 5 but damn, this is gonna be hard. Nas, Biggie, 'Pac, Rakim, Eminem? Damn.

Hip Hop + Hoops (10:13AM):

Black Thought or Kendrick Lamar not in your Top 5. Those emcees are BEASTSSSS!!

Nate (10:15AM):

True that! Can't deny them either. I can also see Kool Moe Dee, Andre 3000, and Mos Def make the top 5 too.

Hip Hop + Hoops (10:16AM):

If you add Mos Def, you gotta add Talib Kweli in there too. And LL Cool J. He definitely changed the game. How about Joe Budden???

Nate (10:18AM):

Hahahahaha! Definitely no Joe Budden! 
Within minutes after the tweet, people around the world jumped into the debate, tweeting their opinions about the Top 50. Whether the Brew Podcast truly believed in their Top 50, it did what it's supposed to do -- ignited a heated conversation among followers and the general public about who belongs in the Top 50 .

It's the second interview with Rob, roughly two weeks after our first interview. I was feeling a lot better than I was the last time we met. The shining sun replaced the wintry rain and I could feel the Hip Hop in the air. I met Rob at this office in the Counseling Center as he was finishing up his lesson plan for his evening class. Rob asked, "We about to talk about some Hip Hop today?" I replied, "Most definitely." Reflecting back at the text messages with my friends, I decided to start the interview by asking him a similar question. I've asked this question many times to so many people and there has never been a true consensus. So I let the question roll off my tongue, "Rob, who would you consider the best lyricist of all time?" As with everyone I've asked, there was not a stillness in the room. Rob leaned back in his chair, swiveled left to right, clasping both hands together, and pondered. His eyes gazed to the ceiling and slowly drifted back down to the table. "Of all time?" he asked. "Can I give you three? I replied, "Sure." He responded back, "Okay, okay, I might have to give you five, Nate." We both laughed in agreement. So, naturally, the question about who was the best lyricist of all-time transformed into a Top 5 list. The mental journey of having to think through this list can be seen on his face as Rob replies:

I look at Kendrick as kind of, I would say, if I could use a comparison, I would say he is the Steph Curry of rap right now. Because he's done a lot, but there's still more to go. There's still more to go. And just by pure virtue of the projects that Kendrick has already put out, I've got to put him in my top five. I've got to put Eminem in my top five. I just have to. You know what I'm saying? Black, white, green, I don't care. That dude is a genius. Just lyrically, he has cadence. His rhyme pattern, the things he can fit into a sentence is insane, dude. And he's got hella different style. So I would say Em. 
So far, so good. I cannot dispute Rob's first two picks. Many folks argue that Kendrick Lamar shouldn't be in the Top 5 or event Top 10 given his current longevity in the game. There's an unwritten rule that to be considered one of the greatest emcees, you have to pay your dues. Rob without skipping a beat continues:

I would, in terms of changing the game and gangsta rap, I've got to put Ice Cube in there. I've got to put Cube in there for the simple fact is he wrote most of the NWA's lyrics to date. And he wrote for himself. He's ghostwritten for other people. He put cats, females like Yo-Yo. And I've got to do the standard Pac and Biggie, you know? For their influence on both coasts, God rest their souls. And nobody wanted to see it, the East West Coast battle, a war like how it was. I am saddened to this day that B.I.G. lost his life in the West Coast, you know what I'm saying? That hurt me, that we just couldn't let him just be, after his album launched, you know what I'm saying?

I still remember the day when 'Pac died. It was surreal. My friends and I were saying, "Tupac is gonna survive this like he always does." And when he didn't, it felt like a piece of us died with him too. Tupac spoke to me in so many ways, inspiring me in my own writing process. I even remembered when my Mom was so upset with me because of how I was doing in high school. One day in hopes of her forgiving me, I made her some breakfast while playing Tupac's song, "Dear Mama." She tossed and turned and told me, "Turn it off, anak!" Well, I tried. But Biggie's death felt different. He, too, was one of my favorite emcees. His death was a reminder of how destructive the West Coast-East Coast rap beef was. I remembered his last radio interview in San Francisco with JV and Elvis on the Doghouse morning show on Wild 107.7 when he was promoting his last album, Life After Death. He paid his respects to Tupac and responded to a question around attending a Hip Hop conference. He said, "I'm down to attend and speak at these conferences but I would never say I'm here to squash this when I don't feel that there was any beef to begin with.” Days later, Biggie was shot dead in Los Angeles. That statement still gets to me to this day because I just remembered how much the 
media was hyping and elevating the West Coast-East Coast beef. As a result, two young Black men died in violence. Before I could segue into my next thought, Rob abruptly interjected:

And then, Outkast, in terms of the South. They changed the game for the South, man. And it's been...I think I'm at six, so I've got to cut it there. But it's been mad, mad folks that I love, you know what I'm saying? If I could do this again, like Nas changed the game for me. Lyrically, my top two would probably be Nas and Em. It's got to be either of them two. For me, for me. You know what I'm saying, where I could listen to it, and take something from it, from pretty much all of their albums, man. And if I had to say number one, it would probably be Nas. Nasir Jones.

I counted 7 emcees on his Top 5 list but that's how it usually goes when we engage in these kinds of debates on who's the greatest lyricist of all time. What emerged for me based on his list was that there were distinct criteria: lyrical skills/wordplay, accolades and awards, and ability to "change the game." I can certainly agree that all of the emcees he mentioned check off all of the boxes.

Within the four elements of Hip Hop, rap or emceeing always comes at the forefront. There was a time in Hip Hop when the DJ was the central figure of the culture. They were the ones controlling the energy of the party with the music while the emcees were their hypemen. You can hear the emcees do a call and response with the crowd yelling, "Throw your hands in the air and wave them like you just don't care. And if you're ready like Freddie to rock real steady, somebody say 'Oh yeah'”. Since then, the emcees began to move towards the forefront where they became the face of Hip Hop. The other three elements of Hip Hop don't necessarily get the same shine today as emceeing. However, they are alive in cultural spaces such as b-boy jams, DMC turntable battles, and Hip Hop conferences. Having witnessed the evolution of Hip Hop, I asked Rob what continues to draw him to Hip Hop. Rob takes a deep breath and replied:

Not to be cliché, but mostly Hip Hop artists are reporting a lived experience. A lot of them are reporting from the streets, the ones that I like. There are some cats that are just 
selling the image, you know what I'm saying? They might not have, never have killed, robbed, or sold dope, or anything, but they talk about it in their rhymes as a way to attract people, and these might not be that lived experiences. But, the Big K.R.I.T.s, the Nas', they tend to keep it a little bit more real. What made Illmatic such a dope album is [that] he gave you a visual of New York, at that time, Queensbridge, you know what I'm saying?

Jay-Z once said in an interview that rap music was like the $\mathrm{CNN}$ for the 'hood. Emcees were rapping about their own lived experiences. When I first heard Nas' Illmatic, I felt like I was transported across the country and landed in Queensbridge. Two summers ago in 2017, we brought our CIPHER Hip Hop Learning Community students to New York City. One of our students had religious commitments and needed to attend church service early that Sunday morning. His church happened to be in Queens, NY, about five blocks away from the Queensbridge Housing Projects where Nas grew up. We both agreed that we'd visit the QB Housing Projects after his church service. So, we took the $\mathrm{C}$ and $\mathrm{F}$ train from Brooklyn to Queens and arrived at our destination about an hour later. Decked out in all black from his button up shirt, slacks, and shoes, my student exited the church and we both started to walk towards Queensbridge. Running parallel to the East River, we walked down 21 st street while folks were lining up for the early morning cup of coffee from the corner store. We continued to walk underneath an overpass that was connected to the Ed Koch Queensboro Bridge passing by warehouses with intricate and colorful graffiti and mural designs. We made a left onto 41 st street where we were two blocks away from the Queensbridge Housing Projects. We were now standing on the street corner where we saw a big blue sign with orange letters that read, "Welcome to Queensbridge North Houses." Looking up, we marveled at the tall, brownstone buildings that occupied the city block. There were kids chasing each other while sounds of jackhammers filled the air. The subway trains were whistling behind us while dozens of people lined up for free bread, fruits, and vegetables at a nearby community center. My student and I 
both paused and took a moment to breathe it all in. This is where Nas grew up. This was the inspiration of Illmatic. We couldn't believe we were actually there. Rob reflected on the documentary, Illmatic, and shared:

And if you look at any documentary about Nas, Queensbridge always felt like the stepson to the other boroughs: Harlem, Brooklyn, Manhattan, Staten Island. They always felt like they were runner up to Brooklyn and the Bronx. So when you have that ... It's just like sports. If you're playing with a chip on your shoulder, you're bound to put more hustle, and put more work in it, and that's what I got from Nas. It's penmanship second to none.

Because Rob was also an author, it was evident that he gravitated to the lyrics. I asked him why

Hip Hop lyrics resonated with him. Rob eloquently reveals:

Just realness. The very first thing that might lock me in is the beat. Somebody could have the tightest bars in the world, but if the beat is whack, it ain't really going to hook me. So it has to be a combination of having that good beat, solid beat, and the lyrics, that are taking you somewhere. I love songs that have to deal with a story. You know what I'm saying? And Illmatic, One Love, he had, it was riddled with stories. One of the stories, he was trying to connect to an army youth that had kind of lost his way, you know what I'm saying? And the young dude was out here in Queensbridge selling dope, and Nas was able to convey this in a rap. It was genius-like. Biggie did the same thing with Ready to Die. He had moments where he was telling his listeners he was suicidal. That's the name of the album, Ready to Die, you know.

You can hear it in Rob's voice how impactful these emcees were for him. The great artists have the ability to take their listeners on a journey through beats and rhymes. Their songs created a feeling; an experience that transported you to where they were from. Rob's excitement even grew more as the volume of his voice began to rise:

These are lived experiences. And I haven't really heard the new dudes coming out really talking about the struggle, but it was a poetic way that Biggie, and Nas, and Pac were able to do it. Me Against the World album, with Tupac, that's arguably one of the best albums of all time, you know what I'm saying? He's talking about his high school. Remember peppermint schnapps in junior high? He was talking about cutting school to go drink some peppermint schnapps. If you know anything about alcohol, that's not something that's going to get you super, super bent. But when you're young, it might. So it made a connection for me. Because I remember cats drinking peppermint schnapps. You know what I mean? 
We both laughed hysterically because we both knew, without even acknowledging it, that we both tried some peppermint schnapps thinking we were tough, grown men in junior high school. That drink tasted like candy canes and if you drink too much it, it'll get your mind thinking it was Christmas in April. Rob continues, "So, if somebody has a way with the pen that's taking you on a journey, you could hook me. It's about that storytelling."

I remember reading about a story when President Jimmy Carter made a surprise visit to the South Bronx in the late 1970s to see what the communities were experiencing. At the time, the number of arsons had risen significantly, unemployment rates were skyrocketing, and gangs began to take over the streets as a means of survival. While this trip was a secret, the Bronx knew he was arriving. The Presidential motorcade arrived with six motorcycle escorts and multiple police cars. Hovering above them, there were three helicopters flying over the Third Avenue bridge and headed towards the Grand Concourse. President Jimmy Carter stopped by a couple of renovation projects to see the conditions that the South Bronx were under. He met with the people in the community to explore ways to help with the progress. South Bronx was experiencing urban decay as President Carter recalled his experience as "a very sobering trip to see the devastation that has taken place in the South Bronx."

Unfortunately, this is not a story that is commonly experienced where the lives of people who live in impoverished conditions are shared and seen. While communities such as the South Bronx are rendered invisible and silenced, there is a fight and resilience that grows among the people. Hip Hop, particularly, rap music, was a way to share these stories about the lived experiences of their communities. You knew about Queensbridge because of Nas. You knew about the Marcy Projects because of Jay-Z. You knew about South Central LA because of NWA. You knew about Oakland because of Too Short, Richie Rich, and Boots Riley of the 
Coup. Rob led off Chapter 2 in his book, Can't Let Nobody Ride My Bike, with the verse from the song, "Dig It" by Boots Riley.

So what happens when a people do not get they dues

Well, let's try it, there's a riot so flip on the news

And let's go reach the 98th here in Oaktown

But let's just say for story's sake that it's in your town

A hundred brothers takin' factories, Warren's law is gutters

And now they handin' out free chicken and free peanut butter

Free food to the people, how it should be

But now let's go a few blocks over to seventy-three

Channel two says at the mall twelve cops got shot

'Cause there's eight hundred sistas takin' over Eastmont.

\section{WE CAN RELATE}

Hip Hop and sports are two topics Rob and I can talk about for long periods of time. I

just finished sharing with him about moving to the Bay Area months after the 1989 Loma Prieta

Earthquake. I remembered vividly sitting at home in North Chicago watching the Bay Area

World Series between the San Francisco Giants and the Oakland A's. I was rooting hard for the

A's to win because the Giants beat our Chicago Cubs in the National League Championship

Series. In the middle of the broadcast, the footage started to shake and zig zag lines started to

appear on the TV screen. As I usually do, I hit the sides of the TV and started to adjust the

antennas that were wrapped with aluminum foil for better reception. Then, the multicolored

Emergency Broadcast System appeared on the screen. Minutes later, we found out that the Bay

Area was rocked with a 6.9 earthquake.

Since moving to the Bay, I have adopted the Bay Area teams as my own and grew up

loving the Golden State Warriors especially during the days of Run TMC with Mitch Richmond,

Chris Mullin, and Tim Hardaway. We talked about Jason Kidd when he was playing at St.

Joseph's High School. I was sharing how JR Rider used to cut hair in the hallways of Encinal

High School. We also both remembered the East Bay Funk dunk that JR Rider did at the Slam 
Dunk competition at the NBA All-Star Game in 1994. We both wondered how someone so talented like Rider fell hard and disappeared from the league. As we shared Bay Area sports stories, Rob was starting to find out that we were probably around the same age. We were definitely connecting on a whole different level. As college counselors, we both understand the importance of connecting with people. Hip Hop culture was about the connections that were being made by the different elements of Hip Hop. I wanted to learn more about how Rob defined Hip Hop pedagogy. Simply put, Rob describes it as "when we talk about Hip Hop as a way of life, it has something to do with how you're connecting with students."

\section{WE RIGHT HERE. I SEE YOU.}

One of the concerns that we get bombarded with when it comes to utilizing Hip Hop pedagogy in our counseling and teaching practices is that not all students identify with Hip Hop culture. I always chuckle to myself when I hear folks from higher education make that comment as if our students of color have never experienced moments of silence and invisibility in classrooms where topics didn't speak to their own cultural experiences. Hip Hop pedagogy is more than just what we utilized to connect with students but more importantly, how we connect with students. Through his book, Can't Let Nobody Ride My Bike, Rob uses Hip Hop as a way to connect to his readers. Not everyone has to know or listen to Hip Hop to understand what Rob was experiencing throughout his childhood. Hip Hop was the canvas for Rob to use to artfully share his experiences. He expands further:

One of my chapters is called Knuckle Up. And I used KRS-One's [song], Love's Going to Get'cha. Because he's talking about how he couldn't be soft, in the hood that he said, "I walked from school to my mom's apartment. I got to tell these suckas every day, don't start it. Because where I'm at if you you're soft, you're lost. So stay on course means to roll with force." So he's trying to let you know, right then and there, I can't be no scrub with how I deliver myself, or how people perceive me. I have to, as your parents tell you, look people in the eye, you know what I'm saying? Walk with your head up, keep your back straight, kind of thing. So I use Hip Hop to contextualize my lived experiences, 
because everything that I've gone through, I can connect that to a song. I can connect it to a verse.

With how the classrooms are traditionally structured particularly in the K-12 settings, it upholds the power and privilege teachers have over their students. Typically, the teachers teach the topics while students are expected to passively take in the information. The types of topics can also be problematic especially if they don't connect to the lived experiences of the students in the classroom. Rob concurs and says, "Students feel like there's a disconnect between them and us. A lot of students feel like the teacher is way up here, and students are way down here.” Rob uses his hands to gesture the hierarchy of power between students and teachers. But by using Hip Hop in our spaces, we begin to level the experiences between the students and teachers. Using the same hands, Rob moves his hands horizontally left to right, painting an imaginary leveled plane. He adds with animation:

But Hip Hop can kind of let them know, "No. We right here, on the same playing field. We right here. I connect with it. I see you. I see your struggle." Hip Hop is about your neighborhood; it's about struggle. It's about making something out of nothing, you know what I mean? And that's what a lot of our students are trying to do, make something out of nothing. When you talk about a first generation college student, they didn't have the red carpet rolled out for them. They're not coming to school with a silver spoon in their mouth. They're trying to make something out of nothing, and that's what Hip Hop is to me.

As scholar Daniel Banks would argue, we need to shift the narrative from "make something out of nothing" to "make something out of something." The phrase, "making something out of nothing" is an aesthetic of Hip Hop. It can be heard in numerous songs and in different ways such as Tupac's line, "I can make a dollar out of fifteen cents." While it can be seen as a phrase that is deficit-based, it also speaks the truth to the experiences of communities of color who have been historically and traditionally marginalized. Related to Hip Hop, Rob makes the historical connection: 
We started just making beats. We started blending two records together, you know what I mean? This is your creative force, without a whole lot of instruments, with a turntable. They were able to do it. And to me, it's essential in connection with our students. It's showing them, like, "Hey, I'm down, I'm relatable. I'm not this academic that's way up here. I'm on the same level. We listen to the same music. I'm all about the struggle. I'm all about uplifting my people." This is everything that Hip Hop represents to me, Nate. Real talk.

By centering our students' experiences, we are acknowledging the community cultural wealth they all possess. If it weren't for Hip Hop pioneers such as Grandmaster Flash, Grand Wizzard Theodore, and DJ Kool Herc, we wouldn't have the innovative sounds of Hip Hop. People forget that these notable DJs were just teenagers when they figured out how to manipulate sounds using two turntables or connecting their DJ equipment to lamp posts at the parks during their community jams. This connection between educators and students becomes tighter when we begin to see our students as knowledge-bearers. We teach you. You teach us. It becomes a community of learners where we are all engaging in cyphers and cogenerative dialogues.

These educational spaces rooted in Hip Hop pedagogy offer experiences that are authentic and welcoming. In any Hip Hop space, showing and proving is an essential part of relationship building. Rob leans forward and tugs on the lapels of his blazer and shares:

Typically on days where I teach, I dress it up. I'll do the hard bottoms and the slacks and the button-up a little bit more. But days where I'm not teaching, I've come to school rocking J's and Air Maxes. I've even be hoodied out. Even how I dress, students will see who I am as a counselor. And a student will be like, "I want to see him." You know what I'm saying? So it further crystallized that connection that I have with students.

Being authentic and how we present ourselves to our students are extremely important in our ability to connect with them. Keeping it real and keeping it one hundred are common sayings we hear from youth and students when it comes to authenticity. Rob shares his perspective within the context of men of color:

So from your swagger, to your dress, to just how Hip Hop informs your life. The connection is an unbreakable bond, almost, being formed, to where that student even 
remembers you years after they left this place. There's not too many male counselors of color to begin with, but if you're coming off like Poindexter, it's going to be less attractive than coming off as somebody that's relatable. Because the majority of our students, they're all listening to Hip Hop. They're connecting with different Hip Hop artists, [even] if it's artists that we don't personally like, you know what I'm saying?

Rob has shared throughout his book many different examples where he and his friends had to present themselves in a certain way. If you were seen differently, you would be labeled as a "sucka", outcast, or punk. Drawing from his own experiences, Rob can empathize with many male students of color he works with who have experienced similar messages. It's important for him to present himself as authentically as possible because it allows his students to feel like they can be their authentic selves. From the metaphorical ICUs to moments of "I see you", students begin to truly see themselves.

\section{CRUSH, KILL, DESTROY STRESS}

It was 1994 and Hip Hop was booming from the West Coast to the East Coast. I can still remember coming home from high school and flipping on the TV to catch BET's Rap City Top Ten. I remembered connecting my Pop's vintage Pioneer CT-1770 double cassette tape deck recorder player to the TV where I would record all of the songs from that show. I vividly recollect two Hip Hop songs that captured my experiences in high school. I was going through a lot of struggles in school and in my personal life. It was either the song, "Slam", by Onyx or "Stress" by Organized Konfusion. Everytime the song, "Slam", played, all of the homies would gather in a circle and smash into each other like we were in a mosh pit. That song always gets me amped up. But the song, "Stress", was the song that really spoke to my soul. The hook and the first verse went like this:

Crush, kill, destroy, stress

Crush, kill, destroy, stress

Crush, kill, destroy, stress

Crush, kill, destroy, stress 


\section{Pain, stress}

My brain, can't even rest

It's hard to maintain the pressure on my chest

Excess frustration strikes!

Blood rushes my head when I come across roads

With dead mics and wack promoted shows it's hard

But with the presence of God

I'm true to the game

So I'm back black, to take change, and recapture

The time, wish it could never be wack, I'm pure

I insert my lifeline into the track, the energy

In me is a poison with no unrevealed remedy.

That song was one of the top Hip Hop songs that year and is considered one of the all-time

classics. While the sounds of that song are recognizable, it was the verses that really connected

with people. Everyone experiences all different types of stress. Our students we serve,

particularly our traditionally and historically marginalized student populations, all experience a

wide range of stress. As counselors, it is important for us to acknowledge the stress but also

address it in a way that centers their experiences. Reflecting back to some of his counseling

appointments, Rob provides a common example:

Just take, for instance, if you are nervous about school, and you're thinking you can't holler at none of these professors, you can't holler at none of these counselors because they are on this platform that's just unreachable, and you come into their office, and they start playing some Hip Hop, or they start talking about, "Well, Lil Pump got his style from such-and-such." That's a direct connection that you have with that student. It can demystify stress. It could tear down some of these perceived barriers that students might have.

Along with engaging in culturally relevant topics, it is also important to create a counseling space that students can draw connections to, both visually and through sound. Rob excitedly tells his experience with a highly popular form of music:

Now we have lo-fi Hip Hop and chill hop. I love it. I could let that run all day, bro. And it doesn't have the lyrics to it, but it's so soothing in the background. And students have literally told me, Nate. They was like, "Man, you're the first counselor I came into the 
office and have music playing in the background." It kind of set the stage for me, you understand?

When we create a space that connects with students and engage in conversations that are culturally relevant and responsive to their needs, we begin to rewrite the narratives of how students view counseling in general. Rob nods his head in agreement and explains:

I think a lot of the negative perceptions of counseling might come from high school because I can't tell you my high school counselor name or what they were about. So, I think that a lot of students have that similar narrative. One student even told me that their high school counselor told him that, "You're good with your hands. Why don't you go into something like plumbing? Why don't you?" Plumbing is not a bad profession. I'm not knocking any of the trades, but this student has so much more. But when that's put on you, we're limited or men of color are limited to going into the trades or a vocation. With that doesn't require education, that's a negative perception. That's a negative stereotype that we're putting on.

Rob adds, "That anxiety level will start to decrease because now, 'I don't see Nate as somebody that's just this super smart dude, to where I can never reach it. I want to be like Nate, know what I'm saying? He's brown like me. I think I could do this school thing., ', Rob also shares a study where the rates of retention, success, and graduation increases when students work with counselors and teachers who look like them and understand their experiences. "There's a study out there that say if you are a black student and you have a black teacher, your chances of graduating from college doubles. If you are a Latino and you have a Latino counselor or teacher, it doubles your graduation, your retention doubles. I believe that."

\section{SEEING THE BEST IN YO(U)}

Hip Hop has always been about survival. Its culture was built on the lived experiences of African Americans and Latinx communities that were affected by the social and economic conditions of the South Bronx. However, despite the fact that we are able to enter the world many artists came from through their music, not everyone from those communities are fortunate enough to get out. The trauma that they have endured can have lasting emotional and 
psychological effects on their lives. Kendrick Lamar in his song, "u", depicts these experiences so vividly illustrating how these impoverished conditions eat at one's mind and soul, making them believe that they are not worthy or not good enough. "Loving you is so complicated" is repeated over and over throughout the song, acknowledging that these repeated messages can crush one's sense of self. As counselors, it is our role and responsibility to be able to recognize these signs of low sense of self-worth. By listening with purpose and intention, we may be able to help students arrive at a place in their lives where they can yell at the top of their lungs, inspired from the words of Kendrick Lamar, "I love myself!"

Hip Hop provides opportunities for voices to be heard and to be amplified. Counseling, within the context of Hip Hop pedagogy, helps make meaning of these voices and experiences. In graduate schools for counseling, we learned about many theories and techniques that we can apply in our college counseling practices. Rob describes his counseling philosophy as holistic and student-centered. He credits Carl Rogers as a major influence on his counseling approach where he was known for his humanistic approach to psychology in which he provided three core conditions to therapeutic change. These conditions consisted of congruence, unconditional positive regard, and accurate empathic understanding. They needed to exist in order for counselors to get students to become the very best versions of themselves. Of the three conditions, Rob resonated most with (u)nconditional positive regard because creating this experience in a counseling session reminded him of Hip Hop:

Unconditional positive regard means that you see the best in everybody that you encounter. And that's what Hip Hop is. You know what I'm saying? A lot of Hip Hop started in the Bronx. It was rampant with violence, and it's the pre-crack epidemic. Fires were sweeping through the Bronx, through the projects. So Hip Hop was able to come out of that and not only be a force, but the Hip Hop artists that I connected with, they saw the best in their lives. They knew that they were brilliant; they knew that they were these creative forces. So I connect that with Rogers' unconditional positive regard when I'm 
working with first generation students, I don't listen to the, "I can't." I'm more of, "You can. And you will." You know what I mean?

Being the best is nothing new in Hip Hop. It's almost a prerequisite to believe you are the best in a music industry that can be competitive. Rap songs are laced with lyrics that illustrate one's belief that they are the best in what they do. Some may argue that Hip Hop can be too egotistical. However, due to Hip Hop's natural tendency to be competitive, it also falls victim to sweeping generalizations that Hip Hop is too braggadocious, egotistical, and hypermasculine. While some artists can be categorized within any of these statements, not all artists represent that. For some, this is a point of self-validation and self-worth in a society that sees them otherwise. Hip Hop pedagogy is an extension to unconditional positive regard. Rob positions himself accordingly to accentuate his point:

To me, that's directly connected to Hip Hop. As I said earlier, it's making something out of nothing, but the main thing for me is seeing something good in everything that we do, in every person that we serve. A lot of counselors, we see ourselves as healers. We really do. I do. I see myself as somebody that has a calling to help people in and outside of my community. So I approach this work very seriously. I try to maximize what a student gets out of each session. I've worked with students sleeping in their cars, I've worked with exfelons. And I always saw the best in them.

For many students, this experience is counter to what they have been accustomed to. Through the support of counselors like Rob, they are seeing a shift in their own narrative; that they are not relegated to a single story. If anyone understood that, it would be Rob. Rob shares an experience that happened in 1996 that he will never forget:

I got arrested for joyriding in a stolen vehicle when I was 18 years old. I was falsely charged with kidnapping, carjacking, and weapons. I was sent to Santa Rita Jail in Alameda County. I was this skinny 18 year old kid in jail surrounded by drug addicts that were going through withdrawals. It was nauseating. I learned how to keep to myself and not let fear show through. My mother had my back and supported me through the whole ordeal. Before my mother posted bail, I was able to beat the case due to a confession. I was exonerated from all charges. 
He shared with me the newspaper article and expressed that he uses it as a reminder of how one mistake can ruin one's entire life and to be mindful of the company we keep. This experience really impacted the way he works with his students. He knew that he could lead as an example. Rob presented a scenario:

And if somebody were to tell me, tell a young, 18-year-old Rob, "This is what your life is going to be about. It's going to be a revolving door, where you're going in and out of jail. You know what I mean? You're not going to make something out of yourself." I wouldn't have believed him, because I knew that I was so much more than a mistake that I made when I was 18. And if you're a community college counselor, that's your job, is to see the best in people.

Jay-Z, Eminem, Lil Wayne, and Drake had songs highlighting themselves as being the best. Nas had a song, "I Can" that inspired the youth that they can be the best. And you had DJ Khaled who popularized the phrase, "You Da Best", reminding us that we can be the best. Hip Hop reminds us that we can be the best despite what the world thinks of us. Rob drops the metaphorical mic in terms of the connection between Hip Hop and counseling:

I'm not on some outlandish far-fetched connection that I'm trying to make. That's what Hip Hop is all about. I see the direct correlation, and seeing the best in your community, seeing the best in the family that you came from. Seeing the best in what you were given, and making something out of that. That's what Hip Hop is about, that's what my counseling philosophy is about. And that's what community colleges are about, really.

\section{CAN'T LET NOBODY RIDE MY BIKE}

Rob teaches a course called Life Skills for Higher Education. This is a course that primarily teaches students various skills and strategies that they can employ while in higher education. Rob shares about one of his assignments that resonated with his students. He had his students write a five-sentence poem on their neighborhood based on where they grew up. "A poem, a rap is just a poem over a beat, right?" Questions he would ask them to think about include: What do you see when you look out of the window? What are the sounds you hear when you step outside of your door? 
Another example of an assignment his students thoroughly enjoyed is the "I Am"

poem. He shares a few examples: "I am a product of Ruth and David." I am a product of the struggle." "I come from strength." Hearing him share these different examples, you can sense the excitement in his voice. Rob explained:

All of these, I have them, it's a formula that I give them, but I have them interject adjectives that they connect with from growing up [such as] culture, tradition, customs, history, and beliefs. You have to address all of those. And to me that's Hip Hop. Because Hip Hop artists, they were the best at, the original Hip Hop artists, they were the best at telling you about where they come from, their lived experiences. And how it doesn't take a backseat to yours, it's just different. And that's what made it a beautiful thing, because people love realness. People love authenticity.

When we ask our students to open themselves up, we're asking them to trust us and to be vulnerable. That is a big ask for students who may not have ever experienced a space where their stories matter. Hip Hop is about authenticity and reciprocity. If students give a piece of themselves to us, Hip Hop demands educators to be vulnerable in their space. To be able to share about ourselves and to be able to show and prove, sharing our stories is counter to what graduate schools have taught us. The spectrum of how much you can self-disclose is arbitrary. It is something you cannot measure. Storytelling is an integral part of communication within cultures. Storytelling is Hip Hop.

As a result, Rob wrote his book, Can't Let Nobody Ride My Bike, which is a collection of stories that include avoiding the entrapments of bullying, peer pressure, not being ready for sex, and avoiding the peer pressure of drugs. Writing a book is similar to creating a Hip Hop album in that in addition to writing the chapters, how those chapters flowed was extremely important. Rob elaborated further:

All of these were connected to an element of Hip Hop. And that's why I chose this format. When I'm giving it to publishers, my editor, they said they've never seen it. So, I was definitely trying to aim to do something groundbreaking. Now I'm just trying to get it 
in the hands of more people because what good is a book if it's shelved? You know what I'm saying?

I shared with Rob one of my favorite assignments. I have students choose any Hip Hop album and write a reflection about the album cover and title. This assignment works best when students choose an album they have never listened to. What does the images represent? Why do you think the artist included those images? What's the meaning of the title? What colors do you see? What fonts are they using? This is such a powerful activity because students are tapping into their own knowledge that is rooted in their own experiences and acquired wisdom. So, I did the same activity for myself when I was looking at the cover of Rob's book. But before I share my thoughts, I wanted to hear the origins of the title from Rob. Reflecting deeply, Rob explained:

The title of my book came from an expression that me and my childhood friends said all the time, "Can't let nobody ride my bike." If you remember, if you saw Friday, when Red got punked for his bike. Friday was so dope because a lot of things that were happening even when Youngster Chris would go by people and kick the garbage can down, all of these were connected to things that were happening in the hood. So Can't Let Nobody Ride My Bike is just a call; a saying that you would tell somebody, a bully, an older cat, that wanted to ride your bike, and you didn't really know him or her like that. And you weren't really sure if your bike would return.

I was gathering at this point the importance of his bike. The bike was just not a bike; it

represented more. Rob expanded on the value of his bike:

You know how it was in the hood, Nate. Your bike is something that you probably got on your birthday or Christmas, basically. Your bicycle usually didn't just come on a regular day. It was a monumental thing to have. And in East Oakland, in the flatlands, your bike was your transportation. We would bike all the way to San Leandro, you know what I'm saying? So, essentially, you let somebody ride your bike and don't come back, that's like taking your car. So that's where my title came from.

The bike was certainly more than just a bike. It was an extension of Rob. It was a vehicle by which he was able to explore his surroundings and make meaning of his experiences. It was the connection to so many stories and experiences that detailed his life during his teenage years in 
Oakland. While his bike represented his past through his memories, it also represented his future.

Throughout his book, he shared his fascination of the sideshows in Oakland. You can imagine 5.0s doing donuts while smoke filled the air. The intersection was filled with so many Hip Hop artists. "You could be at a sideshow in '98 and look to your right, and see Dangerous Dame. You could look to your left and see Poohman. You could look across a sideshow and see Too Short. Fast forward up until now, you could see Dru Down, you could see Mistah F.A.B." Rob and his friends imagined that their bikes would soon become muscle cars whether it was Chevelles, Novas, or Pontiacs and they would participate in sideshows. But as Rob grew older and mature, he recognized that sideshows were unsafe. While sideshows were a cultural fixture of Oakland, he knew he had to approach it with a critical lens, a critical consciousness. For Rob, it was an "awakening."

To experience an awakening, one would have to relieve themselves of their biases and assumptions. One would have to be open-minded and to explore all perspectives to make an informed decision. The awakening can be seen as the moment of "wokeness." In many ways, college counselors co-construct counseling experiences with their students to arrive at their own awakening; their own deep understanding of self. For that to happen, creating counseling spaces that are brave, safe, and humanizing are vital to having strong, authentic working relationships with students. This idea of the "awakening" draws me back to my own understanding of Rob's title, Can't Let Nobody Ride My Bike. The title reminded me of my students who were standoffish and had their guards up. They were like, “I don't know you. You don't know me." These walls that they set up resulted from past experiences that reminded them of varying levels of trauma afflicted by adults of power and authority. These walls were meant to protect 
them. But for me, as a counselor, to reach them, I had to earn their trust. So until then, I imagine a student telling me, "But right now, you ain't riding my bike." Rob leaned back in his chair and with full validation, he responded, "Oh, I like that." 


\section{TRACK EIGHT}

\section{THE REMIX: THE AESTHETICS OF HIP HOP IN COUNSELING}

I adjusted my light brown fedora and tilted it to my right side as I tug down on my knee length brown overcoat that is draped over my black Rock The School Bells sweater. It reads on white text above images that represent the four elements of Hip Hop:

$$
\begin{aligned}
& \text { re://claim } \\
& \text { re://set } \\
& \text { re://mix } \\
& \text { re://establish } \\
& \text { re://educate } \\
& \text { re://imagine } \\
& \text { re://fresh }
\end{aligned}
$$

This text is still relevant today as many community colleges are tasked to reimagine and redesign what educational spaces look and feel like for new, incoming community college students based on recommendations made by the Chancellor's Office of the California Community Colleges in their Vision For Success. I approached the steps of our newly built, Building 12, also known as the Environmental Sciences Building. I took in a deep breath from the cold, crispy air of San Bruno while specks of mist sprinkled my face. I took a step forward and the automatic sliding doors swiftly opened up and immediately I could hear the sounds of DJ Lil Vibey playing, "BOP" by DaBaby. From a distance, I could see the silhouettes of students dancing to the music, dropping to their knees and back up with every bass drop from the beat. The students love their "BOP". One of my student volunteers, wearing the brand-new Rock The School Bells t-shirt with the shiny, shimmery silver logo in the front, jokingly shouted, "Welcome to Rock The School Bells! Which school are you from?" We both laughed but it was that type of energy that got me excited and invigorated for today's 13th Rock The School Bells Hip Hop Conference. As I continued to walk into the lobby, both sides of the room were active with high school 
counselors, teachers, and chaperones checking in their students at the registration tables. While they were checking in their students, our volunteers, all donning the black Rock The School Bells shirts, were ushering all of the high school students to the main floor where chairs were organized in theater style seating and an area where an abundance of pastries such as danishes, muffins, and croissants were waiting for their hungry bellies. There was also a station of carafes that contained beverages to quench people's thirst such as water, iced tea, lemonade, coffee, and tea. As I stepped closer towards the steps that led to the main floor, a colleague of mine from Balboa High School approached me and said, "Wow. We really appreciate the level of coordination and organization you all put in for our high school students. I'm not surprised though, but a five-million-dollar view too?” The new Environmental Science Building has been the talk of the campus and the community. It has become an instant gem of a building that overlooks the Pacific Ocean where the building sits feet away from the ridge. The sun is slightly masked behind some early morning clouds. A few students have already taken advantage of the view, taking selfies of themselves with the ocean and semi-blue sky as their backdrop. My colleague and I both stood quietly admiring the view.

The beats from the music were thumping as the crescendo of voices started to rise as more students began to show up. I looked behind me and saw two charter buses parked in the front as more students began to file out individually. They were all wearing colored wristbands that represented their workshop tracks whether it was for DJing, beatmaking, spoken word, or graffiti. There were workshops for every student. Students also received swag bags with a silver Rock The School Bells logo on the front. A student excitedly pulled out a holographic Rock The School Bells sticker that sparkled as every light reflected off of it. The excitement in the room began to permeate throughout the room. My heart started to beat a little faster as we were five 
minutes away from starting our opening ceremony. I hear, among the cacophony of sounds, light taps walking toward my direction. I turned to my right and saw our interim College President dressed in a gray top with a black velour jacket. She had on some black leather pants and boots and wore a dark gray Kangol hat that covered her golden curls. She held onto her black walking cane and motioned towards me for a hug. We embraced each other and smiled as we glanced at the nearly filled main floor with eager high school students waiting for the start of the conference. She said, "Are we ready to rock?" I nodded and replied, "We ready to rock." I made eye contact with DJ Lil Vibey and she gradually turned down the music. As I'm preparing to introduce the College President for her welcome remarks, I noticed her taking out her black sunglasses and putting them on. I knew it was going to go down. The students have no idea what's about to happen. In fact, with the exception of me, no one in the whole building knew what was about to happen. I handed her the wireless mic and all of the sudden, the beat dropped.

\section{How We Drip: Developing Revolutionary and Innovative Practices}

This was the title of this year's theme for our 13th Annual Rock The School Bells (RTSB) Hip Hop Conference. The theme centered around the word, "drip", which is a word that is highly used in today's youth vernacular. "Drip" refers to something that you wear that is fashionable or vibrant, something that you can be proud of or something you're doing that is extraordinary. This word is synonymous with the word "swag." The theme was suggested by our student leaders who were part of the planning committee and asked a simple question: "What would education look and feel like if it embodied drip?" After a few rounds of cyphers, we landed with the acronym, "DRIP: Developing Revolutionary and Innovative Practices." That whole creative process was so Hip Hop. We took a word and created the foundation of what the conference could potentially look and feel like. The committee wanted cut-out diamonds 
represented in Tiffany colors. They wanted the conference experience to embody drip. While there was so much excitement in the air, my students' question stuck with me.

There have been many educational initiatives within the last two decades that focused on community college access, persistence, and goal completion (Bailey, Jaggars, \& Jenkins, 2015). However, many traditionally and historically marginalized student populations still continue to face challenges such as seeking academic resources and financial challenges. This is also exacerbated when these students experience different levels of oppression, microaggressions, and experiences of isolation (Brooms \& Davis, 2017; Harper \& Hurtado, 2007). The Vision for Success created by the Chancellor's Office of the California Community Colleges recommended that all California community colleges examine and explore ways in which they can ensure that students from all backgrounds succeed in reaching their goals and improving their families and communities (CCCCO, 2019). As a result, it is critical that institutional agents such college counselors build on existing levels of knowledge of how they can facilitate success among all students, especially those who have been traditionally marginalized. Many community colleges have operated from a deficit model that focused on what students were lacking and what colleges needed to do to ensure that they are college ready. Karp and Bork (2014) described common assumptions that colleges have about students that impact their perception of first-time community college students: 1) academic habits, 2) cultural know-how, 3) balancing multiple demands, and 4) help-seeking.

I reflected back at our students' question: "What would education look and feel like if it embodied drip?" Rather than tackle education as a whole, the focus for the present research centered around college counseling practices. What would college counseling look like or feel like if we are creating spaces that are experiential and center our students' stories and lived 
experiences? Academic advising and college counseling have been dominated by practices that are prescriptive and developmental. While these practices may be productive for some students, prescriptive and developmental theories lack the environmental and contextual understanding necessary to deeply explore the experiences of students of color.

This final chapter explores the lived experiences of four California community college counselors and their engagement with Hip Hop culture through the endeavors of portraitures and how their engagement with the culture helps inform their college counseling practices. Rather than focusing on what's problematic within college counseling, I wanted to focus on the "goodness." What are these four college counselors doing that moves away from the traditional forms of counseling? How are they drawing from their own lived experiences in Hip Hop that informs their current counseling practices? What might other counselors learn from these practices that they can apply and adapt into their own practice? How might counseling look and feel like when it embodies drip? Similar to Hip Hop, it provides scholarship around college counseling a fresh, new approach to studying current counseling practices. When the focus is around the deficits, it limits our perception of our world, and creates a smokescreen for what is positive or working well (Brooks, 2017). The four portraits in this study allow us to experience their world and understand deeply how their lived experiences shaped who they are as college counselors today.

Four major themes emerged from the four portraits in terms of how their lived experiences helped inform their own counseling practices: 1) keepin' it real (authenticity), 2) show and prove, 3) politics of space, and 4) sampling and remix. These four themes are also called aesthetics of Hip Hop which is defined as "ways of being and ways of doing" that are endemic to Hip Hop. Aesthetics of Hip Hop are not the elements of Hip Hop and this is a very 
important distinction to make. For example, content is what records a DJ plays; aesthetic form is how they are being played such as cutting, blending, or beat juggling from one record to another (Petchauer, 2009). With this understanding around aesthetics, these themes represent the counseling practices that are informed by their counselors' lived experiences within Hip Hop culture.

First, I will examine the different ways in which counselors practiced authenticity in the counseling spaces as means to establishing trust and genuine rapport with students. Next, I will analyze how they show up intentionally and meaningfully for their students as well as deeply understanding how their intersecting identities can impact their work with students. In addition, I will explore how they create validating spaces for their students. How do they as counselors show and prove? Connecting closely with this idea of "show and prove", I will seek to make understanding on how they actively recreate and redesign their physical space as forms of counseling. In other words, how are counselors actively changing their physical spaces (i.e. offices, classrooms) to be culturally relevant and responsive? Lastly, I will examine how counselors utilize the DJ aesthetics of sampling and remix to provide spaces for students to coconstruct new ways of understanding and learning by acknowledging the wisdom students bring into counseling spaces. In addition to these four themes, I will draw connections from each theme to the elements of Hip Hop. These connections are intended to provide reflective opportunities for counselors to explore how they can operationalize these themes into their own counseling practices.

Listed below are the descriptions of the four community college counselors interviewed for this study: 
Kimberly Davalos, also known as Kim, is currently a Promise Scholars Program counselor at Skyline College and has been in the field of college counseling for 8 years. She is one of the faculty instructors for the CIPHER Hip Hop Learning Community where she teaches a course titled, "Community Engagement and Leadership." She served as the Associate Director for Rock The School Bells, an annual youth Hip Hop conference, for two years. She is also a writer and author of her published book titled, Delilah's Daughter.

Adam Freas, also known as Freas, is an EOPS Counselor and Faculty Equity Coordinator at Sacramento City College and has been in the field of college counseling for 14 years. He is also one of the founders of a non-profit organization called Low End Theory Collaborative that works independently and in conjunction with other organizations to provide customized academic programming, professional career development, and community-based event planning services within the framework and approach centered around Hip Hop culture. He is an emcee in a Hip Hop collective called Bap Notes.

Ken Times, also known as KT, currently works at Sacramento City College as the counselor and coordinator of the UMOJA Program. He is also one of the founders of the aforementioned non-profit organization called Low End Theory Collaborative. He has been counseling in the field for 12 years.

Robert Alexander, also known as Rob, is an academic counselor and instructor at De Anza College and has been in the field of counseling for 14 years. He teaches courses such as Human Sexuality, Career and Life Planning, and Life Skills for Higher Education. In addition, he is also the author of his book titled, Can't Let Nobody Ride My Bike, a personal narrative of his life living in Oakland described through the lens and soundtrack of Hip Hop. 


\section{AESTHETIC \#1: KEEPIN' IT REAL (AUTHENTICITY)}

An emcee approaches the mic stand and surveys the crowd. They grab the mic with the intent of "rocking the crowd." The emcee, $\mathrm{MC}$, is the mic controller, master of ceremonies, and one that moves the crowd. As Travis Jr. (2016) shares, "Beats invite you in. Hooks give you an easy way to participate. Lyrics tell you a story for you to interpret and act upon, or not (p. 8).” Nevertheless, it is the emcee's intention to connect with you with their lyrical prowess, verbal mastery, and cadence control. You will often hear emcees declare that they are always "keepin' it real." There is a power associated with that as "keepin' it real" conjures notions of authenticity where listeners are drawn to words and verses that relate to them. When listeners are hooked, they end up riding with you.

Within the context of college counseling, one of the seminal theorists that centered the experiences of their clients was Carl Rogers. Rogers maintained that there are three core conditions for therapeutic change and one of them is centered around congruence which refers to being real and authentic. Authenticity reflects an honest, intentional sharing of one's insights, emotions, and life experiences to promote the growth and development of the individual and the relationship (Purgason, Avent, Cashwell, Jordan, \& Reese, 2016). Authenticity was displayed and practiced in various ways by different college counselors.

Storytelling using historical and cultural context. Rob expressed his understanding of authenticity through the lens of Hip Hop artists. He shares, "Hip Hop artists were the best at telling you about where they come from and their lived experiences." Armed with this knowledge, he facilitates an activity called the "I Am" poem where students reveal parts of their identity and experience by answering prompts to the poem. Recognizing that this can be a very difficult and emotional activity, Rob models by sharing his poem. Hip Hop comes from an 
authentic space that can be rooted in vulnerability and courage. If we encourage our students during our counseling appointments to share about themselves, I think it is important to share a piece of ourselves as well.

Storytelling is a main component for community building and relational development especially within communities of color. Hula, a traditional dance form in Hawaii, does not dance to the beat but to language. Chinese shadow puppetry tells folk stories, issues moral lessons, and projects local Chinese customs from different dynasty eras. The zajal, originated in Lebanon, is a classical Arabic version of a poetry slam or rap battle where poets rap verses to different topics. The griots from West Africa were storytellers that often play instruments to preserve family and cultural histories. Kuwentuhan is Filipino for "sharing stories"; a central part of Filipino culture as it forms a bridge that connects and strengthens the bonds families have with one another. In many communities of color, storytelling is a way to connect, to move us, to shape us, and to transform us.

Kim also alluded to the importance of learning about your own culture and history. She shared:

Because I first got into Hip Hop Ed and Hip Hop culture because it was the idea of diversity, and then when you get into the culture and seeing that, at the core of the values is indigenous roots, knowing your history, believing in social justice. Then I would learn about African American history and Latinx history, then it came back full circle to myself. Like now I have to understand myself and what it means to be FilipinoAmerican.

She also adds that by doing this, you can be more authentic in the ways you connect and communicate with others outside of your own culture. It also calls for being aware of how our own intersecting identities can give power or marginalize our students in our counseling appointments. In other words, power dynamics within the relationship may work directly against the expression of authenticity (Duffey \& Haberstroh, 2012). For example, a counselor who may 
hold a culturally privileged identity over a student with a culturally oppressed identity; it may influence the ways in which the student may respond in inauthentic ways consciously or unconsciously. Kim shares that the more you understand the core values of your indigenous roots, the more you can become an intersectional advocate for others.

Don't fake the funk. When Hip Hop is brought into the discussion around the applicability in counseling practices, the question of who can use Hip Hop in their practices can be a hot topic. Although there have been issues of educators culturally appropriating Hip Hop in educational spaces, there is value even when educators who don't identify with Hip Hop culture are willing to engage with their students who do identify with the culture. Freas pointed out that it's important to allow students to be their authentic selves in your counseling spaces. Being uncomfortable or not knowledgeable about the culture is a good position because it means that deep learning and understanding can occur if you approach it with genuineness and authenticity. Many K-12 educational systems are built on curriculum that are not reflective of the students they serve yet students are expected to learn it, understand it, and memorize it. Freas also added, "And I think the core piece of the pedagogy is your authentic self. It has to drive everything that happens, meaning you can't fake the funk."

Kim also expressed that counselors need to hold themselves accountable in regard to practicing authenticity when working with students. Reflecting on this notion around accountability, she responded, "Because everything I preach, I have to practice because if I don't, then I'm a fake. And I'm going to get called out."

While counselors may not know in depth their students' cultures, it is important for them to be open to learning about their student's culture and be authentic in the process of doing so. Rather than approach the student's culture saying, "I don't listen to Hip Hop or I don't know 
anything about Hip Hop", counselors can reframe their approach by responding, "Tell me more about your culture or what about Hip Hop culture resonates with you?" Also, counselors need to give themselves permission to not know, be unfamiliar, and be uncomfortable. Students can usually detect when counselors are inauthentic with their practices and can have a lasting effect on how students perceive themselves and how they think others perceive them.

Linguistic and cultural capital. Students want to engage with college counselors who will treat them with authenticity and with a genuine interest in helping them achieve their goals. Emcees will dress in a certain way, rap words in a precise cadence, or move in a way that invites the crowd to connect with them. The best emcees are highly aware and skilled on how to engage effectively with their audience. They meet their listeners where they're at. Language and mannerisms can be very powerful when applied with students who identify with Hip Hop culture. KT describes how his use of language allows him to connect and relate to his students in an authentic way. By providing space for students to be themselves and speak in the ways that makes them feel authentic and real, it acknowledges their linguistic capital that they can bring into the space. It reflects the idea that students of color arrive at school with multiple language and communication skills (Yosso, 2005). Many students often arrive to educational settings feeling like they have to code-switch or be silent. They may see themselves as linguistically deficient because their skills are not reflective of the dominant culture. Sulé (2016) recognizes that allowing students to be themselves provides them with a sense of meaning, authenticity, and belongingness.

Kim also speaks about the intentionality of how she shows up into spaces. She adds, "So swag, fashion, and clothes as a means of expression was always something really personal to me. This allows students to feel like they can be open and authentic with me." KT also 
contributed to the discussion about swag and replied, "My sneaker game is solid, which is one way that students come to trust me." KT and Kim both agree that by allowing themselves to dress freely despite what the dress code at work may be, it gives their students permission to come as they are.

Many students of color who have been traditionally marginalized and minoritized approach college with walls built up so high to protect themselves from enduring social, emotional, and academic trauma. These traumas include experiences such as microaggressions, culturally irrelevant curriculum, and experiences of isolation (Museus, Yi, \& Saelua, 2017). However, when college counselors approach their work with students with genuine compassion and authenticity, they provide students with feelings of encouragement, confidence, comfort, and liberation. "Keepin' it real" allows college counselors to develop meaningful rapport with their students.

\section{AESTHETIC \#2: SHOW AND PROVE}

Watching a breakdance battle is one of the most exciting events in any Hip Hop arena. The dance floor is lit up with spotlights while spectators surround the dance floor as shadows and silhouettes. When the bongo beats drop, the whole room erupts as they know that the unofficial breakdance song, "Apache” by the Incredible Bongo Band, is signaling the start of the battle between two b-boys. The first b-boy jumps in, suited with adidas from top to bottom, colored in black and white. He kicks it off with some footwork and a bit of top rocking. He drops down on all fours and completes a couple rounds of the six-step then lifts himself up in one motion using gravity to propel him into a series of furious windmills. As he's doing this, the crowd is going wild and his opponent is frantically pacing back and forth waiting to jump right in. As he completes the final windmill, he tucks his legs and performs a backspin and stops 
immediately into a chair freeze, a move imitating him sitting on a chair. He holds his position for five seconds as he's staring down his opponent. He gets up, arms stretched out, and yells, "What you got?!" He went up there and did his thing. He was showing and proving.

The crowd immediately turned their attention to the other b-boy. He has a white Universal B-Boy Clothing t-shirt and black Nike sweatpants with Nike running shoes to match. He enters the dance floor with a front flip, lands in a split and sticks his tongue out to his opponent. The crowd mockingly points at his opponent. He gets back up and skips around the floor in a circle to gain speed and momentum to launch himself into a series of windmills that eventually leads to flares, imitating gymnastics moves on the pommel horse. Then he transitions into a UFO where he places both hands faced down between his legs spinning. He then uses his upper body strength to lift himself up so now he's upside down while spinning on his hands. From there, he drops down to his head and begins to spin himself on his head. As he gains more speed and revolution, the crowd gets louder and louder. He takes his hands off the floor to show that he's now just spinning on his head. He lifts himself up from his head and contorts his body to spin to emulate a coin drop where he lands on his back where he stops and poses. The whole crowd goes wild knowing that he just showed up and proved that he was not going to be denied.

In any dance battle, b-boys and b-girls got to be ready to show up and prove that they got what it takes to be the best dancer in that circle. There is a level of preparation and intentionality that goes into a routine. You have to work the crowd with your footwork. Then you have to set yourself up to be able to pull off your major moves. Finally, you have to finish your routine with flair and style so that it's memorable. College counseling is very similar in that you have to get to know your student by taking baby steps and earning their trust. The major moves are the ways 
in which you are responsive to your students' needs. Your final pose or freeze is how you close out your counseling appointment with your student. Students are more likely to come back to see their counselor if they feel a sense of connection and that they feel validated. Rendón (1994) describes validation as "an enabling, confirming, and supportive process initiated by in and out of class agents that foster academic and interpersonal development (p. 44)." A full counseling appointment is very much like a whole dance routine. It's how you show up in counseling spaces and how you prove to your students that you have every intention to co-construct a counseling experience with them. To prove is to validate.

Hip Hop culture allows for the creation of counterspaces where students seek affirmation and social support (Solorzano, Ceja, \& Yosso, 2000). Drawing from cultural identity theory, this notion of "show and prove" plays a pivotal role in reflecting and responding to the various cultural backgrounds and identities that might play a role in positively shaping a student's belonging in college (Museus, Yi, \& Saelua, 2017). This next section details how community college counselors show up in counseling spaces as well as how they validate their students in different ways.

Motivated by their struggles with invalidation. When students feel like they don't belong or experience moments of isolation, they tend to experience lower self-esteem, experience anxiety and depression, and are more likely to stop or drop out of college. Growing up in Stockton, Kim never really realized that race was a thing. She grew up with a set of friends that took her in and profoundly impacted her development as a woman of color. She recalled:

But before I had any of that language, identity, or community of my own people, it was all about my black sisters. Deborah, Ashley, Xiomara, BSU in high school. They took me in. They TOOK. ME. IN. And held me; taught me their culture and values and slang. When my own Filipino community couldn't. So even more than Beyonce and Lauryn Hill, those women and family are Hip Hop to me. And they're the reason why I do the work. 
Having that experience early on made the transition to college unexpectedly difficult. The black students in college didn't identify with her and she didn't identify with the Filipino students at the time. She realized at that moment that she was lost as a student of color which resulted in bouts of mental health issues. Drawing from her own personal experiences of not belonging and feeling isolated, as a counselor, she understands the importance in creating experiences that are validating and humanizing.

KT recalled his own experiences of feeling different even when he was with other African Americans. He described the distinction of being from a different neighborhood versus being bussed in from other neighborhoods. He struggled with understanding that while he was at home, he was highly immersed and surrounded by African culture and history, yet outside of home, he was seen as different. These set of feelings he experienced were ones that he didn't want his students to experience. KT described how music was the thing that got him through. He mentioned, "It was a respite. It was a motivator. It was a counselor. It was a soundtrack." He uses music, specifically Hip Hop, to validate his own experiences growing up, something that he has been consistently practicing with his students. KT and Kim both recalled these experiences as moments of pain and confusion. However, they both view these experiences as motivators to ensure that their students are in spaces where they are seen, heard, and validated.

Feel our presence and existence. What makes Hip Hop culture so powerful for many communities of color is that it is unapologetic, resistant, and deeply personal. It is a culture that creates counterspaces that allow participants of Hip Hop the ability to express their lived realities in a society where they are often marginalized, silenced, and invisibilized. Hip Hop is front and center and boldly in your face. Freas expanded, "Hip Hop is unapologetic. It's the reason why 
folks play it at a loud volume. We want to experience it in our chest because we want to feel that shit. We want you to feel that shit."

Hip Hop centers students' experiences without permission. Freas continued, 'You're going to understand I exist whether you like it or not, right?" He continued to reflect about the high school basketball game where his team was playing for the championship. However, it wasn't so much about winning the championship game that he remembered the most; it was the moment when the song, "Can't Truss It" by Public Enemy played on the loudspeakers when they were warming up. When the beat dropped and the lyrics were booming through their air, looking up into the stands to see communities of color dancing and going wild to the beat meant so much to Freas. He shared, “At the time, I couldn't articulate it, but I know that was the thing, where they felt validated in the space. I was like, 'Yo, this is us,' in a space that it's not really about us. The beats and the folks rocking to it was like, that fed me more."

When we allow our students to be themselves in counseling spaces, we are practicing affirmations. Affirmation is considered emotional support or encouragement. When one feels affirmed, they feel heard, understood, and believed. When counselors begin to question students based on the music they listen to, how they dress, or the language they speak, they are neglecting the different parts of their students' identities which can be very problematic in trying to create authentic working relationships with students. By affirming our students and being intentionally attuned to their culture, we are creating spaces of validation for them. We are declaring to them that our counseling space is a place where they can be their authentic selves.

Utilizing Hip Hop music as a way to engage students in counseling spaces such as oneto-one appointments or in college success classes are powerful mechanisms to affirm our students' experiences. Freas speaks about how he uses music as a way to get students to discuss 
what they are going through in college. He asks students to name a song that describes their current feeling and emotion. That leads to the conversation of why they chose that song and having students make meaning of their analysis of their song choice.

Hip Hop also engages a level of critical consciousness; the ability to examine and interrogate deeply the different experiences, issues, and topics we engage in on a daily basis. KT shares:

But looking back, it taught me a lot about the lies and the hypocrisy that's out there. You know what I mean? As I started to realize those things, Nate, the music was right with me. You know what I mean? The music was validating what I was learning or the hints of things that I was learning on my own.

KT was listening to KRS One, Public Enemy, and Rakim as sources of information that ran counter to the stories told by the status quo. These Hip Hop artists taught him what it meant to be Black in America; something his history books couldn't do. This impacts the way he engages with his students in his counseling spaces. He imparted this same knowledge onto his students and utilized Hip Hop as a tool to engage in critical thought and reflection. He shared, "So that music just validated things for me in terms of being different. You don't have to be what the stereotype is or what the model is of who they think you are."

Rob also shared a similar sentiment when he described his experience living in East Oakland as a young African American boy. He added, "The environment we lived in, we never really looked at education as a way out. Either you was playing sports or you sold coke, you sold dope." Using songs such as Nas' "I Can", allows Rob to help his students understand that they didn't have to embody this singular narrative of what it means to be a Black man.

While many educators may not fully understand the ways Hip Hop educators relate to their students and affirm them in the process, these ways of being and doing are no different than the general kindness and empathy that counselors practice. Given that students of color 
experience microaggressions frequently in educational institutions, practicing microaffirmations through the concept of "show and prove" explicitly recognize and validate individuals in ways that empower them to thrive (Rowe, 2008).

\section{AESTHETIC \#3: THE POLITICS OF S P A C E}

It was the balance of the hustle and the struggle. These were the words from Bay Area rapper, Equipto, in describing the work of Mike "Dream" Francisco who was globally known as one of the greatest graffiti artists in the world. He founded the TDK Collective also TDK Crew in 1985 which stood for "Those Damn Kids" or more recently, "The Dream Krew." Exactly 20 years ago, Mike Dream was senselessly murdered leaving behind a legacy that will be forever etched in Hip Hop history and culture. While he is not with us in the physical form, his legacy through art continues to live on. As a fellow Filipino American, he was someone that I could identify with in terms of using art and words as a form of expression to articulate the lived realities that communities of color were experiencing in the 1990s in the Bay Area, specifically in Oakland.

One of his famous pictures was of him standing in front of his piece that he did with fellow member, Spie, titled, "Tax Dollars Kill." The letters of the words were painted white draped over a dark blue canvas that represented the dark blue skies. The letter "S" was written as a dollar sign. Underneath the words, "Tax Dollar Kills", there was a picture of the White House being struck by lightning igniting flames that also began to burn the American flag. While it was a play on letters based on their crew, TDK, it was also a way to call out social and economic conditions that were plaguing communities of color. Mike Dream's artwork also gave voice to those who were often silenced. In a video interview he did for Hip Hop Slam TV in 1993, he reflected on graffiti's role as an outlet for inner city youth who were living in 
communities afflicted with violence. He shared, "Every time I get hassled by the police, I gotta go out and do me a piece. No Justice No Peace represents the young teenagers in this community who are releasing their anger through this medium."

Twenty years later, graffiti art is slowly being seen as an acceptable form of art. Graffiti artists are being commissioned to create murals and pieces in cities worldwide. Last year, I was able to bring students to New York City as part of their CIPHER Hip Hop Community Engagement and Leadership project. We brought them to "Beyond The Streets", a street art exhibit that celebrated the works of over 150 street artists and muralists including Mike Dream, Lady Pink, Tats Cru, Keith Haring, Jean-Michael Basquiat, and Shepard Fairey. The exhibit spanned over 100,000 square feet across three floors. Resonating with Mike Dream's philosophy around his artwork, "Beyond The Streets" intention and purpose is to challenge the way we look at space. It provided a space for deeper analysis as to how we can redefine and reshape the concept of space.

Mike Dream's legacy continues to live on as he's celebrated each year as part of Dream Day proclaimed by the city of Oakland based on his contributions to Hip Hop history and culture. I had the opportunity to honor Mike Dream through his brother, John Francisco and his son, Akil Francisco, during our 10th Annual Rock The School Bells (RTSB) with our RTSB Legacy Award. It was definitely one of the most memorable moments I've experienced in my work in Hip Hop education. When I asked John how we should remember his brother Mike Dream, he simply said, "TDK meant everything to my brother. But what TDK truly meant was 'Teach Dem Kids'.”

Hip Hop culture, specifically the element of graffiti art, offers college counselors a means to view both the ways that spaces and places are constructed and the various kinds of space or 
place that are constructed. Henri Lefebvre, a French philosopher, is best known for his critique of everyday life, but most notably his philosophy around the construction of social space. He coined the term, "the space of experience", that defines how our social practices and relationships are enacted (Forman, 2002). Lefebvre (1991) also writes that the production of space can either serve as a tool of thought and action or as a means of control (p. 26). Students of color are often negotiating their cultural identities while navigating White spaces that have a long-standing impact on their abilities to advance with their academic and social progress (Yosso, Smith, Ceja, \& Solorzano, 2009). When making the distinction between space and place, Grossberg (1992) expresses place as actual, physical sites of stability where people can stop and act; whereas, space is defined as the parameters of the mobility of people and their practices (p. 295.) In other words, when creating spaces of validation for our students of color, we have to keep in mind how we navigate our counseling spaces collectively with our students in a meaningful and intentional way.

How we redefine space and place. I wrote in one of my poems, "Legacy", a line that said, "We are the writers that spray on walls, carves on classroom desks with textures and colors, not only to be seen but also to be heard." Redefining and redesigning spaces was a common theme for many of the participants. The notion of redefining spaces was a response to the dangers of norming into spaces that didn't represent the cultural values of many students. Freas added, "Spaces normalize. We norm ourselves to the space, like the expectations of the space." When the space doesn't represent energies or cultural values that reflect our students of color, it can create experiences of isolation and a lack of commitment and investment towards the institution. Within the context of college counseling spaces, Mitchell, Wood, and Witherspoon (2010) explored the ways that advising offices ignore the racial nature of the 
environment in that these spaces entrap students of color to embody the policies, practices, hierarchies, and representations that dismisses their own cultural and ethnic identities. For example, many community colleges have policies around class registration. They based priority registration around units completed and grade point averages (GPA). Students who are under academic probation; those with GPAs below a $2.00 \mathrm{GPA}$ are given late registration dates or none at all. This becomes an equity issue in that students on probation have more difficulty in getting the classes they need for their educational goal. Most students who are on academic probation are students of color; however, many of their academic challenges are not tied to academics but other challenges such as limited financial resources, lack of student support, work/school imbalance, and experiences of microaggressions and isolation. Community colleges will need to examine that policy to see how they can provide more equitable solutions in addressing this opportunity gap. This level of intentionality explores how we can change the way students enter our educational spaces.

Freas also shared, "As sterile and as white as a space might be, you throw like that Nipsey Hussle beat in the background, it makes folks rethink about where they're at or it helps channel another layer of who they are in a space that usually doesn't welcome that." Rob agreed by changing the space to reflect his students' identities but facilitating in an authentic way, he had found his students connecting to him much more deeply than other counselors. Whether it is a counseling appointment or a college success class, when a beat is going, it serves as an invitation for many students. Freas also added, "It's like that thing that threads you into the space. It's like these invisible arms reaching out, keeping them in the space like a hug, right?"

The space of experience. When the Chancellor's Office of California Community Colleges provided their statement around the Vision of Success in examining and implementing 
new practices to support all students, it required counseling divisions to revisit and examine their current counseling services and practices to identify potential equity gaps. Through the lens of Hip Hop pedagogy, it is important to create counterspaces that allow students to engage their cultural wealth and increase their feelings of connection to the college campus. One of the ways to do that is to completely redesign the actual place where college counseling exists. Rather than be surrounded by sterile, white walls and posters of students that don't represent those who are traditionally marginalized, Kim and Freas stressed the importance of creating spaces that elicit meaningful and harmonious experiences. Given that counselors usually have 30 minutes for each counseling appointment, how do counselors maximize every minute to build rapport and meet their needs? Utilizing the aesthetics of Hip Hop, redesigning the place allows for access points of conversation. Freas talked about his intentionality in designing his office:

So in my office, you got pictures of John Carlos and Tommie Smith on the Olympic stand with their fists up and you got art from some former students, so graffiti, art panels, canvas art from some of the students, some print art of different Hip Hop stuff, artists, some of the community programming that I've done, the Rock The School Bells stuff that's happened on campus just so they can see that.

Each piece that's on his wall is an opportunity to engage in conversation. While some students do not identify with Hip Hop culture, it still rewrites the narrative around what college counseling spaces should like. It allows students to understand that counselors see their stories as valid and important.

Kim also takes on a similar approach to her office space. She sees her office as a place for invitation; a way to engage students in a non-traditional manner. She explained, "It's about being relevant to our students. I'm always bringing in new artwork or new things, new stickers. Even the littlest thing that I could put up in my office is an invitation to students." What this approach also does is that it invites students to control and facilitate the counseling appointment 
with the knowledge they bring in. Kim shares an example where a simple item like a sticker on her desk created an opportunity for students to enact their own cultural capital. She illuminated:

It invites them to control the counseling session by being able to use, "Oh, I like that sticker." I know I have cultural capital about that sticker. And that makes me confident enough to ask my counselor a question about what do they know about that? Because I know something about that. And then that could shift the whole counseling appointment. Little moments like being attuned to the things that students love to talk about.

This example is part of the SWAG framework that Kim discussed in regards to creating opportunities in counseling spaces for students to build on their sense of agency and advocacy. It is also the shifting of power where the power is not solely in the ownership of the counselor but rather shared between counselors and students.

Acknowledging student voices in spaces. When engaged in Hip Hop pedagogy, the way students occupy and enter our counseling spaces are often renegotiated and transformed. Freas, Guzman, Carnero and Times (2018) revealed the importance of including student voices when deconstructing, modifying, and constructing counseling spaces. KT expanded about his usage of the freestyle in both his counseling appointments and classes. He provides the students with the opportunity to inform what the appointments are going to be about or what topics they should discuss and learn about in their college successes. Using this aesthetic of freestyle, it also highlights KT's intentional approach to entering the space. He adds:

So part of it is the freestyle aspect of how I teach, right, because Hip Hop enacts and reacts, right? So, to me, my classroom and my counseling space is a manifestation of that. So I want to make sure that when I talk about Hip Hop pedagogy, it's not necessarily readily apparent at all times, right? Because, like I said, it could've been in how I developed the assignment or how I speak to students when I'm counseling.

When counselors come from a student-centered perspective, it decreases the likelihood of counselors falling into what Freas describes as "counseling on auto-pilot." By operating under 
autopilot, the counseling approach does not address the various complexities that students bring to the counseling appointments or classroom space.

Kim shares a similar experience regarding engaging student voices in a cypher to create their classroom experience for the semester. She continued:

Then I tell them, 'Okay, now that we can all recognize and acknowledge what are the ways that we don't feel good, and we don't feel free and comfortable. Now, give me what your utopian ideal situation is." And this is where then that students get to co-create the space with me. And I tell them this, "You tell me what you want me to be like as your instructor, and what kind of classroom you want to create in here."

When we are intentional on how we enter spaces, how we create spaces, and how we share spaces by integrating students' voices and knowledge in our counseling spaces, we begin to create more meaningful counseling experiences for students. When students' experience moments of affirmation, validation, and belonging due to the ways we redesign our counseling spaces, students often feel supported, significant, and important. This is absolutely important in college counseling settings as it is critical to students' self-esteem and their journey towards their educational goals.

\section{AESTHETIC \#4: SAMPLED BEATS}

I was in Philadelphia for a Student Success Conference when me and one of my colleagues decided to go record shopping. We took a Lyft to a place called the Milkcrate Cafe, a vinyl record boutique and cafe located in the heart of Fishtown in Philly. When we arrived, there was a big logo of a cow plastered on the cafe window. We walked in and immediately took in the smell of vinyl records, freshly brewed coffee, and baked croissants. The light fixtures were made out of old wooden milk crates with light bulbs protruding out of them. The walls were filled with vinyl records for sale on one-inch shelves that wrapped around the whole coffee shop. I saw various vinyl records ranging from A Tribe Called Quest, to Nas, the Beatles, and 
David Bowie. This shop had everything. I approached the front to figure out what I wanted to eat for brunch. The menu was inspired by musical artists and albums. I was deciding between the Notorious E.G.G., Rock 'N' Pork Roll, the Avocado Toast Malone, and the Biggie. I ended up getting the Biggie which had bacon, egg, and American cheese with caramelized onions on a Philly hoagie roll.

After our meal, we headed downstairs where most of their vinyl record collection was located. There were several people there digging through the multiple crates and shelves. There were four turntables for customers to listen to the records. After an hour of digging, I had secured records of Cymande, Grover Washington, Jr., and DeBarge. My colleague came up to me and said, “Oh, here's a classic one." It was "You Can’t Turn Me Away" by Sylvia Striplin. He found the record stacked on top of other records and didn't have a vinyl cover. It was kept in just the white sleeve that looked worn out while the yellow sticker with the title of the song was slowly fading and ripping off. I pulled the record out and placed it on the turntable. I picked up the earphones, swiveled the turntable arm in position, and dropped the needle on the record. I heard the familiar funky bass line that was sampled onto a Hip Hop classic, Junior M.A.F.I.A. 's song, "Get Money” with Notorious BIG. I have always been enamored with 90's Hip Hop classics and searching for the samples that served as the foundation and blueprint. These classic Hip Hop songs would not exist without the samples provided by other artists. In Hip Hop, one would often hear the phrases, "making something from nothing" or "making a dollar out of fifteen cents." The birth of Hip Hop culture defines a generation that were resourceful and gritty during a time that it was socially, politically, and economically challenging for many communities of color, specifically African-American and Puerto Rican families. 
In my same poem titled, "Legacy", I recite a line that goes, "We are the scientists of wax manipulating sound through scratches and reverbs to create something amazing from something great." While many classic Hip Hop songs by Notorious BIG, A Tribe Called Quest, Nas, and many others sampled beats and instruments from other artists, it can also be argued that these artists also created classics. This concept of sampling rings true in our work as college counselors. How do we create counseling experiences where we are actively engaging in sampling? All of the counselors in this research all agree that we need to draw from the existing knowledge and wisdom that our students are coming in with. The knowledge and wisdom they bring to the counseling spaces are the beats and how we layer and blend our own knowledge and wisdom becomes the sampled beats.

It's that street knowledge. When we center our students' experiences, we begin the process of allowing them to believe that they have ownership of their academic journey. Rob expanded as he reflected on the youth in East Oakland, “They're multi-faceted, they're multitalented. We can let them know that they can be smart and still have some of that street knowledge. I'm a firm believer in that." He also explained the importance of seeing the good in everyone that we serve especially students who come from different cultures we may not be familiar with. This also provides us with an opportunity to critique the Hip Hop phrase, "making something out of nothing." When we allow ourselves to co-construct our counseling spaces with our students, we will find that students are bringing "something" to the table. We begin to shift our lens from "making something out of nothing" to "creating something from something." This acquired knowledge and wisdom comes rooted in what Yosso describes as "community cultural wealth." While Bourdieu (1977) argues that cultural capital is described as the accumulation of income and wealth, students of color draw from their community cultural wealth from various 
forms of capital such as aspirational, social, and linguistic capital. Amplifying students' voices and experiences by acknowledging their cultural capital showed up throughout the different portraits.

KT shared an example of the importance of cultural capital as a young child as he struggled with his own interactions with other African American kids. He reflected, "But that knowledge of music was one thing that brought me together with my people. As a teenager, 13, 14,15 , the last thing you want to do is be separated. The music was what gave me the capital with my folks." To experience the power of music allowed KT to see value in its usage in counseling spaces. He continued to add, "And so even when I talk to my students now, I'm like, "What you slapping? What's in the headphones?" And students have said, "Nobody's ever asked me that before. What am I listening to? An instructor never asked me, or gave a damn what I was listening to."

Kim also shares how acknowledging her students' cultural wealth builds trust and rapport within the counseling space. She reflected:

And so I can remember this one time I have a Chance The Rapper portrait and a student was like, "Oh, you like Chance. I like Chance and then we'll watch. Oh, have you listened to his new album? Yeah. You see, his new video came out, I didn't know that." That's that cultural capital too right there. So, then we get to watch it and share it together and then the trust and the rapport builds from there.

She is very intentional and explicit by including the student in the counseling process. While dominant forms of college counseling and academic advising have been prescriptive and developmental, Kim recognizes the importance of engaging students, specifically students of color, in the process so they can develop their own sense of agency and advocacy. This concept around agency is a large part of the SWAG framework that she employs in her counseling 
practices. She shared that she would tell her students, "You created the space and you chose to be here. You have the power and you have the voice."

When students begin to realize their own wealth of knowledge that they bring into these various counseling spaces, they begin to experience a sense of ownership of their own educational journey. Similarly, Rob shared in his experiences as a college student when he ultimately made a conscious decision to own his education. That, in turn, informed him in the ways he worked with his students, allowing their stories and voices to be amplified.

Check the counseling techniques. Brian Coleman, author of the book Check The Technique: Liner Notes for Hip Hop Junkies, shared about the intentionality and direction of his book. He commented, "I don't really wanna read what critics have to say about the stuff. I wanna read what the artist has to say." This was in response to critics that said his book lacked the sociological, sociopolitical, and academic perspective of Hip Hop. He added, "My goal was to get to the core of it. When artists understood the premise of the book, they appreciated it and certainly opened up accordingly." This book is viewed and received counter to many academic books that highlight Hip Hop as a way to analyze, interrogate, and examine issues impacted by social, economic, and political issues. His book focused primarily on the artist from a personal and intimate perspective, raw and unfiltered.

Similarly, Rendón in her work with Sentipensante Pedagogy draws from this notion around "wholeness." How do we create spaces within education where we can honor and acknowledge our students' “wholeness”? Reflecting on the three goals of Rendón's (2009) Sentipensante Pedagogy, the participants engaged in counseling practices that addressed these goals: 1) disrupt and transform entrenched beliefs about teaching and wholeness that act against wholeness and appreciation of truths of all forms; 2) cultivate "personas educadas", well- 
rounded individuals, who possess knowledge and wisdom; and, 3) instill learners with a commitment to sustain life.

Sentipensante pedagogy focuses on how we engage our students in classroom and counseling spaces. It also proposes the following to exist when we create these counseling spaces. Counselors need to view themselves as both teachers and learners. When we position ourselves in this way, we acknowledge that we don't possess all knowledge and that the key to learning is to remain open to new learning experiences. In addition, it also calls upon what Rendón (2009) terms as "multihuman" curriculum where we "affirm the dignity and worth of all people and respects and honors diverse ways of accessing truth (139)." Lastly, this pedagogy requires us to be thoughtful in creating counseling spaces that allow for students' stories and lived experiences to be heard and to be shared. When we create humanizing, transformative, and liberatory spaces that are rooted in genuine compassion and validation, we help our students find their voices and self-worth.

Weaving together the goals of Sentipensante Pedagogy and the aesthetics of Hip Hop found within the counseling practices of the participants, the counseling techniques they shared are examples of how they center their students' knowledge and wisdom as part of their learning and student development. When counselors are authentic and are intentional in the way they utilize space to validate their students, they begin to recreate what education should look and feel like for many students. Freas thoughtfully added, "When you allow them to offer other aspects of their narrative in different and meaningful ways, it doesn't feel intrusive at all."

The class is in session. Kim talks about the intentional approach of creating collaborative community agreements in her classroom as well as creating her syllabus that is not only aesthetically pleasing but also models after templates such as magazine covers, Instagram 
posts, and social media memes. She stressed the importance of genuinely learning about Hip Hop culture, but more so youth culture in general. Drawing from Kim's example, the more counselors understand what their students are experiencing and the ways they are relating and communicating with the world, the more effective counselors become when they teach and counsel their students. She added, "The slang that they use. The jokes that I know are relevant to them in social media and mainstream media right now." More recently, as the whole country was instructed to practice social distancing and to work from home due to the pandemic of the COVID-19 outbreak, Kim, in true Hip Hop fashion, created something out of something. Utilizing her knowledge around students' affinity towards lofi Hip Hop music, she created an online study session for students on Zoom where live DJs played lofi Hip Hop music while they studied online.

When the counseling spaces are created where students understand that their knowledge and voices matter, counselors are able to be creative in the ways they can amplify their counternarratives. Freas facilitated an activity called "Synonym of Dope" that acknowledged students' use of language as primary in his classroom and counseling sessions. He also utilized the same activity to have students define concepts around success and happiness within the context of their own lived realities as opposed to the way they are defined by the status quo. This activity was powerful in that students felt validated and heard as they wrote and spoke about their own personal experiences. They also felt a sense of community that was grounded and created by Freas's willingness to allow students to be teachers within the space.

In another example, Kim designed a class activity titled, "Brown Bags" where students had to create a collage just using the materials that were in their bags. Each group had different contents in their bags resulting in some groups with more materials than others. While they all 
had different contents, they all were able to produce a final product. In conjunction with Kendrick Lamar's song, “Alright”, students were able to make connections between the song and the collage activity in terms of how they can navigate systems of oppression within higher education. This activity provided a level of depth in how Hip Hop pedagogy can be utilized to question and examine the structures and policies that marginalize and privilege students in educational systems. It also allowed a space, a cypher, where students can brainstorm ideas as to how they can address these issues of oppression. For many students in the classroom, this activity allowed them to draw from their own knowledge and wisdom in dealing with various oppressive scenarios but also allowed them to learn about the different student support services that they can utilize while they are in college.

Attuning to the beat and critical listening. While these examples of how Hip Hop can be utilized in classroom spaces within the context of counseling classes, it can also be adapted and utilized in other counseling practices such as one-on-one appointments and group counseling sessions. However, for counselors to practice and utilize the aesthetics of Hip Hop within their counseling sessions, they themselves have to be attuned to the beat and engage in critical listening. As Pos from De La Soul would say, "The drums say the revolution appeared. Are you listening? Are your eardrums open for christening?" When counselors ask their students to be open so they can best serve their needs, they are asking them to be vulnerable and to trust them. Hip Hop culture requires us to keep it real. It reminds counselors to check themselves when they enter these spaces with their students. Hip Hop is about not faking the funk because students can often sniff the B.S. Hip Hop culture is about accountability and representing yourself in the most authentic way. It is about being fully present and fully engaged with our students. It is about the "beats" they are bringing into the space. Freas speaks about the 
harmony that exists when counselors are fully engaged with their students. It's like nodding your head or tapping your feet to a song you like. Your body is attuned to the beat. Freas shared:

And the importance of finding the rhythm, right? That's an emcee that you find a flow, but also recognize there are rhythms that happen in different spaces depending on the moment. But not just the rhythm of the beat but also the cadence and the moment, right? Together as a beat. So that same kind of acknowledgment of cadence and assessment of that balance between the collective, like a cypher, I think that's applicable to being a counselor.

A college counselor is like an emcee where they are assessing the body language, tone of the students' voice, and their energy level. A professional emcee knows when to engage a crowd and knows when to step back. They pay very close attention to the crowd as counselors do with students. When counseling sessions are flowing in a different direction guided by students, the aesthetics of Hip Hop requires us to flow with it. KT describes this as the "freestyle" nature of counseling. Hip Hop counters the need to flow in the same direction as the status quo. These ruptures within counseling allow us to disrupt the prescriptive and traditional forms of counseling and provide more focus on the "wholeness" of the student.

Kim speaks about the development of the SWAG framework around college counseling and its application when working with college students. The SWAG framework as applied to students consists of four components that are integrated as conversation and activity points for students to engage in during their counseling appointments with Kim. The four components include: 1) understanding sense of self, 2) understanding their why; their purpose, 3) learning about agency and advocacy, and 4) reframing grit as authentic moments of resilience. Essentially, Kim supports her students by co-constructing counseling experiences where they begin to develop their own SWAG. While this framework has been powerful for students, it is equally important and valuable for counselors. 
The SWAG framework was also designed to create accountability for ourselves as college counselors when working with students. Drawing from the aesthetic of keeping it real, there are also four components within the SWAG framework that can be practiced by college counselors. They consist of: 1) positionality awareness, 2) purpose in profession, 3) power within position, and 4) practices for sustainability. Both Kim and Freas spoke about their own power as college counselors in these spaces. Freas articulated that we need to not just listen as we have been trained in graduate programs but to critically listen. Because Hip Hop is so centered around counternarratives and not settling on a singular story, some college counselors may ascribe to more dominant forms of counseling for various reasons such as having a lack of understanding of the lived experiences and cultures of students of color. Freas candidly expressed, "I think that's a common framework of whiteness; a singular story, right? When you start to look at complexities of counternarratives, it creates a discomfort of certain white folks." Complexities, as described by Freas, are more than just the different narratives. He further articulated, "Complexities are relationships to my own identities as a White male and how that muddles my ability to hear something, right?"

Critical listening as a form of self-reflexivity encourages counselors to acknowledge their power and privileges acquired through race, ethnicity, class, gender, and ability. Similarly, Kim alluded to it within her SWAG framework as she urges college counselors to understand their own sphere of power, influence, and locus of control when working with students. She takes it further when she calls upon counselors to have a sense of their positionality within their institution. In other words, how would their support be influenced when they acknowledge their own intersectional identities? Additionally, how do each of these intersecting identities impact equity when working within their institutions? 


\section{THE REMIX: MOVING TOWARDS A SAMPLED CONSCIOUSNESS}

Some of the greatest Hip Hop songs ever made were remixes of the original songs of many renowned artists. Hip Hop has always had a love affair with revisiting certain tracks. Whether it's adding more artists to the same beat or adding obscure samples onto the track to make it unrecognizable, Hip Hop remixes have made a profound impact in Hip Hop culture. Sampling and remixes are like cousins. While sampling is honoring the old by creating something new, remixes take those new sampled songs and create something even more brand new. Some remixes that are legendary Hip Hop classics are "Flava In Ya Ear" by Craig Mack featuring Notorious BIG, Rampage, Busta Rhymes, and LL Cool J, “Shook Ones (Part II)” by Mobb Deep, “Still Not A Player” by Big Pun featuring Joe, and "Buddy” by De La Soul featuring Q-Tip, Phife Dawg, Jungle Brothers, Monie Love, and Queen Latifah.

While these were heavy hitters when they came out on the radio airwaves, my all-time favorite remix was released in 1995, the same year I graduated from high school. Sampling Marvin Gaye and Tammi Terrell's song, "You're All I Need”, Method Man released his remix to his 1994 song, "All I Need", and replaced the gritty chorus lines by the Wu with the voice of the soulful Mary J. Blige. Adding more drum samples and a vocal sample of Notorious BIG, P

Diddy, also known as Puff Daddy, helped produce a remix that earned Method Man his Grammy Award for Best Rap Performance in 1995.

The concepts around "sampling" and "remix" are not new in higher education. Whether it is addressing college access, student success, retention rates, or completion rates, there are numerous educational reforms that have been passed down and implemented during the last three decades. When new initiatives are being discussed to address problems of practice in higher education, oftentimes it can be commonly said that these new initiatives are basically similar 
strategies, programs, and methods from previous initiatives that are just repackaged differently. As a result, there is a reproduction of outcomes that reminds educators of the equity gaps that significantly impact the success of students who are traditionally and historically marginalized.

The remix calls for a deeper exploration of the various policies, practices, and structures that impact the experiences of our college students. Today, efforts to increase college attainment and close equity gaps are priorities at all levels of higher education. Part of these efforts are asking institutions to shift the way they operationalize their services to students from being college-ready institutions to being student-ready institutions. McNair, Albertine, Cooper, McDonald, and Major Jr. (2016) illustrated that student-ready colleges cultivate more effective opportunities to support the academic, social, and financial needs of their students. These colleges engage stakeholders such as faculty, staff, and students as active participants in an ecosystem of complex, evolving interdependent organizations. In addition, these colleges create shared working opportunities to understand and leverage the existing resources across the different organizations while working together to create new innovations to serve all students. As a result, student-ready colleges recognize the importance of working together as opposed to working in silos. Closing equity gaps requires providing the services and resources to students who need them the most, when they need them.

Within the context of college counseling, we need to examine our current counseling practices and generate new ways of creating meaningful counseling experiences with our students. This calls for a remix in college counseling. To be very clear, it is not meant to replace current practices because those practices may be valuable for working with other students. It is meant to add to the scholarship around college counseling practices. Utilizing the aesthetics of 
Hip Hop within college counseling provides an additional resource, pedagogy, and approach to serve students who may find value in it. Just like classic Hip Hop remixes where the original songs still exist, the same can be said with college counseling practices.

The four major themes, or aesthetics of Hip Hop in counseling, that emerged from the four portraits: 1) keepin' it real (authenticity), 2) show and prove, 3) politics of space, and 4) sampling and remix, reminded me that there is a strong focus of "ways of being and ways of doing" that calls on college counselors to practice accountability through critical selfreflection. Freas mentioned that "Hip Hop allows us to problematize anything." It allows us to seek solutions or create a remix to reimagine counseling practices with students. While these aesthetics of Hip Hop in counseling can exist individually in varying counseling contexts, they are not mutually exclusive.

While there were four aesthetics found prominently within the four portraits, the aesthetic of sampling and remix is the aesthetic that can be found in the other three aesthetics. In other words, the aesthetic of "sampling and remix" can be found in practicing authenticity, through moments of validation, and in how space is shared and created. "Sampling" is a way to lift and center our students' voices and experiences and blend them with the counselors' knowledge and experiences. It is an important building block in creating authentic spaces where students feel validated and acknowledged as well as acquiring new co-constructed wisdom and knowledge. Past research has shown that when students don't experience a sense of belonging, endure moments of isolation, and lack institutional support, they are more likely to not complete their educational goals (Bush \& Bush, 2010; Clark, Ponjuan, Orrock, Wilson, \& Flores, 2013; Harris \& Harper, 2008; Ojeda, Navarro, \& Morales, 2010). Given that these four aesthetics of Hip Hop applied in counseling have the potential to create a culturally responsive and 
transformative counseling environment when working with students, the reality is that these aesthetics are not effective if counselors do not engage in a shift of consciousness through continuous critical self-reflection.

The concept of critical consciousness comes from Paolo Friere (1970) who defines "conscientization" as developing consciousness that is understood to have the power to transform reality. Achieving critical consciousness requires a focus on achieving an in-depth understanding of the world, allowing for the perception and exposure of perceived social and political contradictions. Woven throughout the aesthetics of Hip Hop in counseling is a deep and intentional focus on humanizing and collaborative working relationships between counselors and students. While the aesthetics of Hip Hop focus on the "ways of being and ways of doing", this co-constructed counseling experience focuses on the "ways of deep understanding."

This deep focus of understanding is what Karimi (2006) would call the "sampled consciousness." He shared in one of his poems titled, "how i found my inner DJ", that "throughout the history of art, literature, and philosophy, people destroyed the old to create the new (p. 222)." However, Hip Hop culture appreciates both honoring the old and creating the new. The culture itself is not rooted in either/or ideology but rather a both/and where it acknowledges the existence of multiple truths and perspectives. Karimi (2006) defined "sampled consciousness" as such:

Sampled consciousness: $\mathrm{n}$. A state of self (being) created by the act of sampling different experiences: education, stories, interactions, and observations. The individual takes these experiences, knowingly or unknowingly, and makes them part of their worldview, the way they create and interact. The consciousness is continually in flux, alternating, adding, subtracting, choosing. Self (being) is negotiated. We sample, blend, fade in and out the various experiences, remixing the self in service to its goal.

The shift in sampled consciousness moves away from more singular approaches that can be found in more traditional forms of counseling such as prescriptive and developmental 
approaches. It calls for a deep understanding of the complex lived realities of our students. It also calls to attention how our own intersecting identities, assumptions, biases, and experiences can impact our understanding of our students' experiences. Moving towards a sampled consciousness where students and counselors co-construct new knowledge and wisdom in spaces that are rooted in authenticity, validation, and humanity, allows for opportunities where students can harness the power and agency to transform their own realities. 


\section{TRACK NINE}

\section{OUTRO}

When it comes to Hip Hop albums, one of the most overlooked components of the album is the outro. Hip Hop songs are often known as a form of storytelling. They are, as Rob described, a poem over a beat. Some of the greatest Hip Hop albums such as Dr. Dre's The Chronic, Lauryn Hill's The Miseducation of Lauryn Hill, and A Tribe Called Quest's The Low End Theory, have achieved greatness artistically and aesthetically with their careful and thoughtful construction of their albums. The outro, the last song in an album, is often overlooked in terms of its intentional placement. Similarly, TV shows such as the Sopranos and Breaking Bad, all have different finale endings, whether it was the final Sopranos scene abruptly fading to black or Walter White passing away with a grin on his mouth from Breaking Bad. Both shows elicited different feelings, responses, and emotions from viewers based on their connectedness to those shows. The Hip Hop outro is constructed in a comparable manner where the listener is left with something. How does the artist want you to feel after that last song? What is their final impression? How do they tie with the overall album? Often overlooked, with the right and proper song sequencing of an album, it can turn a great Hip Hop album into a classic one.

When I think about outros, there are some stellar and memorable ones. "Last Call" by Kanye West in his album, The College Dropout, clocked in at 12 minutes and 40 seconds, clearly the longest track on that album. He had some amazing lyrical content within that time frame but what stood out was his long talk about how he got into Roc-A-Fella Records. This was important because this was Kanye letting folks know who he is, where he came from, and how 
hard he's going to work in the industry. You couldn't help but think that Kanye in 2004 had a feeling how great he was going to become in the next few years.

Another classic Hip Hop outro was "If I Ruled The World" by Nas featuring Lauryn Hill, in his 1996 Hip Hop album, It Was Written. This album was a follow-up album to his classic album, Illmatic. Nas is considered one of the legendary storytellers in Hip Hop history. His album, It Was Written, was a very evocative and artistic album that really painted the realities of where he was from in Queensbridge, NY. Some of the songs on that album included, "Street Dreams", "Shootouts", and "The Set Up." These tracks really shed light on what it was like living in the projects everyday in Queensbridge. The theme of Nas' album is what makes his outro song, "If I Ruled The World", so stunningly powerful because Nas is envisioning a world that he wants to live in beyond what his current life is representing. It was a song of hope, not just for him, but for many young African American boys who were living in neighborhoods and projects that were steeped with drugs, violence, and poverty. Nas with the power of his pen and his microphone declared loudly, "Imagine that."

While both "Last Call" and "If I Ruled The World" are considered Hip Hop gems in their own right, there are artists today who are also creating outros that are providing purpose and perspective. One artist in particular is J Cole. In Chapter 1 of my dissertation, I used one of his songs, "Love Yourz", as a way to describe what counseling looks and feels like when we enter the counseling relationship with empathy, compassion, and authenticity. I wanted to use one of his outros to describe what this final chapter will encompass. His outro song, "4 Your Eyez Only", from the album of the same name, was a powerfully written narrative that served the purpose to humanize people, specifically communities of color who are often vilified and villainized in society. J Cole is utilizing forms of counternarratives to dispel singular stories that 
are written through layers of whiteness. In an article written by The New York Times (2017), J Cole shared, "The people that I know that live that life and come from that life, or even used to live that life, there's so much more than that. They have multiple sides, and the side that is the strongest is love." Love. This simple four-letter word evokes such a powerful description of what this dissertation stands for. This work that we do in counseling is centered in love. As Freas and KT alluded in their interviews, it is that revolutionary love. It is that type of love that advocates for our students, equips them with the tools to develop self-agency, and constantly centers their experiences.

J Cole’s outro song, “4 Your Eyez Only”, describes in so many layers what I have found in my interviews, coding process, and analysis. It has also provided me with the confidence to know that the choice of methodology in portraiture did exactly what $\mathrm{J}$ Cole was aspiring to achieve in his outro song. How do counselors see the goodness in all students? What can they learn when they engage in thoughtful and authentic relationships? How do they hold themselves accountable and practice deep self-reflection? What biases, assumptions, and prior experiences are shaping the ways they work with their students? The methodology of portraiture and the methods of phenomenological interviewing allowed me to view each participant from different perspectives and vantage points.

When artists develop outros for their albums, they all take different approaches. Some wanted to "drop the mic" like A Tribe Called Quest with their outro song, "Scenario." Some wanted to convey a need to address social justice issues such as "HiiiPoWeR" by Kendrick Lamar. Some wanted to leave us with hope and inspiration like the aforementioned song, "If I Ruled The World." Others, like J Cole, wanted to provide perspectives and insights to ponder and reflect about. 
This dissertation study explored the following research questions to demonstrate how Hip Hop pedagogy informed counselors' approach to college counseling:

1. What are the life stories and experiences of community college counselors who engage in Hip Hop pedagogy?

2. How does their lived experiences and their understanding of Hip Hop shape and inform their college counseling practices?

As the findings indicate, these four aesthetics of Hip Hop were prominent in the ways they informed the participants' approach to counseling. The four aesthetics of Hip Hop include: 1) keepin' it real (authenticity), 2) show and prove, 3) politics of space, and 4) sampling and remix.

This final chapter will discuss the notion of the "hidden track" that sparks the conversation about the potential long-term impact of college counseling within the framework of aesthetics of Hip Hop. I will also discuss implications that impact future research and college counseling practices. Then, I will provide recommendations around the work of aesthetics of Hip Hop in college counseling in relation to professional development, educational leadership, and graduate program development. I also wanted to share my reflections writing my last chapter during the era of COVID-19 and how it has influenced my writing as well as making additional meaning to the findings found in the study. Lastly, related to my reflective piece, I wanted to share my thoughts about envisioning a future in higher education through the lens of Hip Hop.

\section{THE HIDDEN TRACK}

Hidden tracks, also known as secret songs or Easter eggs, are one of the unique aesthetics of the $\mathrm{CD}$ (compact disc) era. Just as audiences sit through the closing credits of a film waiting for that hidden movie scene, listeners would do the same after the last track of the album. They 
would wait seconds or even minutes to see if there are any hidden tracks. Back then when the internet didn't exist, we didn't know if there were any hidden tracks. We had to sit and wait. We didn't have the internet spoil it for us. Sometimes, you may be lucky to be informed about the hidden track by a radio station or another person who had the CD. But, most of the time, it came as a surprise. Arguably, the most famous hidden track in Hip Hop and R\&B is “Can’t Take My Eyes Off You” by Lauryn Hill in 1998. Her cover of Frankie Valli’s biggest hit embodied so much soul, Hip Hop, and artistry, that her version actually rivaled the original song. While being its most popular song, it was not listed as an original track in her album, The Miseducation of Lauryn Hill. I remembered listening to the entire album in my dorm room at San Francisco State University in 1998 with several of my college friends. I remembered during this time, I was in the process of my own critical consciousness. I was deep into learning about my Filipino culture and history. I was heavily involved in the community fighting for immigrant rights and compensation and benefits for our Filipino war veterans. I was also learning about feminism, womanhood, and self-love. When the final song, "The Miseducation of Lauryn Hill” ended, we were all yearning for more. Within moments, you hear someone beatboxing and trumpets in the background. Then, you can hear Lauryn Hill speaking over the beats as you can hear the melodic tunes of the song entering. And with that, Lauryn Hill treated us with her version of "Can’t Take My Eyes Off You."

Hidden tracks are placed there for a variety of reasons. Within the context of the construction of an album, what is being hidden and why? What is the artist's intention? It was a way to end with a celebration. It provided us with an opportunity to re-engage in the album in a different way. It provided us with a different perspective for the entire album. It left us with questions, insights, and ideas. Sometimes, it was just a proverbial middle finger to 
record companies who try to control what songs should be included in albums. Hidden tracks may also represent what the artist defines as "hidden", whether they are hidden feelings, emotions, demons, ideas, or thoughts.

I began to reflect deeply around this notion of the "hidden track" as it relates to the research findings around how the aesthetics of Hip Hop inform college counseling practices. As the findings suggest, for students to feel that their presence and their lived experiences are acknowledged, we need to create spaces of authenticity that provide opportunities for the coconstruction of knowledge, validation, and self-agency (Lee, 2018; Museus, Yi, \& Saelua, 2017; Rodriguez, Massey, \& Saenz, 2016). When it comes to measuring student success, persistence, and retention, it is often difficult to assess whether culturally responsive counseling practices such as one that is informed by the aesthetics of Hip Hop is actually impacting student success. Grade point averages (GPA), degree completion rates, and transfer rates are all examples of metrics to measure student success. As research has shown, students of color, specifically African American, Latinx, and Pacific Islander students, have illustrated lower rates of degree completion, retention, and transfer (Hall, 2017; Newman, Wood, \& Harris, 2015; Wood \& Palmer, 2014. However, educators know that those metrics don't necessarily define the whole student experience within the social, ecological, and environmental perspective.

As community colleges are acknowledging that not all students are equally prepared for college, they are taking the necessary steps to examine and explore their current practices to see where they can identify and address equity gaps that are impacting our traditionally marginalized student population. As college counselors, we are tasked to see how we can serve our students differently and effectively to help close the equity gaps. While we as educators strive to assist our students to earn degrees, transfer to four-year universities, and complete other educational 
goals, we also recognize that measuring success for students can be very complex and nuanced depending on each student. The role of academic advising has been connected to student persistence but very few studies have presented empirical evidence to support that (Hatch \& Garcia, 2018). Other research explored students' perception of the quality of advising and frequency of advising sessions (Swecker, Fifolt, \& Searby, 2013).

Museus, Yi, and Saelua (2017) found that when campus environments are created to be culturally engaging and responsive to students' needs, students of color are more likely to experience a greater sense of belonging. They argued that there is a need to redefine what student success means in the form of conceptual divergences. These consisted of looking at sense of belonging, validating opportunities, and cultural integrity. While these are more difficult to measure in terms of whether or not they directly impact degree completion rates or persistence, they can be seen as conditions that indirectly impact student success. These are the "hidden tracks." When we look at the four aesthetics of Hip Hop within counseling: 1) keeping' it real (authenticity), 2) politics of space, 3) show and prove, and 4) sampling and the remix, there is limited research on each aesthetic's impact on quantitative outcomes of student success, specifically around validation, creating engaging environments, and acknowledging students' cultural wealth (Acevedo-Gil, Santos, Alonso, \& Solorzano, 2015; Barnett, 2011; Museus, Yi, \& Saelua, 2017; Rendón, 1994; Rendón \& Munoz, 2011; Yosso, 2005).

While these "hidden tracks" can have a significant impact on students' sense of belonging, their understanding of self, their ability to practice self-agency, and their ability to navigate systems of oppression, there is a major opportunity to pursue new knowledge on how to measure these aesthetics of Hip Hop in college counseling practices. These aesthetics of Hip Hop have shown to be present in college counseling practices to address students in the "here 
and now." What is the nature and scope of counseling sessions engaged through Hip Hop that may contribute to outcomes of student success? This is an important next step for research when addressing other conceptual divergences of student success particularly when serving traditionally marginalized students who are often invisible, silenced, and hidden.

\section{IMPLICATIONS}

Addressing the counseling needs for students of color is absolutely important and critical in increasing their motivation and ability to achieve their educational goals (Harris \& Wood, 2013; Lee, 2018; Tovar, 2015). When we review degree completion and graduation rates in community colleges for students of color, specifically African American and Latinx students, we see that these students are identified as experiencing disproportionate impact across several performance indicators of success in comparison to their White and Asian counterparts (National Center for Educational Statistics, 2018). This poses a significant social justice and equity issue for this student population. Research shows that students who do not have higher education degrees or certificates will accrue lower lifetime earnings and are more likely to be at or near poverty levels (Museus \& Saelua, 2017). Unless major changes are created, the significantly low graduation rates of students of color will result in lower long-term wealth acquisition, greater income gaps across race and/or educational levels, and a negative impact on the nation's overall intellectual capital and global competitiveness (Hall, 2017).

Revisit counseling student learning outcomes. This study contributes to the scholarship in regards to different pedagogical approaches and considerations around college counseling practices when working with students from traditionally marginalized backgrounds. The research findings suggest a need for more research in the areas of authenticity, validation, usage of space, and students' cultural wealth within the context of college counseling. This 
research argues for the need to review and revise counseling student learning outcomes outside of physical space. In addition, the need to evaluate student experiences in counseling in relation to authenticity, validation, and knowledge sharing has become clear.

Student voices and experiences. Another implication for future research is to explore and examine students' experiences when engaged in college counseling utilizing the aesthetics of Hip Hop. As indicated from the findings, the pedagogical approaches using Hip Hop lead to more humanizing, student-centered, and validating student experiences. Within the last 5 years, there have been educational opportunities in the California community colleges where Hip Hop pedagogy is being implemented and practiced in classroom and counseling spaces. How have these educational experiences impacted students related to retention, persistence, and overall success? This future research of understanding college experiences from the student perspective will provide an additional layer of understanding the value and impact of Hip Hop aesthetics in college counseling spaces.

Need for more community college counseling research. Most of the research around college success has looked at student experiences from the four-year universities. There has been a lack of research on the impact of college counseling on student success and its effectiveness at the community college level, specifically the influence on degree completion, retention, and persistence. While the present study adds to the scholarship for examining counseling practices at community colleges, it was only limited to community colleges in Northern California. The National Academic Advising Association (NACADA) developed the NACADA Academic Advising Core Competencies Model in 2017 that is intended to "identify the broad range of understanding, knowledge, and skills that support academic advising, to guide professional development, and to promote the contributions of advising to student development, 
progress, and success." However, the interpretation and implementation of this core competencies model may be unique across all community colleges. There are several college counselors in Southern California and in other states such as Washington, Georgia, and New York, who are explicitly utilizing Hip Hop pedagogical practices in their counseling practices. Further research with these counselors can potentially yield valuable insights around the similarities and differences in the ways their lived experiences through Hip Hop have shaped and informed their current counseling practices.

\section{RECOMMENDATIONS FOR ACTION}

As California community colleges are engaging in conversations and reviewing their institutional data around student equity, colleges have begun to identify equity gaps throughout their institutions (Ching, Felix, Castro, \& Trinidad, 2018). The way in which counselors advise and perceive their students can significantly impact the way their students navigate institutions of higher education. The literature around Hip Hop education was largely based from research applied in classroom settings. Rose (1994) describes how we might re-imagine utilizing these salient aesthetic forms of Hip Hop in education. In the context of college counseling, what might flow, layering, and rupture look like? How are counselors more present to identify flow between themselves and their students? How might they intentionally layer their own knowledge with the cultural capital and wealth students are bringing in? How might counselors create rupture or disrupt the preconceived beliefs around education that students are led to believe?

Similarly, Rendón's (2009) Sentipensante Pedagogy addressed three goals when engaged with students in counseling sessions. By creating harmony between the knowledge and wisdom possessed by both counselors and students, we meaningfully disrupt the singular stories that privilege the dominant narrative while also providing students with the tools to address systems 
of oppression and other issues around social justice and equity. Based on the research findings, the following recommendations for action include: a) professional development and training, b) counseling evaluations, c) hiring practices and processes, d) curricular integration in counselor education programs, and e) future research in Hip Hop education.

Professional development and training. One of the major questions that surrounds Hip Hop pedagogy in any educational space is: What are the requirements for anyone interested in utilizing Hip Hop as a tool and approach to working with students? Can counselors who don't identify with Hip Hop culture engage in this pedagogy? According to the U.S Department of Education, about $50 \%$ of the public student population are students of color, while nearly $80 \%$ of public school teachers are white. Adjapong (2017) argued that, although teachers may not identify with Hip Hop culture as their students do, it does not prove to be a limitation for utilizing Hip Hop pedagogy. He views educator's minimal knowledge of Hip Hop culture as a strength in learning that encourages teachers to position themselves as a student of their students' culture. Irby and Hall (2013) also point out that "keeping it real" can be stifling in the advancement of Hip Hop-based education. While there have been issues of cultural appropriation and commodification in the misuse of Hip Hop in educational spaces, there are educators who are genuine in wanting to learn deeply about their students' culture.

Professional development and training around utilizing the aesthetics of Hip Hop in college counseling should be available for counselors to add to their existing knowledge. With the ever-changing educational landscape, it is important to be equipped with a wide range of effective practices that we can utilize when working with any student. One of the major aesthetics of Hip Hop is "keeping it real." Part of keeping it real also means being transparent about what counselors don't know. If counselors are interested in this work around Hip Hop 
pedagogy, then they need to ask themselves: Why am I doing this? Who is it for? What is the ultimate goal? This is a necessary step to take as Hip Hop culture has experienced cultural appropriation and commodification in higher education. While scholars and Hip Hop practitioners have different viewpoints in terms of who gets to utilize Hip Hop pedagogy, counselors need to arrive and enter this work with the intention of building and co-constructing educational experiences with their students. They also need to engage in deep self-reflection and reflexibility to ensure that they hold themselves accountable when working with students. It requires counselors to practice the ability to step back, critically listen, and be open to learning a new culture. College counseling is much more than providing information; it is creating spaces for transformation to exist.

Given that conditions of authenticity, validation, knowledge-sharing, reflection, and critical listening are embedded in counselors' ways of doing and being, the next level of professional development and training would consist of specific pedagogical approaches that incorporate the different elements and aesthetics of Hip Hop such as emceeing, turntablism, and graffiti. In other words, how might we utilize the element of graffiti in our counseling practice to promote the importance of visual communication or branding one's identity? For example, as the counselor of the CIPHER Hip Hop Learning Community, I collaborated with a local coffee shop to build a visual art gallery for my students. As part of my identity unit in my college success course, I assigned a visual art project that allowed them to visually respond to the questions: Who are you? What communities are you from? What does community mean to you? Current textbooks around college student development that address identity, if at all, typically provide traditional forms of assessment such as journal entries to respond to the topic of 
identity. The intentional use of the aesthetics of Hip Hop provides a more culturally responsive approach by allowing students to share their responses in different modalities.

Hip Hop pedagogy in counseling graduate programs. The birth of Hip Hop was created by Black and Brown youth in response to the social, political, and economic oppression they experienced in the South Bronx in the early 1970s. It cannot be overstated that Hip Hop culture, which has developed into a multibillion-dollar industry, was created for the youth, by the youth. Hip Hop has certainly evolved over the 40 years from the party rocking movement, to the political rap movement, to the gangster era, and the advent of trap music. While Hip Hop has evolved in many ways, Hip Hop culture is and will always be about telling stories through rap, murals, dance choreography, and musical instrumentation and production. Hip Hop has transformed into a culture that moves beyond just African American culture; it has stretched beyond race, class, gender, ability, sexuality, and education. Due to its unfiltered and unapologetic nature, Hip Hop culture, when engaged authentically and meaningfully in educational spaces, can serve as a bridge and platform to better understand the environmental and ecological contexts our students are experiencing.

There have been strong connections and emphases drawn for integrating training around multicultural and social justice leadership and application. Revised multicultural counseling competencies (MCCs) has raised awareness around the impact of oppression and inequities when working with all students (Ratts, Singh, Nassar-McMillan, Butler, \& McCullough, 2016). When working with students who come from traditionally marginalized populations, it is important for counselors to be culturally competent so they can address systems of oppression and privilege. Grounded in Hip Hop pedagogy, there is a strong focus on centering the students' voices and experiences as well as explicitly naming oppressive structures that impact students' 
experiences. There is a strong need for Hip Hop pedagogy to be included in the educational development and training for upcoming college counselors. While it is important to equip current college counselors with access to new and emerging pedagogical approaches, it is equally important to provide that same access to counselors-in-training. Counselor education programs need to revisit their curricular content to adapt and evolve to intentionally address the needs of students of color in higher education.

There are a few pedagogical approaches that can be included in the curriculum such as Reality Pedagogy (2017) by Dr. Chris Emdin, Pedagogy of Real Talk (2015) by Dr. Paul Hernandez, the SWAG Framework (2019) by Kim Davalos, and Critical Hip Hop Pedagogy (2009) by Dr. Antwi Akom. Because there are very few practitioners engaging with these pedagogical approaches, it would be worthwhile to invite these educators as guest speakers to talk about their pedagogical approaches. While most of these pedagogical approaches have been studied and applied in graduate programs, more notably in teacher education programs, there has been very little application in counselor education programs.

Examine counselor hiring practices. Many community colleges serve our most traditionally marginalized and minoritized students from various racial and cultural backgrounds. Many students of color, specifically African American and Latinx students, attend community colleges because they see these institutions as venues that facilitate their social and economic advancement (Bush \& Bush, 2005). Based on the student enrollment reports from the California Community Colleges Chancellor's Office, over 46\% of all enrolled California community college students are Latinx students in comparison to their White counterparts at 26\% (California Community Colleges Chancellor's Office, 2020). In comparison, 19\% of all enrolled students in degree-granting institutions in Fall 2016 were comprised of Latinx students, 
while their White counterparts represented 56\% of all students (NCES, IPEDS, 2017). Research has shown that students are more successful when they experience a sense of belonging at their institutions and have access to faculty and peer mentoring (Harper, 2015; Harris, Wood, \& Luke, 2014; Tovar, 2013). Additionally, research shows that these students also need counselors who can create meaningful and purposeful relationships, taking into consideration the students' culture, history, and lived experiences (Harrison, 2009; Mitchell \& Rosiek, 2005).

There is extensive research that supports hiring teachers and counselors who represent the same ethnic and cultural identity and experiences as their students (Brooms \& Davis, 2017; Griffin, 2012; Strayhorn, 2008). While it is also argued that just increasing the "number of counselors of color" does not necessarily address the root causes of disproportionate impact students of color are experiencing, there is also extensive research that suggests that students have increased sense of belonging and self-esteem when working with faculty who identify with the same racial and ethnic backgrounds (Brooms \& Davis, 2017; Rodriguez, Massey, \& Saenza, 2016; Tovar, 2015).

Improving the academic achievement and closing the equity gaps will require community colleges to examine their hiring practices to ensure that counselors who are hired are both "a good fit" and a "valuable long-term investment" for the institution (Flanagan, Jones, \& Moore, 2004, p. 827). However, defining "a good fit" has to be further explored. In a conversation with my dissertation chair, Dr. Allyson Tintiangco-Cubales, there has been some extensive work around approaches utilizing culturally relevant and culturally responsive pedagogies. Emerging from her current research and observations, it is not enough to facilitate professional development workshops and trainings who are not representative of a particular culture. While there is value that these educational opportunities provide for educators, 
specifically White educators, there is a greater need to acknowledge the cultural wealth of educators who are rooted in the culture. Dr. Tintiangco-Cubales refers to this as "culturally rooted pedagogy" that places high value on the work, teaching, and the epistemologies of indigenous people and communities of color that have been marginalized, erased, and silenced. (Tintiangco-Cubales, personal communication, May 1, 2020).

As articulated in the findings, the four aesthetics of Hip Hop in college counseling approach the work from a culturally-responsive and arguably, culturally rooted perspective that considers the experiences, realities, and interests of the students. Within the aesthetics of Hip Hop, these practices provide moments of affirmation, support, and advocacy. In addition, this can be further strengthened when community colleges are intentional in hiring counselors that embody these aesthetics of Hip Hop, especially community colleges that serve a large percentage of students who are traditionally and historically marginalized. In their interviews, the participants in this study illustrated that they have experienced various forms of oppression and how they turned to the arts and culture of Hip Hop to help them navigate the challenges posed to them as students.

According to Green and Ciez-Volz (2010), they described there are different steps to hiring exemplary community college faculty such as community college counselors. These steps include: 1) establishing a hiring committee, 2) writing job descriptions and requirements, 3) specifying qualifications, 4) advertising the position, 5) selecting individuals from the candidate pool, 6) prescreening semifinalists, 7) interviewing finalists, and 8) conducting reference checks (p. 87). It is important for the committee to have a mutually agreed criteria that is informed by guiding values, policies, practices, and desired qualities. The research findings of this study can help inform the screening criteria, interview questions, and reference checks. By examining 
counseling hiring practices through the lens of Hip Hop aesthetics and cultural responsiveness, community colleges will be able to identify college counselors who will provide counseling support that is rooted in authenticity, validation, advocacy, and harmony.

\section{Explore a culturally responsive case management model to counseling.}

Given the deep, intentional approach to counseling when engaged with the aesthetics of Hip Hop, it does require an extensive amount of time to develop rapport, understand the complexities of students' realities, and meet their needs related to their educational goals. Time is such a valuable commodity which many college counselors don't have. Most community colleges are able to fund only one counselor for every 800 to 1200 students (Bailey, Jaggars \& Jenkins, 2015). How can one counselor realistically meet the needs of all of their students in a meaningful, culturally responsive way? Because seeing a college counselor is often optional for

students after the first initial appointment, counselors often try to cram as much information into a session anticipating that they may not see them again. These sessions can feel rushed and overwhelming for students. While Bush and Bush (2005) found that many students of color go to community colleges for social and economic advancement and affordability, they are not provided accurate, consistent information and student services support needed to overcome institutional barriers.

Generally, students don't have the opportunity to develop working relationships over the course of their academic journey. Unless they are part of learning communities or categorical programs such as Extended Opportunities Programs \& Services (EOP\&S), students may not have a designated counselor. Thus, they most likely see different counselors throughout their time in college. Different counselors often offer conflicting advice due to the different 
philosophies, perspectives, and various interpretations of requirements and policies (Karp, O’Gara, \& Hughes, 2008).

Karp, O'Gara, and Hughes (2008) argue that the way counseling services are set up may have some unintended consequences that may inadvertently perpetuate and reinforce disadvantage. They contend that students who come with pre-existing social and cultural capital to navigate systems can take advantage of student services. However, students who don't have the social, cultural, and navigational capital may interpret their failure to progress toward a degree as personal, rather than structural.

The structural and institutional ideology of meritocracy must be called out and dismantled in order to provide equitable support services for our students (Ladson-Billings \& Tate, 1995).

Case management models are not new in higher education as many programs and learning communities such as EOP\&S, TRiO, Upward Bound, Puente, CIPHER Hip Hop Learning Community, and the Promise Scholars, are developed to support groups of students with different needs in varying ways. Case management is viewed as a high-touch approach where students receive enhanced counseling services that are centered around the students' needs. Santiago (2008) describes this approach as a way of developing a working relationship with students to enhance the students' ability to reach their educational goals throughout their entire academic journey. Examples of these enhanced services include: a) mandatory meetings, b) designated counselor, c) longer counseling sessions, and d) access to financial resources such as grants, food security, and transportation stipends. Within this model, there is a need to recommend more time with the student. Most counseling appointments are scheduled at 30 minutes; however, more time is necessary for the initial appointment to establish rapport as well as providing necessary information that directly relates to their educational goals. Addressing 
this proposed model through the lens of equity, all students have different needs that may require different levels of support. Students who require high support will have more access to counseling and student services than those who are considered "low support." Equity is defined as providing student support services to those who need them during the time when they need them.

This is a challenge that community colleges face as these enhanced services can be more costly to the overall budget. However, the current counseling model is not working as many students of color stop or drop out of college due to various individual, interpersonal and institutional barriers such as financial obligations, experiences of microaggressions, limited access to navigational capital, and lack of overall student support. Arteaga (2015) found that students emphasized the need and the importance of being able to consistently meet with the same counselor. By maintaining a consistent working relationship with their counselors, she also found that they were developing the potential to empower themselves by building off their existing knowledge and skills through the culturally responsive approach used by their counselors. While the case management model allows students to work with their counselors more frequently and more intentionally, further research is necessary to measure overall student success outcomes.

Examine the evaluation process for college counseling. Based on the standards of practice outlined by the Academic Senate for the California Community Colleges (2008), counseling programs are required to go through regularly scheduled reviews. There are several areas of review such as budgetary planning, decision making processes, and student learning outcomes processes. Developing student learning outcomes is faculty driven and should measure data that can improve the effectiveness of counseling services for students. Based on 
the recommendations made by the Chancellor's Office of the California Community Colleges in their Vision For Success (2020), community colleges were tasked to explore and examine their current policies and practices and identify equity gaps that significantly impacting their students' ability to completing their educational goals. One of the initiatives that the California community colleges are working on is called the Guided Pathways. This initiative is a comprehensive effort for a whole-college redesign that will create clearer pathways for students to navigate from the moment they declare a major to the moment they complete their educational goals. Within the guided pathways, students are engaged closely with student support service personnel such as college counselors.

As a result, counseling functions such as orientation, counseling, and college success courses have been re-examined to see if our current practices and policies are serving all students. Given these new changes, counseling divisions will need to revisit their counseling evaluations to see if they are measuring the appropriate metrics to study effectiveness of service and the impact on student success. It also enhances the ability to identify and advocate for needed resources.

Drawing from the four aesthetics of Hip Hop in counseling, new questions can be created to help measure effectiveness. The following are examples of counseling questions that can be included: 1) Describe the positive counseling experiences, if any, you have built with your college counselor. 2) In what ways, if any, did you feel that your counselor provided the space for you to be your authentic self? 3) Describe the physical space. In what ways did it make you feel comfortable or uncomfortable? 4) In what ways, if any, did you feel validated in the counseling session? 5) In what ways, if any, did you feel that you were able to contribute your knowledge and experience in the counseling session? 6) How would you change or improve 
your counseling session? 7) From a student perspective, what recommendations would you make to ensure a positive counseling experience? 8) Based on your counseling experience, what are reasons you would or would not seek college counseling? 9) On a scale from 1-5 (1-low, 5high), how would you rate the importance of college counseling to your overall college success? The ability to explore or remix counseling evaluation measures allows counseling divisions and departments to get a better understanding of students' needs and how to best address those needs. Collaborating with the college research committee as well as departments that focus on student equity will provide an additional level of depth and breadth in understanding our students' needs.

\section{FUTURE RESEARCH}

Hip Hop Aesthetics within the online ecosystem. At the time of this dissertation writing, we are in the midst of a pandemic inflicted by the novel coronavirus also known as COVID-19 where our lives have been dramatically impacted and altered. In the state of California, we were given a shelter-in-place ordinance which means that people are strongly encouraged to stay indoors except to engage in essential tasks such as going to grocery stores, banks, and hospitals. Also, to slow down the spread of COVID-19, large gatherings over ten are prohibited and social distancing of six feet apart is strongly encouraged. As a result of these precautions, many schools and colleges around the nation have closed down and now have moved all of their operations, specifically, instruction and student services, entirely online.

Within the last two decades, online education has grown steadily in college enrollments (Allen \& Seaman, 2016). In California alone, community college online student enrollments have totaled 860,283 students, accounting for $28 \%$ of the total unduplicated enrolled students in 2017 (California Community Colleges Chancellor's Office [CCCCO], 2017). While online 
instruction has been researched, developed, and implemented during the last two decades, there has been a lack of advancement and research on how to effectively integrate student support services online. Within the context of college counseling, further research is necessary to determine the effectiveness of online counseling in creating authentic spaces for learning and counseling. What are the implications around the usage of space as described in the findings? There is a need for additional exploration on what cultural responsiveness looks like from an online counseling perspective. In addition, there are numerous concerns to address when implementing online student support services such as access to laptops and internet capability, confidentiality issues, and intentional connection to services such as mental health support and food security.

Aesthetics of Hip Hop counseling practices at other community colleges. Given that this dissertation research focused on lived experiences of four college counselors from three Northern California community colleges, it is difficult to generalize the findings to other community colleges, both statewide and across the nation. During the preliminary outreach to seek community college counselors who engaged explicitly with Hip Hop pedagogy in their counseling practices, I received fifteen responses. Respondents came from Central and Southern California, New York, Chicago, and Hawaii. However, due to convenience, my research focused on counselors from Northern California. It would be worth exploring the lived experiences and counseling practices from the various community college counselors more broadly in the state as well as the nation. Moreover, this research can be extended to explore the counseling experiences of students engaged within the aesthetics of Hip Hop. Combined qualitative data of counselors and students could help provide perspectives around counseling practices and modes of delivery. 
In addition to examining students' counseling experiences, it would be valuable to combine quantitative and qualitative data to analyze the impact of counseling practices utilizing the aesthetics of Hip Hop on overall student outcomes such as degree completion, persistence, and retention as well as other conceptual divergences of success such as sense of belonging and level of self-agency. This future research can also extend to students who have already graduated and transferred from community colleges to assess how their counseling experiences impacted their ability to navigate other systems of higher education and career development such as four-year universities and employment opportunities.

Lastly, while the participants in this study provided some counseling techniques that utilized different forms of aesthetics of Hip Hop to work with students, there is a need to concretely provide information about the ways in which the four different elements of Hip Hop are utilized and integrated in various counseling spaces such as one-on-one appointments and college success courses. These practices can take different forms as Hip Hop as a culture is always evolving and changing. This warrant extended research as to how the evolution of Hip Hop impacts the way we work with students today and in the future.

\section{HIP HOP REFLECTION IN THE ERA OF COVID-19}

This research study explored how the lived experiences engaged through and with Hip Hop culture helped inform and shape the counseling practices of four community college counselors. As they shared their stories, rooted in vulnerability, courage, and healing, the interviews gave us a glimpse into their lives and how Hip Hop has allowed them to navigate through various chapters of their lives. The participants experienced moments of invisibility and silence, but they found their presence and voice through words and music. Their stories described the streets of Oakland, the trajectory of their own critical consciousness, the struggle 
and reclamation of their identity, and the ways in which Hip Hop has challenged their own whiteness.

Hip Hop culture is rooted in storytelling through the various elements of Hip Hop ranging from rap, graffiti, dance, or turntablism. There is a story to be told. What makes Hip Hop so powerful and valuable in these counseling spaces is that it provides the conditions through which stories can be shared. As the findings illustrate, counseling practices in the form of one-on-one sessions, college success courses, orientations, and group workshops, should embody these four aesthetics of Hip Hop: a) authenticity, b) importance of spatial awareness, c) validating experiences, and, d) providing opportunities for students to share and co-construct knowledge through sampling. Even though Hip Hop education has been around for over two decades through research and practice, it is still not widely accepted and understood in academia. Students who identify with Hip Hop culture have similar experiences of not feeling accepted for who they are and have experienced moments where they were misunderstood. This is why so many youth gravitate to Hip Hop culture because it is raw, unfiltered, and unapologetic. It is intentional. It is loud. Its emphasis is to amplify many young people's presence in a world that renders them invisible and silent. Hip Hop offers a place where they can experience a sense of community, a place for healing, and a vehicle for selfexpression. Experiencing the global pandemic, COVID-19, the novel coronavirus has further concretized the importance of Hip Hop culture during these uncertain times.

With the shelter-in-place ordinances, the rules of social distancing, and the rising number of people testing positive for COVID-19 globally, we have been forced to adjust and adapt the way we live, work, and interact with others. Our lives have been disrupted to navigate this "new 
normal." Zoom conferences, virtual happy hours and birthdays, food drop-offs, tape on the floors of grocery stores, and TV show binges have become the new norms.

Specifically, in my role as a college counselor, we had to move towards online and phone counseling. As we adapt to the rapid changes impacted by COVID-19, the way we operate and function as student support services are also adapting along with them. Many tasks related to college counseling such as providing orientations, referring students to different resources such as the Health Center or Psychological Services, having transcripts evaluated, and teaching classes have taken some time for the institutions to revise and refine protocols and processes to address all of the various tasks. While there has been research regarding the success of online modalities, it doesn't necessarily work for all students (Budhai, 2020). Currently in my online counseling appointments with students, these are some of the issues and challenges our students are facing when educational institutions are completely offering college education and support services online:

- Not all students have laptops or computers at home.

- Not all students have internet access.

- Students who require academic, physical, mental, and emotional support are having difficulty accessing support such as our non-native English speakers, students with disabilities, foster youth, and concurrent high school students.

- Students who require mental health support.

- Students who require hours for laboratory work such as Cosmetology, Automotive, and Biotechnology.

- Students who live in households that don't offer spaces of confidentiality.

- Students have to share laptops, computers, and workspace with other people in the household.

- Students who rely on the college for food and financial security.

These are just some of the examples of issues that our students are experiencing. In creating a virtual space for students to share their feelings, thoughts, and emotions around the pandemic related to their whole being, they have shared a common theme in the ways they made meaning of these uncertain times. They all, more than ever, value the human connection. They value the 
importance of relationships. If anything, this pandemic has amplified the importance of people connecting and building with each other.

Even though we are experiencing a disruption to our lives, Hip Hop culture has made its presence felt today and created a sense of harmony for people around the world despite this pandemic. DJ D Nice played a ten-hour DJ set on Instagram Live (IGTV) titled, "Homeschool", playing all of the biggest hits of Hip Hop, soul, funk, and R\&B. I went on there and immediately started bobbing my head along with the beat. The next moment, my son and I were dancing in the living room. Then, after two hours, I remember hearing DJ D Nice yell, "I can't believe we hit over 100,000 viewers!” That was unheard of. There were so many people around the world tuning into the DJ set. While I was on there, so many celebrities joined the party such as Steph Curry, Will Smith, Beyonce, Michelle Obama, John Legend, Bernie Sanders, Oprah Winfrey, Ellen, and so many others. But what stood out to me the most was all of the comments that people were writing in the chat box. The comments were centered in themes of healing, self-care, community, gratitude, hope, and love. I cannot count how many times I saw, "Thank you Hip Hop for giving us this space to heal.” Days later, we saw free Hip Hop and R\&B shows for everyone presented by 9th Wonder, QuestLove, H.E.R., John Legend, and many local Hip Hop artists. I texted friends and family about which IGTV room they are in. Hip Hop has built a community of artists that understand the importance and impact of mental health awareness and community care.

Hip Hop has always been seen and viewed as a disruption in educational spaces because it is anti-establishment and counter to the dominant narrative. Hip Hop has provided virtual spaces for communities of color to thrive and survive during these uncertain times. Hip Hop has always been about adapting to new changes. Hip Hop is about the remix and evolution. So, it's 
no surprise that Hip Hop today is significantly impacting the world today. What we are witnessing today is what Hip Hop culture has been saying for the last three decades. If you allow the youth the collective space to share their knowledge, wisdom, skills, art, and talent, you begin to open a new world of creative opportunities and innovative ideas.

\section{HIP HOP FUTURITY}

The pandemic has also provided me with a reflection of what higher education could look like in the future. Patel (2016) talks about learning as an act of futurity. She describes futurity as "the imprint, the scent, the murmur of what is in the future (p. 95)." Essentially, no one can control the future. However, educational institutions have to be open to adapt and evolve when new changes emerge. Brown (2017) expands further with the concept of "collaborative ideation" meaning the birthing of new ideas and sharing that process collectively as early as possible. Many scholars have argued that higher education is built on coloniality, meritocratic philosophies, and race neutrality (Maldonado-Torres, 2007; Love, 2017; Yosso, Smith, Ceja, \& Solorzano, 2009). The more educators engage people to co-construct what education can look like today, the more educational institutions can address the concerns and challenges our students face much more meaningfully and intentionally.

When educational institutions reflect on futurity, they begin to see that learning is an act

of letting go. Institutions of higher education operate from the praxis of control in that they need to create structures to maintain policies that are informed by legislation. These policies then inform the practices by which we serve our students. This top-down approach has been an approach that has resulted in educational equity gaps that continues to significantly impact our traditionally marginalized and minoritized students. Oftentimes, learning holds onto what feels safe and that requires minimum changes and sacrifices (Patel, 2016). To move the needle in 
student success and to address the equity gaps, educational institutions need to assimilate less and take bolder risks.

What does Hip Hop teach educational institutions when we move towards more culturally responsive approaches in college counseling? Hip Hop is a defiance of coloniality that forces these institutions to be okay with not knowing what the future holds. Hip Hop allows these educational institutions to hold sacred what's most important when they work with their students and that is to build authentic human connections through genuine working relationships. We learned and found through the stories of four community college counselors that they provide counseling spaces for their students to be their true, authentic selves. They allow their students to be loud, unfiltered, and unapologetic. They position their students to be at the center of their work. They accomplish this by having the spatial awareness to create counseling experiences that center their students' knowledge and lived experiences grounded in authenticity, moments of validation, advocacy, and revolutionary love. If learning is an act of futurity, then Hip Hop is futurity because to be able to do this counseling work utilizing the aesthetics of Hip Hop, counselors will have to be able to let go and let their students flow. When counselors commit to this, they allow their students to say, in the words of the legendary, Biggies Smalls, "I got a story to tell." 


\section{REFERENCES}

Abes, E. S. (2009). Theoretical Borderlands: Using Multiple Theoretical Perspectives to

Challenge Inequitable Power Structures in Student Development Theory. Journal of

College Student Development, 50(2), 141-156. https://doi.org/10.1353/csd.0.0059

Acevedo-Gil, N., Santos, R. E., Alonso, L., \& Solórzano, D. G. (2015). Latinas/os in community college developmental education: Increasing moments of academic and interpersonal validation. Journal of Hispanic Higher Education, 14(2), 101- 127.

Akom, A. A. (2009). Critical Hip Hop Pedagogy as a Form of Liberatory Praxis. Equity \& Excellence in Education, 42(1), 52-66. https://doi.org/10.1080/10665680802612519

Alim, H. S. (2007). Critical Hip-Hop Language Pedagogies: Combat, Consciousness, and the Cultural Politics of Communication. Journal of Language, Identity \& Education, 6(2), 161176. https://doi.org/10.1080/15348450701341378

Allen, E. I., \& Seaman, J. (2017). Digital learning compass: Distance education enrollment report 2017. Retrieved from https://onlinelearningsurvey.com/reports/digitallearningcompassenrollment2017.pdf

Allen, J. M., \& Smith, C. L. (2008). Importance of, Responsibility for, and Satisfaction With Academic Advising: A Faculty Perspective. Journal of College Student Development, 49(5), 397-411. https://doi.org/10.1353/csd.0.0033

American Association of Community Colleges. (2020, March). Fast facts

2020. https://www.aacc.nche.edu/wp-

content/uploads/2020/03/AACC_Fast_Facts_2020_Final.pdf

Anderson, W., Motto, J. S., \& Bourdeaux, R. (2014). Getting what they want: Aligning student expectations of advising with perceived advisor behaviors. Mid-Western Educational Researcher, 26(1), 27-51.

Anzaldúa, G. (1999). Borderlands: La frontera. San Francisco, CA: Aunt Lute Publishers.

Appleby, D. (2001, March 19). The teaching-advising connection. The Mentor: An Academic Advising Journal. Retrieved from http://www.psu.edu/dus/mentor/ appleby0.htm.

Arteaga, B. E. (2015). Applying cultura in the community college counseling practice. Community College Journal of Research and Practice, 39(8), 708-726. https://doi.org/10.1080/10668926.2013.876374

Asante, M. K. (2008). It's bigger than hip-hop: The rise of the post-hip-hop generation. New York: St. Martin's Press.

Bailey, T., Jaggars, S. S., \& Jenkins, D. (2015). Redesigning America's community colleges: A clearer path to student success. Cambridge, MA: Harvard University Press. 
Banks, D., \& Banks, D. (2017). Hip Hop as Pedagogy : Something from Something Hip Hop as Pedagogy: Something from Something. Theater Topics, 25(3), 243-259.

Barnett, E. A. (2011). Validation Experiences and Persistence among Community College Students. The Review of Higher Education, 34(2), 193-230.

Beach, J. M. (2012). Gateway to opportunity?: A history of the community college in the United States. Sterling, VA: Stylus Publishing, LLC.

Bloom, J. L., \& Martin, N. A. (2002). Incorporating appreciative inquiry into academic advising. The Mentor: An Academic Advising Journal, 4(3). Retrieved from https://www..psu.edu/mentor/

Bloom, J. L., Hutson, B. L., \& He, Y. (2008). How can you empower your students to Optimize their educational opportunities? Appreciative Advising. Retrieved from http://www.appreciativeadvising.net/

Bourdieu, P. \& Passeron, J. (1977). Reproduction in education, society and culture. London: Sage.

Brooks, S. (2017). The song (does not) remain the same: Re-envisioning portraiture methodology in educational research. Qualitative Report, 22(8), 2231-2239.

Brooms, D. R., \& Davis, A. R. (2017). Staying Focused on the Goal : Peer Bonding and Faculty Mentors Supporting Black Males' Persistence in College. Journal of Black Studies, 48(3), 305-326. https://doi.org/10.1177/0021934717692520

brown, a.m. (2017). Emergent strategy: Shaping change, changing worlds. Chico, CA: AK Press.

Budhai, S. S. (2020). Online and engaged: Innovative student affairs practices for online learner success. NASPA Student Affairs Administrators in Higher Education.

Bush, E. C., \& Lawson Bush, V. (2010). Calling Out the Elephant: An Examination of African American Male Achievement in Community Colleges. Journal of African American Males in Education, 1(1), 40-62.

California Community Colleges Chancellor's Office (2018). Student Enrollment Status. Sacramento CA.

California Community Colleges Chancellor's Office (2020). Visions for Success. Sacramento CA. https://vision.foundationccc.org/

Camangian, P. R. (2015). Teach Like Lives Depend on It. Urban Education, 50(4), 424-453. https://doi.org/10.1177/0042085913514591 
Caramanica, Jon (2017, April 14). J Cole, the platinum rap dissident, steps back from the spotlight. New York Times. https://www.nytimes.com/2017/04/14/arts/music/j-cole-4your-eyez-only-hbo-interview.html

Carnevale, A. P., \& Strohl, J. (2013). Separate and unequal: How higher education reinforces the intergenerational reproductions of White racial privilege. Washington, DC: Center on Education and the Workforce, Georgetown University.

Cepeda, R.(2004). And it don't stop? The best American hip-hop journalism of the last 25 years. New York: Faber and Faber.

Chang, J. (2005). Can't stop, won't stop: A history of the hip-hop generation. New York, NY: Picador.

Ching, C. D., Felix, E. R., Fernandez Castro, M., \& Trinidad, A. (2018). Achieving Racial Equity From the Bottom-Up? The Student Equity Policy in the California Community Colleges. In Educational Policy. https://doi.org/10.1177/0895904818802092

Clark, M. A., Ponjuan, L., Orrock, J., Wilson, T., \& Flores, G. (2013). Support and barriers for Latino male students' educational pursuits: Perceptions of counselors and administrators. Journal of Counseling and Development, 91(4), 458-466. https://doi.org/10.1002/j.15566676.2013.00118.x

Cohen, A. M., \& Brawer, F. B. (2003). The American community college. San Francisco: JosseyBass.

Coleman, Brian, and Adam Mansbach. Check the Technique: Volume 2. Everett, MA: Wax Facts, 2014 (ISBN: 978-0- 9903076-0-0).

Cook, L., \& Friend, M. (1995). Co-teaching: Guidelines for creating effective practices. Focus on Exceptional Children, 23, 1-16.

Copperider, D. L, \& Whitney, D. (2000). A Positive revolution in change: Appreciative inquiry. In D. L. Cooperrider, P. Sorensen Jr., D. Whitney, \& T. F. Yeager (Eds.), Appreciative inquiry: Rethinking human organization toward a positive theory of change (pp. 3-27). Chicago, IL: Stipes Publishing

Coronella, T. (2018). Validation Theory Into Practice: Asset-Based Academic Advising With First-Generation Latina Engineering College Students. (May).

Creamer, D. G. (2000). Use of theory in academic advising. In V. N. Gordon \& W. R. Habley (Eds.), Academic Advising: A comprehensive handbook (pp. 18-34). San Francisco, CA: Jossey-Bass.

Crenshaw, K. (1991). Mapping the margins: Intersectionality, identity politics, and the vio- lence against women of color. Stanford Law Review, 43(6), 1241-1299. 
Crisp, G., \& Nora, A. (2010). Hispanic Student Success : Factors Influencing the Persistence and Transfer Decisions of Latino Community College Students Enrolled in Developmental Education. Research in Higher Education, 51, 175-194. https://doi.org/10.1007/s11162009-9151-X

Cuseo, J. (2003). Academic achievement and student retention: Empirical connections and systematic interventions. Retrieved from http:/www.uwc.edu/administration/ academicaffairs/esfy/cuseo/Academic\%20Advisement $\% 20$ and $\% 20$ Student $\% 20$ Retention.doc

Crookston, B.B. (1972). A developmental view of academic advising as teaching. Journal of College Student Personnel, 13(2), 12-17. Retrieved from http://www.nacada.ksu.edu

Darling-Hammond, L. (2015). The flat world and education: How America's commitment to equity will determine our future. New York, NY: Teachers College Press.

Davalos, K. (2019). delilah's daughter. Self-published.

Delpit, L. D. (2012). "Multiplication is for white people": Raising expectations for other people's children. New York, NY: The New Press.

Donaldson, P., McKinney, L., Lee, M., \& Pino, D. (2016). First year community college students' perceptions of and attitudes toward intrusive academic advising. NACADA Journal, 36,30-42. doi:10.12930/NACADA-15-012

Drake, J. K. (2011). The role of academic advising in student retention and persistence. About Campus, 16(3), 8-12. doi:10.1002/abc.20062

Duffey, T., \& Haberstroh, S. (2012). Developmental relational counseling: A model for selfunderstanding in relation to others. Journal of Creativity in Mental Health, 7, 262-271. doi: 10.1080/15401383.2012.711709

Dyson, M. E. (2004). The Michael Eric Dyson reader. New York: Basic Civitas Books.

Emdin, C. (2010). Moving beyond the Boat without a Paddle: Reality Pedagogy, Black Youth, and Urban Science Education. Journal of Negro Education, 54(3), 24-34. https://doi.org/10.2307/2293006

Emdin, C. (2015). Rethinking Pedagogy in Urban Spaces: Implementing Hip Hop Pedagogy in the Urban Science Classroom. 11, 66-77.

Emdin, C. (2016). For white folks who teach in the hood-- and the rest of y'all too: Reality pedagogy and urban education. Boston, MA: Beacon Press.

Flannigan, S., Jones, B. R., \& Moore, W. (2010). An exploration of faculty hiring practices in community colleges. Community College Journal of Research and Practice, 28(10), 823836. 
Forman, M. (2002). The 'hood comes first: Race, space, and place in rap and Hip Hop. Middletown, CT: Wesleyan University Press.

Forman, M., \& Neal, M. A. (Eds.). (2004). That's the joint! The hip-hop studies reader. New York, NY: Routledge.

Freas, A., \& Carnero, M. (2018). Rebirth of slick: Ciphering in community spaces to remix educator praxis. National Forum of Educational Administration and Supervision Journal, 35(4), 2017-2018.

Freire, P. (1970). Pedagogy of the oppressed. New York, NY: Continuum.

Fry, R. (2004). Latino youth finishing college: The role of selective pathways. Pew Hispanic Center. Retrieved June 24, 2004, from www.pewhispanic.org.

Gay, G. (2002). Preparing for Culturally Responsive Teaching. Journal of Teacher Education, 53(2), 106-116. https://doi.org/10.1177/0022487102053002003

George, N. (1998). Hip hop America. New York: Viking.

Ginwright, S., \& James, T. (2012). Youth Development. Rethinking Youth, (96), 51-71. https://doi.org/10.4135/9781446250297.n4

Ginwright, S. (2016). Hope and healing in urban education: How urban activists and teachers are reclaiming matters of the heart. New York, NY: Routledge

Glasser, B.G. \& Strauss, A.L. (1967). The discovery of grounded theory. Chicago: Aldine.

Gosa, T. L., \& Fields, T. G. (2012). Is hip-hop education another hustle?: The (Ir) Responsible use of hip-hop as pedagogy. In B. J. Porfilio \& M. Viola (Eds.), Hip-Hop(e): The Cultural Practice and Critical Pedagogy of International Hip-Hop (pp. 181-196)

Green, D. W., \& Ciez-Volz, K. (2010). Now hiring: The faculty of the future. New Directions for Community Colleges, 152, 81-92.

Griffin, K. A. (2012). Black professors managing mentorship: Implications of applying social exchange frameworks to analyses of student interactions and their influence on scholarly productivity. Teachers College Record, 114(5), 1-37. Retrieved from:

http://www.tcrecord.org/library/pdf .asp?ContentId=16419

Grossberg, L. We gotta get out of this place: Popular conservatism and postmodern culture. New York, NY: Routledge

Gurin, P., Dey, E., Hurtado, S., \& Gurin, G. (2002). Diversity and higher education: Theory and impact on educational outcomes. Harvard Educational Review, 72, 330-366. 
Hale, M., Graham, D., \& Johnson, D. (2009). Are students more satisfied with academic advising when there is a congruence between current and preferred advising styles? College Student Journal, 43(2), 313-324.

Hall, H. B. (2017). Deeper than Rap: Expanding Conceptions of Hip-hop Culture and Pedagogy in the English Language Arts Classroom. Research in the Teaching of English, 51(3), 341351.

Hall, M. R. (2011). Education in a Hip-Hop Nation: Our Identity, Politics \& Pedagogy. 268. Retrieved from http://scholarworks.umass.edu/open_access_dissertations

Hall, T., \& Martin, B. (2013). Engagement of African-American college students through the use of hip hop pedagogy. International Journal of Pedagogies and Learning, 8(2), 93-105.

Harper, S. R. (2015). Success in These Schools? Visual Counternarratives of Young Men of Color and Urban High Schools They Attend. Urban Education, 50(2), 139-169. https://doi.org/10.1177/0042085915569738

Harper, S. R., \& Hurtado, S. (2007). Nine themes in campus racial climates and implications for institutional transformation. In S. R. Harper \& L. D. Patton (Eds.), Responding to the realities of race on campus (New Directions for Student Services, No. 120, pp. 7-24). San Francisco, CA: Jossey-Bass.

Harris III, F., \& Wood, J. L. (2013). Student Success for Men of Color in Community Colleges: A Review of Published Literature and Research, 1998-2012. Journal of Diversity in Higher Education, 6(3), 174-185. https://doi.org/10.1037/a0034224

Hatch, D. K., \& Garcia, C. E. (2018). Academic Advising and the Persistence Intentions of Community College Students in their First Weeks in College (Vol. 40).

He, Y., \& Hutson, B. (2018). Appreciative Assessment in Academic Advising. 39(2), 213-240.

Henry, W., West, N. M., \& Jackson, A. (2010). Hip-hop's influence on the identity development of Black female college students: A literature review. Journal of College Student Development, 51, 237-251

Hernandez, P. (2016). The Pedagogy of Real Talk: Engaging, Teaching, and Connecting With Students at Risk. Thousand Oaks, CA: Corwin Publishing.

Hill, M. L. (2009). Wounded Healing: Forming a Storytelling Community in Hip-Hop Lit. Teachers College Record, 111(1), 248-293.

hooks, b. (2000). Feminist theory: From margin to center. Boston, MA: South End Press.

Irby, D. J., Hall, H. B., \& Hill, M. L. (2013). Schooling teachers, schooling ourselves: Insights and reflections from teaching K-12 teachers how to use hip-hop to educate students. International Journal of Multicultural Education, 15(1), 1-18. 
Jones, S. R. \& Stewart, D. L. (2016). Critical perspectives on student development theory. San Francisco, CA: Jossey-Bass.

Jurgens, J. C. (2010). The evolution of community colleges. College Student Affairs Journal, $28(2), 251$.

Karimi, Robert. 2006. "How I Found My Inner D.J.” pp. 219-232 in Total Chaos: The Art and Aesthetics of Hip-Hop. Edited by Jeff Chang. New York, NY: Basic Books.

Karp, M., \& Bork, R. (2014). "They never told me what to expect, so I didn't know what to do": Defining and clarifying the role of a community college student. New York, NY: Community College Research Center.

Karp, M. M., Hughes, K. L., \& O'Gara, L. (2010). An exploration of Tinto's integration framework for community college students. Journal of College Student Retention: Research, Theory and Practice, 12(1), 69-86.

Ladson-Bllings, G., \& Tate, W. F. (1995). Toward a Critical Race Theory of education. Teachers College Record, 97, pp. 47-68. https://doi.org/10.3102/0013189X033007003

Lefebvre, H. (1991). The production of space. Oxford: Basil Blackwell.

Leigh Kelly, L. (2016). Broken Glass Everywhere : Deconstructing Popular Identities Through Critical Hip Hop Literacy.

Kimball, E., \& Campbell, S. M. (2013). Advising strategies to support student learning success: Linking theory and philosophy with intentional practice. In J. K. Drake, P. Jordan, \& M. A. Miller (Eds.), Academic advising approaches: Strategies that teach students to make the most of college (pp. 3-16). San Francisco, CA: Jossey-Bass.

Kline, C. (2007). Represent!: Hip-hop and the self-aesthetic relation (Unpublished doctoral dissertation). Indiana University, Bloomington

Kohle Paul, W., \& Fitzpatrick, C. (2015). Advising as servant leadership: Investigating student satisfaction. The Journal of the National Academic Advising Association, 35(2), 28-35.

Kolodner, M. (2015). Why are graduation rates at community colleges so low? Retrieved from http://hechingerreport.org/new-book-addresses-low-community-college- graduation-rates/

Krims, A. (2000). Rap music and the poetics of identity. Cambridge, UK: Cambridge University Press.

Kuhn, T., Gordon, V. N., \& Webber, J. (2006). The Advising and Counseling Continuum: Triggers for Referral. NACADA Journal, 26(1), 24-31. https://doi.org/10.12930/0271-951726.1.24

Ladson-Bllings, G., \& Tate, W. F. (1995). Toward a Critical Race Theory of education. Teachers College Record, Vol. 97, pp. 47-68. https://doi.org/10.3102/0013189X033007003 
Lawrence-Lightfoot, S., \& Davis, J. H. (1997). The art and science of portraiture. San Francisco: Jossey-Bass.

Lawton, J. (2018). Academic Advising as a Catalyst for Equity. New Directions for Higher Education, 2018(184), 33-43. https://doi.org/10.1002/he.20301

Lee, J. A. (2018). Affirmation, Support, and Advocacy: Critical Race Theory and Academic Advising. NACADA Journal, 38(1), 77-87. https://doi.org/10.12930/NACADA-17-028

Levy, I., Emdin, C., \& Adjapong, E. S. (2018). Hip-Hop Cypher in Group Work. Social Work with Groups, 41(1-2), 103-110. https://doi.org/10.1080/01609513.2016.1275265

Lewis, J., Arnold, M., House, R., \& Toporek, R. (2003). Advocacy competencies. Retrieved August 4, 2007, from http://www.counseling. org/Counselors/

Love, B. L. (2015). What is hip hop based education doing in nice fields such as early childhood and elementary education? Urban Education, 50(1), 106-

131. https://doi.org/10.1177/0042085914563182

Love, B. L. (2016) Complex personhood of hip hop \& the sensibilities of the culture that fosters knowledge of self \& self-determination. Equity \& Excellence in Education, 49(4), 414-427, DOI: $10.1080 / 10665684.2016 .1227223$

Maldonado-Torres, N. (2007). On the coloniality of being: Contributions to the development of a concept. Cultural Studies, 21(2-3), 240-270. https://doi.org/10.1080/09502380601162548

McNair, T., Albertine, S., Cooper, M.A., McDonald, N., \& Major, Jr., T. (2016). Becoming a student-ready college: A new culture of leadership for student success. San Francisco, CA: Jossey-Bass.

Mitchell, R., \& Rosiek, J. (2005). Searching for the knowledge that enables culturally responsive academic advising. Journal on Excellence in College Teaching, 16(2), 87-110.

Mitchell, R. W., Wood, G. K., \& Witherspoon, N. (2010). Considering race and space: Mapping developmental approaches for providing culturally responsive advising. Equity and Excellence in Education, 43(3), 294-309. https://doi.org/10.1080/10665684.2010.496691

Morrell, E., \& Duncan, J. M. R. (2002). Promoting Academic Literacy with Urban Youth through Engaging Hip-Hop Culture. The English Journal, 91(6), 88-92. https://doi.org/10.2307/821822

Mullin, C. M. (2010). Rebalancing the mission: The community college completion challenge (Policy Brief 2010-02PBL). Washington, DC: American Association of Community Colleges. Retrieved from http:/www.aacc.nche.edu/Publications/

Briefs/Documents/rebalancing_06152010.pdf

Museus, S. D., \& Quaye, S. J. (2018). Toward an Intercultural Perspective of Racial and Ethnic Minority College Student Persistence. 33(1), 67-94. 
Museus \& Ravello, J. N., S. M. (2010). Characteristics of academic advising that contribute to racial and ethnic minority student success at predominately white institutions. NACADA Journal, 30(1), 47-58. https://doi.org/10.12930/0271-9517-30.1.47

Museus, S. D., Yi, V., \& Saelua, N. (2017). Sense of Belonging The Impact of Culturally Engaging Campus Environments on Sense of Belonging. 40(2), 187-215.

NACADA: The Global Community for Academic Advising. (2017). NACADA academic advising core competencies model. Retrieved from https://www.nacada.ksu.edu/Resources/Pillars/CoreCompetencies.aspx

Nadal, K. L., Wong, Y., Griffin, K., Sriken, J., Vargas, V., Wideman, M., \& Kolawole, A. (2011). Microaggressions and the multiracial experience. International Journal of Humanities and Social Sciences, 1(7), 36-44.

National Center for Education Statistics (2015). College enrollment rates at degree-granting postsecondary institutions in Fall 2012. Washington DC: U.S. Department of Education, National Center for Education Statistics.

Noel-Levitz. (2014). The 2014 national student satisfaction and priorities report. Retrieved from https:/www.noellevitz.com/papers? research-higher-education/2014/2014? nationalstudent-satisfaction-and-priorities? report

Nutt, C. L. (2003). Academic advising and student retention and persistence. NACADA Clearinghouse of Academic Advising Resources Web site. Retrieved from http://www.nacada.ksu.edu/tabid/3318/articleType/ArticleView/article/6336/article

Ojeda, L., Navarro, R. L., \& Morales, A. (2011). The Role of la familia on Mexican American men's college persistence intentions. 12(3), 216-229. https://doi.org/10.1037/a0020091

Pabon, J. (2006). Physical graffiti: The history of hip-hop dance. In J. Chang (Ed.), Total chaos: The art and aesthetics of hip-hop (pp. 18-26). New York, NY: Basic Civitas.

Pascarella, E. T., \& Terenzini, P. T. (2005). How college affects students: A third decade of research. San Francisco, CA: Jossey-Bass.

Patel (2016). Decolonizing educational research: From ownership to answerability. New York, NY: Routledge.

Pérez Huber, L., Huidor, O., Malagón, M.C., Sanchez, G., \& Solórzano, D. G. (2006). Falling through the cracks: Critical transitions in the Latina/o educational pipeline. CSRC Research Report, 7, 1-14

Petchauer, E. (2009). Framing and Reviewing Hip-Hop Educational Research.

Petchauer, E. (2011). "I feel what he was doin"”: Responding to justice oriented teaching through hip-hop aesthetics. Urban Education, 46, 1411-1432. 
Petchauer, E. (2014). Sampling Memories: Using Hip-Hop Aesthetics To Learn From Urban Schooling Experiences. Educational Studies, 48(2), 137-155.

https://doi.org/10.1080/00131946.2011.647148

Petchauer, E. (2015). Starting With Style: Toward a Second Wave of Hip-Hop Education Research and Practice. Urban Education, 50(1), 78-105. https://doi.org/10.1177/0042085914563181

Purgason, L. L., Avent, J. R., Cashwell, C. S., Jordan, M. E., \& Reese, R. F. (2016). Culturally relevant advising: Applying relational-cultural theory in counselor education. Journal of Counseling and Development, 94(4), 429-436. https://doi.org/10.1002/jcad.12101

Pusser, B., \& Levin, J. (2009) Re-imagining community colleges in the 21st century. Retrieved from https://docs.google.com/document/d/ 1Nh_Z6aWaydzQx1H77B46HSME_bMU9ZRpq38dnMHoh8/edit\#

Ratts, M.J., Singh, A.A., Nassar-McMillan, S., Butler, S.K. and McCullough, J.R. (2016), Multicultural and Social Justice Counseling Competencies: Guidelines for the Counseling Profession. Journal of Multicultural Counseling and Development, 44: 28-48. doi:10.1002/jmcd.12035

Rendón, L. I. (1994). Validating culturally diverse students: Toward a new model of learning and student development. Innovative Higher Education, 19(1), 33-51.

Rendón, L. I. (2009). Sentipensante pedagogy: Educating for wholeness, social justice, and liberation. Sterling, VA: Stylus Publishing.

Rice, J. (2003). The 1963 hip-hop machine: Hip-hop pedagogy as composition. College Composition and Communication, 54, 453-471.

Robertson, R. Von, \& Chaney, C. (2016). Racism and the Experiences of Latina / o College Students at a PWI ( Predominantly White Institution ). https://doi.org/10.1177/0896920514532664

Rodríguez, L. F. (2009). Dialoguing, Cultural Capital, and Student Engagement: Toward a Hip Hop Pedagogy in the High School and University Classroom. 42(1), 20-35. https://doi.org/10.1080/10665680802584023

Rodriguez, S. L., Massey, K., \& Sáenz, V. B. (2016). Engaging Latino Men in Community Colleges: The Role of Student-Faculty Interactions. Journal of Applied Research in the Community College, 23(2).

Rose, T. (1994). Black noise: Rap music and Black culture in contemporary America. Middletown, CT: Wesleyan University Press.

Santiago, D. A. (2008). Modeling Hispanic-serving institutions (HSIs): Campus practices that work for Latino students. Washington, D.C.: Excelencia in Education. 
Schloss, J. G. (2004). Making beats: The art of sample-based hip-hop. Middletown, CT: Wesleyan University Press.

Schott Foundation for Public Education (2012). The urgency of now: The Schott 50 state report on public education and black males. Cambridge, MA.

Schreiner, L.A., Noel, P., Anderson, E., Cantwell, L. (2011). The impact of faculty and staff on high-risk college student persistence. Journal of College Student Development, 52(3), 321338. doi:10.1353/csd.2011.0044

Schur, R. (2009). Parodies of ownership: Hip-hop aesthetics and intellectual property law. Ann Arbor: University of Michigan Press.

Seidel, S. (2011). Hip hop genius: Remixing high school education. New York, NY: Rowman \& Littlefield.

Seidman, I. (2013). Interviewing as qualitative research. 4th ed. New York, NY: Teachers College Press.

Shapiro, D., Dundar, A., Ziskin, M., Chiang, Y., Chen, J., Torres, V., \& Harrell, A. (2013). Baccalaureate attainment: A national view of the postsecondary outcomes of students who transfer from two-year to four-year institutions. Herndon, VA: National Student Clearinghouse Research Center.

Smith, C. L., \& Allen, J. M. (2014). Does Contact With Advisors Predict Judgments and Attitudes Consistent With Student Success? A Multi-institutional Study. NACADA Journal, 34(1), 50-63. https://doi.org/10.12930/nacada-13-019

Smitherman, G. (1977). "Talkin and testifyin: The language of Black America." Detroit: Wayne State University Press

Solórzano, D., Ceja, M., \& Yosso, T. (2000). Critical race theory, racial microaggressions, and campus racial climate: The experiences of African American college students. Journal of Negro Education, 69(1/2), 60-73

Solórzano, D. G.,\& Yosso, T. (2002). A critical race counterstory of race, racism, and affirmative action. Equity and Excellence in Education, 35(2), 155-168.

Soria, K. M., Laumer, N. L., Morrow, D. J., \& Marttinen, G. (2017). Strengths-Based Advising Approaches: Benefits for First-Year Undergraduates. NACADA Journal, 37(2), 55-65. https://doi.org/10.12930/nacada-16-010

Stone, A. G., Russell, R. F., \& Patterson, K. (2004). Transformational versus servant lead? ership: A difference in leader focus. The Leadership \& Organization Development Journal, 25(4), 349-361. doi: 10.1108/01437730410538671

Stovall, D. (2006). We can relate: Hip-hop culture, critical pedagogy, and the secondary classroom. Urban Education, 41(6), 585-602. 
Stovall, D. (2013). 14 souls, 19 days and 1600 dreams: Engaging critical race praxis while living on the "edge" of race. Discourse Studies in the Cultural Politics of Education, 34, 562-578.

Strauss, A. (1987). Qualitative analysis for social scientists. New York, NY: Cambridge University Press

Strayhorn, T. L. (2008). "Sentido de pertenencia": A hierarchical analysis predicting sense of belonging among Latino college students. Journal of Hispanic Higher Education, 7(4), 301320.

Sulé, V. T. (2016). Hip-Hop is the Healer: Sense of Belonging and Diversity Among Hip-Hop Collegians. Journal of College Student Development, 57(2), 181-196. https://doi.org/10.1353/csd.2016.0022

Swecker, H. K., Fifolt, M., \& Searby, L. (2013). Academic advising and first-generation college students: A quantitative study on student retention. NACADA Journal, 33(1), 46-53. http://dx.doi.org/10.12930/NACADA-13-192.

Tintiangco-Cubales, A. (2020, May 1). Personal interview with Dr. Allyson TintiangcoCubales.

Tinto, V. (2012 ). Completing college: Rethinking institutional action. Chicago, IL: The University of Chicago Press.http://dus.psu.edu/mentor/.

Tovar, E. (2013). A Conceptual Model on the Impact of Mattering, Sense of Belonging, Engagement / Involvement, and Socio-Academic Integrative Experiences on Community College Students 'Intent to Persist By Esau Tovar A dissertation submitted to the Faculty of Claremont.

Tovar, E. (2015). The role of faculty, counselors, and support programs on Latino/a community college students' success and intent to persist. Community College Review, 43(1), 4671. https://doi.org/10.1177/0091552114553788

Townsend, B. K., Donaldson, J., \& Wilson, T. (2004). Marginal or monumental? Visibility of community colleges in selective higher education journals. Community College Journal of Research and Practice, 29, 123-135

Travis, R. (2013). Rap Music and the Empowerment of Today's Youth: Evidence in Everyday Music Listening, Music Therapy, and Commercial Rap Music. Child and Adolescent Social Work Journal, 30(2), 139-167. https://doi.org/10.1007/s10560-012-0285-X

Travis, R. (2016). The healing power of Hip Hop. Santa Barbara, CA: ABC-CLIO, LLC.

Vianden, J. (2016). Ties That Bind: Academic Advisors as Agents of Student Relationship Management. NACADA Journal, 36(1), 19-29. https://doi.org/10.12930/NACADA-15-026a

Vygotsky, L. S. (1978). Mind in society: The development of higher psychological processes. Cambridge, MA: Harvard University Press. 
White, E. R. (2015). Academic Advising in Higher Education: A Place at the Core. Source: The Journal of General Education The Journal of General Education: A Curricular Commons of the Humanities and Sciences, 64(4), 263-277.

https://doi.org/10.5325/jgeneeduc.64.4.0263

Williams, A. D. (2009). The Critical Cultural Cypher: Remaking Paulo Freire's Cultural Circles Using Hip Hop Culture. International Journal of Critical Pedagogy, 2(1), 1-29.

Wood, B. J. L. (2012). Black Males in Community Colleges. (June), 30-33. https://doi.org/10.1002/abc.21078

Wood, J. L., \& Williams, R. C. (2013). Persistence Factors for Black Males in the Community College: An Examination of Background, Academic, Social, and Environmental Variables. Spectrum: A Journal on Black Men, 1(2), 1-28. https://doi.org/10.2979/spectrum.1.2.1

Yosso, T. J. (2005). Whose culture has capital? A critical race theory discussion of community cultural wealth. Race Ethnicity and Education, 8(1), 69-91. https://doi.org/10.1080/1361332052000341006

Yosso, T. (2006). Critical race counterstories along the Chicana/Chicano educational pipeline. New York: Routledge.

YoungJones, A. D., Burt, T. D., Dixon, S., \& Hawthorne, M. J. (2013). Academic advising: does it really impact student success? Quality Assurance in Education, 21(1), 7-19.

https://doi.org/10.1108/09684881311293034 
Appendices

Appendix A: Institutional Review Board (IRB) Consent Form

I Got A Story To Tell: How Hip Hop Pedagogy Informs College Counseling Practices

\section{A. PURPOSE AND BACKGROUND}

The purpose of this research study is to learn more about how college counselors from California community colleges draw from their life stories and experiences as sources of knowledge and how these experiences in their lives are utilized to inform their understandings of their counseling practices when engaged in Hip Hop pedagogy. The researcher, Nathaniel Nevado, is a doctoral student at San Francisco State University conducting research for an EdD in Educational Leadership. You are being asked to participate in this study because:

1. You serve as California community college counselor.

2. You identify as a professional who utilizes Hip Hop pedagogy in your counseling practice.

3. You can articulate how your lived experiences help inform your current work as a college counselor when engaged in Hip Hop pedagogy.

\section{B. PROCEDURES}

If you agree to participate in this research study, the following will occur:

- You will be interviewed 2-3 times for 60 to 90 minutes at a time, over the course of approximately 4 months (August - December 2019).

- The interview will take place at a time and (quiet) location most convenient for you.

- The researcher may contact you later to clarify your interview answers via email or by phone.

- The researcher will visit your classroom, if you teach courses, 1-2 times over the course of approximately 4 months (August - December 2019).

- Your statements will be recorded on multiple modes of technology to ensure accuracy.

- You will be given the chance to review and edit the electronic recordings and/or transcripts prior to researcher's submission of this dissertation project to ensure authenticity and accuracy.

1. What are the life stories and experiences of community college counselors who engage in Hip Hop pedagogy?

2. How does their lived experiences and their understanding of Hip Hop shape and inform their college counseling practices?

\section{RISKS}

The risks of this project are minimal. All information gathered will remain strictly confidential. Real names of participants will not appear in publications or presentations derived from this 
research unless permission to use real names is granted. If you prefer NOT to use your real name, please initial here . No other risks are known to be associated with participation in this project.

\section{BENEFITS}

Participation in this study has no direct benefits for participants. However, the research will make substantial contributions to the fields of student development, counseling and academic advising, education, and educational leadership by providing examples of how Hip Hop pedagogy can inform counseling practices, professional development, and curriculum design.

\section{E. CONFIDENTIALITY}

The interviews are completely confidential. No one will have access to your interview results except the Principal Investigator. All signed consent forms, audio-recorded interviews, and transcribed data will be stored in a lock and key filing cabinet in the researcher's office. I will separate any identifying information that you provide from the responses that you give.

\section{F. RIGHTS OF RESEARCH PARTICIPANTS}

You have the right to review, edit, or erase the research audio files in whole or in part. You also have the right to discontinue participation without penalty.

\section{G. PERSON TO CONTACT}

If you have any questions, complaints, concerns, or feel that you have been harmed as a result of this project, please contact Nate Nevado at 415-519-9786 or Dr. Allyson Tintiangco-Cubales at 415-218-9181. You may also email Nate Nevado at nevadon@smccd.edu.

\section{H. INSTITUTIONAL REVIEW BOARD}

Please contact the Institutional Review Board (IRB) if you have questions regarding your rights as a research participant. Also, contact the IRB if you have questions, concerns, or complaints that cannot be discussed with the principal investigator. San Francisco State University IRB can be reached at 415-338-7094 and orsp@sfsu.edu.

\section{COSTS AND COMPENSATION TO PARTICIPANTS}

There are no costs and/or compensation associated with this project.

\section{J. CONSENT}

By signing this consent form, I confirm I have read the information in this form and have had the opportunity to ask questions. I understand my participation is voluntary and that I am free to withdraw at any time, without giving a reason. I will be given a signed copy of this consent form. I voluntarily agree to take part in this study. 
Printed Name of Participant

Signature of Participant

Date

Printed Name of Person Obtaining Consent 


\section{HIP HOP PEDAGOEY IN COLLEGE COUNSELING}

Be part of an exploratory study looking at how the lived experiences and stories of community college counselors who engage in Hip Hop practice and pedagogy inform college counseling practices.

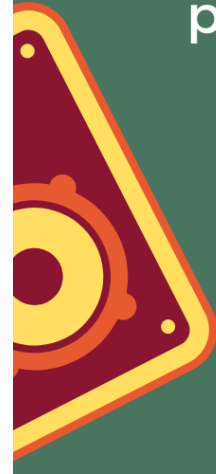

+ Be employed at a California Community College + Be a College Counselor

+ Have earned a MA/MS in Counseling

+ Have experience in engaging in Hip Hop practice and/or scholarship

If you are interested, please contact Nate Nevado at nevadon@smccd.edu.
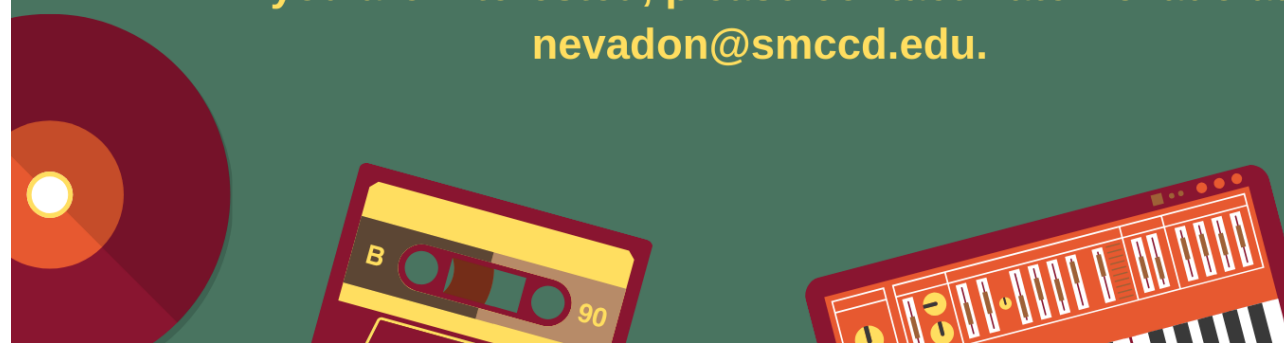
Appendix C: Online Pre-Survey

Online Pre-Survey: Hip Hop Counseling Pedagogy

This form is an initial assessment on the utilization of Hip Hop in college counseling practices such as one-to-one appointments, college success courses, and student success workshops. I am currently doing research on how Hip Hop pedagogy informs college counseling practices in California community colleges. Please answer the questions to the best of your ability and as honestly as possible.

Name:

Email contact:

Which community college are you currently working at? If you work at multiple community colleges, please list them all.

How many years have you been a community college counselor?

- $1-5$ years

- 6-10 years

- $11+$ years

If you are a Hip Hop practitioner, which element(s) of Hip Hop best describes you?

- Emcee

- B-Boy/B-Girl (also known as breakdancer)

- DJ/Turntablist

- Aerosol Writer/Graffiti Artist/Muralist

- Beat Producer

- Beatboxer

- Musician (i.e. drums, piano)

- Spoken Word Artist/Poet

- Fashion Designer

- Business Entrepreneur

How do you define Hip Hop pedagogy?

Which statement best describes you when it comes to facilitating one-to-one college counseling appointments?

- I explicitly use Hip Hop pedagogy in my counseling appointments.

- I think I use Hip Hop pedagogy in my counseling appointments.

- I don't use Hip Hop pedagogy in my counseling appointments. 
If you think or explicitly use Hip Hop pedagogy in your counseling appointments, how often?

- Most or all of my counseling appointments

- Sometimes

- Sometimes, when I see/feel that it is appropriate

If you teach or have taught college success, first-year experience, or student development courses, do you use Hip Hop pedagogy?

I am doing a preliminary assessment on community college counselors in California who engage with Hip Hop and/or Hip Hop pedagogy. Would you be open to being part of a larger research that is examining how Hip Hop pedagogy informs community college counseling practices?

Are there other California community college counselors that may be engaging in Hip Hop pedagogy in their counseling practices that I should reach out to? 
Appendix D:

Interview Questions

Life Histories

- Where did you grow up? What was it like? What were some vivid memories you have to describe your hometown/neighborhood/block?

- Were there influential community members you remember growing up in your neighborhood? In what ways did they impact you?

- In what ways has your life histories influence and impact you as a person?

\section{Educational Experiences}

- How would you describe your educational journey from elementary through high school?

- What were some vivid memories of educational experiences that you had with a teacher? What made these experiences stand out to you? What made these teachers great/worst?

- At what point in your educational journey did you begin to realize your "place" in society? How did you make meaning of these experiences?

- What were some counseling experiences you remember the most? In what ways have those experiences impacted the way you practice counseling?

Occupation

- Please describe your occupation.

- Where do you work?

- How long have you been working here?

- What is your definition of college counseling?

- What is your counseling philosophy?

- What motivated you in becoming a college counselor? Have you always imagined this as your career? What prompted the pivot into counseling?

- What makes this work meaningful?

- Do you also teach? If so, what do you teach?

Hip Hop Lived Experiences and Pedagogy

- What is your relationship to Hip Hop?

- What are your earliest memories of Hip Hop?

- How did it impact you during that time?

- How long has this relationship been?

- What draws you to Hip Hop?

- Where do you see yourself within Hip Hop?

- How do you define Hip Hop pedagogy?

- What informs your definition and understanding of Hip Hop pedagogy?

$\circ$ What is the purpose of Hip Hop pedagogy? 
- Why do you practice Hip Hop pedagogy?

- How does your background, lived experiences, and identity impact and inform how you practice Hip Hop pedagogy?

- What benefits and outcomes have you observed when counseling students engaged in Hip Hop pedagogy?

- When did you start utilizing Hip Hop pedagogy in your counseling practices?

- What prompted you in utilizing Hip Hop pedagogy?

- How is your counseling philosophy and Hip Hop pedagogy connected in your counseling work?

- In what ways does your counseling philosophy inform your practice in Hip Hop pedagogy? 